\title{
Effects of Marine Reserve Protection on Adjacent Non-protected Populations in New Zealand
}

\author{
by \\ Daniela Díaz-Guisado
}

\author{
A thesis submitted to \\ Victoria University of Wellington \\ in fulfilment of the requirements for the degree of \\ Doctor of Philosophy in Marine Biology.
}



This thesis was conducted under the supervision of:

Associate Professor James J. Bell (Primary supervisor)

Victoria University of Wellington,

Wellington, New Zealand

and

Professor Jonathan P.A. Gardner (Secondary supervisor)

Victoria University of Wellington,

Wellington, New Zealand 



\section{Abstract}

Marine reserves (MRs) have been established in many parts of the globe for a variety of reasons and there is an increasing body of evidence that indicates they provide a wide range of benefits that can extend beyond their boundaries. In the present study, the biological effects of protection provided by MRs in New Zealand were evaluated, particularly focusing on the potential impacts of reserves on non-protected areas in terms of export of biomass.

First, the biological response of two exploited species to MR protection in New Zealand was quantified by comparing meta-analysis results based on response ratio (RR) analysis and Hedges' $g$ statistics. Then, effect of MR size and age on those biological responses was determined. Most MRs supported a greater density of larger individuals than unprotected areas. Results indicated that the benefits provided by MRs scale with reserve size. Also, MR age explained a significant amount of the variation in the density and length of both species. Comparison of the performance of RRs with Hedges' $g$ revealed that RR analysis is an appropriate alternative to Hedges' $g$ statistic for meta-analyses of MR effectiveness because of its ease of use and interpretation.

Then, a 14-year time series of fish density data was analyzed to determine early changes in a multi-species fish assemblage inside the Taputeranga Marine Reserve (TMR) compared to adjacent fishing grounds using a Before and After Control-Impact 
Paired Series (BACIPS) design. This analysis was performed in order to detect changes in fish density due to protection. Commercial, recreational and traditional fisheries are important in this region and the biomasses of several exploited species have been substantially depleted as a result of fishing. The exclusion of fishing from the area should enable at least some species to recover inside the reserve, as has happened in other reserves in New Zealand. The faster growing, more productive species, and those that have been heavily exploited are expected to recover within a few years. Early changes in density were evident in the area protected by the TMR for most of the species surveyed in terms of the effect size analysis. However, most of the changes were too small to be detected with the statistical analyses that were performed.

To determine the most appropriate methodology to be used in a later survey in the study area, two Baited Underwater Video (BUV) methodologies (Horizontal versus Vertical set-up) were compared in terms of their ability to record the density and size of reef fish. Results indicated that both the horizontal and vertical BUV techniques are able to detect both conspicuous and cryptic species and both techniques were effective in the detection of carnivorous species, especially large predatory species such as blue cod, but also effective in the detection of fish species that have been overestimated in terms of abundance by other methodologies. The horizontal BUV technique seems to be a better technique for evaluating reef fish size, especially when measuring large fish that exhibit highly aggressive behaviour. The horizontal BUV technique was later used in conjunction with the Underwater Visual Census (UVC) technique to assess the effects of the protection provided by the TMR. A multispecies analysis was carried out to detect any differences in density and length of fish between reserve and fished areas and to detect gradients of fish density across reserve boundaries that could be related to the occurrence of spillover from the reserve to adjacent fished areas. Density gradients provide indirect evidence of spillover, defined as the movement of adult individuals from reserve to adjacent non-protected areas. Little evidence consistent with a positive effect of reserve protection in the TMR was found. Also, little evidence of spillover was found, with theexception of two target species (blue cod and blue moki). In contrast with the findings of previous studies, density gradients were found for both sedentary and vagile species. These results are consistent with the occurrence of density independent 
spillover that is expected to occur as soon as the density inside reserve areas is higher compared to fished areas.

To further understand the patterns of fish movement relative to the effect of protection provided by MRs, spatial differences in density, length and survival of blue cod inside the TMR and adjacent fishing grounds and the movement patterns of the species across the boundaries of the reserve through a capture-mark-recapture (CMR) analysis were examined. CMR studies can provide direct evidence of spillover. Evidence of a positive effect of reserve protection in the TMR for blue cod in terms of increased density, length and survival in reserve areas was found. Also, evidence of high site fidelity of blue cod in both reserve and fished areas, with the majority of individual moving only short distances was found. However, the potential for this species to also travel long distances $(>100 \mathrm{~km})$ was confirmed, suggesting the possibility for spillover of the species from reserved to fished areas.

Overall, the results of my thesis indicate that New Zealand MRs, consistent with a large body of earlier evidence, are having positive effects on the abundance and size of the species that afford protection to. These results also highlight that both MR age and area are important factors determining the response to protection both in terms of the effects within reserves and on adjacent non-protected areas. Finally, my results highlight the fact that the greater benefits in terms of increased abundance and size, and also movement across reserve boundaries, are obtained for highly exploited species that can potentially move between areas. 
Dedicated to my son; Daniel 


\section{Acknowledgments}

The completion of this dissertation was made possible through the support of many people that have contributed to my continued development as person and as a scientist. First of all, I am deeply grateful of both my supervisors, Dr James J. Bell and Professor Jonathan P.A. Gardner, for their guidance, encouragement and patience.

Much of the fieldwork necessary for the completion of the present study was only possible with help of many people. I would particularly like to acknowledge the support of the technicians at the Victoria University Coastal Ecology Laboratory (VUCEL), John Van der Sman and Daniel McNaughtan. Also, many thanks to Don Nelson, for his skills as a skipper, for passing on local knowledge of the Wellington area and spending long hours onboard the VUW vessel. Thanks to the many field assistants that lent me a hand in the field, often at short notice and thanks to all my dive buddies specially Cesar Cardenas and Tyler Eddy. I am also grateful to my boat skippers, especially to Danelle Lekan, Jenny Oliver, Alejandro Perez-Matus and Ian Geeson. Also thanks to all those friends that helped me during the many field trips particularly to Sergio Carrasco, Mauricio Cifuentes, Paul Mensink, David Burr, Ryan Hughes, and Hayden Smith.

I would also like to thank the Department of Conservation, especially Helen Ketles, Debbie Freeman, John Henry, John Adams, Danica Stent and Hawea Tomoana for their support during the monitoring survey of the TMR. Tyler Eddy providing me with some 
of the data I used in the analysis of the effects of protection in the TMR. Thanks also to Russell Cole, Robert Davidson, Debbie Freeman, Shane Kely, Alison Macdiarmid, Anjali Pande, Rob Stewart and Carl Struthers for providing me with much of the data I used in the meta-analysis in chapter one and for their comments as co-authors of a published manuscript. Also a special thanks goes to Malcolm Francis (National Institute of Water and Atmospheric Research, NIWA) for teaching me the tagging techniques I used in the capture-mark-recapture (CMR) survey.

I am also grateful to Tim Jones, Shane Geange, and Mauricio Cifuentes for their statistical advice, and also to Dalice Sim for helping me to getting started with the statistical software $\mathrm{R}$ and providing valuable statistical advice. Thanks to Shirley Pledger for introducing me to the software program MARK and guiding me through the analysis of the CMR data in chapter six.

I am grateful to my colleagues at VUCEL for their support and for making my time in New Zealand so enjoyable. A great group of friends have also supported me throughout this process, especially Claudia Campos, Rodrigo Gomez, Gelant Vilches, Leasa Mead, David Irvine and Julie and Steve Gianoutsos who always lent me a hand when I needed it.

This dissertation was possible with financial support of CONICYT (Chile) and Victoria University of Wellington (VUW - CONICYT scholarship).

Finally, I would like to thank my family, my sister Alejandra and her family for their support, my dad Nelson for his encouragement and especially my mum for teaching me the passion for learning and for being a great example to me. Also, I wish to thank my son Daniel for accompanying me in this journey and for being part of my life. 


\section{Contributions to this Thesis}

\section{Chapter two}

Dr. Russell G. Cole, Dr. Debbie J. Freeman, Dr Shane Kelly, Dr. Anjali Pande, Dr. Alison MacDiarmid A, Rob Stewart, Carl Struthers M.S., and Rob J. Davidson provided some of the data used in the meta-analysis of New Zealand MRs performed in chapter two.

\section{Chapter three}

Dr. Tyler Eddy and Dr. Anjali Pande provided some of the data used in the analysis performed in chapter three.

\section{Chapter four}

Dr. Dalice Sim and Dr. Shane Geange provided statistical advice for the implementation of the Linear Mixed Effect Model I performed in chapter four (and in other chapters) 
and for the use of the Statistical computing software R.

Dr. Tim Jones provided statistical advice for the implementation of the Bayesian analysis performed in chapter four.

\section{Chapter five}

Dr. Tyler Eddy provided some of the data used in the analysis performed in chapter five.

\section{Chapter six}

Dr. Shirley Pledger provided advice for the use of the software Program MARK and the catch- mark- recapture analysis performed in chapter five. 


\section{Publications from this Thesis ${ }^{1}$}

\section{Published Articles}

Díaz- Guisado D., Cole RG, Davidson RJ, Freeman DJ, Kelly S, MacDiarmid A, Pande A, Stewart R, Struthers C, Bell JJ, Gardner JPA (2012). Comparison of methodologies to quantify the effects of age and area of marine reserves on the density and size of targeted species. Aquatic Biology 14: 185-200. doi: 10.3354/ab00391

Author contribution: D.D. and J.P.A.G. analyzed the data. D.D. wrote the manuscript. J.J.B and P.A.G. edited the manuscript. 


\section{Conference Proceedings \& Reports ${ }^{1}$}

Díaz-Guisado D, Gardner JPA,. Bell JJB (2011) Effects of Marine Reserve protection on adjacent non-protected populations in New Zealand. Proceedings of the Australian Society for Fish Biology Conference, Townsville, Australia.

Author contribution: D.D. and J.P.A.G. analyzed the data. D.D wrote the manuscript and presented the oral paper. J.J.B and P.A.G. edited the manuscript.

Díaz-Guisado D, Gardner JPA,. Bell JJB (2009). Effect of Marine Reserve protection on blue cod and rock lobster. New Zealand Marine Science Society Conference, Auckland, Nez Zealand.

Author contribution: D.D. conducted the research, analyzed the data, wrote the manuscript and presented the oral paper. J.J.B and J.P.A.G. edited the manuscript.

${ }^{1}$ As of June 2014 


\section{Contents}

1 General Introduction $\quad 1$

1.1 Overview of the use of conventional fishery management tools .............................2

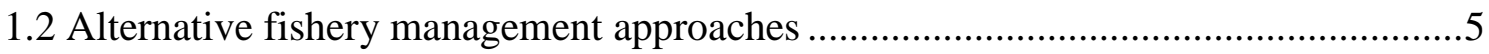

1.3 Marine reserves in New Zealand ..................................................................

1.4 Thesis structure

2 Comparison of Methodologies to Quantify the Effects of Age and Area of Marine Reserves on the Density and Size of Targeted Species 13

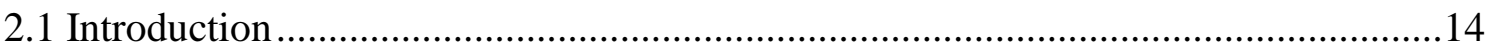

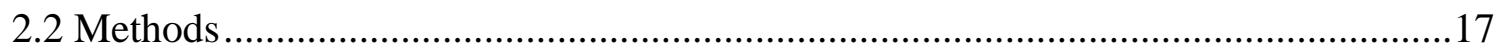

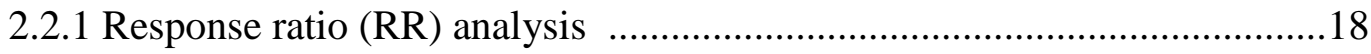

2.2.2 Effect of MR area and age on biological response ................................21

2.2.3 Comparison of RRrecent versus Hedges' $g$ statistics ..............................22

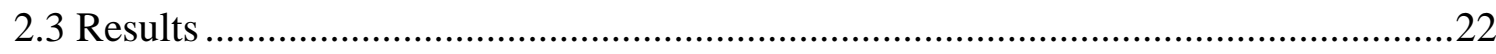


2..3.1 RRrecent analyses for blue cod .23

2.3.2 RRmax analyses for blue cod ..........................................................23

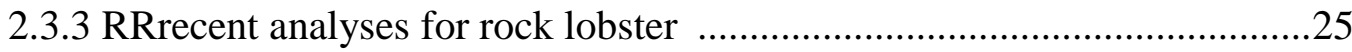

2.3.4 RRmax analyses for rock lobster ....................................................27

2.3.5 Comparison of RRrecent versus Hedges' $g$ statistics.............................29

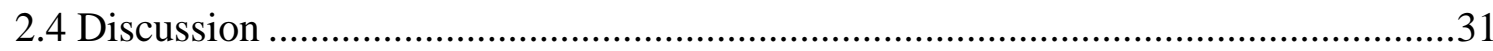

2.4.1 Effects of MR size on biological response ............................................32

2.4.2 Effects of MR age on biological response ...........................................35

2.4.3 Use of RR indices and curve fitting .....................................................36

2.4.4 Use of the RR approach for assessing MR effectiveness.....................38

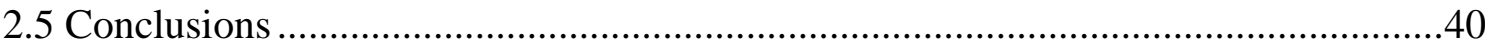

3 A Multispecies Analysis to Detect Changes in Reef Fish Abundance and Size Using Underwater Visual Census (UVC) in the Taputeranga Marine Reserve, New Zealand $\quad 41$

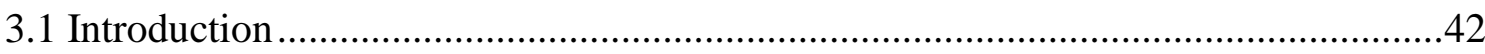

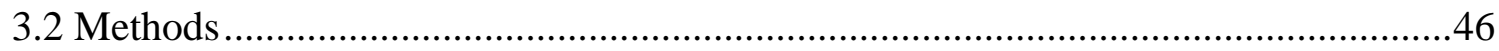

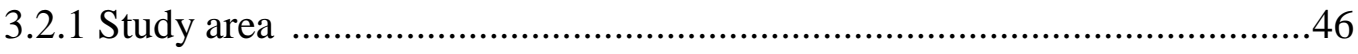

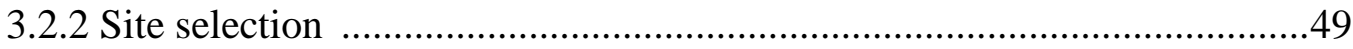

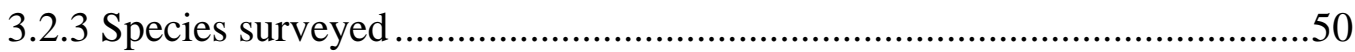

3.2.4 Survey methodology: underwater visual census (UVC) survey ................51

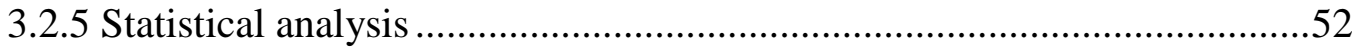

3.2.5.1 Response ratio (RR) analysis ...........................................52

3.2.5.2 Before and after control- impact paired series (BACIPS)

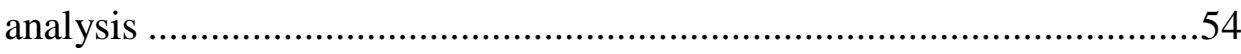

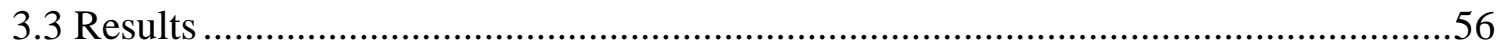

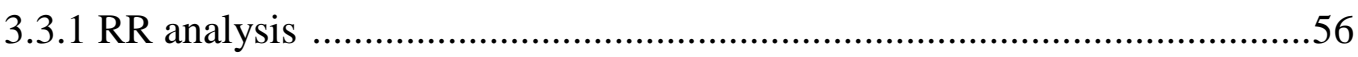

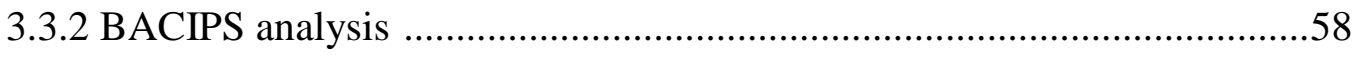


3.4.1 Early changes in fish density in the Taputeranga Marine Reserve 63

3.4.2. Trends in fish density related to species characteristics .........................64

3 .4.3 Use of RR and BACIPS for assessing MR effectiveness .......................66

3.5 Conclusions

.69

\section{Comparison of Two Baited Underwater Video (BUV) Methods for the Determination of Reef Fish Abundance and Size

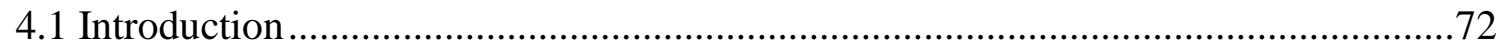

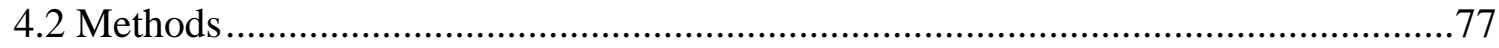

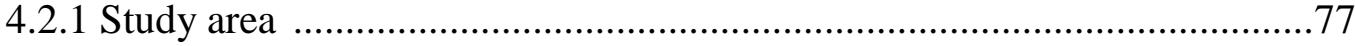

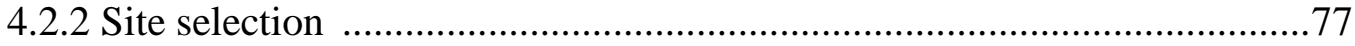

4.2.3 Survey methodology: baited underwater video (BUV) surveys ..............77

4 .2.4 Video footage analysis: density and length estimations .........................78

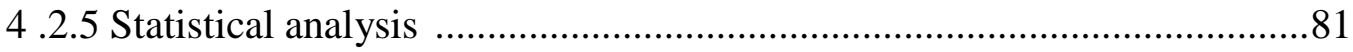

4.2.5.1 Density and length analysis ................................................81

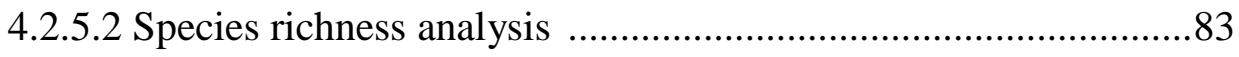

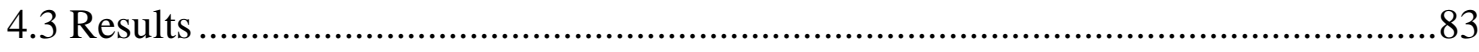

4.3.1 Differences in species richness between methodologies ..........................83

4.3.2 Differences in species density between methodologies ...........................85

4.3.3 Differences in species length between methodologies ............................86

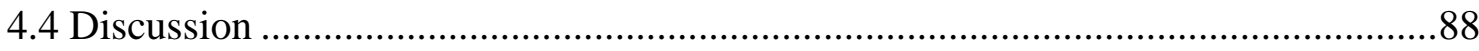

4.4.1 Effect of the orientation of the BUV station on species richness ..............89

4.4.2 Effect of the orientation of the BUV station on fish density .....................92

4.4.3 Effect of the orientation of the BUV station on fish length .....................93

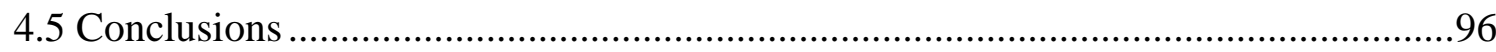

5 Potential of the Taputeranga Marine Reserve to Export Reef Fish Biomass to 


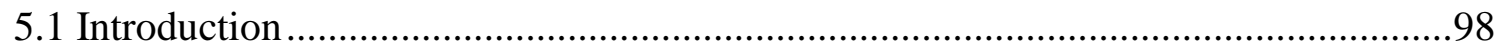

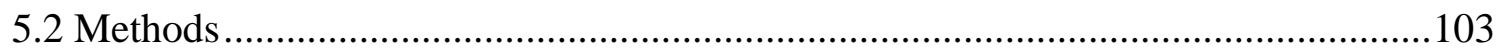

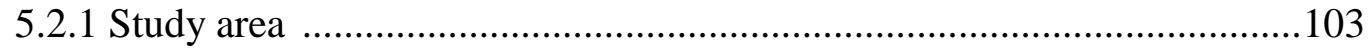

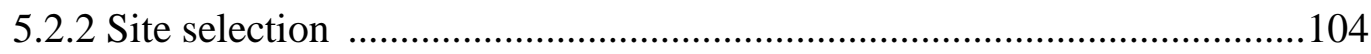

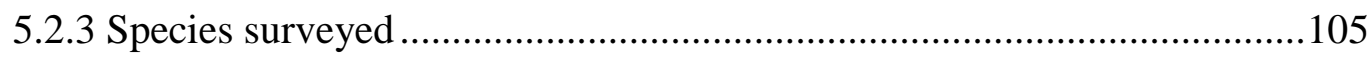

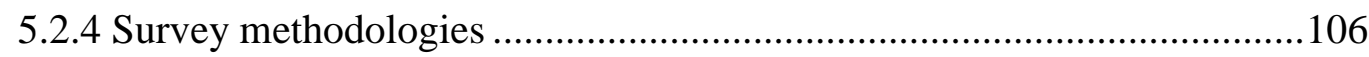

5.2.4.1 Underwater visual census survey .............................................106

5.2.4.2 Baited underwater video survey ................................................107

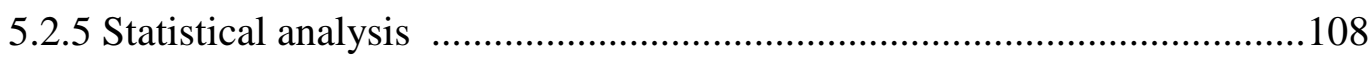

5.2.5.1 Spatial differences in fish density, species richness and individual length between reserve and fished areas ..............................108

5.2.5.2 Trends in fish density across reserve boundaries ........................109

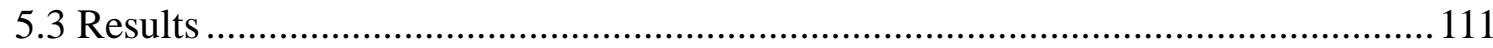

5.3.1 Differences between reserve and fished areas .......................................112

5.3.1.1 Species richness ……………………………..........................112

5.3.1.2 Fish density and length ............................................................113

5.3.1.2.1 Underwater visual census ...........................................113

5.3.1.2.2 Baited underwater video ...........................................117

5.3.2 Trends in fish density across reserve boundaries ....................................121

5.3.2.1 Underwater visual census ........................................................121

5.3.2.2 Baited underwater video ........................................................121

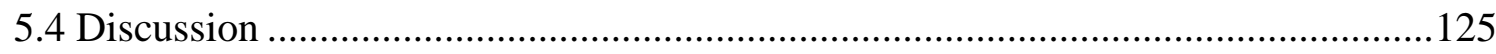

5.4.1 Patterns of species richness across the boundaries of the Taputeranga

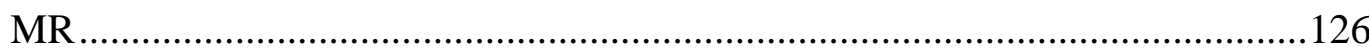

5.4.2 Patterns of individual species density and length across the boundaries of the Tapuetarnga MR ……………………………………............................127

5.4.3 Trends in fish density across the boundaries of the Taputeranga MR .....129

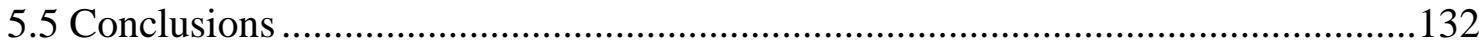




\section{Movement patterns of Blue Cod Across the Boundaries of the Taputeranga}

Marine Reserve: Evidence for Spillover $\quad 133$

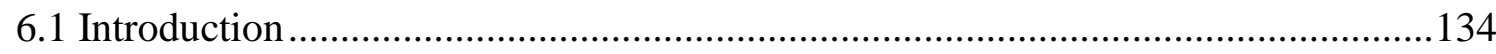

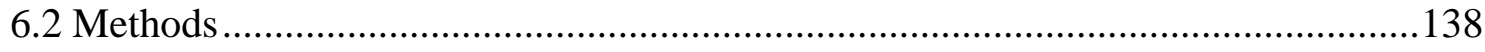

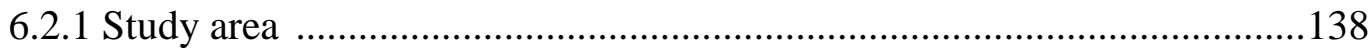

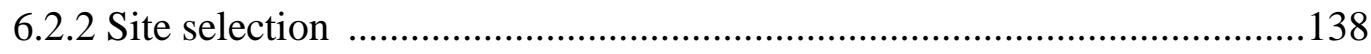

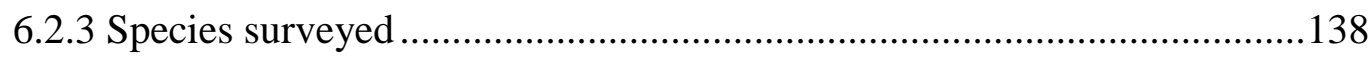

6.2.4 Survey methodology: catch- mark- release (CMR) survey .....................139

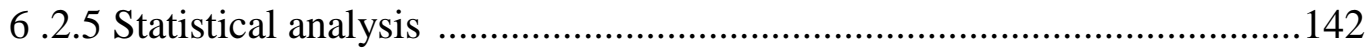

6.2.5.1 Differences in fish density, length and weight between areas .143

6.2.5.2 Analysis of survival and recapture probabilities ......................144

6.2.5.3 Analysis of the movement patterns of blue cod across reserve

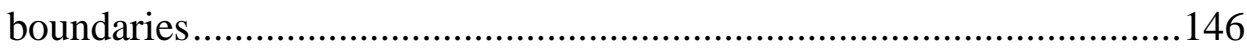

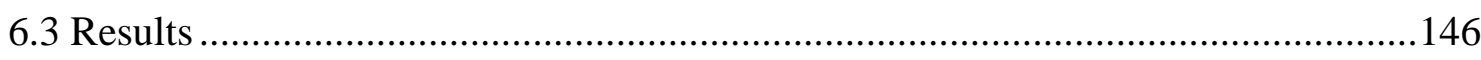

6.3.1 Differences in fish density, length and weight between areas .................147

6.3.2 Differences in survival and recapture probabilities between areas ..........150

6.3.3 Movement patterns of blue cod across reserve boundaries .....................153

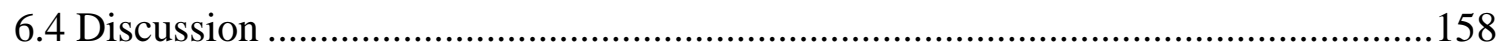

6.4.1 Effect of protection on the density, length and weight of blue cod ..........159

6.4.2 Effect of protection on blue cod survival ........................................... 161

6.4.3 Movement patterns of blue cod across MR boundaries ..........................162

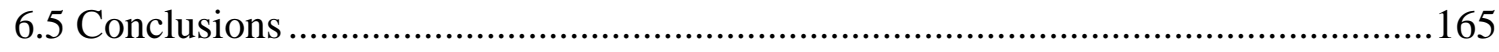

7 General Discussion $\quad 167$

7.1 Direct effects of MRs on target and non- target species ...................................168 
7.2 MR effects related to species characteristics ......................................................171

7.3 Effects of MR age and size in the response of targeted species ............................172

7.4 The effect of MRs in adjacent non-protected areas ..............................................174

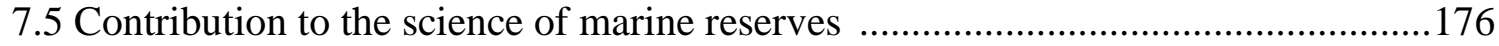

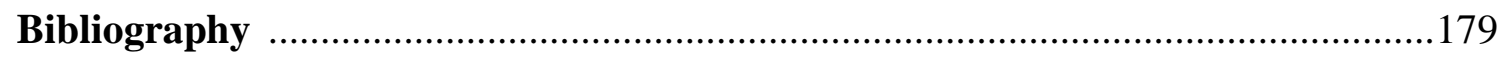

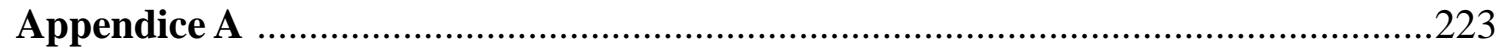




\section{List of figures}

2.1 Location of New Zealand marine reserves included in the response ratio (RR) analysis

2.2 Best-fit relationship for the scatter plot of response ratio values (RRrecent) as a function of marine reserve (MR) size and MR Age 24

2.3 Best-fit relationship for the scatter plot of response ratio values (RRmax) as a function of marine reserve (MR) size and MR age ......................... 26

2.4 Best-fit relationship for the scatter plot of response ratio values (RRmax) as a function of marine reserve (MR) size for small and large reserves and as a function of MR age for young and old reserves

2.5 Species-specific relationships between response ratio values (RRrecent) and Hedges' $g$ statistic 30

2.6 Hedges' $g$ statistic as a function of response ratio values (RRrecent)... 31 
3.1 Map of study area showing the sites surveyed inside the Taputeranga MR and in the adjacent fishing grounds

3.2 New Zealand Fisheries Management Areas as established in the Fisheries Act 1996

3.3 Response ratio (RR) values as a function of time (sampling occasion) for each species 59

3.4 Difference between mean fish density in reserve and fished sites (BACIPS analysis) for each species 61

4.1 Map of the study area showing the sites surveyed 78

4.2 BUV camera view. (A) vertical BUV camera stand and (A) horizontal BUV camera stand. 79

4.3 Relationship between fish head length $(\mathrm{cm})$ and total length $(\mathrm{cm})$ for blue cod 81

4.4 Mean species richness \pm SE recorded at all the sites surveyed with both BUV techniques

4.5 Mean density (Nmax) \pm SE for each fish species recorded with the two BUV methodologies (Horizontal/Vertical). (A) blue cod, (B) spotty and (C) other species. 86

4.6 Mean length $(\mathrm{cm}) \pm \mathrm{SE}$ for each fish species recorded with the two BUV methodologies (Horizontal/Vertical).

4.7 Number of fish measured as function of fish abundance. Expected values (dotted line) with corresponding 95\% confidence intervals (solid line) ..... 88 
5.1 Map of the study area showing the sites surveyed inside the Taputeranga MR and in the adjacent fishing grounds 104

5.2 Mean species richness \pm SE recorded at each site in 2011 and 2012 for the two different methodologies: (A) Underwater Visual Census (UVC); and (B) Baited Underwater Video (BUV). 114

5.3 Mean density \pm SE recorded with the UVC methodology at each site in 2011 and 2012 for common species: (A) blue cod, (B) scarlet wrasse, (C) spotty, (D) blue moki, (E) banded wrasse, and (F) butterfish 115

5.4 Mean density \pm SE recorded with the UVC methodology at each site in 2011 and 2012 for uncommon species: (A) leatherjacket, (B) jack mackerel, (C) marblefish, (D) red moki, (E) kahawai, (F) pufferfish (G), tarakihi .. 116

5.5 Mean length $(\mathrm{cm}) \pm \mathrm{SE}$ recorded with the UVC methodology at each site in 2011 and 2012 for common species: (A) blue cod, (B) scarlet wrasse, (C) spotty, (D) blue moki, (E) banded wrasse, and (F) butterfish 118

5.6 Mean density \pm SE recorded with the BUV methodology at each site in 2011 and 2012 for common species: (A) blue cod, (B) spotty, and (C) banded wrasse

5.7 Mean density \pm SE recorded with the BUV methodology at each site in 2011 and 2012 for uncommon species: (A) scarlet wrasse, (B) butterfish, (C) blue moki, (D) tarakihi (E) kahawai, and (F) leatherjacket 120

5.8 Mean length $(\mathrm{cm}) \pm \mathrm{SE}$ recorded with the BUV methodology at each site in 2011 and 2012 for common species: (A) blue cod, (B) spotty, and (C) banded wrasse 123 
5.9 Best fit relationships between mean fish density and distance from the boundaries of the Taputeranga MR. (A) blue moki (UVC survey) best fit linear decay model, (B) butterfish (UVC survey) best fit linear decay model and $(\mathrm{C})$ blue cod (BUV survey) best fit exponential decay model

6.1 Map of the study area showing the sites surveyed. Green areas correspond to intertidal reef.

6.2 Photographic sequence showing the tagging procedure on board the Victoria University research vessel. (A) fish inside the holding tank aboard the vessel, (B) measuring fish length, (C) inserting the tag at the base of the dorsal fin, and (D) tagged individual before being released 141

6.3 Denison gun (tag applicator) with T-bar anchor tags inserted and ready for application 142

6.4 Mean blue cod CPUE (number of fish per hook per min) \pm SE in each season for reserve and fished areas in 2010 and 2011 148

6.5 Mean blue cod length $(\mathrm{cm}) \pm \mathrm{SE}$ recorded in 2010 and 2011 in reserve and fished areas. (A) fished area 2010 survey, (B) fished area 2011 survey, (C) reserve area 2010 survey and (D) reserve area 2011 survey 149 6.6 Length-frequency distribution of blue cod recorded in 2010 and 2011 in reserve and fished areas. (A) fished area 2010 survey, (B) fished area 2011 survey, (C) reserve area 2010 survey and (D) reserve area 2011 survey .. 150

6.7 Estimated parameters ( $\pm 95 \%$ CI, represented by dashed lines) of blue cod in reserve and fished areas, according to model Phi $\left(\mathrm{s}^{*} \mathrm{t}\right) \mathrm{p}(\mathrm{t})$. (A) estimated and $(\mathrm{C})$ estimated capture probability 153

6.8 Map of study area and surrounding locale showing the direction of 
movement and distance travelled by fish recaptured inside the study area (short distance movement).

6.9 Relationship between blue cod length $(\mathrm{cm})$ and distance moved $(\mathrm{km})$ for fish recaptured. (A) fish recaptured inside the study area (short distance movement), (B) fish recaptured outside the study area (long distance

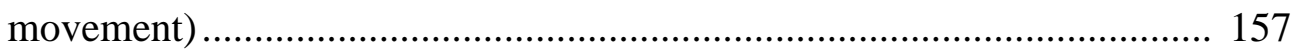

6.10 Map of study area and surrounding locale showing the direction of movement and distance travelled $(\mathrm{km})$ by fish recaptured outside the study area (large distance movement) ....................................................... 158 


\section{List of Tables}

2.1 Marine reserve variables (area, year of establishment and age) and species-specific data sets used in the analysis.... 20

2.2 Test results (linear and non-linear functions plus Spearman's rank correlation analysis) for the response ratio (RRrecent) for blue cod (BC) and rock lobster (RL) density and size with respect to marine reserve (MR) area and age. 25

2.3 Test results (linear and non-linear functions plus Spearman's rank correlation analysis) for the response ratio (RRmax) of blue cod (BC) and rock lobster (RL) density and size with respect to marine reserve (MR) area (small $[\leq 1000 \mathrm{ha}]$ and large $[>1000 \mathrm{ha}]$ ) and age(young $[\leq 10 \mathrm{yr}]$ and old $[>10 \mathrm{yr}])$. 27

3.1 Underwater Visual Census survey information (year, season and sites surveyed). Observer: Pande (Pande \& Gardner 2009), Eddy (Eddy 2011), Diaz-Guisado (this thesis) .53

3.2 BACIPS analysis on the effects of marine reserve protection on the abundance of fish species in the Taputeranga MR 60

4.1 Abundance (number of fish) and occurrence (number of deployments xxiii 
where fish were recorded) of fish species for both BUV methodologies. Also, the average number of that species recorded per deployment and the standard errors are shown

5.1 Sites surveyed with each methodology in the 2011 and 2012 surveys. Status; F (fished) and R (reserve) 106

5.2 Classification of target species according to mobility patterns 109

5.3 Species recorded with each methodology in the 2011 and 2012 survey

5.4 Details of significant linear regressions of density versus distance at the western and eastern boundary of the Taputeranga MR and the output for the best model fit found in the analysis

6.1 Summary table of the total numbers of fish tagged in the catch-markrecapture survey and additional information. Total catch included tagged fish, recaptured fish, dead fish and injured fish that were released

6.2 Descriptive statistics derived from the blue cod length frequency distribution analysis 148

6.3 A summary of blue cod resighting information based on the number of individuals released on each occasion, and when (and how many) they were captured on subsequent occasions.

6.4 Summary of blue cod movements derived from the analysis of fish recaptures inside the study area 156

6.5 Summary of blue cod movements derived from the analysis of fish recaptures outside the study area..... 
Chapter 1

\section{General Introduction}




\subsection{Overview of the use of conventional fishery management tools}

Marine ecosystems worldwide are seriously threatened by human activities (Claudet et al. 2010, Navarrete et al. 2010). Fishing is one of most serious impacts on marine systems (Hyrenbach et al. 2000, Jackson et al. 2001). Evidence suggests that major structural and functional changes have occurred in marine systems due to overfishing over many centuries (Botsford et al. 1997, Jackson et al. 2001, Vié et al. 2009). Reviews of the impact of fishing on a range of marine ecosystems show that harvesting of some species, especially predators, can have a major impact on ecosystems (Jennings \& Kaiser 1998, Pauly et al. 1998, Jackson et al. 2001, Worm et al. 2006). Interestingly, ecological changes due to overfishing are strikingly similar across ecosystems and the magnitude of losses have been enormous in terms of biomass and abundance of large animals (Jackson et al. 2001). For example, Worm et al. (2009) found an increasing trend of stock collapses over time, such that $14 \%$ of assessed stocks (from a total of 166 stocks evaluated) had collapsed in 2007. They used $10 \%$ of unfished biomass as a level to define collapse suggesting that at such low abundance recruitment may be severely limited and species may cease to play a substantial ecological role. However, Worm et al. (2009) also found that the average exploitation rate was at or not far below the rate predicted to achieve maximum sustainable yield. This estimate is in the same range as figures provided by the United Nations Food and Agriculture Organization (FAO), which estimated that $19 \%$ of stocks were overexploited and $9 \%$ depleted or recovering from depletion in 2007 (FAO 2009). Also, the FAO in 2012 estimated that most of the stocks of the top ten species, which account in total for about $30 \%$ of world marine capture fisheries, are fully exploited and therefore have no potential for increases in production. In a global meta-analysis of overfished stocks, Neubauer et al. (2013), suggested that the majority of stocks are resilient to moderate overfishing and have a good chance of recovering within 10 years if fishing pressure is reduced rapidly and substantially, but for many currently depleted stocks, continued overfishing not only delays rebuilding but also substantially increases the uncertainty in recovery times. In addition, the impacts of fishing are not only on the target species, but there are also 
unintended consequences of fishing including habitat destruction, incidental mortality of non-target species, evolutionary shifts in population demographics, and changes in the function and structure of ecosystems (Botsford et al. 1997, NRC 2002, Pikitch et al. 2004, Harnik et al. 2012).

A growing awareness of the number of managed fisheries that have declined to low levels has led to disenchantment with conventional fishery management tools (Browman \& Stergiou 2004, Botsford et al. 2009). It has been argued that conventional management approaches like Maximum Sustainable Yield (MSY) have contributed to the failure of regulations that aim to sustain fisheries mainly due to the substantial uncertainty associated with fishery stock assessment and management. In many cases the relationship between sustainable yield and fishing effort is not known with sufficient confidence to prevent pressure for increased yields from driving fishing rates to excessive levels (Ludwig et al. 1993, Botsford et al. 1997, Hart 2013). However, Hilborn (2007a) suggested that there is a conflict in the perceptions of the status of fisheries and marine ecosystems that comes from a focus on abundance-based analysis as opposed to sustainable yield and that some fish stocks might be at relatively low abundance, indicating failed management to some, while still producing at or near MSY, indicating success to others. Thus, in terms of MSY, declines in abundance as the fishery develops are an inevitable consequence of achieving sustainable yield, but are often seen as signs of serious concern by those interested primarily in abundance (Hilborn 2007a). It is important to clarify that successive fisheries modelling derivations have been proposed in order to reduce in fishing mortality near $\mathrm{F}_{\mathrm{MSY}}$ (fishing mortality needed to achieve MSY), and consequently reduce the probability of overfishing and stock collapse, in exchange for slightly reduced expected yield (e.g., Hart 2013).

On the other hand, it has been argued that for many temperate species there is nothing fundamentally wrong with either the methodology of stock management or the available effort controls used in conjunction with other management tools (e.g., Total Allowable Catches and Quotas) and that, in those cases when fishing effort has been implemented effectively, fisheries have been managed successfully (Cunningham 2005, Kaiser 2005). Hilborn (2007a) suggested that the effectiveness of fisheries management world-wide differs considerably, and fisheries management is working in some places 
and failing in others, suggesting that in many countries (e.g., USA, Iceland, New Zealand and Australia) management systems, such as dedicated access privileges (e.g., Cooperatives, Community Development Quotas and Individual Transferable Quotas), are working to achieve sustainable fisheries. Furthermore, Halpern et al. (2012) created an index to assess the health and benefits of the couple human- ocean system. The index comprised ten diverse public goals for a healthy system (e.g., biodiversity, coastal protection, fisheries and clean waters among others). They found that, globally, the overall index score was 60 out of 100 (only 5\% of the countries scored higher than 70 and 32\% scored lower than 50). "Biodiversity" scores were surprisingly high reflecting that relatively few know marine species risk extinction (Halpern et al. 2012).

While there is disagreement over just how severely depleted some fish stocks are, and on whether and how quickly they will recover, all agree that many stocks are overexploited and current levels of overcapacity in the world's fishing fleets are not sustainable (Browman \& Stergiou 2004). Although for a long time the goal of management, generally based on single-species assessments (see Botsford et al. 1997), was to manage populations for maximum possible output for humans, over the last few decades there has been increasing recognition within fisheries management agencies that there are a range of benefits to be obtained by maintaining fish stocks at levels higher than would produce MSY and that traditional fisheries management objectives of maximizing yield and employment lead to heavily exploited stocks (Hilborn 2007a, b). Probably, the major problem is that the concept has rarely been treated seriously as a fishing target and is therefore routinely exceeded, often substantially (Browman \& Stergiou 2004). Indeed, fishing mortality rates exceeding 2 to 3 times the single-species optimum have been common in the past and still exist in many fisheries, usually driven by political pressure to allow greater short-term benefits to society (Botsford et al. 1997, NOAA 2002, ICES 2003, Browman \& Stergiou 2004). However, Costello et al. (2008), by compiling a global database of fisheries institutions and catch statistics, showed that rights-based catch shares can provide individual incentives for sustainable harvest and promote local stewardship, sometimes stopping, and even reversing, the global trend toward widespread collapse. Costello et al. (2008) suggested that institutional regulations have the potential for greatly altering the future of global fisheries. 


\subsection{Alternative fishery management approaches}

In light of documented effects of fishing on the marine ecosystems, in recent decades there has been a growing call for biological objectives associated with reducing fishing impacts and the protection of non-target species and ecosystems (Pikitch et al. 2004, Hilborn 2007b, Halpern et al. 2010, Fraschetti et al. 2011). Increasingly, attention has focused on alternative management approaches, including Marine Protected Areas (MPAs) defined by the International Union for Conservation of Nature (IUCN) as "a clearly defined geographical space, recognized, dedicated and managed, through legal or other effective means, to achieve the long-term conservation of nature with associated ecosystem services and cultural values". MPAs have been considered a precautionary approach to deal with management failures in case of poor stock assessments and/or inadequate political will to set adequate management tools at biological and economic sustainable levels. Furthermore, MPAs are especially important in light of environmental fluctuations that are recognized as a source of major uncertainty in fisheries (Lauck et al. 1998, Sanchirico 2000, Allison et al. 2003). However, in many countries, the broad concept of MPAs has little practical value for marine planning and management (Ballantine 1999, Ballantine \& Langlois 2008, FAO 2012). MPAs vary greatly in their regulations and their utility for conservation likely varies considerably based on the level of protection afforded, making it difficult to generalize the benefits of MPAs (Mora et al. 2006, Lester \& Halpern 2008). Indeed, some studies have shown that MPAs do not offer effective protection for some species and habitats (see Kelleher et al. 1995, Kaiser 2005).

In contrast to the broad term 'MPAs', marine reserves (i.e., MRs areas of the oceans where no disturbance is allowed; Lubchenco et al. 2003), have emerged as a more simple concept for marine planning that can be easily understood by non-experts (Ballantine 2014). MRs offer the greatest protection for marine resources and ecosystem and represent the extreme case of the precautionary approach to managing marine resources and do not replace other management systems, but are additional to, and supportive of them (Lubchenco et al. 2003, Browman \& Stergiou 2004, Roberts et al. 2005, Ballantine 2008, Lester et al. 2009, FAO 2012). 
Worldwide, MRs have been established for a variety of reasons and supported by a variety of legislation, with many scientists believing that they provide a wide range of benefits (Lubchenco et al. 2003, Roberts et al. 2005). Today, under a variety of names, MRs exist in many biogeographic regions of the world, and protect a wide range of habitats. They can operate successfully for a range of cultures, economies and government systems and there are reasons to believe that they would function equally well in all regions and provide wider benefits (Ballantine 1999, Ballantine \& Langlois 2008). Effects of reserves vary for different taxonomic groups and for taxa with various life stories characteristics as a function of MR design (e.g., Blyth-Skyrme et al. 2006, Lester et al. 2009, Claudet et al. 2010). In conservation terms MRs may allow the recovery, defined as the increase in abundance and/or size of individuals inside MRs, of a full range of marine biodiversity protecting both species and their habitat, providing favourable conditions for the development of populations and allowing the maintenance of natural ecosystem structure and functioning (Roberts \& Hawkins 2000, Ballantine 2014).

The recovery of previously targeted species is one of the most commonly reported effects of MRs. Several studies have suggested that many species, especially those that are actively targeted by fisheries, increase in density and/or size inside MRs (e.g., Mosquera et al. 2000, Côté et al. 2001, Halpern \& Warner 2002, Halpern 2003, Pande et al. 2008, Lester et al. 2009). Also, several studies have suggested that the response to protection occurs rapidly after only a few years following reserve establishment (Halpern \& Warner 2002, Ballantine \& Langlois 2008, Díaz- Guisado et al. 2012). Even though many reports evaluating the impacts of MRs have been published worldwide but it is difficult to identify general trends in MR performance for different species at different geographic locations and for different time periods. Also it is difficult to predict the biological outcomes because MRs vary considerably in the extent and direction of their response (Pande et al. 2008). Furthermore, very few studies have reported the effect of marine reserves at broader scales and included long-term data (but see Davidson et al. 2009, Stobart et al. 2009, Babcock et al. 2010, Rife et al. 2013). 


\subsection{Marine reserves in New Zealand}

In New Zealand (NZ), MRs are areas where all forms of extractive use including commercial, traditional and recreational fishing are prohibited and have been created under The Marine Reserves Act 1971 for the purposes of "preserving the marine environment in the natural state as the habitat of marine life for scientific study". In fact NZ MRs have constituted an important tool that have allowed scientists to collect information on coastal marine environments because they act as a control or baseline reference of how marine systems are structured and function in the absence of disturbance produced by fisheries (e.g., Pande et al. 2008, Eddy 2011, Ballantine 2014). Indeed the establishment of MRs allows a whole range of new comparisons to be made and ultimately, such knowledge is important for successful conservation and management of exploited areas, allowing more informed decision making about marine conservation (Creese \& Jeffs 1992, Ballantine 1991, Halpern \& Warner 2002). Also, recently, reserves have been incorporated into assessment models for data-limited fisheries management becoming a key reference point for estimating spawning potential and yield per recruit. Wilson et al. (2013) suggested that the use of reserve- based approaches can be carried out in many fisheries for sedentary near-shore species with a dispersive larval stage and may provide a simple and cost-effective strategy for the management of local resources.

The first reserve in NZ, the Cape Rodney - Okakari Point (CROP) MR, was established in 1975 and after nearly 40 years there are now 37 no-take MRs, protecting $\sim 7.0 \%$ of NZ's territorial waters (Department of Conservation 2014). In the CROP MR, it took more than 20 years before major habitat changes occurred (Babcock et al. 1999), but after that several studies have suggested the recovery of previously target species, mainly fishes, but also some invertebrates (Kelly et al. 2000, Taylor et al. 2003, Haggitt \& Kelly 2004, Haggit et al. 2008). Some of these studies have detected indirect changes in this reserve, for example, trophic cascades that have been caused by the recovery of previously fished predators such as snapper (Pagrus auratus), which were almost absent from the region before the reserve was established, and also rock lobster (Jasus edwardsii). From the experience of the CROP MR ecological changes in MRs are 
considered to be complex and often ecologically important; they can also occur a long time after the reserve is established and there is no theoretical limit to this development (Ballantine \& Langlois 2008).

In the last few decades scientific research has increased in NZ and ecological monitoring programmes have been established in many of the existing MRs. As for the CROP MR, many other NZ MRs have reported similar effects for specific species, with most of the emphasis focusing on the economically important species such as blue cod (Parapercis colias) and rock lobster (J. edwardsii). Both these species are widely distributed throughout New Zealand and are under heavy fishing pressure because they are targeted by both the commercial and recreational sector and also have a large Mãori customary value in many areas (Ministry of Fisheries 2008).

Even though the first years after the establishment of the first MR in NZ were difficult, considerable progress has been made and after more than 30 years the creation of new reserves is still a priority for the government and therefore the generation of new information on the effects of reserve protection is still valuable. The evidence and theory from examples worldwide shows that MRs perform vital roles in ecosystem protection. Consequently many managers and politicians world-wide have stated their intent to establish networks of MRs to protect all different types of marine habitats (Pande et al. 2008, Walls 2008). In some countries this is already happening, for example, the first representative system of marine reserves in the world was established in Victoria, Australia in 2002 and a year later a representative and replicated system was created around the northern Channel Islands off the California coast. Also, in 2004 a major system of MRs was established in the Great Barrier Reef Marine Park (Australia). Appropriately designed and managed MR networks can have many benefits compared with a single MR. A network may be more flexible with regard to the distribution of social and economic costs and benefits among various stakeholders and users, while still achieving fisheries management and biodiversity conservation objectives (Gaines et al. 2010, FAO 2012).

Even though a large body of literature exists, i.e., several monitoring results have shown increases in the mean size and/or density of some species at MR sites compared with unprotected areas (e.g., Kelly et al. 2000, Taylor et al. 2003, Freeman 2008, 
Davidson et al. 2009), it is still difficult to assess the possible conservation benefits of multiple MRs across NZ based on individual studies. Indeed, the responses in newlycreated reserves are not predictable even after 50 years of experience with MRs (Langlois \& Ballantine 2005). Furthermore, there is very little information on the biological or economic effects of MRs outside the protected areas and how these factors can affect success. The lack of information inhibits policymakers from assessing the true net costs and benefits of establishing MRs, and from gaining a true picture of where and under what conditions they will be effective (Sanchirico 2000). Even though fisheries enhancement is not a primary reason for MR designation in many countries, in general, fully protected areas are expected to support external fisheries by the net exportation of biomass in the form of larval export ("recruitment effect") and the export of juvenile and adults, hereafter referred as "spillover" (Gell \& Roberts 2003a). Larval replenishment through dispersal of larvae from females protected within reserves has received far greater conceptual emphasis than spillover (Kellner et al. 2008). Although many scientists believe that larval export occurs from protected areas, it has been very difficult to demonstrate (Pelc et al. 2010). Inherent difficulties in collecting and interpreting the data needed to document larval export may explain the relative scarcity of empirical evidence (but see Bell 2008, Cudney- Bueno et al. 2009, Pelc et al. 2010, Harrison et al. 2012). Therefore, spillover is usually referred as the only tangible index of potential fishery benefit of MRs. There have been several well documented cases of spillover for a wide range of exploited species (see Russ 2002, Gell \& Roberts 2003a). Although potential gains from spillover are predicted to be only moderate compared to those derived from larval export, the occurrence of spillover may play a critical role in convincing fishermen to support establishment and maintenance of reserves (Russ \& Alcala 1996, Abesamis et al. 2006a). However, more convincing evidence is still required.

The Taputeranga Marine Reserve (TMR), located on the south coast of the capital of New Zealand, Wellington, was gazetted in 2008. This reserve, like most of reserves in the country had a long period of gestation (i.e., formal application for the reserve was made in October 2000) that have involved the work of local residents, scientists at Victoria University of Wellington and the Royal Forest and Bird Protection Society of 
New Zealand (Gardner et al. 2008). As part of the process, a baseline survey was conducted during an early stage of the proposal for the reserve, between 1998 and 2000. The historical assessment of the efficacy of MRs in NZ has not been possible (but see Pande \& Gardner 2008) and, as a consequence, monitoring typically involves the comparison of sites inside MRs with non-MR or control (fished) sites (i.e., 'inside' versus 'outside' comparisons). In this context, the study of the changes occurring in the TMR provided a unique opportunity to quantify the ecological changes associated with a newly established full no-take marine reserve and further monitoring of the reserve will represent one of the most comprehensive and robust baseline data sets available anywhere in the world.

\subsection{Thesis structure}

In this thesis, the biological effects of protection provided by MRs in New Zealand were evaluated, particularly the potential impacts of reserves on non-protected areas in terms of export of biomass.

The specific objectives of this thesis are to: (i) quantify the effects of age and size of marine reserves on the density and size of targeted species to determine the biological effects of protection provided by marine reserves using New Zealand examples; (ii) examine changes in density and size of fish species protected in the Taputeranga Marine Reserve (TMR) and adjacent fishing grounds to determine early changes in the fish assemblage due to protection; (iii) examine spatial differences in fish density and size between reserve and fished areas and movement of fish through the boundaries of the TMR to determine the occurrence of spillover from the reserve to fished areas.

In chapter two, a meta-analysis was carried out in order to detect the effect of New Zealand marine reserves in the density and size of two targeted species, blue cod and rock lobster. Both published and unpublished data were used, including data from 13 New Zealand MRs, each of which was sampled at different times over a maximum time period of $\sim 30 \mathrm{yr}$. A comparison of a meta- analysis based on Hedges' $g$ statistics and a new approach based on a response ratio (RR) analysis was performed. Also, the effect of 
MR size and age on biological responses was evaluated.

In chapter three, a multispecies analysis was carried out in order to detect early changes in the fish assemblage inside the TMR and in the adjacent fishing grounds in the form of spatial differences in fish density. Both a before- after control -impact paired series design (BACIPS) and a response ratio (RR) analysis were used to analyse a dataset that consisted of a 14-year time series obtained from several underwater visual census (UVC) surveys performed in the study area.

In chapter four, a field survey was carried out in order to compare two baited underwater video (BUV) methodologies (horizontal versus vertical set-up) in terms of their ability to record density and length of reef fish to determine the most appropriate methodology to be used in a later study.

In chapter five, a multispecies analysis was carried out to assess the changes inside the TMR and in adjacent fishing grounds in order to detect spatial differences in fish density and length that could be related to the occurrence of spillover from the reserve to adjacent fished areas. I used data obtained from both an UVC and a BUV survey.

In chapter six, spatial differences in density and size of blue cod inside the TMR and adjacent fishing grounds were examined. The movement patterns of the species across the boundaries of the reserve through a capture- mark- recapture (CMR) analysis were evaluated. Also, the recaptured histories of the recaptured fish and the differences in survival and recapture probabilities inside versus outside the reserve were examined. 


\section{Chapter 2}

Comparison of Methodologies to Quantify

the Effects of age and size of Marine

Reserves on the Abundance and Size of

Targeted Species 


\subsection{Introduction}

While no-take marine reserves (MRs) have become a highly advocated form of marine conservation, there is a widespread recognition of the need to quantify the conservation benefits they provide (Allison et al. 1998, Halpern \& Warner 2002, Pande et al. 2008, Botsford et al. 2009). Because MRs in different parts of the world are set up and managed for different purposes (e.g., fisheries enhancement, biodiversity protection, and scientific research), the extent and direction of their biological outcomes may vary considerably. However, several recent reviews that have evaluated results from separate studies worldwide to quantify MR outcomes suggest that many species, especially those that are actively targeted by fisheries, increase in abundance and/or size inside MRs (Halpern \& Warner 2002, Halpern 2003, Pande et al. 2008, Lester et al. 2009, Babcock et al. 2010, Claudet et al. 2010, Guarderas et al. 2011, Nursey-Bray 2011, Fenberg et al. 2012).

In New Zealand (NZ), MRs have been established for the purposes of "preserving the marine environment in the natural state as the habitat of marine life for scientific study" (Marine Reserves Act 1971). The first MR in New Zealand was established in 1975, and as of early 2014 there are 37 no-take MRs (Department of Conservation 2014). Established reserves cover a wide latitudinal range, including the sub-Antarctic region, and protect a wide range of habitats from estuaries, harbours and fiords, to all types of open coast areas including off-shore islands (Ballantine 2014). Partially or wellestablished ecological monitoring programmes exist in many of these MRs but due to the lack of baseline data (i.e., very few baseline data sets have been gathered to allow 'before versus after' comparisons) historical assessments of the efficacy of MRs are usually not possible. Consequently, monitoring typically involves the comparison of sites inside MRs with non-MR 'control' or fished sites (i.e., 'inside' versus 'outside' comparisons). Although some monitoring results have shown increases in the mean density and/or mean size of some species at MR sites compared with unprotected sites, it is still difficult to assess the possible conservation benefits of MRs in NZ based on individual studies because the generality of response cannot be determined from single MRs (Kelly et al. 2000, Willans 2003, Pande et al. 2008, Davidson et al. 2009). 
Nonetheless, the aim of the NZ government is to protect $10 \%$ of the coastal marine environment via the establishment of Marine Protected Areas (MPAs, defined here as any form of protection and not just no-take MRs) to assure the maintenance and recovery of biological diversity at the habitat and ecosystem level. A key component of this strategy is to monitor MPAs to assess their effectiveness at achieving biodiversity conservation objectives (Department of Conservation and Ministry of Fisheries 2005).

A variety of statistical approaches can be used to quantify MR effects. Commonly, meta-analysis is used to combine the results of multiple independent studies, all of which have tested the same hypothesis. This approach determines if enough evidence exists in the combined studies to detect an 'overall' outcome. This statistically rigorous approach moves beyond simple 'vote counting' or narrative review because it is a quantitative synthesis that allows for objective appraisal of the evidence (Arnqvist \& Wooster 1995, Egger et al. 1997, Osenberg et al. 1999a, b). Perhaps because of its lack of familiarity to marine scientists or because of its statistical complexity (e.g., Berman \& Parker 2002), or because of the lack of accurate error estimates in the studies being reviewed, few meta-analyses of this type have been conducted for MRs or MPAs. However, those that have been conducted have reported that MRs support more and larger individuals of many species than neighbouring unprotected areas (e.g., Mosquera et al. 2000, Côté et al. 2001, Pande et al. 2008, Lester 2009, Molloy 2009, Guarderas et al. 2011).

The most frequently employed effect size metric in meta-analysis (Hedges' $g$ ) requires that variances, as well as means, are known, but in fact this is often not the case from published reports (Mosquera et al. 2000). From this information the magnitude and significance of an overall effect can be calculated across all studies. The overall effect size is calculated from the effect size of each individual study. An important step in this meta-analysis is the calculation of effect size homogeneity across all studies. If the test fails, then the meta-analysis stops at this stage due to the significant difference among the effects that individual MRs have on the biological index and it is assumed that it is inappropriate to combine 'heterogeneous' data from the separate studies. Pande et al. (2008) employed the Hedges' $\mathrm{g}$ index to assess the response of blue cod (Parapercis colias) and rock lobster (Jasus edwardsii) to full no-take MR protection in NZ. These 
authors observed significant differences amongthe effects that individual MRs had on the variables studied and they were unable to combined the results of the individual studies to provide an overall significance estimate of the effect that all MRs had on these species. However, they found evidence of a significant positive effect of reservation status on the size and abundance of the species analysed (i.e., Hedge's g values suggested greater abundance and size of species inside reserves).

An alternative approach to Hedges' statistic meta-analysis is the response ratio (RR) meta-analysis that has been used widely to describe the effects of MRs. This method does not require knowledge of variances because it quantifies the proportional change resulting from MR implementation by measuring the relative differences in a biological response (e.g., size or abundance) inside versus outside the MR (Adams et al. 1997, Goldberg et al. 1999, Hedges et al. 1999, Gates 2002). While it is possible to test RRs for homogeneity of responses analogous to the effect size test described above (Mosquera et al. 2000), very few analyses employing RR do so. Recent studies by Halpern \& Warner (2002), Halpern (2003), Micheli et al. (2004), Lester et al. (2009), Molloy et al. (2009) and Guarderas et al. (2011) all calculated RRs from multiple MRs worldwide to evaluate effects of protection on many invertebrate and fish species. They found consistent positive effects of MRs, suggesting that MRs achieve their stated or implicit conservation goals.

Overall, both forms of meta-analysis have demonstrated that marine protection can increase species abundance and size, particularly for species targeted by fishers. Most of these studies have demonstrated that the response to MR protection may be independent of MR size (e.g., Côté et al. 2001, Halpern 2003, Pande et al. 2008, but see Claudet et al. 2008, Guarderas et al. 2011) but influenced by MR age (Claudet et al. 2008, Molloy et al. 2009 but see Guarderas et al. 2011), and it is usually dependent on the species being analysed (Mosquera et al. 2000, Micheli et al. 2004, Lester et al. 2009). Despite the burgeoning publication of papers that use results from multiple studies to test hypotheses about biological change resulting from marine protection, there is presently no standard statistical approach for such studies.

The aim of the present study was two-fold: (1) to compare the efficacy of the commonly used Hedges' $g$ meta- analysis against the less commonly used meta-analysis 
based on RRs to determine ease of use and comparability of results; and (2) to quantify, using the RR analysis, the biological response of two heavily exploited species to MR protection along a north-south latitudinal gradient of $\sim 11$ degrees $(\sim 1250 \mathrm{~km})$ in New Zealand.

\subsection{Methods}

The study combined published and unpublished data from 13 New Zealand MRs (Fig. 2.1), each of which was sampled at different times over a maximum time period of $\sim 30$ yr (Table 2.1). Two widely distributed species in New Zealand were selected for this analysis; blue cod and rock lobster. Both species are targeted by both the commercial and recreational sector and also have a large Mãori customary value in many areas (Ministry of Fisheries 2008) and have been monitored in a number of MRs. Comparable data for other NZ species do not exist. For both species, density (no. ind. $\mathrm{m}^{2}$ ) and length (cm) data were extracted from studies using only the underwater visual census (UVC) methodology (McCormick \& Choat 1987). The blue cod analysis used data from 8 MRs, including 20 separate studies (density: $8 \mathrm{MRs}$; length: $5 \mathrm{MRs}$ ). The rock lobster analysis used data from 13 MRs, including 24 separate studies (density: 13 MRs; length: 12 MRs): see Table 2.1 for details. All studies included measurements from inside MRs and from at least one control area outside the same reserve and in close proximity to it. This is the same data set used by Pande et al. (2008) for their Hedges' $g$ meta-analysis but with the addition of new survey periods and new sites (blue cod: 8 versus $5 \mathrm{MRs}$; rock lobster: 13 versus $10 \mathrm{MRs}$ ). All original studies included in the analyses were specifically conducted for the purposes of monitoring either blue cod or rock lobster, and as such all were conducted in habitat appropriate for each taxon.

It was noted that in an ideal world the MR sites will be the same in all respects as the nearby fished sites. Also, it was also noted that spillover from the MR into the fished region may actually reduce the chance of seeing a significant difference between the $\operatorname{MR}(\mathrm{s})$ and the fished sites. Thus, analyses of this type may tend to be conservative. However, the spillover effect may be counteracted by other factors, such as increased 
fishing effort in the fished region (i.e., displacement of fishing activity from the MR to regions just outside). Because of the absence of knowledge about site-specific spillover and displaced fishing activity, analytical consideration of such matters is not possible in any meta-analysis. While the number of sites surveyed, the duration (total no. of years) of each study, and the timing of surveys all varied among studies, all studies were given equal weight in the analyses because there was no a priori reason to provide greater weight to any one study or group of studies than to the rest.

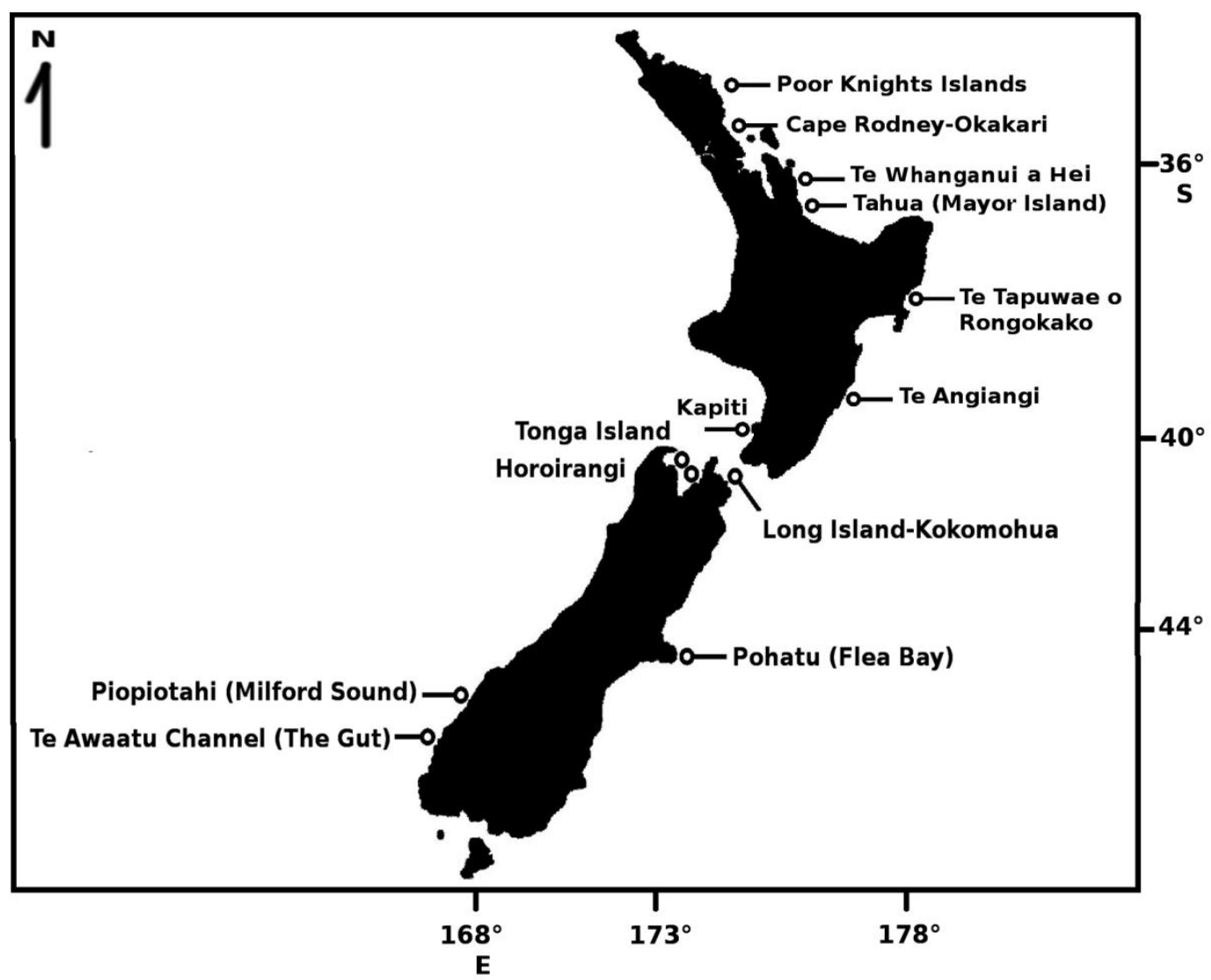

Figure 2.1: Location of New Zealand marine reserves included in the response ratio (RR) analysis.

\subsubsection{Response ratio $(\mathrm{RR})$ analysis}

Consistent with their use elsewhere (e.g., Halpern \& Warner 2002, Halpern 2003, Lester et al. 2009), response ratios (RRs) were calculated by dividing values of mean density or 
mean length inside the reserve by values from fished sites. RRs $>1$ indicate individuals are bigger or more abundant inside reserves relative to fished sites. RRs are site-specific and therefore reflect local conditions. For example, where increased growth rates of blue cod in colder waters may be expected, this will be true of the cold-water MR sites and its neighbouring fished sites. Thus, the RR calculated for this site may be compared directly with the RR calculated from a northern, warm water site because both tell us about the magnitude of the local response. In this context, RR were compared across all sites with the expectation that every other local conditions were constant but I recognise that this may not be case, i.e., maybe warmer temperatures influence several other variables (e.g., increased macroalgal growth, or increased rates of predation). Nonetheless, RR is a valid index for comparing the MR responses at many sites - indeed it is often the only index than can be use for comparison. However, the RR values do not provide information about actual fish density or length inside versus outside the MR, or about actual fish density or length when comparing between cold and warm sites.

For the purposes of statistical analysis, two data sets were generated. First, for both the blue cod and rock lobster density and length data sets, the single most recent survey regardless of its date (and its associated RR value) per marine reserve was identified. This data set was called RRrecent because it contains a single value per MR based on only the most recent survey. This approach gives no weighting or consideration to earlier survey data - that is, the history of change is not considered - with the result that the data set may be strongly influenced by one unusual data point for any one MR. Second, for all data sets, individual RR values were calculated for each year of each survey for each MR. The strength of this approach is that individual MRs contributed many year-specific data points reflecting their history of change. The weakness is that such data points are not independent in a statistical sense. Non-independence of data in meta-analyses may be a problem (e.g., Mosquera et al. 2000, Gates 2002, Pande et al. 2008), and for this approach many of the points within this data set are not independent. Nonetheless, this approach is informative and was used here to better understand the responses of blue cod and rock lobster to protection and the effect of MR age and size on these species. This approach was called RRmax because it provides the maximum number of data points per analysis. 
Table 2.1: Marine reserve variables (size, year of establishment and age) and species-specific data sets used in the analysis. *Negative age of reserve at time of study (yr) implies that data were collected before time of establishment of the MR in question.

\begin{tabular}{|c|c|c|c|c|c|}
\hline Marine reserve & $\begin{array}{l}\text { Reserve } \\
\text { size(ha) }\end{array}$ & $\begin{array}{c}\text { Year of } \\
\text { establishment }\end{array}$ & $\begin{array}{l}\text { Age of reserve } \\
\text { at the time of } \\
\text { study } \\
(y)^{2}\end{array}$ & $\begin{array}{l}\text { Data sets used in blue cod } \\
\text { response ratios analysis } \\
\text { (year of study) }\end{array}$ & $\begin{array}{c}\text { Data sets used in rock lobster } \\
\text { response ratios analysis } \\
\text { ( year of study) }\end{array}$ \\
\hline $\begin{array}{l}\text { Cape Rodney to } \\
\text { Okakari Point }\end{array}$ & 518 & 1975 & $10-29$ & $\begin{array}{l}\text { Taylor et al. 2003; } \\
2002-2003\end{array}$ & $\begin{array}{l}\text { MacDiarmid \& Breen (1993); } \\
1992 \\
\text { A. MacDiarmid, unpubl. data; } \\
1995 \\
\text { Babcock et al. (1999); } 1995 \\
\text { S. Kelly unpubl. data; } \\
1995 \text { - } 2002 \\
\text { Haggit \& Kelly (2004); } \\
2003 \text { - } 2004\end{array}$ \\
\hline Poor Knights Islands & 2400 & 1981 & 4 & & $\begin{array}{l}\text { A. MacDiarmid, unpubl. data; } \\
1985\end{array}$ \\
\hline Kapiti Island & 2167 & 1992 & $0-11$ & $\begin{array}{l}\text { Battershill et al. (1993); } \\
1992 \\
\text { Pande (2001); } \\
1998 \text { - 2000 } \\
\text { St ewart \& MacDiarmid } \\
\text { (2003);1999 - 2000 } \\
\text { Struthers (2004); } 2003\end{array}$ & $\begin{array}{l}\text { Stewart \& MacDiarmid } \\
(2003) ; \\
1999-2000\end{array}$ \\
\hline Mayor Island (Tuhua) & 1060 & 1992 & 4 & & S. Kelly, unpubl. data; 1996 \\
\hline $\begin{array}{l}\text { Te Whanganui A Hei } \\
\text { (Cathedral Cove, Hahei) }\end{array}$ & 840 & 1992 & $4-9$ & & $\begin{array}{l}\text { S. Kelly, unpubl. data; } \\
1996 \text { - } 2001\end{array}$ \\
\hline $\begin{array}{l}\text { Te Awaatu Channel } \\
\text { (the Gut) }\end{array}$ & 93 & 1993 & $6-10$ & & $\begin{array}{l}\text { S. Kelly, unpubl. data; } 1999 \\
\text { Smith (2001); 2001 } \\
\text { Williams (2003); } 2003\end{array}$ \\
\hline Piopiotahi & 690 & 1993 & 7- 10 & & $\begin{array}{l}\text { Munn (2000); } 2000 \\
\text { Smith (2002); } 2002\end{array}$ \\
\hline $\begin{array}{l}\text { Long Island - } \\
\text { Kokomohua }\end{array}$ & 619 & 1993 & $-1-11$ & $\begin{array}{l}\text { Davidson (2001a); } \\
1992 \text { - 1997 } \\
\text { Davidson (2004); } \\
1998 \text { - 2003 } \\
\text { R. Cole unpubl. data; } 2001 \\
\text { Davidson et al. (2007); } 2004\end{array}$ & $\begin{array}{l}\text { Davidson (2004); } \\
1992 \text { - } 2003\end{array}$ \\
\hline Tonga Island & 1835 & 1993 & $0-14$ & $\begin{array}{l}\text { Davidson (1999); } \\
1993 \text { - 1994 } \\
\text { Davidson (2001b); } 1999 \\
\text { Davidson et al. (2007); } 2000 \\
\text { - } 2007 \\
\text { R. Cole unpubl. data; } 2001\end{array}$ & $\begin{array}{l}\text { Davidson et al. (2002); } \\
1998 \text { - } 2000 \\
\text { Davidson et al. (2007); } \\
2002 \text { - } 2007\end{array}$ \\
\hline Te Angiangi & 446 & 1997 & $-2-8$ & $\begin{array}{l}\text { Freeman \& Duffy (2003); } \\
1995 \text { - } 2003 \\
\text { Department of Conservation } \\
\text { unpubl. Data; } 2004 \text { - } 2005\end{array}$ & $\begin{array}{l}\text { Freeman }(2008) ; \\
1995 \text { - } 1998 \\
\text { Freeman }(2008) ; \\
1999 \text { - } 2005\end{array}$ \\
\hline Pohatu (Flea Bay) & 215 & 1999 & $1-3$ & $\begin{array}{l}\text { Davidson et al. (2001); } 2000 \\
\text { Davidson \& Abel (2002); }\end{array}$ & $\begin{array}{l}\text { Davidson et al., (2001); } 2000 \\
\text { Davidson \& Abel (2002); }\end{array}$ \\
\hline $\begin{array}{l}\text { Te Tapuwa e o } \\
\text { Rongokako }\end{array}$ & 2452 & 1999 & $1-6$ & $\begin{array}{l}\text { Freeman (2001); } 2000 \\
\text { Freema n (2005); } \\
2001 \text { - } 2004\end{array}$ & $\begin{array}{l}\text { Freeman (2008); } 2000 \\
\text { Freeman (2008); } \\
2004 \text { - } 2005\end{array}$ \\
\hline Horoirangi & 904 & 2006 & 0 & Davidson (2006); 2006 & Davidson (2006); 2006 \\
\hline
\end{tabular}


For only the RRmax analyses the MRs were separated into two groups to test specific patterns, where the size of the data set permitted. Based on size MRs were separated into two groups, small and large MRs ( $\leq$ or $>1000$ ha), whilst based on age they were separated into young and old reserves $(\leq$ or $>10 \mathrm{yr})$. While these distinctions are somewhat arbitrary there is some theoretical underpinning to support these cut off points in terms of the average size and age of NZ MRs, the rate of biological response recorded from various regions, and the life history characteristics of the species in question (Halpern \& Warner 2002, Halpern 2003, Micheli et al. 2004, Pande et al. 2008, Lester et al. 2009, Molloy et al. 2009). Importantly the divisions at $10 \mathrm{yr}$ and 1000 ha allow for sufficient data points for analysis of young versus old and small versus large data sets, and minimise the bias caused by having data from only one or two older (larger) and well monitored MRs. The two RR indices are appropriate for answering different questions and their applicability depends on the type of data available. RRrecent is appropriate for assessment of overall reserve effect, whereas RRmax is appropriate for assessment of temporal changes within reserves. Both indices were used here to be able to explore both aspects (overall reserve effect on blue cod and rock lobsters and temporal change).

\subsubsection{Effect of MR size and age on biological response}

To evaluate the effects of MR size and age on biological response for both data sets, RR values were plotted against MR size (ha) and age (yr) (Table 2.1). Linear and non-linear functions were fitted to species-specific plots to determine the best fits based on correlation coefficient values (SlideWrite Plus v.3, Advanced Graphics). This approach permits the identification of the best-fit relationship without a priori knowledge of the trajectory of the relationship being examined, or without imposing assumptions about the nature of the response. This approach was used as an exploratory tool to see if a pattern exists within the data that may help to better understand the generalised trajectory of the response for the two different species. As a third and final approach, a Spearman's rank correlation analysis (1-tailed tests) was used to test the statistical basis 
of the linear relationship between RR and MR size and age. This analysis was used because it is a non-parametric (rank) test of a linear relationship with minimal assumptions about data distribution. This analysis was conducted using the Statistica software (v 7.1 StatSoft Software). In all cases where fitted lines/curves were highly leveraged by a single point, that point was removed from the data set and the line/curve were re-fitted to re-test for significance.

Based on Mosquera et al. (2000), the homogeneity statistic of Hedges \& Olkin (1985) was used to determine if all biological responses were homogeneous using . In all instances, the test statistic was non-significant ( $p>0.05$ ), indicating that each data set was homogeneous, and that no single MR had an undue effect.

\subsubsection{Comparison of RRrecent versus Hedges' $g$ statistics}

Finally, to compare directly between the RR and Hedges' approaches, RRrecent were plotted against Hedges' $g$ for all comparisons where such data exist. The Pearson's correlation coefficient was used to test for any linear relationship between the two different indices.

\subsection{Results}

In most instances the values for both $\mathrm{RR}$ indices for both species were $>1.0$, indicating greater mean density or length inside the MR than outside (RRrecent: Fig. 2.2; RRmax: Fig. 2.3). Spearman's rank correlation analyses are presented as rank-rank plots. Because of the different number of data points per analysis (see degrees of freedom columns, Tables $2.2 \& 2.3$ ) the two RR indices have different powers to detect significance. 


\subsubsection{RRrecent analyses for blue cod}

The relationship between blue cod density and MR age was statistically significant for all three tests (Fig. 2.2B, Table 2.2). The best fit was observed for the non-linear model, but the two linear models both had $\mathrm{R}$ values similar to that reported for the non-linear model. Removal of one outlier (data point at $28 \mathrm{yr}$ ) removed the significant nature of the relationship for both the parametric and non-parametric linear fits, but increased the significance of the non-linear fit. None of the other analyses of RRrecent were statistically significant i.e., MR size did not explain variation in RRs for either the density or length of blue cod in any of the three separate analyses (i.e., RR indices were constant among different MR sizes) and neither did MR age for blue cod length (i.e., RR was constant among different MR ages) (Figs. 2.2, Table 2.2).

\subsubsection{RRmax analyses for blue cod}

There was a statistically significant positive relationship between MR age and the density (Fig. 2.3B) and length (Fig. 2.3F) of blue cod for all three tests (Table 2.3). In both cases there was no difference (to 3 decimal places) between the correlation coefficients for the linear and non-linear (exponential) relationships. MR size did not explain variation in RRs for either the density or length of blue cod in any of the three separate analyses (i.e., RR indices were constant among different MR sizes) (Figs. 2.3 \& 2.4; Table 2.3). Because of small sample sizes, it was not possible to test the blue cod data set for the effect of MR age (young versus old reserves). 

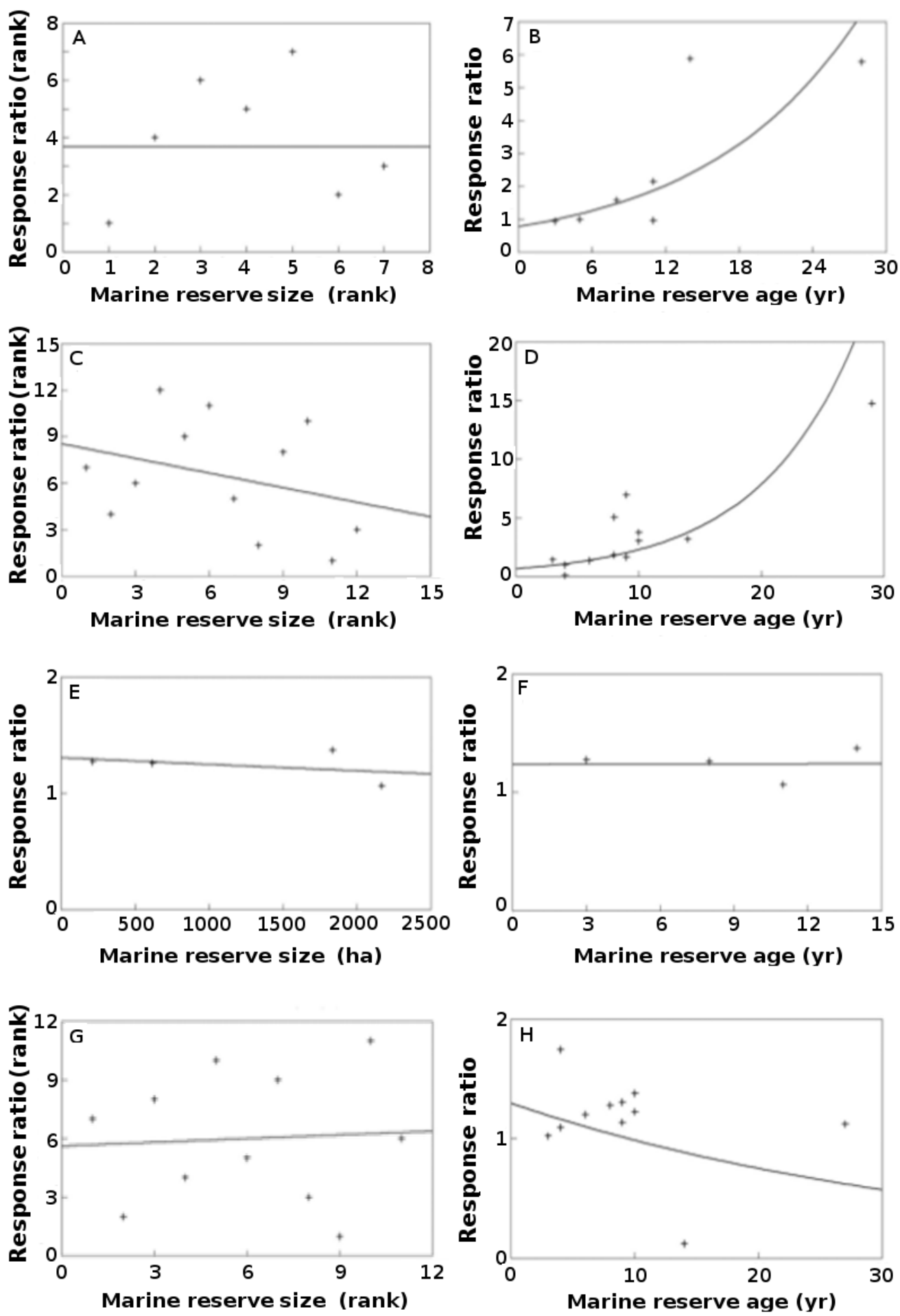

Figure 2.2: Best-fit relationship for the scatter plot of response ratio values (RRrecent) as a function of marine reserve (MR) size and MR age.(A) blue cod density as a function MR size, and (B) MR age, (C) rock lobster density as a function of MR size, and (D) MR age, (E) blue cod length as a function of MR size, and (F) MR age, (G) rock lobster length as a function of MR size, and (H) MR age. 


\subsubsection{RRrecent analyses for rock lobster}

Statistically significant results for all three analyses were observed for rock lobster density and MR age (Fig. 2.2D, Table 2.3). The best fit was for the non-linear model, but the linear parametric model had only a slightly lower $\mathrm{R}$ value. Dropping one outlier from this analysis resulted in only the Spearman's rank correlation being statistically significant. The only other statistically significant model was the non-linear fit for rock lobster length and MR age; this relationship was negative and only significant after an outlier had been dropped (Fig. 2.2H, Table 2.3). MR size did not explain variation in rock lobster length or density in any of the analyses performed (i.e., RR indices were constant among different MR sizes) (Figs. 2.2, Table 2.2).

Table 2.2: Test results (linear and non-linear functions plus Spearman's rank correlation analysis) for the response ratio (RRrecent) for blue cod (BC) and rock lobster (RL) density and length with respect to marine reserve $(M R)$ size and age. Bold values are significant at $\mathrm{p}<0.05$; ns: not significant. ${ }^{*}$ One data point has been dropped from the analysis because it appeared to have undue influence.

\begin{tabular}{lllccccc}
\hline $\begin{array}{c}\text { Index - RRrecent } \\
\text { (Figure reference) }\end{array}$ & \multicolumn{4}{c}{ Best fit relationship analyses } & \multicolumn{3}{c}{$\begin{array}{c}\text { Spearman Rank } \\
\text { correlation results }\end{array}$} \\
& & \multicolumn{2}{c}{ linear model } & non-linear model & \\
\hline & df & R & p & R & p & R & p \\
\hline BC density vs. MR area & 5 & -0.079 & NS & -0.033 & NS & 0.107 & NS \\
BC density vs. MR age & 5 & $\mathbf{0 . 8 1 3}$ & $<\mathbf{0 . 0 5}$ & $\mathbf{0 . 8 2 2}$ & $<\mathbf{0 . 0 5}$ & $\mathbf{0 . 8 1 1}$ & $<\mathbf{0 . 0 5}$ \\
& $4^{*}$ & $\mathbf{0 . 7 2 2}$ & NS & $\mathbf{0 . 9 8 0}$ & $<\mathbf{0 . 0 0 1}$ & $\mathbf{0 . 7 5 4}$ & NS \\
BC length vs. MR area & 2 & -0.363 & NS & -0.813 & NS & -0.4 & NS \\
BC length vs. MR age & 2 & 0.045 & NS & 0.616 & NS & 0.2 & NS \\
\hline RL density vs. MR area & 10 & -0.264 & NS & -0.315 & NS & -0.315 & NS \\
RL density vs. MR age & 10 & $\mathbf{0 . 9 0 0}$ & $<\mathbf{0 . 0 0 1}$ & $\mathbf{0 . 9 1 0}$ & $<\mathbf{0 . 0 0 1}$ & $\mathbf{0 . 7 8 7}$ & $<\mathbf{0 . 0 5}$ \\
& $9 *$ & $\mathbf{0 . 5 4 3}$ & NS & $\mathbf{0 . 5 4 8}$ & NS & $\mathbf{0 . 6 9 3}$ & $<\mathbf{0 . 0 5}$ \\
RL length vs. MR area & 9 & -0.0268 & NS & $<0.001$ & NS & 0.0636 & NS \\
RL length vs. MR age & 9 & -0.289 & NS & -0.353 & NS & -0.050 & NS \\
& $8^{*}$ & -0.552 & NS & -0.871 & $<0.01$ & 0.031 & NS \\
\hline
\end{tabular}



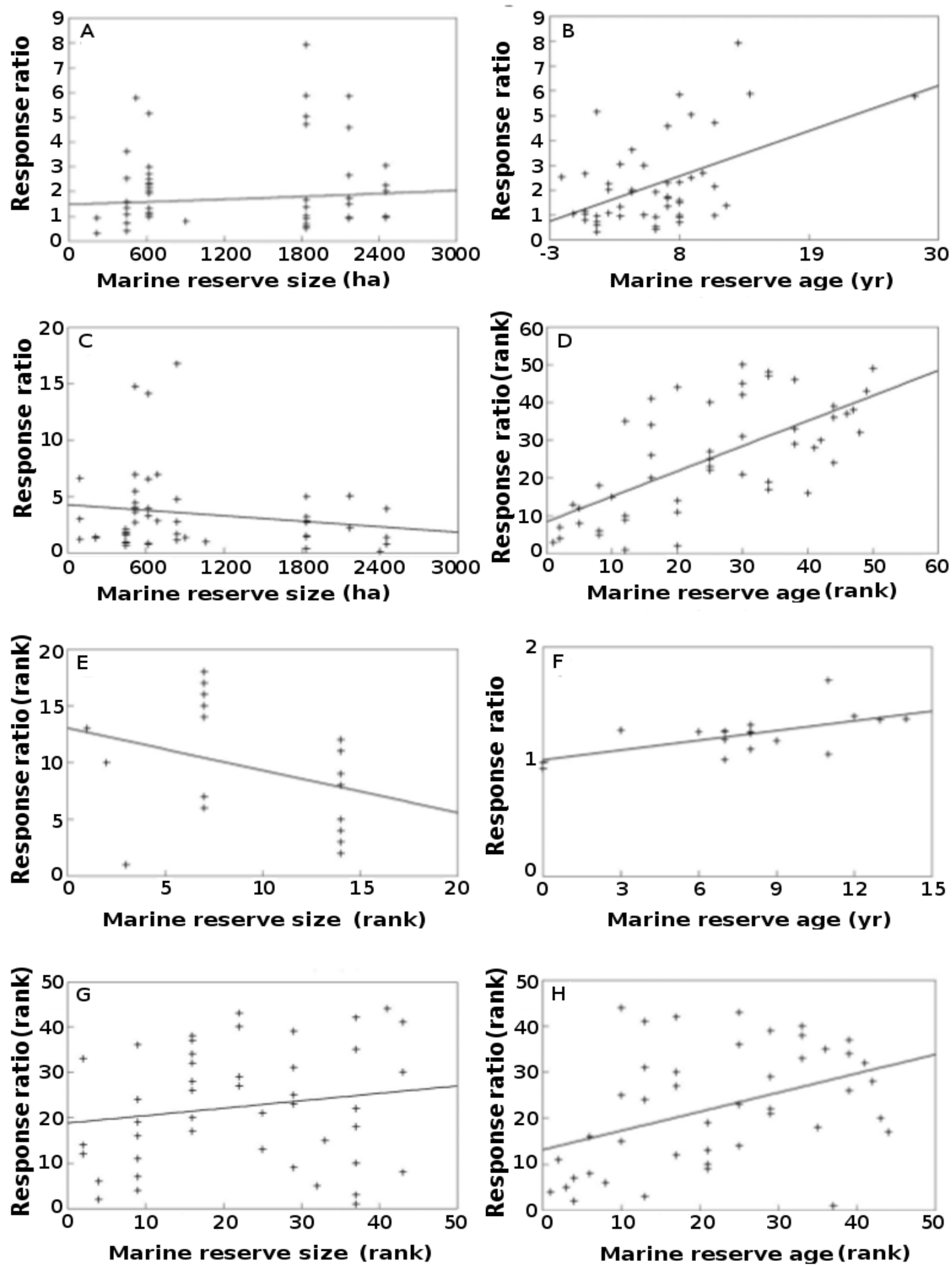

Figure 2.3: Best-fit relationship for the scatter plot of response ratio values (RRmax) as a function of marine reserve (MR) size and MR age. (A) blue cod density as a function of MR size, and (B) MR age, (C) rock lobster density as a function of MR size, and (D) MR age, (E) blue cod length as a function of MR size, and (F) MR age, $(\mathrm{G})$ rock lobster length as a function of MR size, and $(\mathrm{H}) \mathrm{MR}$ age. 


\subsubsection{RRmax analyses for rock lobster}

There was a statistically significant positive relationship between MR age and rock lobster density (best fit $=$ linear rank relationship; Fig. 2.3D) and between MR age and rock lobster size (best fit = linear rank relationship; Fig. 2.3H, Table 2.3). In young MRs, the best fit was a linear rank relationship with rock lobster density (Fig. 42.C), whereas in old MRs the best fit was an exponential relationship with density (Fig. 2.4H). For rock lobster length, the best fit relationship with MR age among young reserves was a linear rank relationship (Fig. 2.4E), whilst the relationship between MR age and rock lobster length for old reserves was not significant (Fig. 2.4J, Table 2.3). MR size did not explain variation in rock lobster density or length in any of the analyses performed (i.e., RR was constant among different MR sizes) (Figs. $2.3 \& 2.4$, Table 2.3).

Table 2.3: Test results (linear and non-linear functions plus Spearman's rank correlation analysis) for the response ratio (RRmax) of blue cod $(\mathrm{BC})$ and rock lobster (RL) density and length with respect to marine reserve $(\mathrm{MR})$ area (small $[\leq 1000 \mathrm{ha}]$ and large $[>1000 \mathrm{ha}]$ ) and age (young $[\leq 10 \mathrm{yr}]$ and old $[>10 \mathrm{yr}]$ ). Bold values are significant at $\mathrm{p}<0.05$; ns: not significant.

\begin{tabular}{|c|c|c|c|c|c|c|c|}
\hline \multirow[t]{3}{*}{$\begin{array}{c}\text { Index - Rrmax } \\
\text { (Figure reference) }\end{array}$} & \multirow[b]{3}{*}{ df } & \multicolumn{4}{|c|}{ Best fit relationship analyses } & \multicolumn{2}{|c|}{$\begin{array}{l}\text { Spearman Rank } \\
\text { correlation results }\end{array}$} \\
\hline & & \multicolumn{2}{|c|}{ linear model } & \multicolumn{2}{|c|}{ non-linear model } & \multirow[b]{2}{*}{$\mathrm{R}$} & \multirow[b]{2}{*}{$\mathrm{p}$} \\
\hline & & R & $p$ & $\mathrm{R}$ & $p$ & & \\
\hline BC density vs. MR area & 47 & 0.123 & NS & 0.221 & NS & 0.106 & NS \\
\hline $\begin{array}{l}\text { MR area - small reserves } \\
\text { MR area - large reserves }\end{array}$ & $\begin{array}{l}23 \\
22\end{array}$ & $\begin{array}{c}0.179 \\
-0.163\end{array}$ & $\begin{array}{l}\text { NS } \\
\text { NS }\end{array}$ & $\begin{aligned} & 0.318 \\
< & -0.001\end{aligned}$ & $\begin{array}{l}\text { NS } \\
\text { NS }\end{array}$ & $\begin{array}{l}0.258 \\
0.079\end{array}$ & $\begin{array}{l}\text { NS } \\
\text { NS }\end{array}$ \\
\hline$B C$ density vs. MR age & 47 & 0.487 & $<0.001$ & 0.487 & $<0.001$ & 0.351 & $<0.02$ \\
\hline BC size length vs. MR area & 16 & $<-0.001$ & NS & -0.077 & NS & -0.345 & NS \\
\hline BC size length vs. MR age & 16 & 0.617 & $<0.010$ & 0.617 & $<0.010$ & 0.564 & $<0.02$ \\
\hline RL density vs. MR area & 48 & -0.167 & NS & -0.167 & NS & -0.055 & NS \\
\hline MR area - small reserves & 34 & 0.191 & NS & 0.191 & NS & 0.231 & NS \\
\hline MR area - large reserves & 12 & 0.033 & NS & -0.206 & NS & -0.064 & NS \\
\hline RL density vs. MR age & 48 & 0.412 & $<0.01$ & 0.434 & $<0.01$ & 0.665 & $<0.0001$ \\
\hline MR age - young reserves & 37 & 0.49 & 0.001 & 0.5 & $<0.001$ & 0.693 & $<0.05$ \\
\hline MR age - old reserves & 9 & 0.653 & $<0.05$ & 0.883 & $<0.001$ & 0.798 & $<0.01$ \\
\hline RL length vs. MR area & 42 & 0.086 & NS & $<0.001$ & NS & 0.162 & NS \\
\hline MR area - small reserves & 30 & 0.199 & NS & 0.247 & NS & 0.282 & NS \\
\hline MR area - large reserves & 10 & 0.302 & NS & 0.369 & NS & 0.291 & NS \\
\hline RL length vs. MRage & 42 & 0.084 & NS & $<0.001$ & NS & 0.414 & $<0.01$ \\
\hline MR age - young reserves & 32 & 0.444 & $<0.02$ & 0.466 & $<0.01$ & 0.549 & $<0.001$ \\
\hline MR age - old reserves & 8 & 0.312 & NS & 0.316 & NS & -0.129 & NS \\
\hline
\end{tabular}



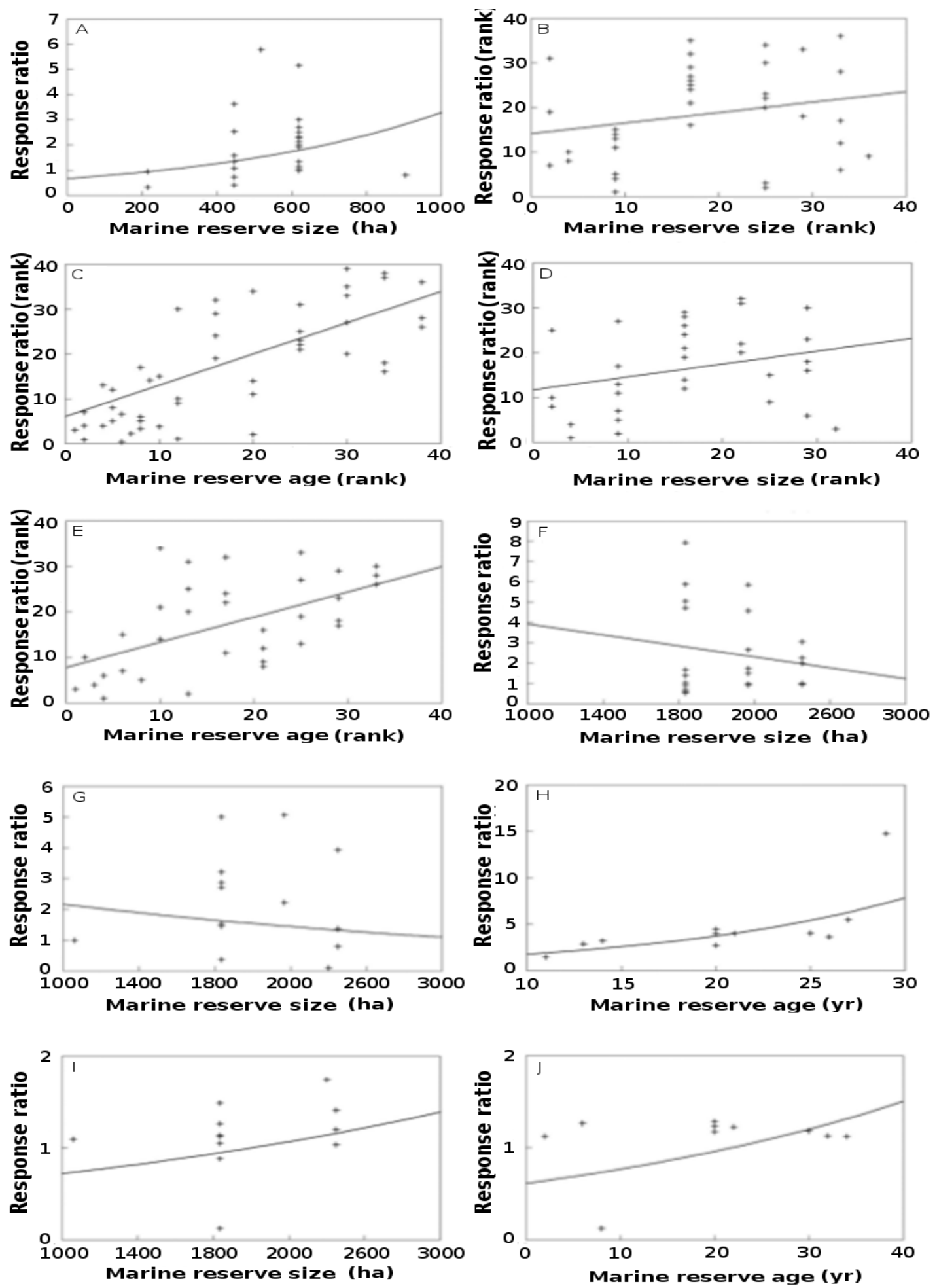

Figure 2.4: Best-fit relationship for the scatter plot of response ratio values (RRmax) as a function of marine reserve (MR) size for small and large reserves and as a function of MR age for young and old reserves. (A) blue cod density as a function of MR size for small, and (F) large re-serves, (B) rock lobster 
density as a function of MR size for small, and (G) large reserves, (C) rock lobster density as a function of MR age for young, and (H) old reserves, (D) blue cod length as a function of MR size for small, and (I) large reserves, (E) rock lobster length as a function of MR age for young, and (J) old reserves.

\subsubsection{Comparison of RRrecent versus Hedges' $g$ statistics}

Plots of Hedges' $g$ statistic as a function of RRrecent revealed no obvious linear relationship for the blue cod density data set $(n=5, p=0.489$, Fig. 2.5a) or for the rock lobster length data set $(n=8, p=0.069$, Fig. $2.5 \mathrm{~d})$, but did reveal significant linear relationships for the blue cod length data set $(n=4, p=0.048$, Fig. 2.5b) and for the rock lobster density data set $(n=10, p=0.043$, Fig. $2.5 \mathrm{c})$. When all data was pooled and plotted together, a non-statistically significant positive relationship was observed $(\mathrm{n}=$ $27, p=0.206$, Fig. 2.6a) and it was heavily influenced by a single point. When this point (for rock lobster density from the Cape Rodney to Okakari Point MR) was removed, a non-statistically significant negative relationship $(\mathrm{n}=26, \mathrm{p}=0.212$, Fig. $2.6 \mathrm{~b})$ between RRrecent and Hedges' $g$ statistic was observed. 


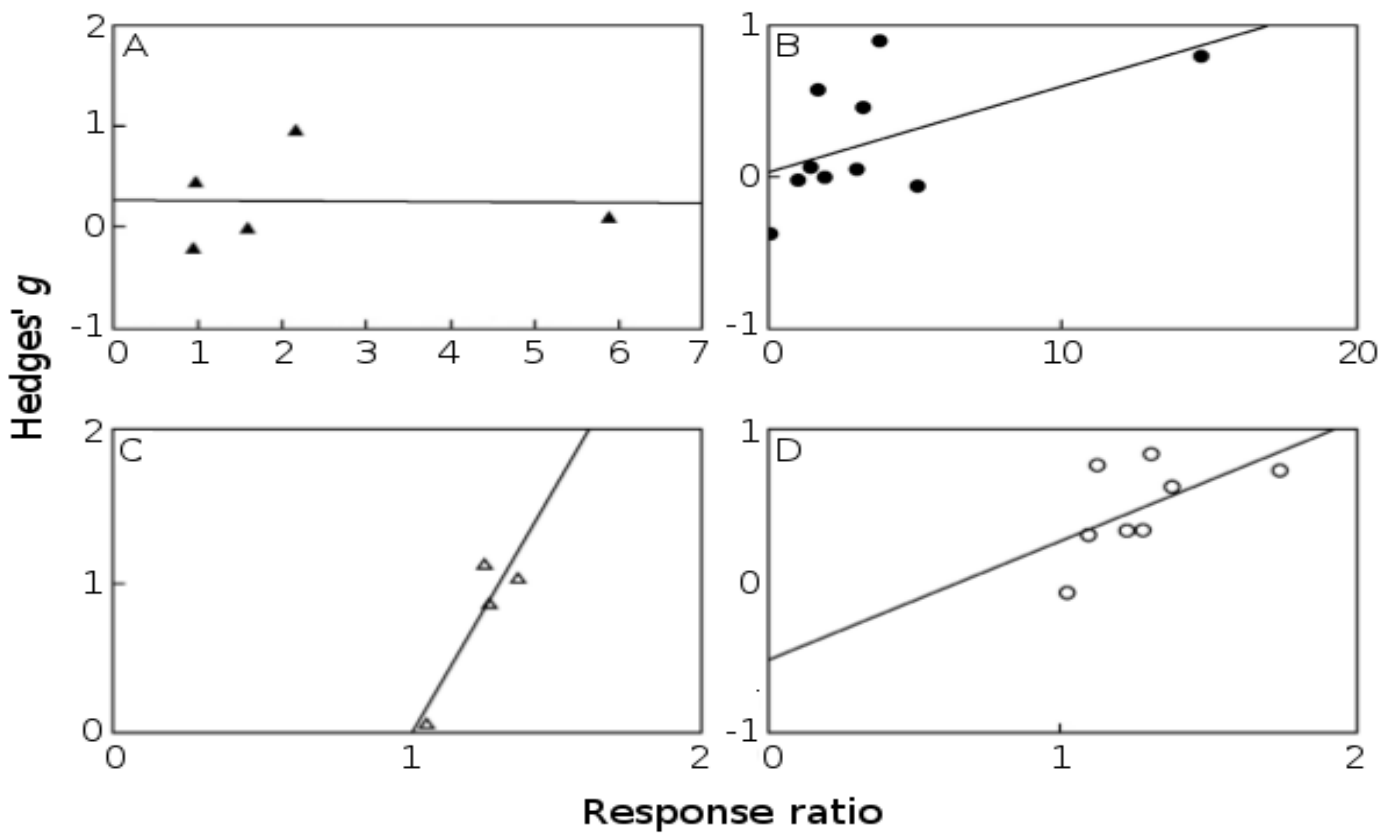

Figure 2.5: Species-specific relationships between response ratio values (RRrecent) and Hedges' $g$ statistic. (A) blue cod density data $(n=5),(B)$ blue cod length data $(n=4),(C)$ rock lobster density $(n=$ $10)$, and (D) rock lobster length data $(n=8)$. 


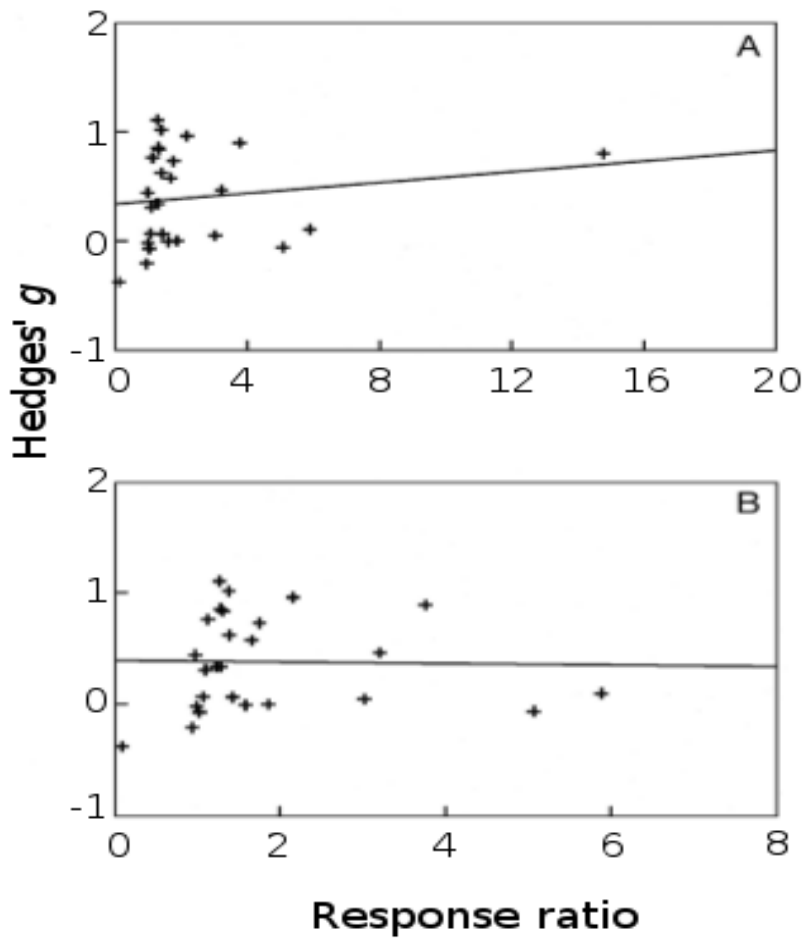

Figure 2.6: Hedges' $g$ statistic as a function of response ratio values (RRrecent). (A) all data $(n=27)$ and (B) all data with a single heavily weighted point for rock lobster density at the Cape Rodney to Okakari Point Marine Reserve removed $(\mathrm{n}=26)$.

\subsection{Discussion}

The main aim of this chapter was to compare the RR approach with the Hedges' statistic meta-analysis approach to quantifying biological responses in MRs using NZ examples, but also to determine how MR age and size affect the biological responses of two targeted species. To do this, the results of the RR analysis were compared with the findings from the Hedges' $g$ meta-analysis performed by Pande et al. (2008).

As expected, results indicate positive effects of MRs on the abundance and length of both blue cod and rock lobster (i.e., RR values $>1$ for almost all but four MRs used in the analysis). Based on the RR values, the biological responses observed for both species were greater for density than for length, and were generally, but not consistently, greater for rock lobster than for blue cod. Overall, and consistent with other studies 
(e.g., Mosquera et al. 2000, Côté et al. 2001, Halpern \& Warner 2002, Halpern 2003, Pande et al. 2008, Lester et al. 2009), these results demonstrate that MRs produce increases in the abundance and length of species that are heavily targeted for recreational, customary, and/or commercial harvesting.

\subsubsection{Effect of MR size on biological response}

Previous meta-analyses indicate that MR size may not always influence the biological response to MR protection (e.g., Côté et al. 2001, Halpern \& Warner 2002, Halpern 2003, Guidetti \& Sala 2007, Pande et al. 2008, Lester et al. 2009 but see Claudet et al. 2008 for counter example). Most evidence demonstrates that when a MR is established the biological response is rapid and occurs independently of MR size (Halpern \& Warner 2002, Halpern 2003, Micheli et al. 2004), at least over the range of MR sizes and species so far considered. However, theoretical studies suggest that larger MRs should be more effective than smaller MRs, mainly because larger reserves allow more mobile species with wide home ranges to remain protected inside reserves. Larger MRs may also increase self-recruitment by protecting areas of settlement for larvae produced inside reserves (Botsford et al. 2003, Hastings \& Botsford 2003).

In the present study, all of the analyses performed revealed no positive statistic relationship between MR size and the density or length for both blue cod and rock lobster, i.e., constant RR values were found across a wide range of MR sizes ( mean size $=1144.5$ ha for blue cod; mean size $=1095.3$ ha for rock lobster). These findings indicated that the biological response scales linearly with MR size. For example, if the density ratio is the same in both a small reserve and a large reserve, and the large reserve has twice the size of the small one and also twice the total number of individuals, the effect on the protected population in a large reserve will be twice as big as in the small reserve. From a conservation or fisheries perspective, this indicate that large reserves may be more effective than small reserves because the benefits provided by MRs scale directly with size.

In terms of the relationship between MR size and species mobility, it has been argue 
that only sedentary species are expected to benefit from MR protection, According to the literature, large reserves are expected to better protect mobile species (Botsford et al. 2003, Hastings \& Botsford 2003). However, Claudet et al. (2010) in a recent metaanalysis of Mediterranean MPAs, found that the effect of protection was at least as strong for mobile species as it was for sedentary ones. In terms of the species studied, both species have been described to be sedentary but they do display some movement ability. For example, tagging studies examining the movement patterns of rock lobster and blue cod have shown that most of the recaptured individuals moved less than $1 \mathrm{~km}$ (e.g., Cole et al. 2000, Carbines 2003, Struthers 2004, Freeman 2008 and see chapter six). However, seasonal inshore-offshore movements on a scale of up to over $4 \mathrm{~km}$ but generally in the order of 1-2 km have been detected for rock lobster (Freeman 2008). Also, according to a tagging study performed in chapter six, from the total number of fish recaptured (48),4,2\% moved between $10-50 \mathrm{~km}, 4,2 \%$ moved between $50-100 \mathrm{~km}$ and $8,3 \%$ moved $>100 \mathrm{~km}$. According to the this evidence, blue cod could be classified as a species with moderate mobility. Therefore, the results of the present study indicated that $\mathrm{MR}$ in $\mathrm{NZ}$, at least over the range of MR sizes considered here, are having a positive effect in both sedentary species and species with moderate mobility.

It is also important to notice that, MR size is not the only factor determining the effect of protection, i.e., differences in the responses observed across a gradient of MR sizes can not be attributed solely to MR size. Indeed, other features or properties that are specific to each MR may influence the response, for example, the effect of protection in each individual reserve may be determined by many local factors, including reserve location, site-specific coastal oceanography, physical complexity and habitat quality, and extent and distribution of the habitat (Freeman et al. 2009). The latter two factors are very difficult to evaluate and are likely to be independent of reserve size, but nonetheless are expected to contribute substantially to the biological responses observed in each MR (Halpern \& Warner 2003, Guidetti \& Sala 2007).

Other important factors determining the effect of reserve protection that were not considered in the analysis performed in the present study, are the distribution of the fishing effort outside MRs and the location of the sampling points both inside and outside the reserve relative to its boundaries. "Fishing the line", defined as the 
redistribution of the fishing effort at the boundary of the reserves in order to enhance catch rates, is a frequent harvesting tactic in communities where marine reserves are designated (Goñi et al. 2006). Since fishing the line essentially captures fish that spend part of their life under the protection of the reserve, the spatial distribution of fish inside and outside the reserve should be strongly affected by the distribution of fishing effort outside reserves (Kellner et al. 2007). In this context, even supposing densities in all MRs were the same, RR may vary enormously if there is spatial variability in fishing mortality outside the reserves. In terms of the consideration of the sampling points both inside and outside the reserve relative to its boundaries, Kellner et al. (2007) suggested that ignoring the locations of sampling within and outside the MR can greatly influence the resulting response ratios (i.e., the magnitude of measured reserve impacts). They suggested that for most species, except sedentary ones, comparisons between sites outside reserves with sites inside reserve but close to the boundaries should suggest smaller benefits than those comparisons with reserves sites closer to the centre of the reserve. These limitations can be addressed by incorporating these variables in the analysis. For example, weighted meta- analyses increase the precisions of the combined estimates and increase the power of tests by giving more weight to the studies with the most powerful experimental designs (i.e. those with greater and more appropriate replication) (Gurevitch \& Hedges 1999).

Finally, it was noted that enforcement (policing of the no-take areas) has been identified as being a key factor contributing to MR success (e.g., Samoilys et al. 2007, Claudet \& Guidetti 2010). Because no data exist about levels of illegal extractive use or about enforcement differences across the MRs studied here, it was not possible to know if or how this factor may have contributed to the present study. However, based on anecdotal information from the NZ Department of Conservation, it is unlikely that differences in enforcement explain the results reported here. 


\subsubsection{Effect of MR age on biological response}

All analyses performed here revealed the importance of MR age as a factor explaining positive biological responses. Reserve age is usually considered to be an important factor in MR effectiveness, because the response of individuals to protection is thought to depend upon the relationship between life-history traits of the species protected and the duration of protection (Guidetti \& Sala 2007, Molloy et al. 2009). Also, different species react to MR status in different ways and at different rates. For example, decadalscale indirect effects on taxa that occur as a consequence of cascading trophic interactions may take longer to develop than direct effects on target species (Babcock et al. 2010). Evidence indicates that a new reserve results in a rapid and significant increase in average levels of density, biomass, and diversity within 1 to $3 \mathrm{yr}$ before the response slows down or stabilises (e.g., Halpern \& Warner 2002, Halpern 2003, Micheli et al. 2004). However, a recent meta-analysis of the response of fish populations to MR protection determined that older reserves $(>15 \mathrm{yr})$ are more effective than younger reserves $(\leq 15 \mathrm{yr})$ at increasing fish densities, indicating that MR age is an important factor explaining biological response (Molloy et al. 2009). My results demonstrated that MR age has a strong positive effect on the biological responses of blue cod and rock lobster. For the RRrecent analyses a strong positive effect of MR age on blue cod and rock lobster density but not length was observed, despite the fact that most RR values for length for both species were $>1.0$, indicating larger individuals exist inside versus outside MRs. For the RRmax approach, results demonstrate that MR age has a strong positive effect on the density and length of blue cod and the density of rock lobster. Evidence of significant positive relationships for all analyses except for that between rock lobster length and old (>10 yr) reserves was found.

Overall, these findings indicate that both species respond rapidly to protection, with RR values $>1$ being recorded in the first few years after MR designation for at least two reserves in the case of rock lobster and three reserves in the case of blue cod, consistent with estimates of species-specific growth rates and also density-dependent responses (e.g., Cole et al. 2000, Davidson 2001a, Davidson et al. 2002, Freeman 2008 and references therein). When analysed as a function of time, the best-fit response in all 
cases was linear. The association between rock lobster abundance and MR age for young reserves was best described by a linear relationship, whereas that for old reserves was best described by a non-linear relationship (despite a small sample size for this latter analysis a significant relationship was observed, $\mathrm{p}<0.001$ ). This difference in agedependent response may reflect density-dependent factors, as rock lobsters increase in density towards site-specific carrying capacity. The association between rock lobster length and MR age for young reserves was linear and strongly positive, but was not significant among the old reserves. These results suggest that rock lobster length can respond rapidly and positively after MRs are declared, but after $\sim 10 \mathrm{yr}$ the response becomes independent of MR age. This may reflect the biological ability of rock lobsters to grow to larger sizes as a rapid response to MR protection, but after $10 \mathrm{yr}$ such a response is no longer possible because a growth response plateau has been achieved. Thus, in terms of size response, the notable changes occur rapidly, but plateau (reach an asymptote) after $\sim 10 \mathrm{yr}$.

\subsubsection{Use of $R R$ indices and curve fitting}

Response ratios (RR) may easily be calculated in different ways, as demonstrated by the use in the present study of RRrecent and RRmax. Despite the different origins of the two RR indices (RRrecent: the most recent survey only; Rrmax: an average value calculated from all surveys) and also their different properties (RRrecent: independence of data points; RRmax: non-independence of points leading to pseudo-replication), both tended to give very similar results. RRrecent was surprisingly informative given its limited power to detect significance (low degrees of freedom because one RR value was obtained per study). Three different best fit approaches (parametric linear and nonlinear, rank linear) were used to test for a relationship between RR and MR age or size for each biological response. This is a powerful approach in the absence of a priori knowledge about the biological response to MR protection, and provides new insights into the trajectories of change that can be expected for two target species. Although in all cases except one the best line relationship was curvilinear, the goodness of fit (as 
judged by the correlation coefficients) for the linear functions was only fractionally less than that for the non-linear functions. Thus, in terms of predicting or modelling biological responses, it is reasonable (at least for these two species and presumably other species with similar life-history characteristics and histories of extractive use) to employ a linear function, which is simple to fit and more easily understood and interpreted in a biological sense. The consistency of outcomes across both analyses (two different RR indices and three different curve-fitting approaches) provides some degree of confidence in the interpretation of the quantifiable biological responses of blue cod and rock lobster to protection in NZ.

Direct comparison of the RRrecent values with the Hedges' $g$ values for speciesspecific responses revealed that three of the four comparisons had positive slopes, and two of the four comparisons were borderline statistically significant (0.05>p>0.04), suggesting that a linear relationship may exist between the two indices (Fig. 2.5). Given that both metrics are measuring the comparative biological response inside versus outside the MR in question, one might reasonably expect that a (linear) relationship exists between them. However, when the data for both species and both biological measures were combined, the relationship between RRrecent values and Hedges' $g$ values was positive but not statistically significant $(\mathrm{p}=0.206, \mathrm{n}=27$ ) or slightly negative when one point heavily influencing the plot (RRrecent for rock lobster density at Cape Rodney to Okakari Point MR) was removed ( $\mathrm{p}=0.212, \mathrm{n}=26$ ) (Fig. 2.6). Thus, overall, there is little evidence to indicate that a simple relationship exists between RRrecent values and Hedges' $g$ values. The reason for this is because the RR values are calculated as a simple function of mean length or density inside versus outside each MR; this ratio therefore is independent of any estimate of variance. In contrast, Hedges' $g$ is not calculated as a ratio, but as an estimate of mean length (or density) inside minus mean length (or density) outside the MR and then divided by a pooled variance estimate. The absence of a variance component in the RR statistic and the inclusion of a pooled variance component in the Hedges' $g$ statistic therefore generates two indices that are largely independent. From a biological perspective, it might be argued that the Hedges' $g$ statistic is in fact more meaningful than the RR statistic because its calculation includes the pooled variance estimate, thereby reflecting variability in length (or 
density), which is known to be ecologically important. This apparent shortcoming of the $\mathrm{RR}$ index could be addressed by taking an approach that includes a variance component (e.g., Lajeunesse 2011).

\subsubsection{Use of the RR approach for assessing MR effectiveness}

Meta-analyses based on Hedges' $g$ are computationally difficult to conduct (e.g., Berman \& Parker 2002, Pande et al. 2008) when compared to other approaches such as response ratios; they require knowledge of sample variance that are often not reported in the literature, and they also include steps such as testing for differences in 'effect size', which, if significant, will preclude the completion of the meta-analysis. Whilst this latter step may be included in a RR analysis (e.g., Mosquera et al. 2000, present study), this is rarely done. Using a similar data set to that tested in the present study, Pande et al. (2008) observed significant differences in 'effect size' in their meta-analysis of blue cod and rock lobster length and density data. This meant that data from the different studies could not be combined to provide an overall significance estimate of the effect that all MRs had on these species. The significant differences in 'effect size' highlighted the significant differential contribution that individual MRs had on the length and abundance of both species (although it was not possible to identify the nature of that response), and also precluded the completion of the analysis. In contrast, the RR analyses presented here are less constrained because the testing did not reveal a significant effect size, and have, as a consequence, permitted us to contribute significant new findings to the results of Pande et al. (2008). Nonetheless, I recommend that all RR studies should test for heterogeneity of the data set because such heterogeneity points to the differential effects across MRs, something that the researcher needs to appreciate. The inclusion of a pooled variance estimate in the Hedges' $g$ index is likely to reflect biologically significant information that is lost in the present RR approach. It is clear that this loss of information represents a limitations and that those factors that were ignored in the present analysis warrant far more attention. Further investigation of an RR index that incorporates variance estimates may be an interesting approach to test that 
could help resolve some of the common challenges faced when undertaking a metaanalysis (Lajeunesse 2011).

The meta-analysis of Pande et al. (2008) did not identify either MR age or size as being significant factors explaining the biological responses of both species. Contrastingly, the RR analyses presented here have identified MR age and size, as being important. While contrasting results between meta-analysis, regarding the effect of MR size and age, have been reported in the literature, many individual studies have demonstrate a positive effect of MR age and size on the response to protection (e.g., Castilla 1999, Kelly et al. 2000, McClanahan 2000, Russ \& Alcala 2004 among others). In this context, comparisons across multiple MRs from very different areas seem to offer very weak tests of the effect of MR age and size probably because meta-analyses usually do not take in account several variables that influence the response to protection while studies on single MRs do. As previously established, this limitations can be addressed by incorporating these variables in the analysis.

Despite the discrepancy between the RR and Hedges' meta-analyses in terms of the detection of MR size and age effects, both analysis reported consistent positive effects of MRs (i.e., increased fish density and length inside reserves). The general concordance between the two analytical approaches is encouraging (notwithstanding the importance difference identified above) and suggests that the Hedges' statistic approach and the RR approach are equally valid for the evaluation of the overall effect of MRs. At the moment it is not possible to know if this statement holds true for only the NZ data set or for other data sets, but the comparison indicates that further exploration of this is worthwhile. Given that the RR approach does not require estimates of variance (which are often not provided in papers), there is a clear advantage to using this technique over the Hedges' statistic meta-analysis technique. 


\subsection{Conclusions}

The RR analyses of blue cod and rock lobster data from NZ MRs are consistent with a body of evidence that indicates that MRs are having consistent and positive effects on the density and length of protected species. My results offer evidence that at the national level MRs of all sizes can generate positive biological responses but large reserve may be more effective than small reserves. Also, it was evident from this analysis that MR age is an important variable determining the response to protection.

Considering these results, I suggest that response ratio analysis should be used in preference to the Hedges' statistic meta-analysis because it is easier (less timeconsuming) to employ, has fewer limitations, provides at least as much information as Hedges' statistic, and because its results are easier to interpret. I suggest that the next important step in this line of investigation is to determine why and how individual MRs respond differently in their biological outcomes, that is, to test why a significant 'effect size' exists. 


\section{Chapter 3}

A Multispecies Analysis to Detect Early Changes in Reef Fish Abundance and Size in the Taputeranga Marine Reserve, New Zealand 


\subsection{Introduction}

Worldwide, there is strong evidence to show that marine reserves (MRs) are an effective management option for restoring and sustaining marine ecosystems within their boundaries (Lester et al. 2009). The recovery of previously targeted species is one of the most commonly reported effects of MRs and it seems to occur rapidly after only a few years following reserve establishment (e.g., Halpern \& Warner 2002, Ballantine \& Langlois 2008, Díaz - Guisado et al. 2012). Although marine reserves (MRs) have been established in many parts of the world and recently several studies have been performed on the effects of protection provided by them, comparatively few studies have established biological baselines describing the presence/absence of species, their abundance and/or their size before the establishment of the reserves (Pande \& Gardner 2008, but see Claudet et al. 2006, Horta e Costa et al. 2013). It has been suggested that without adequate baseline data (i.e., data which defines the status of a species or community in an area before some change or impact; Kingsford \& Battershill 1998) for a proposed reserve area it is difficult to establish the effect of reservation on individual species or on community structure and functioning (Pande \& Gardner 2008).

Environmental monitoring of MRs typically involves the use of effect-size based methods, in which the effects of the restoration activity (e.g., increase in the abundance of a threatened species caused by the establishment of a marine reserve) are quantified by comparison with similarly degraded or control areas (Edgar et al. 2004a, Osenberg et al. 2006, Osenberg et al. 2011). This approach, known as control-impact (CI) design, involves multiple sampling occasions at an impact (protected) site and at least one control (fished) site. This effect-size based assessment aims to establish the state of the system after the establishment of a reserve compared to the state of the system that would have existed if the area had not been protected (Stewart-Oaten et al. 1986, Stewart-Oaten 1996a). Of course, the latter cannot be observed and must be therefore be estimated (Osenberg et al. 2006). Control and impact sites are compared statistically to determine if the two sites differ and if they do then one could conclude that there was an 
effect of the restoration activity, in this case the protection of the area (Osenberg et al. 2006). However, it has been suggested that the CI design confounds the effect of the restoration project with other processes that produce spatial variation in parameters (i.e., natural small-scale environmental heterogeneity) because even though control and impact sites may be similar, no two sites are identical and there will likely be statistically significant differences between the two sites even before the establishment of the reserve (Edgar et al. 2004a, Osenberg et al. 2006). Much data presently exist to document the fact that the number and sizes of species protected inside reserves are usually greater inside the reserve after a biologically meaningful period of time has elapsed since the establishment of the reserve based on the CI design (e.g., Pande et al. 2008, Lester et al. 2009, Díaz- Guisado 2012 among others). However, it can always be argued that this same situation existed before the establishment of the reserve and that the same general pattern has continued in time after the reserve has been established (Osenberg et al. 2006, Pande 2008). Osenberg et al. (2006) also suggested that the CI design is likely to underestimate true local effects because the reserve site response will cause a concordant response at the control site (i.e., they are not independent).

Green (1979) described several designs that might be useful for assessing conservation effects provided, for example, by marine reserves (MRs). First, he developed the before-after design (BA design) that attempts to deal with spatial variation by sampling only the impact site both before and after the establishment of the reserve. Based on this model, later he developed a more complex model that attempts to deal with both spatial and temporal variation by sampling at one or more control site(s) and the impact site both before and after the establishment of the reserve (before and after control - impact design or BACI design). To date, relatively few BACI studies have been performed to evaluate the effects of MRs (but see Edgar \& Barrett 1999, Barrett et al. 2007). Unfortunately, the interpretation of the BACI design is still problematical because the discovery of a difference between the two sites that is of different magnitude from the difference existing before the putative disturbance does not demonstrate that the human activity caused the impact, and also, there is no reason to expect two sites will have the same time-course of changes for example in the mean 
density of a given species (Underwood 1991). More recently, based on Green's design and popularized by Stewart-Oaten et al. (1986), the before and after control - impact paired series (BACIPS) design was developed. This design involves sampling at both control and impact sites simultaneously several times before and after the establishment of the reserve. The parameter of interest is the difference in a chosen variable between the control and impact sites estimated on each sampling date. Each difference from the before period provides an estimate of the spatial variation between control and impact sites and thus is an estimate of the expected difference that should exist in the after period in the absence of an effect of the intervention (Stewart-Oaten et al. 1986, Osenberg et al. 2006). The rationale behind the design is that replicated sampling in time gives an indication of the differences over several periods of potential change between control and impact sites. For example, if the establishment of a MR causes some change in the mean abundance of the sampled organisms, there will be a different magnitude of difference between sites after the establishment of the reserve from that before (Underwood 1991). By having several replicated times of sampling, it is possible to control for some random elements of the difference between control and impact sites so it is no longer possible for the regions (i.e., control and impacts) to differ after the putative impact simply because, at a single time of sampling, they happen to have a different pattern of difference from that before (Underwood 1991). Overall, the BACIPS design removes the effect of background sources of variation that are common to both control and impact sites (e.g., responses to climate events) and accounts for some sources of variation ignored in the CI, BA and BACI designs (Stewart-Oaten et al. 1986, Stewart-Oaten 1996a, b).

Another approach that has been used to quantify MR effects is meta-analysis. Several meta-analyses have been performed to describe the effects of MRs (e.g., Mosquera et al. 2000, Côté et al. 2001, Halpern \& Warner 2002, Halpern 2003, Micheli et al. 2004, Pande et al. 2008, Lester et al. 2009, Molloy et al. 2009, Díaz- Guisado 2012). Different effect-size metrics have been frequently employed in meta-analysis, including the response ratio (RR). The $\mathrm{RR}$ is a unit-less metric that quantifies the proportional change resulting from MR implementation by measuring the relative differences in a biological 
response (e.g., density) inside versus outside the MR (Adams et al. 1997, Goldberg et al. 1999, Hedges et al. 1999, Gates 2002). The response ratio metric is biologically more relevant than other metrics e.g., hedges' $g$, that is most commonly used and which does not yield a clear biological interpretation (Hedges et al. 1999, Osenberg et al. 1999b, Díaz - Guisado et al. 2012). Meta-analysis of MRs has been criticised due to the majority of studies they examine are CI designs (Edgar 2004). Also a dichotomy exists in the literature on the utility of once-only spatial comparisons of reserve and fished areas to infer recovery rates (Russ et al. 2005). However, Russ et al. (2005) suggested that it is possible to make useful inferences about rates of recovery in MRs of different ages from once-only spatial comparisons of reserve and fished sites, provided that such inferences are derived from carefully designed studies.

The Taputeranga Marine Reserve (TMR), located on the south coast of the capital of New Zealand, Wellington, was gazetted in 2008. Many fish species have been harvested along the Wellington's south coast since Mãori have inhabited New Zealand for an estimated 800 years, and as a consequence the abundance and size of the most popular food fishes have decreased, particularly during the last few decades (Francis 2008). According to Eddy (2011), as a result of the construction of present (2010) and historic (i.e., prior to large scale exploitation in the area) ecosystem models, biomasses of targeted species and trophic groups at the TMR and adjacent fished sites have been substantially depleted due to fishing. Results from the present ecosystem model indicated that commercial fisheries operating in the area for lobster and butterfish have the greatest impacts on the ecosystem. Recreationally, blue cod fisheries have the greatest impact on the ecosystem. This reserve, like most of reserves in the country had a long period of gestation (i.e., formal application for the reserve was made in October 2000) (Gardner et al. 2008). As part of the process, a baseline survey was conducted during an early stage of the proposal for the reserve, between 1998 and 2000. In this earlier study eight fish species were surveyed at eight sites (ultimately, three inside and five outside the reserve) before the establishment of the reserve (see Pande \& Gardner 2008) and subsequent monitoring surveys have been carried out (e.g., Eddy 2011, Byfield unpublished data). This data set represents one of the most comprehensive and 
robust baseline data sets available anywhere in the World (Pande \& Gardner 2008).

In this chapter I assessed changes in the abundance of eight fish species in the TMR using a database that consisted of a 14-year time series of density data. I used the existing data for the TMR (e.g., Pande 2001, Eddy 2011) and also collected my own data to examine early changes in the community within the MR.

\subsection{Methods}

The study experimental design aimed to detect early changes in abundance of a multispecies fish group in the TMR using the analysis of a 14-year time series of data. I performed a response ratio (RR) analysis and a before and after control - impact paired series (BACIPS) analysis.

In terms of the approaches used in the present study, the effect-sizes used in both analyses were based on a CI comparison but have a time component associated with them. The methods based on effect-sizes are considered to be a descriptive statistical approach that express the estimated magnitude of a relationship without making any statement about whether the apparent relationship in the data reflects a true relationship. However, null hypothesis testing was possible with these designs. In the present study, the RR and the BACIPS analyses are comparable to due to the fact that both analyses are based on a long-time series of data. However, both analyses are statistically different.

\subsubsection{Study area}

The present study was conducted on the south coast of New Zealand's capital, Wellington (Fig. 3.1). The coastline in the study area is indented by small, south-facing bays, separated by headlands of greywacke rock that extend seaward as reefs and 
submarine outcrops that occur out to $35 \mathrm{~m}$ water depth (Carter 2008). The south coast of Wellington is a high energy environment, with its tidal and oceanic flows strongly influenced by Cook Strait weather (Carter 2008). The area is subject to deep-ocean southerly swell enhanced by the strong and frequent southerly winds (Grapes \& Goh 2008).

The history of human impact on the Wellington's south coast began long before European arrival, with the coast providing food and shelter to the local Mãori population with a large dietary reliance on coastal marine resources (Leach 2006). The contents of middens associated with some Mãori villages along the south coast, indicate that the coast dwellers relied fairly heavily on fish as their main food supply with shellfish being secondary (Goh 2008). Since the arrival of the first Europeans in the Wellington, coastal resources have provided a vital means to sustain small communities in the area. However, as a greater number of people were attracted to the Wellington's south coast after the late 1890s, these resources became even more vital for the economic growth of the area and fishing, which was initially for personal consumption and/or trading, became more organised and also a source of income for many fishers (Goh 2008).

At the present time, the inshore finfish fishery in Fisheries Management Area (FMA) 2, which stretches from East Cape to the Wellington's west coast (Fig. 3.2), is a shared fishery, used by customary, recreational and commercial fishers. However, on the Wellington's south coast, most fishing pressure comes from recreational fishers with much of the recreational catch in FMA 2 coming from the heavily populated Wellington region. For example, recreational fishers take around 100-200 tonnes of blue cod and 30-80 tonnes of butterfish annually from FMA 2, while commercial catches of blue cod in this region are negligible, and butterfish catches are about 50 tons per year (Francis 2008). 


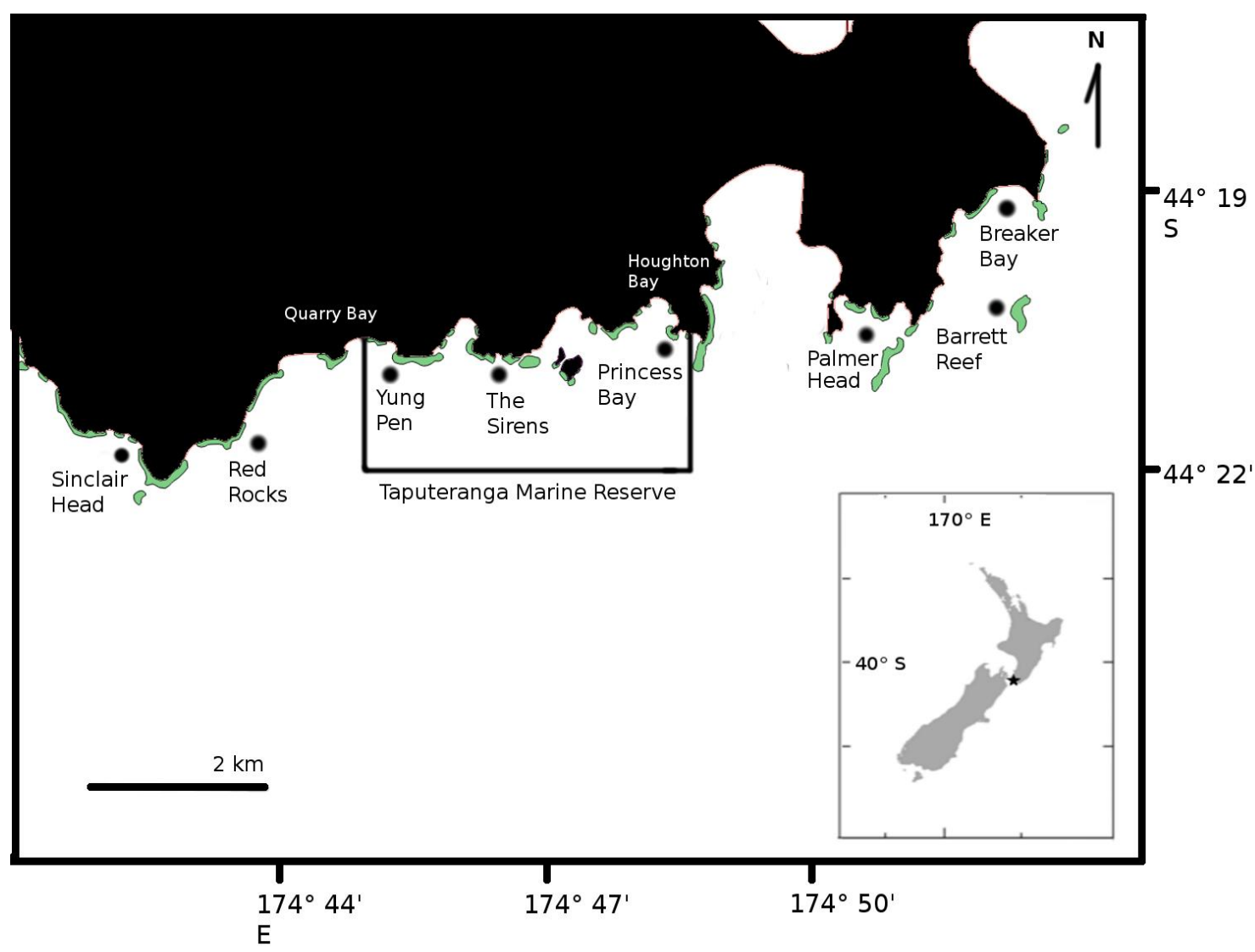

Figure 3.1: Map of study area showing the sites surveyed inside the Taputeranga MR and in the adjacent fishing grounds. From west to east: Sinclair Head, Red Rocks, Yung Pen, The Sirens, Princess Bay, Palmer Head, Barrett Reef, and Breaker Bay. Green area corresponds to intertidal reef.

The TMR protects 854.79 hectares of coastal water, extending from Princess Bay on the eastern boundary to Quarry Bay on the western boundary (Fig. 3.1). Habitats protected by the TMR include wave exposed rocky reef, wave sheltered rocky reef, cobble beach and sandy shores (Eddy et al. 2008). Much of the bottom type is characterized by greywacke reef, which is structurally complex. The area is home to a diverse assemblage of algal species including macroalgal stands resulting in high invertebrate and fish diversity (Francis 2008, Eddy 2011). 


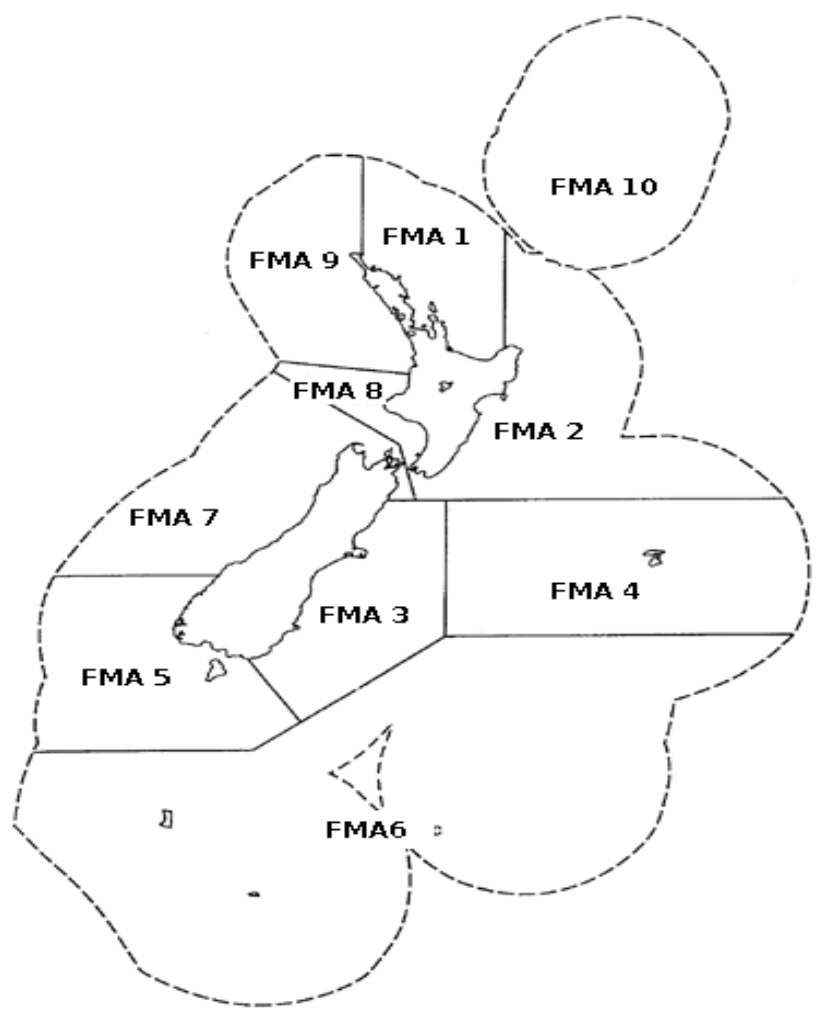

Figure 3.2: New Zealand Fisheries Management Areas as established in the Fisheries Act 1996.

\subsubsection{Site selection}

In the baseline survey conducted between 1998-2000, eight sites were surveyed. These sites were selected based on the boundaries of the TMR as proposed in 1996 (before the first formal application in 2000). An equal number of sites were chosen inside and outside the proposed boundaries at that time. During the course of the baseline study the boundaries were changed, resulting in a reduction in size of the proposed reserve, meaning that the sites chosen were no longer equally spread amongst the proposed reserve and control (fished) areas. However, these sites are well spread over the $\sim 12 \mathrm{~km}$ stretch of coast and provide a good representation of the south coast so they have been 
monitored since the baseline study (i.e., Pande 2001, Pande \& Gardner 2008, Eddy 2011, Byfield unpublished data).

The sites chosen were (from west to east): Sinclair Head, Red Rocks, Yung Pen, The Sirens, Princess Bay, Palmer Head, Breaker Bay and Barrett Reef (Fig. 3.1). Of these, Yung Pen, The Sirens and Princess Bay are all inside the reserve boundaries. The other sites were used as controls - they are all outside TMR (Fig. 3.1).

\subsubsection{Species surveyed}

Surveys to date have focused on the monitoring of macroalgae, macroinvertebrates and fishes at each of the eight monitoring sites. However, the present study focused only on fish. A total of 33 different fish species were surveyed in the baseline survey of the area, but because most of these occurred at low density only a subset of eight species were included in the baseline analysis. Those same eight species were included in the present study: Notolabrus fucicola (banded wrasse), Parapercis colias (blue cod), Latridopsis ciliaris (blue moki), Odax pullus (butterfish), Cheilodactylus spectabilis (red moki), Notolabrus celidotus (spotty), Nemadactylus macropterus (tarakihi), and Pseudocaranx dentex (trevally). With the exception of banded wrasse and spotty, these species are all

important for the commercial or recreational fisheries in the area, or both, and most of them are common along the Wellington's south coast. The larger edible species of fish have been harvested along the Wellington's south coast for more than 150 years, and this has inevitably shaped their populations; the abundance and size of the more popular food fishes are known to have declined over time (Francis 2008).

Some species, like the blue moki and blue cod, are known to show a marked response to reservation status (reviewed by Pande et al. 2008). Thus, both species are likely to be good indicators of change in the TMR and have been suggested as indicator species to determine how their numbers and distribution change over time as a result of marine reserve protection (Pande 2008, Pande \& Gardner 2008). Banded wrasse and spotty 
were chosen because they are abundant in the study area (Choat \& Ayling 1987, Francis 2008, authors personal observations) and because density changes in these unexploited species will provide a contrast to changes in species subject to fishing pressure (Pande \& Gardner 2008).

\subsubsection{Survey methodology: underwater visual census (UVC) survey}

The data used in the present study were obtained from previous underwater visual census (UVC) surveys conducted by Pande \& Gardner (2008) (1998-2000) and Eddy (2011) (2007-2010). To complete the database, a UVC survey was performed during summer-autumn (February-March) 2011 and summer (February) 2012 in conjunction with the Department of Conservation. The full database consisted of a 14-year time series (for a summary refer to Table 3.1).

The UVC surveys were performed following the same methodology used in previous surveys (e.g., Pande \& Gardner 2008, Eddy 2011). At each site, fish density and total fish length was recorded along nine transects randomly distributed in a rocky reef habitat. Divers swam a $25 \mathrm{~m}$ strip transect along a measuring tape, counting fish $2.5 \mathrm{~m}$ either side of the tape. Thus, fish were counted in a $25 \mathrm{~m}$ x $5 \mathrm{~m}$ corridor $(2.5 \mathrm{~m}$ high)(Cole 1994). Each transect was started five meters from where the transect tape was set in order to minimize inaccurate counts of fish attracted or repelled from the disturbance (Cole et al. 1990, Cole 1994). Typically there were two teams of two divers performing the visual fish censuses. In each team, one diver counted the fish and the other indicated the start and end of each transect. Fish were counted as the transect tape was being deployed and then divers swam back the length of the transect and recorded any species that was not observed during the actual count. However, such species were not included in the total count. Nine replicates were conducted at each site, giving a total area of $1125 \mathrm{~m}^{2}$ sampled per survey per site. Density was expressed as the number of fish per $125 \mathrm{~m}^{2}$. 


\subsubsection{Statistical analysis}

For the analysis of the data I recognized different sampling occasions within each survey period. A total of 19 sampling occasions were recognized, 12 before and seven after the establishment of the TMR (Table 3.1). I performed two different analyses, a response ratio (RR) analysis and a before and after control - impact paired series (BACIPS) analysis. Both analyses consider before and after comparisons between reserve and control (fished) areas, with multiple sites examined within each area. The analysis was carried out using the R statistical software (R Core Team 2012).

\subsubsection{Response ratio (RR) analysis}

I calculated the mean density (number of fish per area) for all the fish species for reserve areas (i.e., mean from the three reserve sites) and fished areas (i.e., mean from the five fished sites). For each sampling occasion during both the "before" and "after" reserve periods I calculated the RR, consistent with their use elsewhere, by dividing values of mean density inside the reserve by values from fished sites. RRs $>1$ indicate individuals are more abundant inside reserves relative to fished sites. Even though reserve sites were not protected until sampling occasion 13, for analysis purposes they were classified as reserve sites in both the before and after periods. 
Table 3.1: Underwater Visual Census survey information (year, season and sites surveyed). Observer: Pande (Pande \& Gardner 2008), Eddy (Eddy 2011), Díaz-Guisado (this thesis).

\begin{tabular}{|c|c|c|c|c|c|c|}
\hline Period & Observer & Year & Month & Sampling occasion & $\begin{array}{l}\mathrm{N}^{\circ} \text { of reserve } \\
\text { sites surveyed }\end{array}$ & $\begin{array}{l}\mathrm{N}^{0} \text { of control } \\
\text { sites surveyed }\end{array}$ \\
\hline \multirow[t]{12}{*}{ Before } & Pande & 1998 & Jan./ Feb. & 1 & 3 & 5 \\
\hline & & 1998 & Sept/Dec. & 2 & 3 & 5 \\
\hline & & 1999 & Jan. & 3 & 3 & 5 \\
\hline & & 1999 & Mar. & 4 & 3 & 5 \\
\hline & & 1999 & May/Jul. & 5 & 3 & 5 \\
\hline & & 1999 & Sept. /Oct. & 6 & 3 & 5 \\
\hline & & 1999 & Nov. & 7 & 3 & 5 \\
\hline & & 2000 & Jan. & 8 & 3 & 5 \\
\hline & Eddy & 2007 & Mar. & 9 & 1 & 2 \\
\hline & & 2007 & Aug./Sept. & 10 & 3 & 3 \\
\hline & & 2008 & Jan./Feb. & 11 & 3 & 5 \\
\hline & & 2008 & Mar. & 12 & 3 & 5 \\
\hline \multirow[t]{7}{*}{ After } & Eddy & 2008 & Sept./Nov. & 13 & 3 & 5 \\
\hline & & 2008 & Dec./Jan. & 14 & 3 & 5 \\
\hline & & 2009 & Feb./Mar. & 15 & 3 & 5 \\
\hline & & 2009 & Nov./Dec. & 16 & 3 & 5 \\
\hline & & 2010 & Feb. & 17 & 3 & 5 \\
\hline & Díaz-Guisado & 2011 & Feb. & 18 & 3 & 5 \\
\hline & & 2012 & Mar. & 19 & 3 & 5 \\
\hline
\end{tabular}

On many occasions, for a given survey period, there were no fish recorded in any of the transects at all sites within the reserve and/or all sites outside, and I was not able to calculate a genuine RR value. In terms of statistical analyses this can present a problem, because of the small size of the dataset to be analyzed. When this happened I tried two approaches in order to include data from those sampling occasions and being able to show the real relationship between reserve and fished areas. The first approach consisted in adding one to the raw density estimates every time where an observed value was zero; the second one consisted in adding a small constant value of 0.0001 to all raw density 
estimates, following Molloy et al. (2009) and Mitchell (2012).

To determine if RR values were significantly different from 1, I performed a one sample t-test. The analysis was performed for each species for both periods separately (i.e., before and after) and also for the complete dataset (i.e., before and after values pooled together). When significant differences were found I performed a new t-test to determine if the RR was greater or lower than 1. To examine differences in the RR values between periods, I performed a two samples t-test (before versus after). Normality was tested using a Shapiro- Wilk's normality test and homogeneity of variances was tested using a Bartlett test (lawstat R package; Gastwirth et al. 2013). When the assumptions of normality and homoscedasticity were not met I used a Wilcoxon Rank Sum and Signed Rank Tests.

\subsubsection{Before and after control - impact piaired series (BACIPS) analysis}

Based on Osember et al. (2006) I calculated the difference (hereafter referred to as "delta" or $\Delta$ ) between the fished and reserve sites for each sampling date as follow:

$$
\Delta \mathrm{P}_{i}=\mathrm{Cp}_{i}-\mathrm{Ip}_{i}
$$

where $C \mathrm{p}_{\mathrm{i}}$ and $\mathrm{Ipi}_{\mathrm{i}}$, are estimates of the parameter (density or length) at the fished and reserve sites on the ith date of the period P: i.e., before or after.

I calculated the average delta for each period and the effect-size (E) as follow:

$$
\mathrm{E}=\Delta_{B}-\Delta_{A}=\sum\left(\frac{\Delta_{\mathrm{B}, \mathrm{i}}}{n_{B}}\right)-\sum\left(\frac{\Delta_{\mathrm{A}, \mathrm{i}}}{n_{A}}\right)
$$


and the variance in differences pooled across periods $\left(\mathrm{S}^{2}\right)$ as follows:

$S_{\Delta}^{2}=\frac{S_{B}^{2}}{n_{B}}+\frac{S_{A}^{2}}{n_{A}}$

where for period $\mathrm{P}$,

$S_{p}^{2}=\left[\sum\left(\Delta_{\mathrm{p}, \mathrm{i}}-\Delta_{\mathrm{p}}\right)^{2}\right] / n_{p}-1$

I also used a linear mixed - effects model (LMEM) to determine differences in mean density of each fish species between fished and reserve sites between periods. This analysis was used due to the nature of the data (i.e., counts). Also, in the UVC surveys, overdispersion can arise due to pseudoreplication, that is, due to correlation between replicates that result from the sampling design (Hurlbert 1984). For example, the nine transects surveyed at each site cannot necessarily be considered to be truly independent replicates from the survey area because of between-site variability. Here, the overdispersion induced by the sampling design was explicitly accounted for in the analyses of the UVC data by the inclusion of random effects.

I calculated the mean density for all eight fish species at all reserve and fished sites. I fitted a model using the generic function lme of the nlme R package (Pinheiro et al. 2011). The model was fitted with period (before/after) and status (reserve/fished) as fixed factors, and with time (19 sampling occasions) as random factor. I also tested for the interaction between the fixed factors (i.e., period $\mathrm{x}$ status). A log-linear model was used to describe the expected counts and was fitted using maximum likelihood. Data were log transformed to improve assumptions. I ran a separate analysis for each species. I also fitted another model excluding the before data. This model was fitted with status as fixed factors, and with time (7 sampling occasions) as random factor. I used the Bonferroni correction for multiple comparisons.

Finally, I also used a two sample t-test (fished versus reserve). The analysis was 
performed for each species for both periods separately (before and after) and also for the complete dataset (i.e., before and after values pooled together). Normality was tested using a Shapiro-Wilk normality test and homogeneity of variances using a Bartlett test (Gastwirth et al. 2013). I also used an F-test to compare the variances of the two samples (R Core Team 2012) and when variances were equal I performed a two sample t-test for equal variances. When the assumptions of normality and homoscedasticity were not met not I used Wilcoxon Rank Sum and Signed Rank Tests.

\subsection{Results}

Trevally was not included in the analyses as this species was not observed at all in any of the surveys performed since sampling occasion nine (before reserve establishment) (Fig. 3.3h). This made it impossible to make any comparison between periods (before versus after). Even though tarakihi was only occasionally observed after the reserve establishment (Fig. 3.3g), this species was included in the analysis as a comparison between periods was possible.

\subsubsection{RR analysis}

As the results of both approaches used in order to included data from those sampling occasions where fish were absent from either the reserve or the fished sites were very similar, I chose to report only the results of the first approach (adding one to the raw density estimates every time where an observed value was zero).

For all of the species, except banded wrasse, RR values varied greatly before the establishment of the reserve (being both $>1$ and $<1$ ), but after reserve establishment (from sampling occasion 13) most of the values were $>1$ (i.e., mean density was higher in reserve). For example, for blue cod, mean RR values were $3.0 \pm 1.49$ and $4.8 \pm 0.59$ 
for the periods before and after reserve respectively, with all RR values recorded after sampling occasion 15 being $>1$ (Fig. 3.3b). For blue moki mean RR were $2.0 \pm 0.93$ and $1.9 \pm 0.75$ for the periods before and after reserve respectively and for butterfish mean RR were $1.9 \pm 0.53$ and $2.5 \pm 0.83$ for the periods before and after reserve respectively. For both these species most of the RR values (all but one) recorded after sampling occasion 14 were $>1$ (Fig. 3.3c, d). For blue cod, blue moki and butterfish RR values varied greatly among sampling occasions. Greater variation was observed for RR values $>1$ as very high values were observed i.e., maximum RR values of 18.8, 11.6 and 6.1 for blue cod, blue moki and butterfish respectively, while variation was lower for $\mathrm{RR}$ values < 1, i.e., minimum RR values of $0.31,0.19$ and 0.2 , respectively (Fig. $3.3 \mathrm{~b}, \mathrm{c}, \mathrm{d})$. Mean RR values for red moki were $1.1 \pm 0.16$ and $1.1 \pm 0.12$ for the periods before and after reserve respectively and for spotty mean RR values were $0.70 \pm 0.18$ and $1.5 \pm 0.26$ for the periods before and after reserve respectively. For both these species, most RR values recorded after sampling occasion 13 were $>1$ and RR values varied greatly among sampling occasions but not as much as for the other species, i.e., maximum RR values of 1.6 and 2.4, for red moki and spotty respectively and minimum RR values of 0.11 and 0.12 , respectively (Fig. 3.3e, f). For red moki, no fish were observed both inside and outside of the reserve on sampling occasions 17 and 18 and for tarakihi, no fish were recorded in sampling occasions 9-13 and in most of the surveys after reserve establishment (i.e., only during three of the six sampling occasions) (Fig. 3.3g). Despite the differences between periods observed for most of the species, the results of the t-test performed for each period separately indicated that the RR values were not statistically different from 1 in either period (before and after) ( $p>0.05$ ), suggesting no differences between periods.

For banded wrasse, in both periods RR values were found to be significantly lower than 1 ( $\mathrm{p}=0.017$ and $\mathrm{p}=0.0004$, for before and after respectively). For this species, all RR values were $<1$ except for sampling occasion four suggesting differences between reserve and fished areas i.e., higher abundance outside the reserve (mean RR values were $0.7 \pm 0.12$ and $0.5 \pm 0.08$ for the periods before and after reserve respectively). The results of the t-test performed for each period separately indicated that RR values for 
this species are statistically different from zero for both the before and after period $(\mathrm{p}=$ 0.034 and $p=0.00083$ respectively), suggesting no differences between periods.

When all the RR values (before and after) were pooled together, $R R$ values were found to be significantly different from 1 only for banded wrasse (mean $R R=0.6 \pm$ $0.08)(\mathrm{p}=0.0024)$, blue cod (mean $\mathrm{RR}=3.6 \pm 0.10)(\mathrm{p}=0.035)$ and butterfish (mean $R R=2.1 \pm 0.44)(p=0.040)$. For both blue cod and butterfish, most of the RR values were $>1$ (i.e., 13 out of 19 for both species) and they were found to be significantly greater than $1(\mathrm{p}=0.017$ and $\mathrm{p}=0.02$ respectively), suggesting differences between reserve and fished areas i.e., higher abundance inside the reserve (Fig. 3.3b, d). For banded wrasse the RR was found to be significantly lower than 1 ( $p=0.0012)$, also suggesting differences between reserve and fished areas i.e., higher abundance outside the reserve (Fig. 3.3a).

Results of the t- test to detect differences in RR values between period (before and after) suggested no significant differences in mean density between periods for any of the species surveyed ( $p>0.05)$ (Fig. 3.3), except for spotty $(p=0.01516)$ (Fig. 3.3f).

\subsubsection{BACIPS analysis}

The average delta values for both periods $\left(\Delta_{\mathrm{A}}\right.$ and $\left.\Delta_{\mathrm{B}}\right)$, the difference between those deltas (E) and their respective variation $\left(\mathrm{S}_{\mathrm{A}}{ }_{\mathrm{A}} \mathrm{S}_{\mathrm{B}}{ }_{\mathrm{B}}\right.$ and $\left.\mathrm{S}^{2}{ }_{\Delta}\right)$ are shown in Table 3.2. The maximun delta values for both periods were observed for spotty and the minimum values were recorded for red moki. The minimum and maximum effect-sizes were recorded for spotty and red moki, respectively. The effect-sizes indicated that the magnitude of change between periods was greater for spotty tarakihi and banded wrasse. For all the species except for blue moki, butterfish, and spotty, the delta values for the before periods were lower than the delta values in the after period (i.e., greater difference between fished and reserve sites in the after period). Variability in the beforeperiod was greater for all the species except tarakihi. 

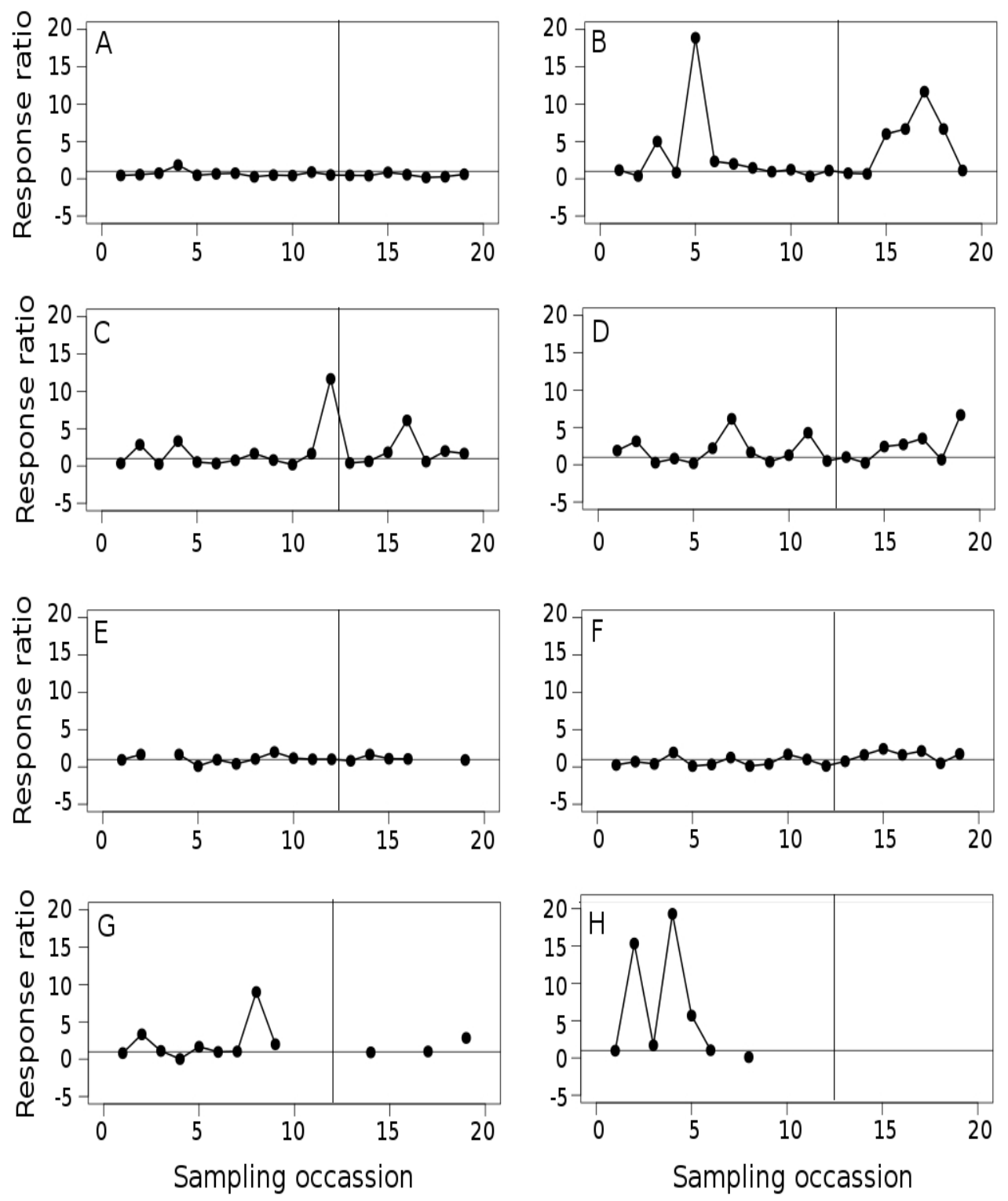

Figure 3.3. Response ratio (RR) values as a function of time (sampling occasion) for each species. (A) banded wrasse, (B) blue cod, (C) blue moki, (D) butterfish, (E) red moki, (F) spotty, (G) tarakihi and (H) trevally. Sampling occasions 1-12 correspond to the period before reserve establishment (1998-2008) and sampling occasions 12-19 correspond to the period after reserve establishment (2008-2012). The vertical line indicates the division between periods (before/after). 
Table 3.2: BACIPS analysis on the effects of marine reserve protection on the abundance of fish species in the Taputeranga MR.

\begin{tabular}{lccc}
\hline \multicolumn{1}{c}{ Species } & $\Delta_{\mathrm{B}}\left(\mathrm{S}_{\mathrm{B}}^{2}\right)$ & $\Delta_{\Lambda}\left(\mathrm{S}_{{ }_{\mathrm{N}}}\right)$ & $\mathrm{E}\left(\mathrm{S}^{2}\right)$ \\
\hline Banded wrasse & $-0.3722(0.1571)$ & $-0.4942(0.0907)$ & $0.1220(0.0761)$ \\
Blue cod & $0.0985(0.1643)$ & $0.1196(0.1311)$ & $-0.0211(0.0855)$ \\
Blue moki & $0.1312(0.4860)$ & $0.0392(0.1003)$ & $0.0920(0.1033)$ \\
Butterfish & $0.1892(0.2457)$ & $0.1566(0.1290)$ & $0.0326(0.0926)$ \\
Red moki & $0.0022(0.0115)$ & $0.0032(0.0017)$ & $-0.0010(0.0148)$ \\
Spotty & $-1.7624(7.8355)$ & $1.3714(3.3929)$ & $-3.1383(0.4964)$ \\
Tarakihi & $-0.1312(0.2052)$ & $0.2571(0.4960)$ & $-0.3883(0.1384)$ \\
\hline
\end{tabular}

Results of the LMEM suggested no significant differences in mean density between periods (before versus after) for any of the species surveyed ( $p>0.05$ ) (Fig. 3.4). Significant differences in mean density between reserve and fished areas were only observed for banded wrasse $(\mathrm{p}<0.001)$ and spotty $(\mathrm{p}<0.001)$. Banded wrasse density was higher in the fished area (outside the reserve) on all sampling occasions except one (Fig. 3.4a), and spotty density was higher in the fished area (outside the reserve) in 10 of the 19 sampling occasions (Fig. 3.4f). No significant interaction between factors (period $x$ status) was detected for any of the species surveyed ( $p>0.05$ ), except for spotty ( $p<$ 0.001 ), with density in fished sites being higher overall before the reserve establishment and lower after, while in reserve sites density was lower overall before the reserve establishment and higher after (Fig. 3.4f). When I removed the interaction term from the model the differences between periods previously reported for spotty were not observed $(p=0.6808)$. Significant differences between sampling occasions were found for all the species except for blue cod and blue moki $(\mathrm{p}<0.05)$.

When excluding the before dataset, similar results were obtained as significant differences in mean density between reserve and fished areas were only observed for banded wrasse $(p<0.0001)$ and spotty $(p<0.001)$. Banded wrasse density was higher in the fished areas (outside the reserve) 

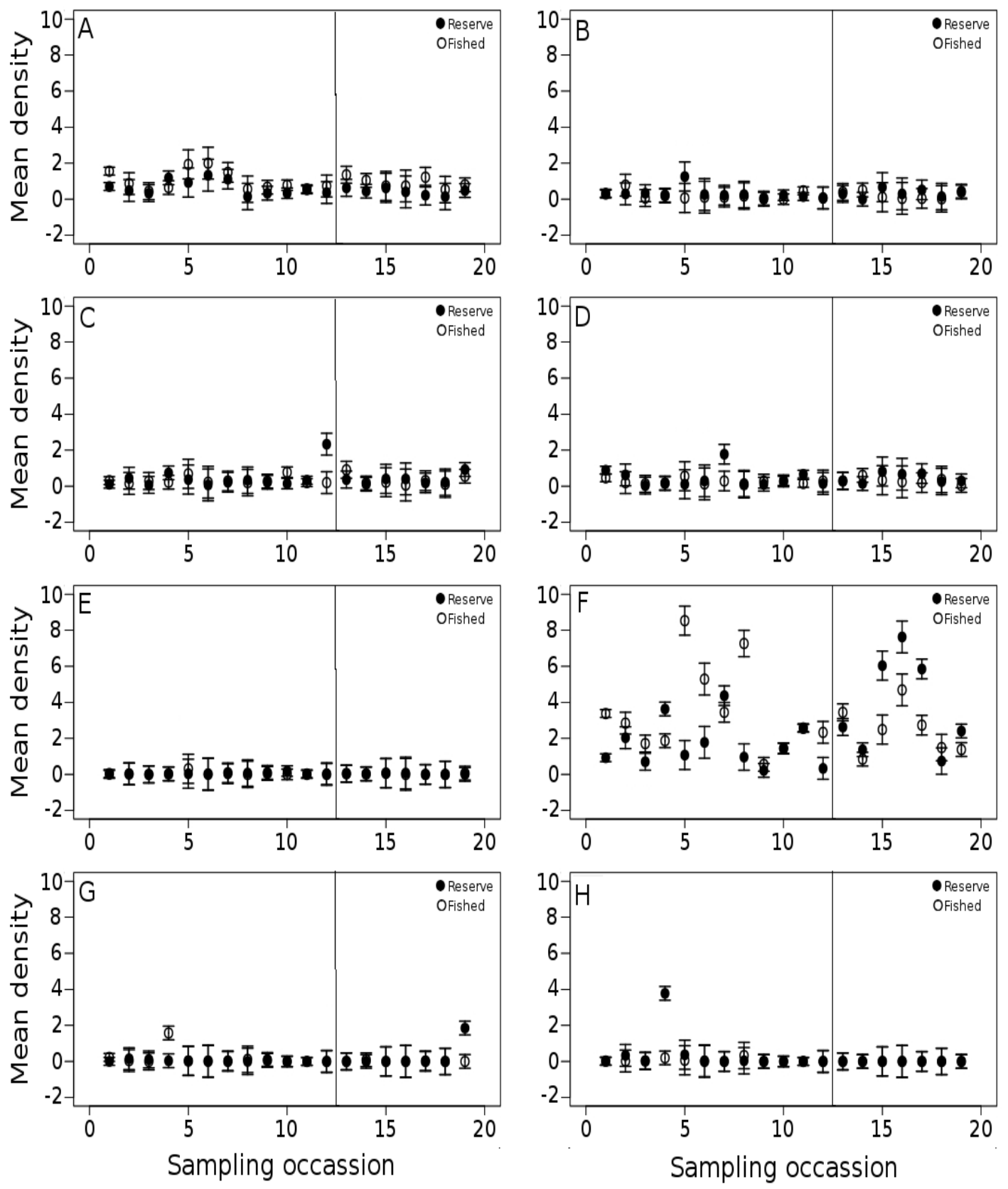

Figure 3.4: Difference between mean fish density in reserve and fished sites (BACIPS analysis) \pm SE for each species. (A) banded wrasse, (B) blue cod, (C) blue moki, (D) butterfish, (E) red moki, (F) spotty, (G) tarakihi, and $(\mathrm{H})$ trevally. Sampling occasions 1-12 correspond to the period before reserve establishment (1998-2008) and sampling occasions 12-19 correspond to the period after reserve establishment (20082012). The vertical line indicates the division between periods (before/after). 
On all sampling occasions (Fig. 3.4a). Spotty density was higher in reserve areas for 5 of the 7 sampling occasions (Fig. 3.4f). Significant differences were found between sampling occasions only for blue moki and spotty $(\mathrm{p}<0.05)$.

Results of the t-test suggested no significant differences in mean density between reserve and fished areas both before and after the establishment of the reserve for any of the species surveyed ( $p>0.05$ ), except for banded wrasse and spotty. Banded wrasse mean density was higher at fished sites compared to reserve sites in the period after reserve establishment $(\mathrm{p}=0.003)$ (Fig. 3.4a) and for spotty mean density was higher at fished sites compared to reserve sites in the period before reserve establishment $(\mathrm{p}=$ 0.043) (Fig. 3.4f). When all the RR values (before and after) were pooled together, significant differences were only detected for banded wrasse $(p=0.0012)$.

\subsection{Discussion}

The aim of this chapter was to detect early changes in the abundance of eight fish species in the area protected by the TMR. Monitoring the density of large predatory reef fishes can be an good indicator of the effect of protection because this index usually increases rapidly after the establishment of an MR or MPA (e.g., Halpern \& Warner 2002, Halpern 2003, Micheli et al. 2004, Pande et al. 2008, Babcock et al. 2010, DíazGuisado et al. 2012). It has been suggested that, as has happened in other MRs in New Zealand, the exclusion of fishing from the area should enable at least some species to recover inside the reserve, particularly targeted species (Ballantine \& Langlois 2008, Pande 2008, Walls 2008). The faster growing, more productive species like blue cod and butterfish are expected to recover within a few years, though they may take a decade or more to return to something resembling their natural state (Francis 2008). 


\subsubsection{Early changes in fish density in the Taputeranga MR}

Based on the result of the RR analysis performed in the present study, early changes in density are evident for most of the species surveyed (all except banded wrasse). For these species; most of the RR values after reserve establishment (after sampling occasion 13) were $>1$, while they varied greatly before the establishment of the reserve. Despite those differences, RR analyses suggested no differences between periods for any of these species, except for spotty (mean RR values were $0.7 \pm 0.12$ and $1.5 \pm 0.08$ for the periods before and after reserve respectively) (Fig. 3.3f). Blue cod density showed the greatest differences between periods (i.e., mean RR values were $3.0 \pm 0.49$ and $4.8 \pm 0.56$ for the periods before and after reserve respectively). However, results suggested differences between fished and reserve areas for this species were present in both periods (RR values were $>1$ in 13 out of 19 sampling occasions) (Fig. 3.3b). The reason why differences between periods were not detected for spotty and not for blue cod even though blue cod density showed the greatest differences between periods (greater than the difference found between periods for spotty) could be the great variability associated to the RR values for blue cod).

Consistent with the RR results, the analysis of the delta values (BACIPS) indicated a greater difference between fished and reserve sites in the after period for most of these species and greater variability in the before period. However, the results of the LMEM BACIPS analysis suggested no differences between periods for any of the species surveyed. Different results were found with the t-test BACIPS analysis, which suggested differences between periods for banded wrasse and spotty, even though those differences were not evident when observing the data (Fig. 3.4a and f). These differences were consistent with the results of the analysis of the delta values (BACIPS) as those species (banded wrasse and spotty) had greater effect-sizes i.e., a greater magnitude of the environmental impact (Table 3.2).

Neither of the methodologies used in the present study detected differences between periods for tarakihi. This species was not frequently recorded in the period after reserve 
establishment. Tarakihi have been described as a highly migratory species and this behavior may explain the patterns of abundance observed in the present study. For example, Davidson \& Richards (2005) found that mean numbers of tarakihi were generally higher inside Tonga Island MR, but this difference was relatively small as many sites had no tarakihi. As in the present study, tarakahi was detected in many of the sampling occasions before the establishment of the reserve but not often after the establishment of the reserve, this difference could indicate changes in the species composition in the area of study due to MR protection.

For most of the species surveyed in the present study, i.e., all except banded wrasse and also excluding tarakihi, most of the RR values were found to be $>1$ after approximately 1 to $3 \mathrm{yr}$ post-reserve establishment, depending on the species. Even though not significant, these results suggest early changes inside the TMR. This findings are consistent with those reported in chapter two for both blue cod and rock lobster, as both species respond rapidly to protection, with RR values $>1$ being also recorded in the first few years after MR designation in most of the MRs studied.

\subsubsection{Trends in fish density related to species characteristics}

Eddy's future ecosystem scenario prediction (for 2050) for the TMR, based on an ecosystem model, indicated that some fish species will respond positively to MR protection. According to the model predictions, species that are highly mobile may not experience increases on biomass (Eddy 2011). Many theoretical studies on the topic have reported results that are consistent with these predictions (e.g., Moffitt et al. 2009, Langebrake et al. 2011). However, Claudet et al. (2010) in a recent meta-analysis of Mediterranean MPAs, defined here as any form of protection and not just no-take MRs, calculated the relative densities of fish inside versus outside MPAs, and compared the results for species with low, medium or high adult mobility and found that the density of fish inside of MPAs (relative to outside) did not decrease as mobility increased. 
Several spatial and temporal CI comparisons have been performed in New Zealand MRs reporting benefits for both sedentary and mobile species. For example, Pande \& Gardner (2012) performed a spatial and temporal comparison in the Kapiti MR after eight years of protection and detected that reservation status has had a significant effect on density or length for four fish species (banded wrasse, blue cod, butterfish and blue moki), which is consistent with reports from other MRs in New Zealand (e.g., Davidson \& Abel 2002, Taylor et al. 2005, Davidson et al. 2007, 2009, Díaz- Guisado et al. 2012 among others). My findings, especially the results of the RR analysis, indicated that the TMR is having an effect on most of the species surveyed, but specially on blue cod. Tagging studies examining the movement patterns of blue cod have shown that most of the recaptured individuals moved less than $1 \mathrm{~km}$ (e.g., Cole et al. 2000, Carbines 2003, Struthers 2004, and see chapter six). However, according to a tagging study performed in chapter six, from the total number of fish recaptured (48), 4,2 \% moved between 10$50 \mathrm{~km}, 4,2 \%$ moved between 50-100 km and 8,3\% moved $>100 \mathrm{~km}$. According to the this evidence, blue cod could be classified as a species with moderate mobility. It is important to notice that, blue cod is one of the most popular species of fish among recreational fishers in the study area and have been heavily fished in the study area, therefore it is predicted to benefit from MRs.

The only highly mobile species for which a reserve effect was detected in the present study, was blue moki (i.e., tarakihi and trevally were only detected on few occasions after reserve establishment). Other studies of NZ MRs have also shown signs of recovery for this species for example, Davidson et al. (2007) found that blue moki have shown relatively small but positive changes in the Tonga Island MR and the Long Island-Kokomohua MR. However these authors suggested that no detectable patterns of change in blue moki density can be attributed to reservation status in the Tonga Island MR due to the fact that densities inside and outside reserve were low with occasional individuals being recorded. In the present study, blue moki was recorded in small numbers, on 18 out of 19 sampling occasions. However, the behaviour of this species could influence its detectability and lead to inaccurate abundance estimations. Blue moki usually camouflage themselves amongst vertical kelp strands and spend a lot of 
time in caves and crevices, only venturing into the open to feed mainly at dawn and dusk (Francis 2008). Blue moki is a highly valuable commercial and customary resource, especially in the northern territory. Adult individuals (larger than $40 \mathrm{~cm}$ ) join the spawning stocks offshore (Francis 2008). The legal size for the species is $40 \mathrm{~cm}$, therefore, the fishing effort concentrates in deeper areas. However, no formal statistics on fishing effort in the study area exists.

In terms of the non-target species surveyed in the present study, the results suggested that banded wrasse, a sedentary species, has not been positively affected by the TMR. These results contrast with those reported by Pande \& Gardner (2012) in the Kapiti Marine Reserve and Haggitt et al. (2008) in the Cape Rodney to Okakari Point Marine Reserve. However, my results are consistent with many other studies around New Zealand (e.g., Denny et al. 2003, Taylor et al. 2003, Davidson et al. 2007). However, non-target species have not usually been the focus of monitoring surveys and not too much evidence is available to allow comparisons. The other non- target and also sedentary species, spotty, has responded positively to MR protection in the TMR. Spotty was one of the most abundant species in the present study, and also in the baseline study performed by Pande et al. (2008), and given their abundance and widespread distributions they are likely to have an ecologically important role in the community (Pande \& Gardner 2008). It has been established that reserve effects are not restricted to the recovery of target species alone and the recovery of such predatory or 'keystone' species has considerable influence on the abundance of other species in the reserve (e.g., Castilla 1999, Babcock 2003, Shears \& Babcock 2003), therefore changes in abundance of non-target species are expected and should be monitored.

\subsubsection{Use of RR and BACIPS for assessing MR effectiveness}

Pelletier et al. (2008) suggested that the examination of the status of protected areas reveals that methodologies for assessing conservation and fisheries-related effects of 
protected areas could be improved. In this context, even though many metrics have been contemplated for studying protected areas, only few appear to be relevant and effective (Pelletier et al. 2005). It has been suggested that, coupling historical data from before and after the establishment of a reserve, in which variables related to ecological changes in the assemblages are monitored, may help to understand the sources of ecological variability at different scales, as well as the response of different systems to conservation and fisheries measures that have usually been overestimated due to the reliance on assessment designs that confound pre-existing differences with intended differences of protection (Pelletier et al. 2008, Osenberg et al. 2006, Osenberg et al. 2011).

The methodologies used in the present study (RR and BACIPS) are based on the evaluation of long-time series of data. Both RR and BACIPS are not the traditional approaches used for the evaluation of the effects of protection provided by MPAs and MRs. Results reported in chapter two indicated that the RR meta- analysis is easier (less time-consuming) to employ and the results are easier to interpret compared to the most frequently employed effect-size, Hedges' $g$. With respect to the BACIPS analysis, this method has been identified as the most powerful assessment design to detect change in MRs according to Osenberg et al. (2006), but it is rarely used. Here, both the RR and BACIPS analysis were used as a descriptive approach whereas a null hypothesis testing analysis was also performed.

Overall, the results of the effect-size analysis, both RR and BACIPS, indicated differences between periods for most of the species surveyed but apparently the changes were too small and not enough to be detected with the statistical analysis performed here, likely, due to the high variability observed in the dataset. These results suggested that, even though non-significant differences were observed, a reserve effect is evident. Differences between the analyses performed (descriptive versus null hypothesis testing) suggest differential power to detect change in protected areas between this methodologies. In this context, it has been suggested that the focus of assessment studies should be on the magnitude of effects and their uncertainty, and less about whether there is a demonstrable (but possibly tiny) effect (Stewart-Oaten 1996a, Osenberg et al. 
2006). To compare the power of the analyses performed here would be useful to design an analysis to calculate the minimum effect size (e.g., RR or delta values) required to detect an effect of a given size with the statistical analyses performed (e.g., t-test and LMEM). This may provide an indication of the power of the effect size analyses in terms of their ability to detect the magnitude of the changes occurring in MRs.

An important limitation of the methods used in the present study is related to the lack of consideration on both the distribution of the fishing effort outside the MR and the location of the sampling points both inside and outside the reserve relative to its boundaries. The spatial distribution of fish inside and outside the reserve should be strongly affected by the distribution of fishing effort outside reserves (Kellner et al. 2007). All the species surveyed, with the exception of banded wrasse and spotty, are important for the commercial or recreational fisheries in the area, or both. The larger edible species of fish have been harvested along the Wellington's south coast for more than 150 years and at the present time, most fishing pressure comes from recreational fishers. In the case of blue cod, one of the most popular fish species in the study area, there are not official data available on the distribution of the fishing effort of recreational fishers in the area but based on personal observation fishing effort is high in areas adjacent to the boundaries of the reserve. This may lead to the overestimation of differences between reserve and fished areas (e.g., high RR values). In the present study, very high RR values were recorded for blue cod, especially after reserve establishment. In this context, it would be worth to incorporate harvester behaviour as a variable in the analysis of MR effects when using the RR and BACIPS methodologies.

In terms of the consideration of the sampling location both inside and outside the reserve relative to its boundaries, Kellner et al. (2007) suggested that ignoring the locations of sampling within and outside the MR can greatly influence the resulting response ratios (i.e., the magnitude of measured reserve impacts). They suggested that for most species, except sedentary ones, comparisons between sites outside reserves with sites inside reserve but close to the boundaries should suggest smaller benefits than those comparisons with reserves sites closer to the centre of the reserve. The scale of movement rates and the fishery are both likely to play large roles in this variation 
(Kellner et al. 2007). In terms of the design of the present study, the monitoring sites are well spread over a $12 \mathrm{~km}$ stretch of coast and they provide a good representation of the variety of the shore line and its biota (Pande \& Gardner 2008), i.e., a well balanced design.

Overall these results, i.e., positive changes in density for most of the species surveyed in the area protected by the TMR, suggested that the TMR is having a positive effect on several fish species, including target and non-target species and highly mobile and sedentary species. Eddy (2011) predicted that further changes will occur in the TMR. According to his model, the overall biomass of the ecosystem protected is predicted to increase and return to a more historical (10\% greater average biomass per unit area in comparison to the present ecosystem) state in the absence of fishing.

\subsection{Conclusions}

Overall the results of the effect-size analyses (both RR and BACIPS) based on the differences between fished and reserve areas over a 14-yr period indicate that early changes are evident in the area protected by the TMR for most of the species surveyed. The present study represents a valuable contribution in terms of the comparison of descriptive and null hypothesis testing approaches. Also, the data set used in my analysis represents one of the most comprehensive and robust baseline data sets available in New Zealand and also worldwide for quantifying MR effects. 


\section{Chapter 4}

Comparison of Two Baited

Underwater Video (BUV) Methods

for the Determination of Reef Fish

Abundance and Size 


\subsection{Introduction}

Estimating the abundance of organisms is central to many ecological field studies and essential to any ecological model (Thompson \& Mapstone 1997, Cole et al. 2007, Colton \& Swearer 2010). Abundance is a commonly used proxy for population size and is thought to reflect the status of a population within a specific location; for example, whether or not the population is growing over time (Pomeroy et al. 2004). Species abundance is also one of the most widely used biological measures of 'success' and has been widely used to determine the effectiveness of Marine Protected Areas (MPAs), including all form of protection, not only no-take reserves or marine reserves (MRs) (see Pomeroy et al. 2004, Pande et al. 2008, see chapter two). Furthermore, the ability to make accurate estimates of relative abundance is the basis of both ecological and environmental studies (Gardner \& Struthers 2012). However, accurately assessing population abundance in the marine environment is very challenging due to the interspecific differences in body size, habitat association, aggregative behaviour and mobility among species (Ward-Paige et al. 2010, Bozec et al. 2011). Therefore, it is not surprising that numerous techniques have been developed to sample subtidal marine communities (Kingsford 1998, Willis \& Babcock 2000, Colton \& Swearer 2010).

The most common fishery-independent methodology to assess reef fish populations is in situ observation. Among these methods, underwater visual census (UVC) performed by divers is one of the most popular and practical methods for studying the distribution and abundance of reef fish populations (Kingsford 1998, Langlois et al. 2006). The UVC survey allows for the collection of a great variety of other variables (e.g., species composition, habitat characteristics and fish size) (Stobart et al. 2007). UVC has been frequently used to investigate changes in fish abundance in MPAs/MRs due to its nondestructive nature (Hannah \& Blume 2012). However, despite its widespread use, limitations of the method are well known as there are a number of methodological errors in almost all applications of visual surveys, most of which result in inaccurate estimations of population abundance or failure to correctly estimate the length of individuals (Sale \& Sharp 1983, Bell et al. 1985, Harvey et al. 2001, Edgar et al. 2004b, Dickens et al. 2010, Ward-Paige et al. 2010, Jind 2012). 
Problems associated with the UVC include observer errors, e.g., those related to the diver's ability to identify and accurately count individuals (Harvey et al. 2004). Unfortunately, due to the growing demand for large-scale, long-term monitoring that requires large amounts of fieldwork, it is inevitable that observers will change from place to place and through time so it is essential to be able to distinguish observer bias from real spatial or temporal patterns (Thompson \& Mapstone 1997, Kingsford 1998). However, some authors have noticed that despite preliminary training and the use of experienced observers, bias between observers persisted (St. John et al. 1990, Mapstone \& Ayling 1993, Thompson \& Mapstone 1997). Another potentially serious problem in UVC sampling is the reaction of the fish to the diver, the so-called diver effect. It has been reported that probably, the greatest source of heterogeneity in detectability was caused by species characteristics, e.g., behaviour (Sale \& Douglas 1981, Kulbicki 1998, Watson \& Harvey 2007, Pelletier et al. 2011, Ward-Paige et al. 2010, Bozec et al. 2011). The behaviour of many fishes changes in the presence of divers, some fish tend to move away or hide while others may be attracted, decreasing or increasing counts correspondingly (e.g., Watson et al. 1995, Kulbicki 1998, Willis et al. 2000, Willis 2001, Langlois et al. 2006, Watson \& Harvey 2007). Negative interactions with divers have been repeatedly documented (e.g., Kulbicki 1998, Kulbicki \& Sarramegna 1999). Dickens et al. (2010) recorded a marked decline in fish abundance as a result of ongoing diver presence while conducting UVC surveys. They reported the diver effect resulted in a $52 \%$ decrease in the mean number of individuals recorded, with declines of up to $70 \%$ in individual families. Similar results were found by Stanley \& Wilson (1995) (mean fish density declined between $41 \%$ and $77 \%$ ). Other studies have also suggested that behavioural responses of fish to fishing pressure have implications for marine science, predicting that responses could vary between protected and fished areas, i.e., between protected and fished sites in studies monitoring the effect of protected areas, leading to the underestimation of the biomass in fished areas (e.g., Feary et al. 2010). Human activities in protected areas could result in fish becoming accustomed and attracted to divers possibly due to the long-term interactions with divers (Cole et al. 1990, Cole 1994). Therefore, the potential for inaccurate fish abundance measurements is high in monitoring surveys, which may lead to the overestimation of differences between fished 
and protected areas (e.g., Willis et al. 2000). Cole (1994) and Cole et al. (1990) stated that fish feeding by visitors at the Cape Rodney - Okakari Point (Leigh) Marine Reserve in New Zealand has resulted in snapper exhibiting diver-positive behaviour at some sites inside the reserve while outside the reserve they actively avoid divers. This has resulted in higher abundance estimates at sites subjected to very high levels of usage by divers even though the transect sampling technique used in the study was designed to minimize the possibility of diver-oriented behaviour interfering with density estimates. There is also a possibility that certain sizes of fish may avoid or positively react to the presence of divers, for example, it had been reported that large blue cod in MRs regularly follow and often bite divers (Davidson \& Richards 2005). These variables combined with diver estimate variation lead to the possibility of large inaccuracies in the estimation of fish abundance and size. For example, St John et al. (1990) suggested that it is difficult to obtain highly accurate estimates of biomass for populations of reef fish using UVC even under very favourable circumstances so that accurate estimates of biomass derived from this technique are likely to be more difficult to obtain for large, highly mobile species of reef fishes.

Biases in underwater surveys can vary between methods, as well as between species. These biases can be sufficiently strong to produce erroneous conclusions and/or inconsistencies across survey methods. Therefore it is of vital importance that the survey method is chosen with this in mind (Willis et al. 2000). To avoid the biases introduced by UVC due to changes in fish behaviour, remote (surface-based) sampling methods have been introduced, including a variety of electronic media, for example baited underwater video (BUV) techniques (see Jennings \& Polunin 1995, Willis \& Babcock 2000, Cappo et al. 2006, Willis et al. 2003a). Application of this technique has increased markedly in recent years (e.g., Denny et al. 2004, Watson et al. 2005, Langlois et al. 2006, Hannah \& Blume 2012). The technique has evolved and the use of bait was a solution to the problem of low fish counts as bait can greatly increase the sampling area by attracting fish from potentially large areas. In addition, BUV has the added advantage of recording non-predatory species that are attracted due to curiosity as well as those species that would be passing through the field of view (Cappo et al. 2004, 2006). 
Willis et al. (2000) through a comparative study (BUV vs UVC) found that BUV surveys returned more precise (i.e., lower variability) estimates than UVC, especially for snapper, a large predatory fish, probably due to the extreme between-site variability in the response of this species to divers in the area of study. In the same study, with the exception of just one individual in an fished area, snapper where detected by divers only in reserve areas where fish are known to exhibit diver-positive behaviour, while other methods (e.g., angling an BUV surveys) showed that snapper were present in all of the fished areas. Willis et al. (2000) suggested that the results of UVC are likely to be less reliable than remote-sampling methods for snapper. Other studies have also reported that UVC underestimates the abundance of common species (i.e., fish from the family Labridae) (Brock 1982, Watson et al. 2005), cryptic species (Brock 1982, Ackerman \& Bellwood 2000, Willis 2001), and large predatory species (Davis \& Anderson 1989, Cole 1994, Jennings \& Polunin 1995, Willis \& Babcock 2000). Gardner \& Struthers (2012), in a comparison among survey methodologies to test for abundance and size of blue cod, found that the BUV methodology was more efficient, had lower levels of estimate variation than UVC and also recorded more fish and individuals from a greater size range than UVC, and had fewer zero count replicates. The BUV methodology also revealed highly significant differences in the abundance and size of fish between sites (reserve vs fished), whereas UVC revealed no such differences. Colton \& Swearer (2010) found that neither UVC nor BUV was particularly effective at observing cryptic species and while BUV can sometimes underestimate the density of species that form schools (i.e., there is an upper limit to the number of fish that can be viewed in a frame), UVC could overestimate the density through the recounting of individuals. Overall, several authors have suggested that BUV is the best method for observing mobile predators and species targeted by fishing (e.g., Willis \& Babcock 2000, Watson et al. 2005, Colton \& Swearer 2010). Finally, Willis \& Babcock (2000) and Watson et al. (2005) found that some species that have shown diver avoidance in previous studies were only detected by BUV, this being of particular interest in the case of protected areas, as fish behaviour can vary markedly among sites, leading to inaccurate measurements. 
In general, BUV has been particularly important for surveying the abundance and size of fish species in protected areas where non-destructive sampling is essential (e.g., Willis et al. 2000, Westera et al. 2003, Denny \& Babcock 2004, Denny et al. 2004, Langlois et al. 2006). Other advantages of BUV include the acquisition of a permanent record that can be checked by several observers as many times as necessary and removes the need for specialist observers to conduct all fieldwork (Cappo et al. 2006). Despite this, several studies have suggested that a combination of techniques is likely to be necessary when multispecies analyses are being performed (Willis \& Babcock 2000, Watson et al. 2005).

It is also important to recognize the limitations of BUV techniques that include for example, difficulties in determining area sampled when using bait which will vary depending on currents, wave action, topography, fish appetite, feeding activity and bait type amongst others (Priede \& Merret 1996, Priede et al. 1998, Sainte-Marie \& Hargrave 1987, Bailey \& Priede 2002, Cappo et al. 2004), or competitive exclusion of some species by others attending the bait (Willis \& Babcock 2000, Bailey \& Priede 2002, Cappo et al. 2006). Also, Willis et al. (2000) and Willis \& Babcock (2000) recognized an important limitation of the technique that is related to the fact that there is an upper limit to the number of fish that can simultaneously occur in the BUV field of view, which would possibly cause underestimates of abundance at high density sites that may be problematic when attempting to detect differences between areas of high versus low fish abundance.

The aim of the present study is to address this latest limitation by exploring differences between two BUV techniques in terms of their ability to record abundance and size of reef fish. While the BUV methodology has been previously used in the determination of fish abundance to assess differences between protected and fished areas, the two commonly used BUV techniques (vertical and horizontal deployment) have not been evaluated. The present study will represent a valuable contribution in terms of the determination of the best methodology to accurately assess the abundance of fish populations in situ and this method will be subsequently used in chapter five. 


\subsection{Methods}

The study experimental design was based on the detection of differences in species richness, abundance (expressed as density, i.e., number of individuals per area) and size (total length) of reef fishes between two BUV methodologies.

\subsubsection{Study area}

The study took place on the south coast of Wellington (Fig. 4.1). Refer to chapter three for a detailed description of the study area.

\subsubsection{Site selection}

Four sites along the Wellington south coast were chosen for the study (Fig. 4.1). Two of those sites, Yung Pen and Princess Bay have been focus of monitoring surveys for the Taputeranga Marine Reserve (TMR) since the establishment of the reserve (see chapter three) and the other two sites, Island Bay and Waitaha Cove were chosen because they were also surveyed in a BUV survey and a catch - mark - release (CMR) survey (see chapters five and six) and are easily accessible sites that had good conditions for the deployment of the BUV (i.e., high availability of flat substratum).

\subsubsection{Survey methodology: baited underwater video (BUV) survey}

BUV surveys were conducted on near shore rocky reefs at the four selected sites between September and October 2011. Based upon recommendations made by Willis \& Babcock (2000), substrata with high vertical relief were avoided and the camera was normally placed on flat sandy substratum adjacent to the reef edge to ensure the stability of the BUV station and also to avoid the presence of kelp that could interfere with the 
fish counts and length measurements. The depth of deployment was limited to a maximum of $\sim 10 \mathrm{~m}$ due to the nature of the habitat and visibility, allowing divers to visualize the substratum where the camera was deployed from the surface to avoid high relief areas.

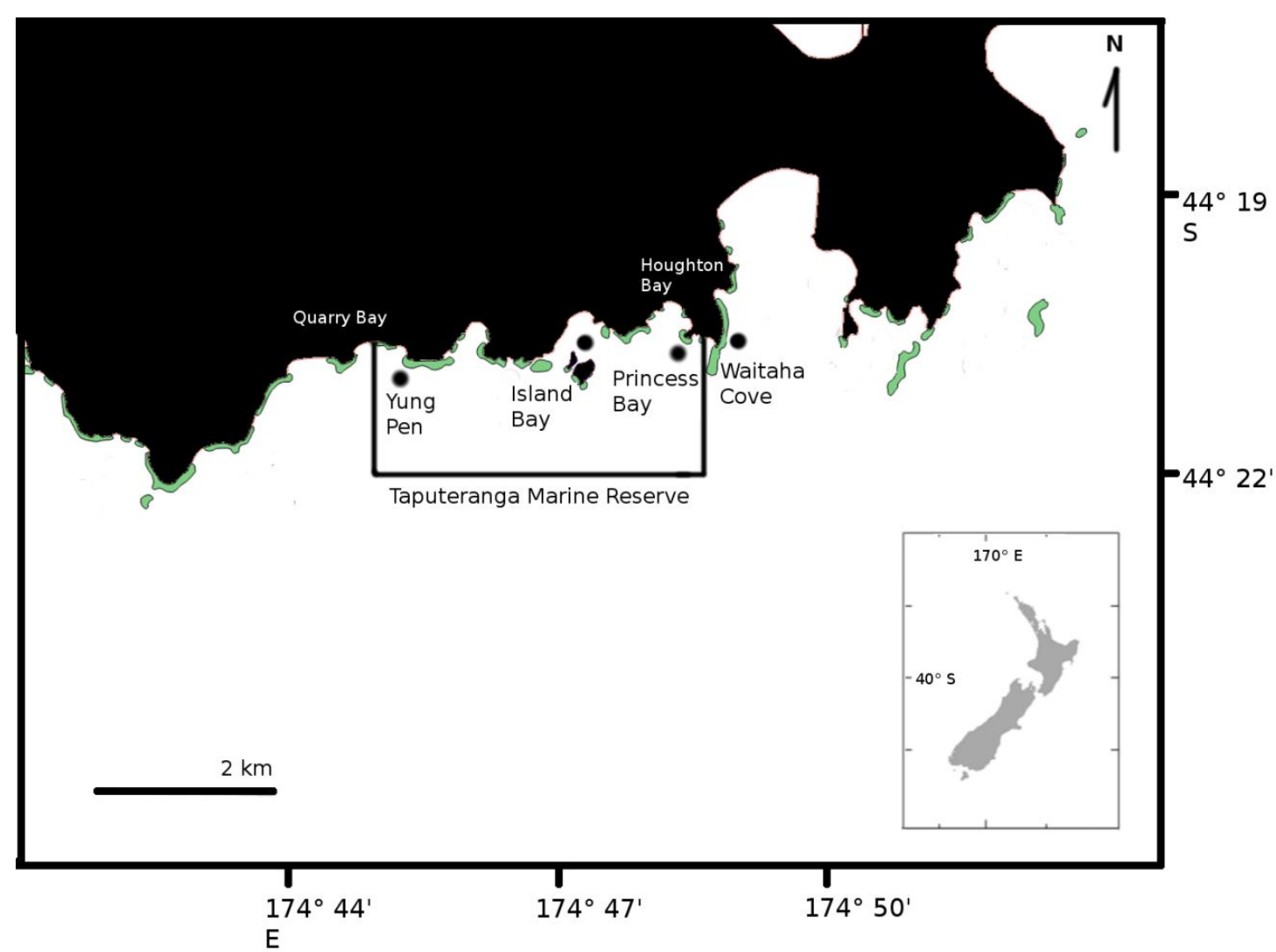

Figure 4.1: Map of the study area showing the sites surveyed. From west to east: Yung Pen, Island Bay, Princess Bay, and Waitaha Cove. Green area corresponds to intertidal reef.

Underwater video footage was captured using a Cannon MV500i video camera in an Ikelite $^{\mathrm{TM}}$ underwater housing mounted into a tube steel frame. Two different BUV techniques were evaluated, a vertical set up, based upon the format of Willis \& Babcock (2000) and Willis et al. (2000) as modified and employed by Gardner \& Struthers (2012), and an horizontal set up based upon the format of Cappo et al. (2004) and Langlois et al. (2006). The former had a triangular base with a vertical pole from the 
base reaching to $115 \mathrm{~cm}$ above the substratum and the camera was mounted facing directly down towards the substratum where a bait pot was placed directly below the camera's central field of view (Fig. 4.2a). The latter had a rectangular base with a pole extending from the frame's base and the bait pot was placed at the end of the pole. The camera was mounted facing forward towards the bait pot (Fig. 4.2b). In both cases the pole where the bait pot was placed was marked with five $\mathrm{cm}$ graduations to allow the measurement of fish during the analysis in the laboratory. Approximately $200 \mathrm{~g}$ of crushed pilchard was used for bait and also a piece of squid was attached to the top of the bait pot to attract the fish.

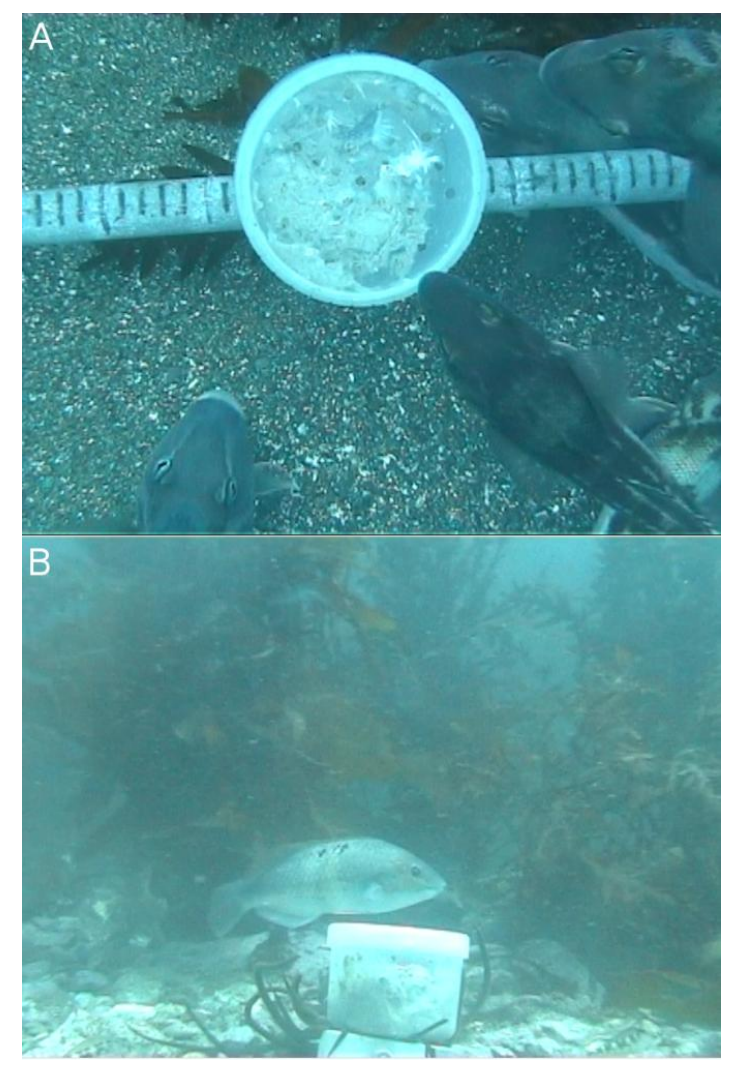

Figures 4.2: BUV camera view. (A) vertical BUV camera stand and (A) horizontal BUV camera stand

The camera was deployed from a boat onto or immediately next to a flat substratum. Usually two divers assisted the deployment; this involved divers entering the water to 
search for suitable flat substrate before each deployment. Recording was initiated before the deployment of the camera. Sampling consisted of three randomly replicated $15 \mathrm{~min}$ deployments of both of the BUV techniques at each of the four sites (total of 24 drops). Replicates were deployed within a radius of approximately 10 to $50 \mathrm{~m}$ depending on the site.

\subsubsection{Video footage analysis: density and length estimations}

In the laboratory, analysis of the BUV data consisted of downloading the video footage to the computer for storage and subsequent analysis. Analysis of the footage was initiated once the stand had reached the bottom. The video was divided up into $30 \mathrm{sec}$ intervals within which the numbers of blue cod and any other fish species present were recorded. For each $15 \mathrm{~min}$ of footage the maximum number of individuals of each species observed in a single frame (Nmax) was recorded. Nmax is a conservative measure of relative density that avoids the recounting of individuals that repeatedly visit the bait. This index was only recorded once per deployment and consistently with its use in previous studies the mean relative density indices were expressed in units of Nmax per 15 min, the maximum number of fish in the 15 minutes of deployment (e.g., Willis \& Babcock 2000, Willis et al. 2000, Gardner \& Struthers 2012).

For the most frequently observed species (blue cod and spotty), the total length to the nearest $1 \mathrm{~cm}$ of each individual present in each Nmax frame was measured by comparing the fish total body length to the five $\mathrm{cm}$ gradations marked on the camera stand. Measurements were made only of those fish present when the Nmax was recorded to avoid repeated measurements. Only those fish that were close to the graduated pole were measured to ensure accuracy. Therefore on many occasions it was not possible to measure all the fish in each Nmax frame. When measuring the length of blue cod from the vertical BUV station footage, the size of the fish was estimated by measuring the length of the fish's head (mouth to gill cover) instead of the total length due to the fact that many times fish were actually larger than the field of view and could not be accurately measured. The total length of blue cod was then calculated based on a 
previously estimated relationship between head length and total length based on data recorded on the CMR survey performed in chapter $\operatorname{six}(n=107, \mathrm{R} 2=0.9075, \mathrm{p}<0.001)$ (Fig. 4.3).

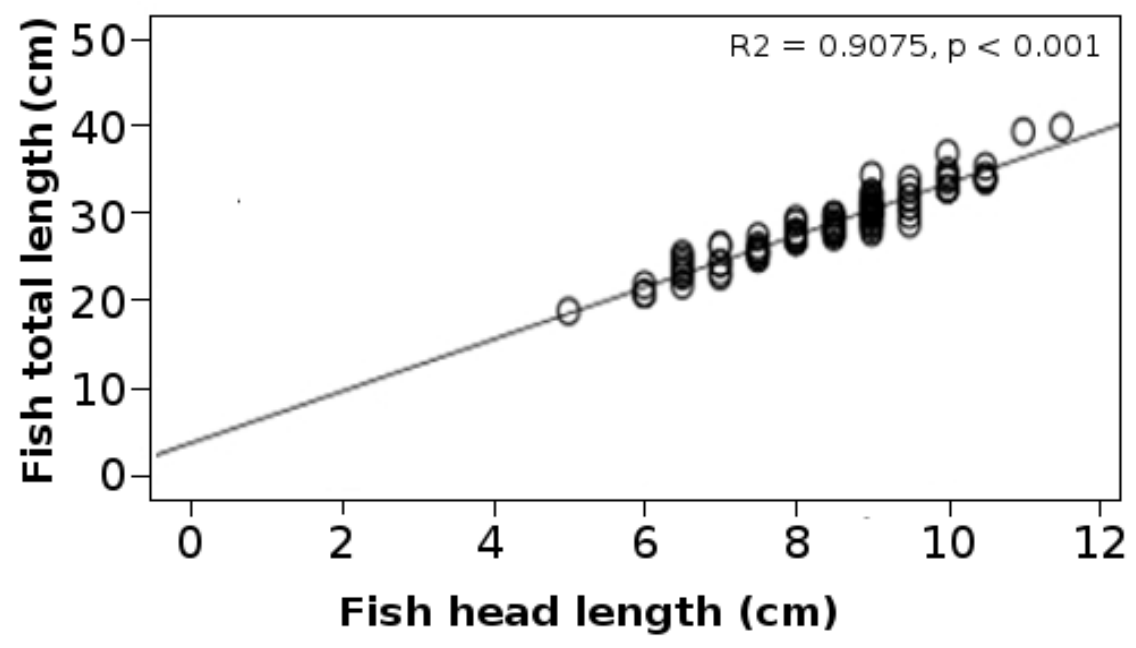

Figure 4.3: Relationship between fish head length $(\mathrm{cm})$ and total length $(\mathrm{cm})$ for blue cod.

\subsubsection{Statistical analysis}

\subsubsection{Density and length analysis}

To detect differences in mean density recorded with each methodology I calculated Nmax (per $15 \mathrm{~min}$ ) for the most frequently observed species, blue cod and spotty, and for the less common species as a single group ( 5 and 6 species for the vertical and horizontal BUV technique respectively) due to the low abundance recorded for those species.

Due to the nature of the data (i.e., counts) a Linear Mixed-Effects Model was used to determine differences in density expressed as Nmax per 15 min of camera deployment between the two BUV techniques (vertical versus horizontal). Also, in BUV surveys, overdispersion can arise due to pseudoreplication, that is, due to correlation between 
replicates that result from the sampling design (Hurlbert 1984). For example, three deployments taken at each site cannot necessarily be considered to be truly independent replicates from the survey area because of between-site variability. Here, the overdispersion induced by the sampling design was explicitly accounted for in the analyses of the BUV data by the inclusion of random effects.

The analysis was carried out using the $\mathrm{R}$ statistical software package ( $\mathrm{R}$ Core Team 2012). The model was fitted using the generic function lme of the nlme $R$ package (Pinheiro et al. 2011). The model was fitted with orientation (vertical/horizontal) as a fixed factor, and with site as random factor. Any interaction between factors was also tested (i.e., orientation $\mathrm{x}$ site). A log-linear model was used to describe the expected counts and was fitted using maximum likelihood. Data were log transformed to meet the test assumptions. I ran separate analyses for blue cod, spotty and the less common species as a single group.

To detect differences in mean length recorded with each methodology I calculated the mean fish length only for the most common species, blue cod and spotty. The same model used in the density analysis was used in the length analysis. As previously established, it was not possible to measure all the fish in each Nmax frame leading to missing data. This did not represent a problem because it has been suggested that likelihood based methods are useful tools to handle missing data (Little \& An 2004, Hedeker \& Gibbons 2006).

To determine the ability of each BUV methodology to measure fish length, a Bayesian analysis was performed in order to predict and compare the number of fish measured per methodology during each deployment. The analysis was carried out in the statistical package IBM SPSS Statistics 20.0 (IBM Corp. 2011). The model fitted assumed that the probability of measuring a fish is linear (on the logit link scale) with the abundance of fish able to be measured. This was fitted with a binomial model. The binomial model is such that it describes the probability of obtaining $\mathrm{n}$ successes given $\mathrm{N}$ trials. As such it is ideal for analysing these data. I treated each replicate as $\mathrm{N}$ trials where $\mathrm{N}$ is the abundance, and the number of measured fish is the number of successes, $\mathrm{n}$. This is governed overall by a probability of success P. I modelled the logistic of P (i.e., $\log (\mathrm{P} /(1-\mathrm{P}))$ as a linear relationship of abundance with parameters Intercept and 
Slope, governed by the equation.

$$
\log (P /(1-P))=\text { Intercept }+ \text { Slope } * N
$$

The models were run with standard non informative priors (Int $\sim$ dnorm $(0,0.0001)$, Slope $\sim$ dnorm $(0,0.0001)$. The expected values were modelled by multiplying the density by the modelled probability for that abundance.

\subsubsection{Species richness analysis}

To detect differences between the number of species observed with each methodology I used Margalef's richness index (Margalef 1968):

$\mathrm{d}=\frac{(S-1)}{\left(\log _{e} N\right)}$,

where $\mathrm{S}$ is the total number of species and $\mathrm{N}$ is the total number of individuals in the sample.

To detect differences in mean species richness (Margalef's index) recorded with each methodology I used the same model used in the density and length analysis.

\subsection{Results}

\subsubsection{Differences in species richness between methodologies.}

A total of seven species were recorded using the horizontal BUV technique, and six species using the vertical BUV technique, five of them being common between the two methodologies (Table 4.1). From those five species that were observed using both 
techniques, two of them were wrasses that belong to the family Labridae, spotty (Notolabrus celidotus) and banded wrasse (N. fucicola). Less abundant, but also common across the two methodologies were the common conger eel (Conger verreauxi) and trumpeter (Latris lineata). Blue cod (Parapercis colias) from the family Pinguipedidae was also common between the two methodologies. Blue cod and spotty were the most frequently observed species in the study (Table 4.1).

Table 4.1: Abundance (number of fish) and occurrence (number of deployments where fish were recorded) of fish species for both BUV methodologies. Also, the average number of that species recorded per deployment and the standard errors are shown.

\begin{tabular}{lcccc}
\hline \multicolumn{1}{c}{ Species } & \multicolumn{2}{c}{$\begin{array}{c}\text { Number of fish } \\
\left(\mathrm{n}^{\circ} \text { of deployments) }\right.\end{array}$} & \multicolumn{2}{c}{ Average $\mathrm{n}^{\circ}$ fish \pm S.E. } \\
\hline Horizontal & Vertical & Horizontal & Vertical \\
\hline $\boldsymbol{P}$. colias (blued cod) & $36(7)$ & $43(10)$ & $3 \pm 1.1$ & $6 \pm 1$ \\
$\boldsymbol{N}$. celidotus (spotty) & $35(10)$ & $19(8)$ & $2.99 \pm 0.84$ & $1.68 \pm 0.46$ \\
C. verreauxi (conger eel) & $1(1)$ & $2(2)$ & $0.08 \pm 0.08$ & $0.17 \pm 0.11$ \\
$\boldsymbol{L}$. lineata (trumpeter) & $1(1)$ & $1(1)$ & $0.08 \pm 0.08$ & $0.08 \pm 0.08$ \\
$P$. miles (scarlet wrasse) & $2(2)$ & & $0.17 \pm 0.11$ & \\
S. papillosus (dwarf scorpionfish) & & $1(1)$ & & $0.08 \pm 0.08$ \\
L. ciliaris (blue moki) & $1(1)$ & & $0.08 \pm 0.08$ & \\
\hline
\end{tabular}

Two species were only observed when using the horizontal BUV technique; one of them was scarlet wrasse (Pseudolabrus miles) a labrid, the other was blue moki (Latridopsis ciliaris) from the family Latridae. Finally, one species was only observed using the vertical BUV technique, the dwarf scorpionfish (Scorpaena papillosus), which belongs to the family Scorpaenidae.

No significant differences were detected in the mean species richness (Margalef's index) between techniques $(p=0.8034)$ or between sites $(p>0.05)$, and there was no significant interaction between factors (i.e., orientation $x$ site) ( $p>0.05)$ (Fig. 4.4). 


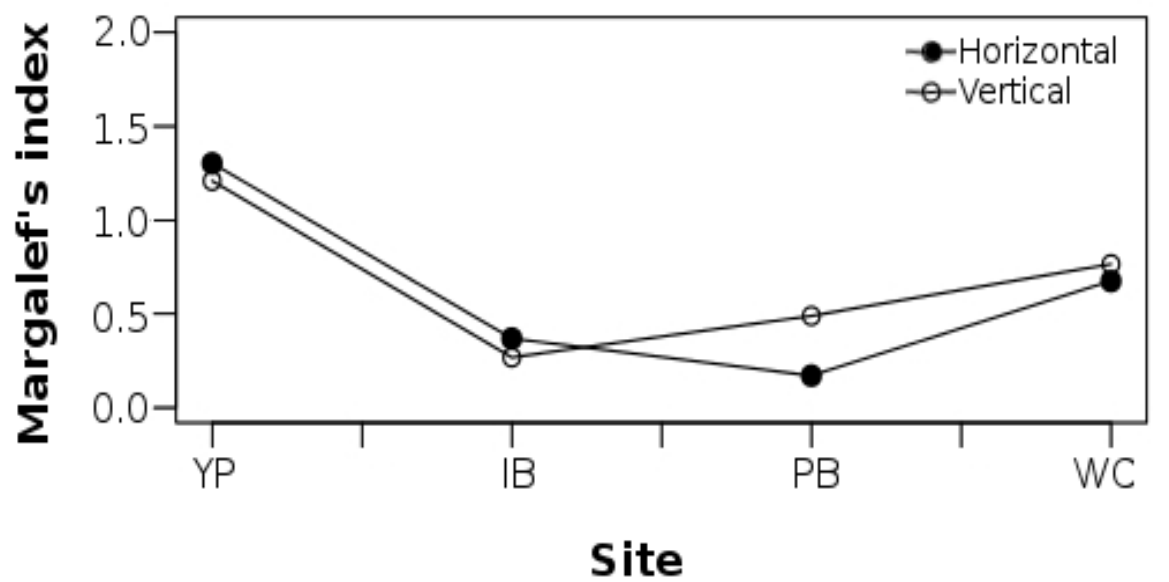

Figure 4.4: Mean species richness \pm SE recorded at all the sites surveyed with both BUV techniques. YP: Yung Pen; IB: Island Bay; PB: Princess Bay; WC: Waitaha Cove.

\subsubsection{Differences in species density between methodologies.}

Overall no significant differences were observed in the mean density between techniques for blue cod $(\mathrm{p}=0.594)$, spotty $(\mathrm{p}=0.178)$ and the 'other' species group $(\mathrm{p}=$ 1) (Fig. 4.5). Significant differences in mean density between sites was only observed for blue cod and the other species group ( $\mathrm{p}<0.05)$, but not for spotty ( $\mathrm{p}>0.05)$ (Fig. $4.5 \mathrm{~b})$. Blue cod mean density recorded with both techniques was substantially higher in the western sites (i.e., YP and IB) being almost 20 times higher at the highest density site compared with the site were the lower density was detected for the horizontal methodology (i.e., Nmax of 6.33 versus 0.33 ), and 10 times higher for the vertical methodology (i.e., Nmax of 6.33 versus 0.66 ) (Fig. 4.5a). The mean density of the other species recorded with both methodologies was higher in the far west site (Yung pen), being five times higher compared with the site where the lowest density was detected with the horizontal methodology and six times higher compared with the site were the lowest density was detected with the vertical methodology (Fig. 4.5c). There was no significant interaction between factors (i.e., orientation x site) (p>0.05) (Fig. 4.5). 

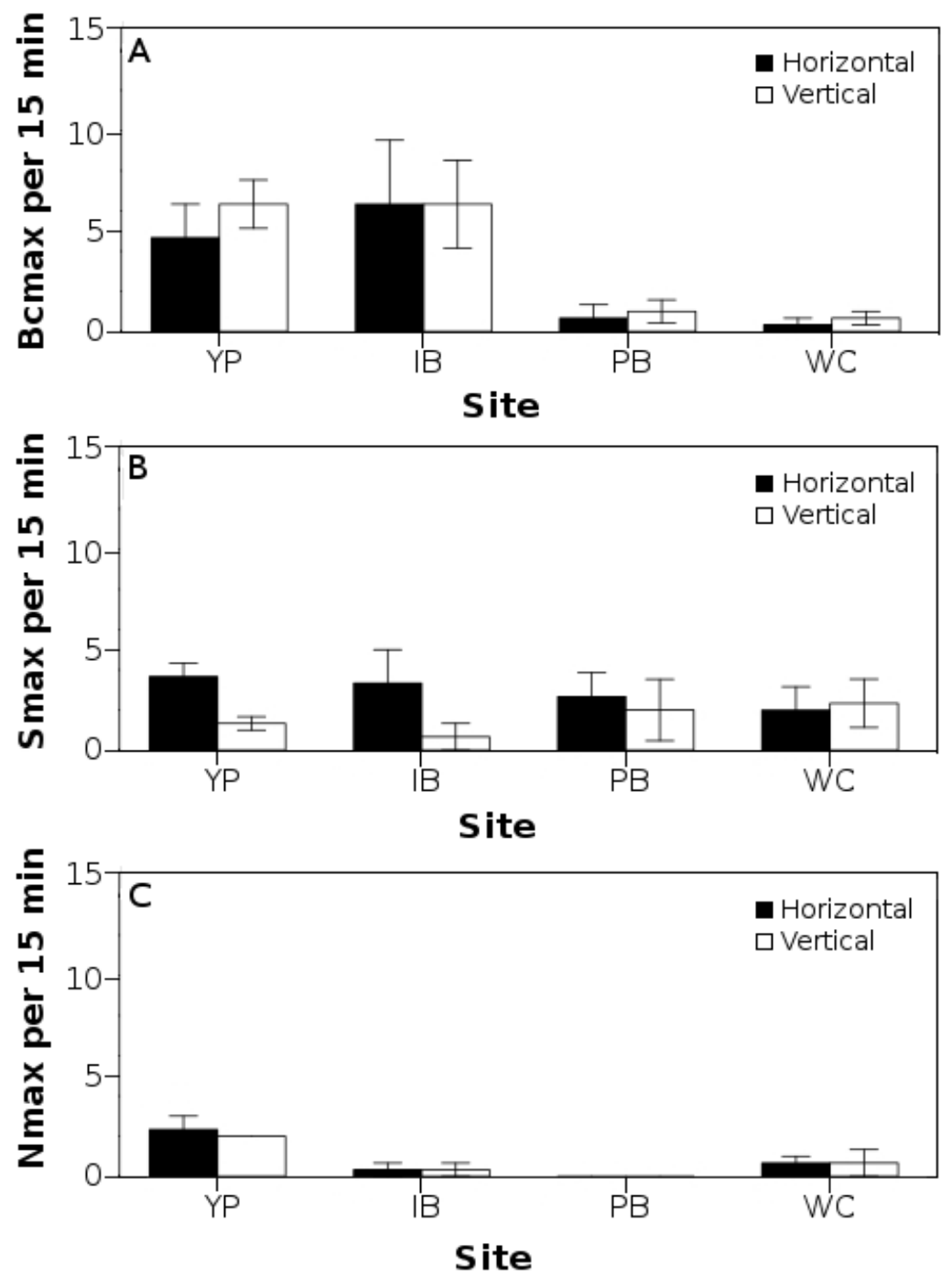

Figure 4.5: Mean density (Nmax) \pm SE for each fish species recorded with the two BUV methodologies (Horizontal/Vertical). (A) blue cod, (B) spotty and (C) other species. No error bars are displayed when the SEs are too small. YP: Yung Pen; IB: Island bay; PB: Princess Bay; WC: Waitaha Cove.

\subsubsection{Differences in species length between methodologies.}

Overall the effect of the orientation of the camera on fish length was significant for both blue cod $(p<0.00001)$ and spotty $(p=0.0145)$, with mean fish length estimates being greater for the vertical BUV station (Fig. 4.5). For blue cod, at Waitaha Cove (far east sites), the length estimates were more than twice as high for the vertical BUV station 
compared to the horizontal BUV station (Fig. 4.5a). No significant differences in mean fish length were found between sites for blue cod or spotty ( $p>0.05)$ and there were no significant interactions between factors (i.e., orientation x site) ( $p>0.05)($ Fig. 4.5).
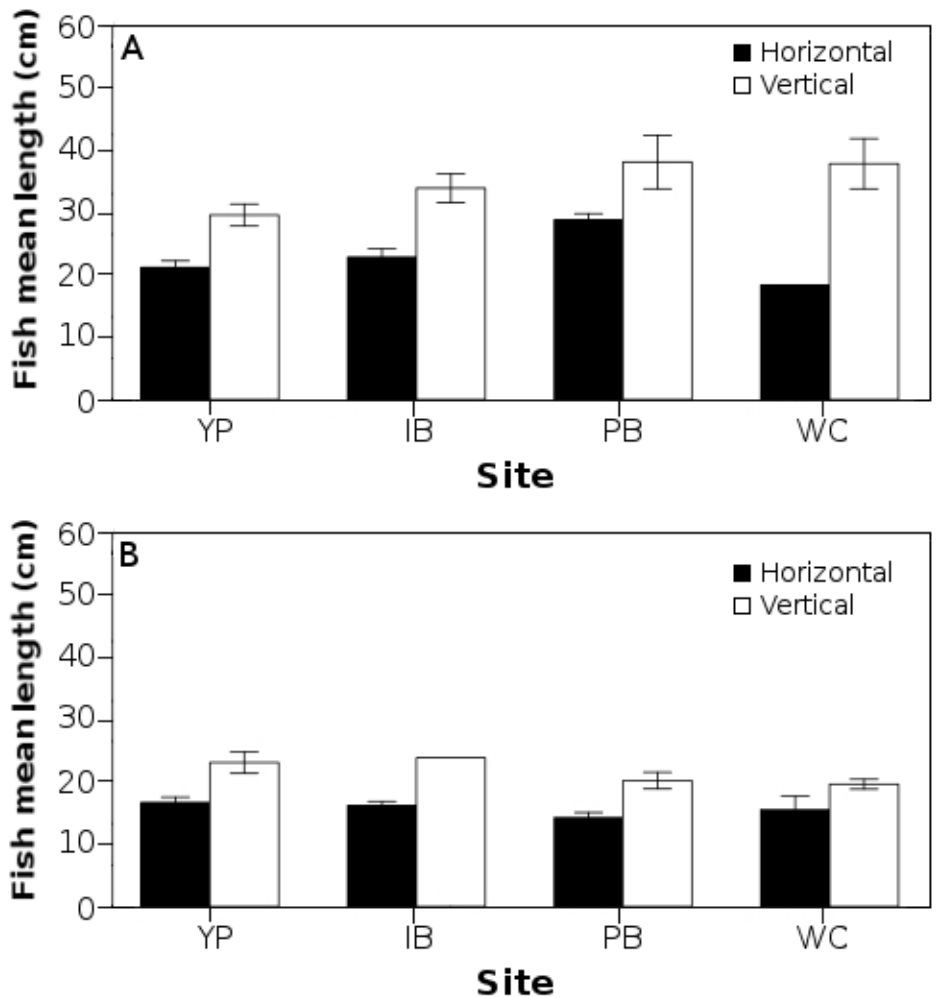

Figure 4.6: Mean length $(\mathrm{cm}) \pm \mathrm{SE}$ for each fish species recorded with the two BUV methodologies (Horizontal/Vertical). (A) blue cod and (B) spotty. No error bars are displayed when the SEs are too small. YP: Yung Pen; IB: Island Bay; PB: Princess Bay; WC: Waitaha Cove.

The expected values predicted by the Bayesian analysis with the corresponding confidence intervals (95\%) were plotted in Fig. 4.7. The curves overlapped at low abundance levels, but as abundance increased (i.e., over 8 fish were recorded) the curve representing the vertical BUV technique seemed to reach a point of stability, while the curve representing the horizontal BUV technique kept increasing, suggesting that the horizontal BUV technique will allow the measurement of more fish compared to the vertical BUV technique. Confidence intervals increased as the abundance of fish 
increased for both the horizontal and vertical BUV technique and whilst they do overlap they follow the curve trajectory.

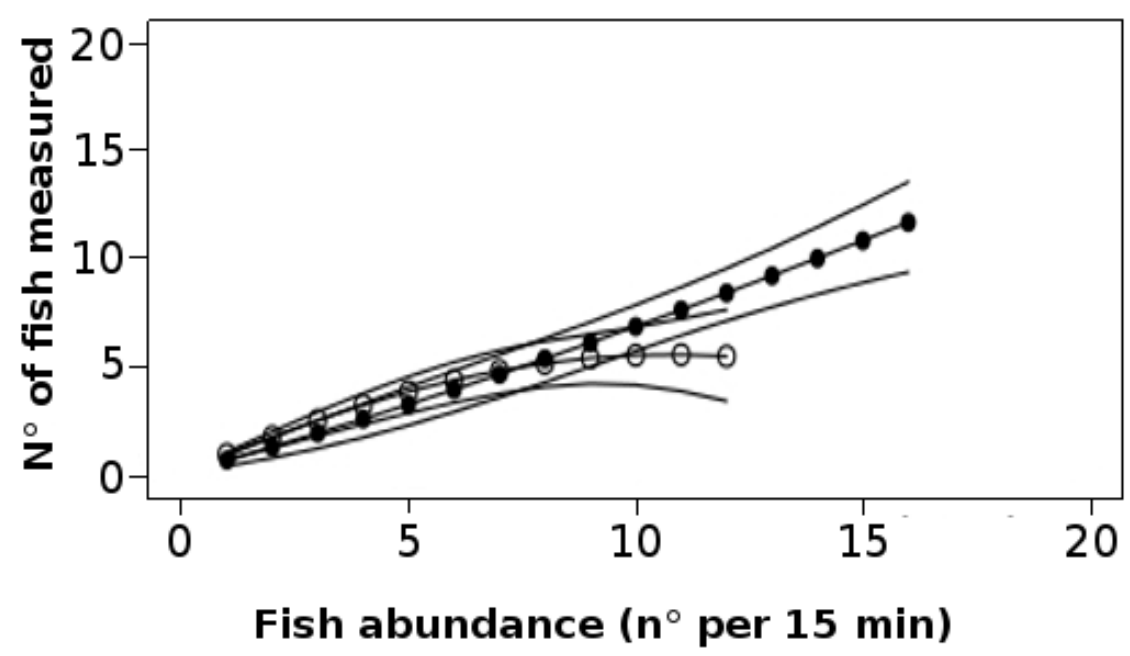

Figure 4.7: Number of fish measured as function of fish abundance. Expected values (dotted line) with corresponding 95\% confidence intervals (solid line). YP: Yung Pen; IB: Island Bay; PB: Princess Bay; WC: Waitaha Cove.

\subsection{Discussion}

The aim of this chapter was to detect differences between two BUV methodologies in order to determine the best methodology to estimate reef fish density and length. The reliability of BUV has been compared to other commonly used methodologies and some authors have recognized several limitations of the more traditional approaches, recognizing that the BUV provided the most reliable measure of density of reef fishes (e.g., Willis et al. 2000, Gardner \& Struthers 2012). However, Willis et al. (2000) suggested that some methodological approaches that may be appropriate for one species may not be appropriate for another and consequently different survey methods should be considered according to the biology and behaviour of the species of interest. Several studies have suggested that the BUV technique is a good methodology for the 
quantification of conspicuous species, for example, mobile predators and species targeted by fishing (e.g., Willis \& Babcock 2000, Cappo et al. 2004, Watson et al. 2005, Watson \& Harvey 2007, Gardner \& Struthers 2012). Indeed, the BUV method has been used in a number of monitoring surveys around New Zealand only for the estimation of abundance and size of carnivorous species that are difficult to survey with traditional diver mediated census techniques, for example, snapper and blue cod (e.g., Babcock et al. 1999, Taylor et al. 2003, Denny et al. 2004, Gardner \& Struthers 2012). However, to my knowledge, no previous study has evaluated the differences between the two commonly used BUV techniques (vertical and horizontal set up).

\subsubsection{Effect of the orientation of the BUV station on species richness}

The results of the present study suggested that there are no major differences between the techniques in terms of their ability to detect reef fish species, i.e., no significant differences in species richness between the two BUV techniques, between sites or significant interaction between factors (i.e., orientation x size). Indeed five species were common to the two BUV techniques. From those five species, blue cod, spotty and banded wrasse are conspicuous carnivorous species commonly found in shallow rocky reef habitats in the study area (Francis 2008). Blue cod and spotty were the most abundant species recorded in the study, while banded wrasse was less abundant but still common. Spotty are much smaller than blue cod (i.e., maximum length of approximately $30 \mathrm{~cm}$ compared to $60 \mathrm{~cm}$ ) but they are very inquisitive and usually approach divers. Blue cod is characterised by a fearless and inquisitive behaviour, being also described as a dominant and aggressive species (Francis 1988, 2008). Blue cod, spotty and banded wrasse were among the most common species found during UVC surveys performed in the study area, i.e., present in most of the sites surveyed and/or in greater abundance compared to other species (see chapter three and five). Banded wrasse and spotty are both wrasses from the family Labridae. Colton \& Swearer (2010) found that conspicuous species from the family Labridae were frequently observed in BUV samples (i.e., observed in $89 \%$ of the samples) and Denny et al. (2003) reported 
similar results. In this context BUV provides an advantage over other methodologies, for example the UVC that have been found to underestimate the abundance of common labrids species (Brock 1982, Watson et al. 2005). However labrids species have been among the most abundant species found with the UVC methodology in the study area (see chapter three and five).

The two other species common between the two BUV techniques, the common conger eel and the trumpeter are also conspicuous species that can reach large sizes (i.e., maximum length of approximately $200 \mathrm{~cm}$ and $110 \mathrm{~cm}$ for conger eel and trumpeter respectively), both are common in the study area (Francis 2008, Díaz-Guisado unpublished data). Conger eels are cryptic species that usually hide deep in holes and crevices by day and at night they leave the shelter and rove around searching for prey (Francis 2008). Colton \& Swearer (2010) suggested that stationary cameras were less effective than other methodologies in the detection of cryptic species. However, in the present study the conger eel was recorded at one site with both BUV techniques. Conger eels are carnivorous and therefore attraction to the bait could explain the occurrence of the species in the proximity of the baited stations. On the other hand, juvenile trumpeter live in shallow reef habitats year-round before migrating to deeper grounds and are often seen singly or in small groups (Francis 2001). Trumpeter is also carnivorous species that has been reported, also in very low abundance and in only a few sites, with the UVC methodology in the study area (Díaz-Guisado unpublished data).

From those species that were only observed with the horizontal BUV technique, scarlet wrasse also belongs to the family Labridae and even though it is less common than spotty and banded wrasse it is still common in the study area, being frequently found under the kelp canopy in deeper rocky reef habitats (Francis 2008). The species is described as uncommon partly because of its shy behaviour, and they are often hidden from view (Francis 2008). Indeed, the species has not been included in monitoring surveys performed in the study area since before the reserve establishment due to its low abundance. However, the species was classified as a common species in a UVC survey performed in chapter five and was found in most of the sites surveyed (i.e., seven out of eight). Scarlet wrasse is an herbivorous species and even though Colton \& Swearer (2010) found that BUV recorded more carnivorous than herbivorous species, others authors have reported that the BUV methodology has the added advantage of recording 
non-predatory species that are attracted due to curiosity as well as those species that would be passing through the field of view (e.g., Cappo et al. 2004, 2006). Harvey et al. (2007), when comparing baited and unbaited underwater video stations, also found that both BUV techniques recorded herbivorous as well as carnivorous species. The other species, blue moki, is a bottom-feeding species that form schools. Juvenile and sub-adult fish inhabit shallow waters and schools of blue moki are frequently seen in the study area (Francis 2008). However the UVC performed in chapter three and five detected that the species abundance is low compared to other species as blue moki were found in only a few sites in the study area. Finally, the dwarf scorpionfish, only observed with the vertical BUV technique, is also common in the study area (Francis 2008). This is a cryptic species usually found under the kelp canopy and is hard to see because it is extremely well camouflaged. These fishes are more active at night when they look for prey but it is also carnivorous and even though they are usually more active at night the presence of bait may explain the occurrence of the species in the proximity of the baited stations as in the case of the conger eel. In this context, my results suggest that both techniques were able to detect cryptic species. Cryptic species abundance is usually underestimated by other methodologies (i.e., UVC) (Brock 1982, Ackerman \& Bellwood 2000, Willis 2001). Clearly both BUV methodologies are able to detect a greater number or conspicuous species compared to cryptic species, especially the horizontal methodology.

It is important to notice that, even though the diversity estimates obtained with both BUV techniques are similar, both methodologies sub-sample reality, i.e., they both detect only a small part of the total species present in the study area. For example, according to Pande \& Gardner (2008) a total of 33 fish species were surveyed with the UVC methodology in the baseline study performed in the study area between 1998 2000. Most of these species occurred at low density and only eight fish species were included in their analysis. Later, Eddy (2011), in a monitoring survey in the study area surveyed 19 fish species with the UVC methodology but due to the low abundance of most of the species, only 10 were included in his analysis, the eight species reported by Pande \& Gardner (2008) and two new species. Finally, in the monitoring surveys (UVC) I performed in 2011 and 2012 in the study area, 12 fish species were surveyed but only 
the eight species analysed by Pande \& Gardner (2008) were included in the analysis (see chapter three). Clearly all the UVC surveys performed in the study area have detected far more fish species than those detected in the present study with the BUV methodology, both vertical and horizontal. From the species reported by Pande \& Gardner (2008) and also in chapter three, only three were reported with the BUV methodologies in the present study, i.e., blue cod, spotty and blue moki. However, two of the species reported with the BUV methodologies here were not reported by any of the UVC surveys performed in the study area (i.e., conger eel and dwarf scorpionfish).

The results of the present study highlight the need to recognize the limitations of these methodologies and the considerable importance of the use of adequate methodologies depending on the focus of the study or, if necessary, the use of a combination of methodologies to be able to sample a variety of species.

\subsubsection{Effect of the orientation of the BUV station on fish density}

Overall, the results of the present study, i.e., no significant differences between methodologies and no significant interaction between factors (i.e., orientation $\mathrm{x}$ site) suggested that the orientation of the camera (vertical vs horizontal) did not have an effect on the recorded density of any fish species. In terms of density differences between sites, significant differences were found for blue cod and the other species group with mean density being higher in the western sites (reserve sites) with both methodologies, while spotty mean density was similar at all sites surveyed. Several times blue cod density has been described to be higher inside reserves compared to fished areas (e.g., Cole et al. 2000, Willis et al. 2000, Pande 2001, Davidson \& Abel 2002, Davidson 2004, Taylor et al. 2003, Haggitt et al. 2008, see chapter two). Two of the sites that had the highest density in the present study were in fact reserve sites. In chapter three, the results of the comparison between reserve and fished sites (RR analysis) revealed differences between reserve and fished sites (i.e., higher density in reserve sites in most of the sampling occasions) for both blue cod and spotty. For blue cod RR obtained in the sampling occasion corresponding to 2011 (same year the present 
study was performed) indicated that blue cod density was substantially higher in reserve sites compared to fished sites (e.g., RR > 5). However, the RR obtained in the sampling occasion corresponding to 2011 for spotty indicated that density was higher outside reserve compared to reserve sites. Differences in density for the other species group could be due to the fact that those species were rare, i.e., they were only recorded in a few sites and in very low density. Overall these results indicated that both BUV methodologies provide reliable estimates of fish density and also valid comparisons between reserve and fished sites.

\subsubsection{Effect of the orientation of the BUV station on fish length}

When comparing fish length recorded by the two BUV techniques for the two most abundant species blue cod and spotty, the orientation of the camera had an effect on fish length. Mean fish length estimates recorded with the vertical BUV technique were higher than those recorded with the horizontal BUV technique, being twice as high at one of the sites. This difference could be due to the fact that I was not able to measure the full length of the blue cod when using the vertical BUV technique (many times fish were actually larger than the field of view). Therefore, total length was extrapolated from head length which, in many cases, was hard to measure from the video footage as fish were seen from above and the gill cover was hard to recognize. This could represent a problem that could results in erroneous estimates of fish length. Based on the data obtained during the CMR survey in the study area performed in chapter six, I suggest that the vertical BUV technique overestimated the length of blue cod because the mean length recorded with this technique was consistently higher than mean length recorded in the CMR survey at the same depth range, e.g., most of the fish observed with the vertical BUV methodology were over $30 \mathrm{~cm}$ (total length) in both reserve and fished sites. This is consistent with the fish sizes recorded in reserve areas in chapter six, but not with the sizes reported for fished areas (e.g., 60.7\% of blue cod in reserve sites were $>33 \mathrm{~cm}$ long, compared to $10.8 \%$ in nearby areas in 2010 while, in $2011,51.2 \%$ of blue

cod in reserves sites were $>33 \mathrm{~cm}$ long compared to $16.2 \%$ in nearby areas). The fact that 
the differences in fish length were also recorded for spotty, may suggest that overestimation can occur even for smaller individuals whose full size can be measured. Another possible explanation for differences in size estimates between methodologies is related to the spatial segregation of sizes relative to the bait. Given that the vertical BUV looks at a smaller area, if spacial segregation of sizes occurs, this could lead to predictable differences in mean size estimates. Willis et al. (2000) tested the reliability of the BUV methodology compared with UVC and an experimental angling survey (EA) at the Cape Rodney-Okakari Point Marine Reserve and found that mean sizes recorded with the BUV methodology were higher than those recorded with the other two methodologies. In this context, the horizontal BUV technique seems to be a better technique to minimize the overestimation of fish length that has been reported for the BUV methodology. Accurate estimations of fish length are very important when evaluating the response to reserve protection and in this context it is important to minimize sources of inaccuracy.

The results of the Bayesian analysis suggest that the horizontal BUV technique will allow the measurement of more fish compared to the vertical BUV technique. Confidence intervals (CIs) increase in width as the density of fish increases for both the horizontal and vertical BUV technique, which suggests a decrease in the accuracy of length determination as the density of fish increases and the CIs do overlap but follow a trajectory leading to the conclusion that the horizontal BUV technique is a better technique for the estimation of fish length. In this context, an important limitation of the BUV methodology, especially for species like blue cod that exhibit a highly aggressive behaviour, is related to the saturation of the field of view. In the present study I observed blue cod excluding other fish species and also conspecifics of minor length on a number of occasions from the area of the bait pot, especially when using the vertical BUV technique. Competitive exclusion has been previously reported in BUV studies (e.g., Willis \& Babcock 2000, Bailey \& Priede 2002, Cappo et al. 2006). As I observed in the video footage, at high density sites blue cod tends to overcrowd the field of view making density estimation and individual measurements difficult, especially for the horizontal technique, as fish tend to end up on top of each other. This could represent a problem in areas of high fish density, for example in reserve areas, which could lead to inaccurate measurement of fish. Davidson \& Richards (2005) detected the same problem and stated 
that this could also produce conservative contrasts between areas with high and low fish density and may also result in the failure to detect a difference between two areas where densities were different but high enough to saturate the field of view. In this context, one of the advantages of the horizontal technique is that it can detect fish over a larger area compared to the vertical technique (view area is limited by the sea floor). With the horizontal technique fish occurring in the background are as easy to identify as the ones next to the bait pot and this could be an added advantage not only in terms of the making easy measurement of the fish but also making it easy to identify fish, even though it depends on the visibility. At high density sites counting individuals with the vertical BUV technique would be harder as the field of view will become crowded as fish tend to swim over the bait pot obstructing the field of view. For a dominant species such as blue cod that usually stays close to the bait pot and excludes other species, the orientation of the camera may not be a problem but the detectability of other species such as spotty, that are excluded by more aggressive species, might be reduced.

Finally, as previously established, visibility is an important factor influencing the detectability of fish occurring in the field of view when using the horizontal BUV technique as changes in water visibility between times and locations will affect the field of view in which fish are identified and counted (Cappo et al. 2006). This could be an important limitation in areas of poor visibility, particularly in my study area where visibility during most of the deployments was low (i.e., 2-3 m). Ideally, changes in visibility among times and locations should be accounted for in the later analysis (Cappo et al. 2006). Macroalgae are another factor influencing the ability to count fish as they make it harder to see fish if they cover part of the field of view. Davidson \& Richard (2005) recognized this problem and found that the field of view may be obscured by kelp on shallow reefs, inhibiting the accuracy of counts and length measurements. The presence of macroalgae was a problem especially when using the vertical BUV technique because the frame that the camera is mounted on is much bigger than the one used in the horizontal set up and as a consequence it is very difficult to handle making it hard to place it on an appropriate substratum or move if it landed in an area dominated by kelp. 


\subsection{Conclusions}

My results suggest that both the horizontal and vertical BUV techniques are able to detect both conspicuous and cryptic species. However, density of cryptic species was very low compared to the other species observed. Overall, both BUV techniques were effective in the detection of carnivorous species, especially large predatory species as blue cod, but also effective in the detection of fish species that have been overestimated in terms of abundance by other methodologies. Also, both BUV techniques were found to be equally effective in terms of the estimation of reef fish abundance and comparisons of density estimates of the BUV and UVC methodology (chapter three) indicated that both BUV methodologies provide reliable estimates of fish density and also valid comparisons between reserve and fished sites. However, the horizontal BUV technique seems to be a better technique to evaluate reef fish size, especially when measuring large fish that exhibit a highly aggressive behaviour. 


\title{
Chapter 5
}

\section{Potential of the Taputeranga Marine}

\section{Reserve to Export Reef Fish Biomass to}

\author{
Adjacent Fished Areas
}




\subsection{Introduction}

No-take marine reserves (MRs) have been widely promoted as conservation and fisheries management tools to restore habitats and protect over-harvested stocks (Roberts \& Polunin 1991, Roberts \& Hawkins 2000, Gell \& Roberts 2003b, Hilborn et al. 2004, Sale et al. 2005). However, recently, the potential for MRs to improve fishery yield has received far greater emphasis. For example, MRs might be expected to provide benefits to local fisheries (increasing fishing yields) due to the migration of biomass from the reserve to surrounding exploited areas (Gell \& Roberts 2003a, Sale et al. 2005, Osenberg et al. 2006, Ballantine \& Langlois 2008, Goñi et al. 2008). Even though fisheries enhancement is not a reason for MR designation in many countries including $\mathrm{NZ}$, in general, fully protected areas are expected to support fisheries beyond the boundaries of the MR by the net export of adults, hereafter refereed as "spillover" and propagules (larval export) (Bohnsack 1998, Allison et al. 1998, Bell 2008, CudneyBueno et al. 2009, Pelc et al. 2010, Harrison et al. 2012). If MRs are set up for fisheries enhancement, it should be expected that the long-term benefits of establishing a reserve should at least compensate for the inevitable loss of the fishing area required to set up the reserves (Russ 2002, Zeller et al. 2003, Hilborn et al. 2004). Spillover effects from an MR can result in positive net economic benefits (e.g., Grafton et al. 2009, McClanahan 2010)

In many countries, the creation of marine reserves is often controversial (Smith et al. 2010). Proposals to establish marine reserves are often met with hostility by fishing communities, usually because they focus on potential short-run costs, primarily in the loss of fishing opportunities (Bernstein et al. 2004). Specially, the opposition from fishers is often important when it comes to decide the size of the reserve (Gardner et al. 2008, Roberts 2012, Sala et al. 2013). Because of this tension it is usually the case that when marine reserves are established they are too small to promote spillover, something that might happen if reserves were larger. For example, Vanderperre et al. (2011) determined that Southern European MPAs showed clear effects on the surrounding fisheries (CPUE analysis) and suggested that catch rates of selected fisheries that were expected to benefit most from protection increased when the no-take area was larger. In 
this context, a more robust approach for the evaluation of benefit beyond boundaries is still required and may be critical to the successful establishment of further marine reserves.

Spillover is a process often assumed to be driven by density-dependent interactions inside reserves. Higher rates of aggressive interactions due to the increased biomass inside reserves are predicted to induce subordinate individuals to relocate their home range to outside the reserve (Roberts \& Polunin 1991, Rakitin \& Kramer 1996, Kramer \& Chapman 1999, Sanchez Lizaso et al. 2000, Sutherland et al. 2002, Russ 2002). Density-dependent spillover will only begin to operate when the density in reserves is high enough to induce home-range relocation. Under such circumstances, the detection of spillover at any given time after reserve establishment depends on the recovery rate of the species and the local environmental conditions (Abesamis \& Russ 2005). A common theme found in the literature is that the abundance of a target species often increases rapidly following establishment of marine reserves (Halpern \& Warner 2002, DíazGuisado et al. 2012, Rife et al. 2013), but clearly more time might be required to achieve a multispecies response (McClanahan \& Mangi 2000, Russ \& Alcala 2004). For example, some studies have shown that significantly higher reserve biomass was not reached until 10 years after their establishment (e.g., Russ et al. 2005, Claudet et al. 2006), while others have observed similar results after only 1-3 years (e.g., Halpern \& Warner 2002, Halpern 2003, Micheli et al. 2004, Díaz-Guisado et al. 2012, Horta e Costa et al. 2013). However, it is often also assumed that spillover may occur through occasional density-independent emigration (Roberts \& Polunin 1991, Russ 2002, Gell \& Roberts 2003b, Abesamis \& Russ 2005). Density-independent movements imply a simple diffusion-type equilibrium that may occur as soon as density is higher inside reserves than outside, which may be expressed quicker than density-dependent spillover (Abesamis \& Russ 2005).

Several factors may influence the occurrence of spillover, among them, the distribution of habitat types relative to reserve boundaries is an important factor that can determine the movement of species (Buechner 1987, Chapman \& Kramer 1999, Kramer \& Chapman 1999, Freeman et al. 2009). For example, individuals living on habitat patches that cross reserve boundaries are more likely to move to unprotected areas than individuals living on patches insulated from reserve boundaries by natural barriers in the 
form of unsuitable habitat (e.g., areas with low habitat complexity, very shallow or deep water) (Roberts \& Polunin 1991, Barret 1995, Kramer \& Chapman 1999, Freeman et al. 2009). Research on this topic, mostly on reef fishes, has confirmed that export from reserves is usually greater when habitat patches cross reserve boundaries (Tewfik \& Bene 2003, Topping et al. 2005, Tupper 2007, Forcada et al. 2009). In addition, the propensity for individuals to cross physical barriers in response to habitat availability and quality may depend on the mobility and behavioural patterns of the species involved (Roberts \& Polunin 1991, Edgar \& Barrett 1999, Jennings 2000, Kellner et al. 2008). Research has shown that fish species with home ranges that are large relative to the size of MRs and those which readily relocate home ranges are more likely to cross reserve boundaries (Chapman \& Kramer 1999, Zeller et al. 2003). Consequently, it is imperative that studies attempting to quantify spillover examine a combination of species in multiple reserve and control locations (Zeller et al. 2003).

The role of spillover in determining protected area effectiveness has been addressed in both modelling and empirical studies. Most spillover evidence comes from ecosystem-level models, measures of changing fisheries yield or profit adjacent to reserves and from studies of small-scale adult movement patterns across reserve boundaries. Even though modelling studies do not have the constraints associated with empirical studies (i.e., empirical studies are generally restricted to small scale effects on local fisheries; Abesamis et al. 2006a, Goñi et al. 2010), modelling studies rely on many assumptions and have been criticised as unrealistic and offering conflicting conclusions (e.g., Willis et al. 2003b). Empirical evidence has shown that the spatial extent of detectable spillover effects is thought to be limited to a few hundred to a few thousand meters from MR boundaries, depending on species mobility and habitat characteristics, although it has been considered that this extent is strongly affected by fishing effort near boundaries and gear efficiency (e.g., McClanahan \& Mangi 2000, Russ et al. 2004, Abesamis \& Russ 2005, Murawski et al. 2005, Abesamis et al. 2006b, Goñi et al. 2006, 2008, Forcada et al. 2009, Januchowski-Hartley et al. 2013).

Gradients of fish abundance or catch have been advocated as a simple tool to provide evidence of spillover across reserve boundaries and to assess the distance of influence of the reserve (e.g., Rakitin \& Kramer 1996, Ashworth \& Ormond 2005, Abesamis et al. 2006b, Goñi et al. 2008, Harmelin-Vivien et al. 2008). Net emigration of adult fish from 
a reserve (driven by density-dependent interactions), combined with fishing mortality outside the reserve, may produce such a decreasing pattern of abundance (Abesamis et al. 2006b, Kellner et al. 2007). The number of fish that move outside the reserve due to density-dependent interactions is expected to decrease with increasing distance from the reserve boundary (Kramer \& Chapman 1999, Sutherland et al. 2002, Kellner et al. 2007). Alternatively, a decreasing gradient of abundance may result for some fish that reside near the reserve boundary and have home ranges that overlap the boundary (Kramer \&Chapman 1999). Kellner et al. (2007, 2008) and Perez-Rusafa et al. (2008) have previously shown the density-dependent movement across many MR boundaries produces sigmoid shaped spillover curves. Steeper gradients and inflection points closer to the reserve boundary may imply less spillover than flatter gradients and inflection points further from the reserve boundary (Kellner et al. 2007). However, the absence of gradients can be explained by factors other than lack of spillover, and these factors include concentrated fishing effort near borders ("fishing the line") and high organism mobility (Goñi et al. 2006, Abesamis et al. 2006b, Kellner et al. 2007, Halpern et al. 2010), and habitat distribution patterns (Goñi et al. 2008, Harmelin-Vivien et al. 2008, Forcada et al. 2009). Stobart et al. (2009) suggested that, due to a "spillover effect", the community in the fished areas closest to the reserve will resemble the community inside the reserve more than those further away not only in terms of abundance and biomass, but also in terms of other community metrics (i.e., species richness, community size structure and species composition).

One prediction derived from both empirical and theoretical studies, particularly from studies of coral reef fish, is that the slope of gradients of abundance across reserve boundaries should vary depending upon the catchability and mobility of fish and the redistribution of the fishing effort outside reserve boundaries. Assuming equal mobility, the gradient will be steeper for fish more vulnerable to fishing gears (Rakitin \& Kramer 1996, Kaunda-Arara \& Rose 2004), and no gradient should be observed for non-target species (Rakitin \& Kramer 1996), unless non-target species are caught unintentionally (e.g., as bycatch). In terms of fish mobility, according to predictions, reserves are most likely to benefit fisheries relying on species with moderate vagility (mobility). Lowvagility fish species are expected to benefit from MRs (increased abundance inside reserves) but they do not move enough to significantly contribute to spillover, while 
high-vagility fish abundance is not greatly increased in reserves (McClanahan \& Mangi 2000), but see recent work by Malvadkar \& Hastings (2008) and Haggitt (2011). In this context, under equal catchability conditions, the gradient should be steeper for more sedentary species (Rakitin \& Kramer 1996, Kaunda-Arara \& Rose 2004) whilst highly vagile species may display a very weak gradient of abundance across reserve boundaries (Rakitin \& Kramer 1996, Kaunda-Arara \& Rose 2004). In terms of the effect of the redistribution of fishing effort outside reserve, since fish captured outside the reserve probably spend part of their life under the protection of the reserve and part outside it, the spatial distribution of fish inside versus outside the reserve should be strongly affected by the distribution of fishing effort (Kellner et al. 2007). If fishing effort is high close to the border of the reserve, this may lead to the overestimation of differences between reserve and fished areas (e.g., large differences between density inside versus outside reserve) and consequently steeper gradients outside the reserve boundary while flat gradients would be observed if fishing effort is distributed uniformly (Kellner et al. 2007). Ultimately, MR size has been also identified as an important factor determining the shape of the gradients (Kellner et al. 2008).

The Taputeranga Marine Reserve (TMR) located on the south coast of the capital of New Zealand, Wellington, was gazetted in 2008. Many fish species have been harvested along the Wellington south coast since Mãori first settled New Zealand $~ 800$ years ago. As a consequence of centuries of exploitation of coastal resources, the abundance and size of the most popular food fishes have decreased, particularly during the last few decades (Francis 2008). It has been suggested that, as has happened in other MRs in New Zealand, the exclusion of fishing from the area should enable at least some species to increase in abundance and size inside the reserve, particularly targeted species (Ballantine \& Langlois 2008, Walls 2008, Pande \& Gardner 2008, see chapter three).

The aim of the present study was to perform a multispecies analysis using two survey methodologies, a baited underwater video (BUV) survey and a underwater visual census (UVC) survey, to quantify spatial differences in abundance, species richness and individual size of both target and non-target reef fish species across the east and west boundaries of the TMR and to quantify spillover of these species. 


\subsection{Methods}

The study experimental design was based on the detection of differences in community metrics (species richness, fish density and fish length) between areas (reserve/fished) and the detection of gradients of abundance across the boundaries of the TMR using two different survey methodologies over two consecutive years in the same season (surveys where carried out in summer 2011 and 2012).

\subsubsection{Study area}

The present study took place in the Taputeranga Marine Reserve (TMR) and surrounding fishing grounds located on the south coast of Wellington (Fig. 5.1). The survey was conducted in a $\sim 12 \mathrm{~km}$ long section of shallow reef slope including a $\sim 3.8$ $\mathrm{km}$ section protected inside the TMR and two sections extending $\sim 1.6 \mathrm{~km}$ and $\sim 2.6 \mathrm{~km}$ outside to the west and east lateral boundaries of the reserve, respectively. For a detailed description of the study area refer to chapter three.

The habitat distribution on the south coast of Wellington, as mapped by side-scan sonar in a study performed by the National Institute of Water and Atmospheric Research (NIWA), is characterised by submarine extensions of the rocky headlands that define the bays. According to Eddy (2011) substrate types can be classified into the following two categories: hard substrate (i.e., intertidal and subtidal reef) and soft mobile substrate that can be found inside the bays and extending towards the deep contours separating the extensions of the rocky headlands that define the bays (hard substrate). The western boundary of the reserve lies on a soft substrate area and the distance from the reef protected inside the reserve (nearest to the west boundary) to the nearest reef outside the reserve is $\sim 800 \mathrm{~m}$. From that reef, a complex reef system extends towards the west (i.e., shallow and deep reef terrain). Contrastingly, the eastern boundary lies on a hard substrate area that is part of a large reef system that extends deeper inside reserve $(\sim 2.1$ $\mathrm{km})$ and in fished areas $(\sim 3 \mathrm{~km})$. To the east of that reef a large area is characterised by an extensive soft substrate layer (Lyall Bay) (Fig. 5.1). The distance from the reef 
protected inside the reserve (east boundary) to the nearest reef outside the reserve is $\sim 800 \mathrm{~m}$. Further east, a shallow reef extends towards the entrance of Wellington Harbour.

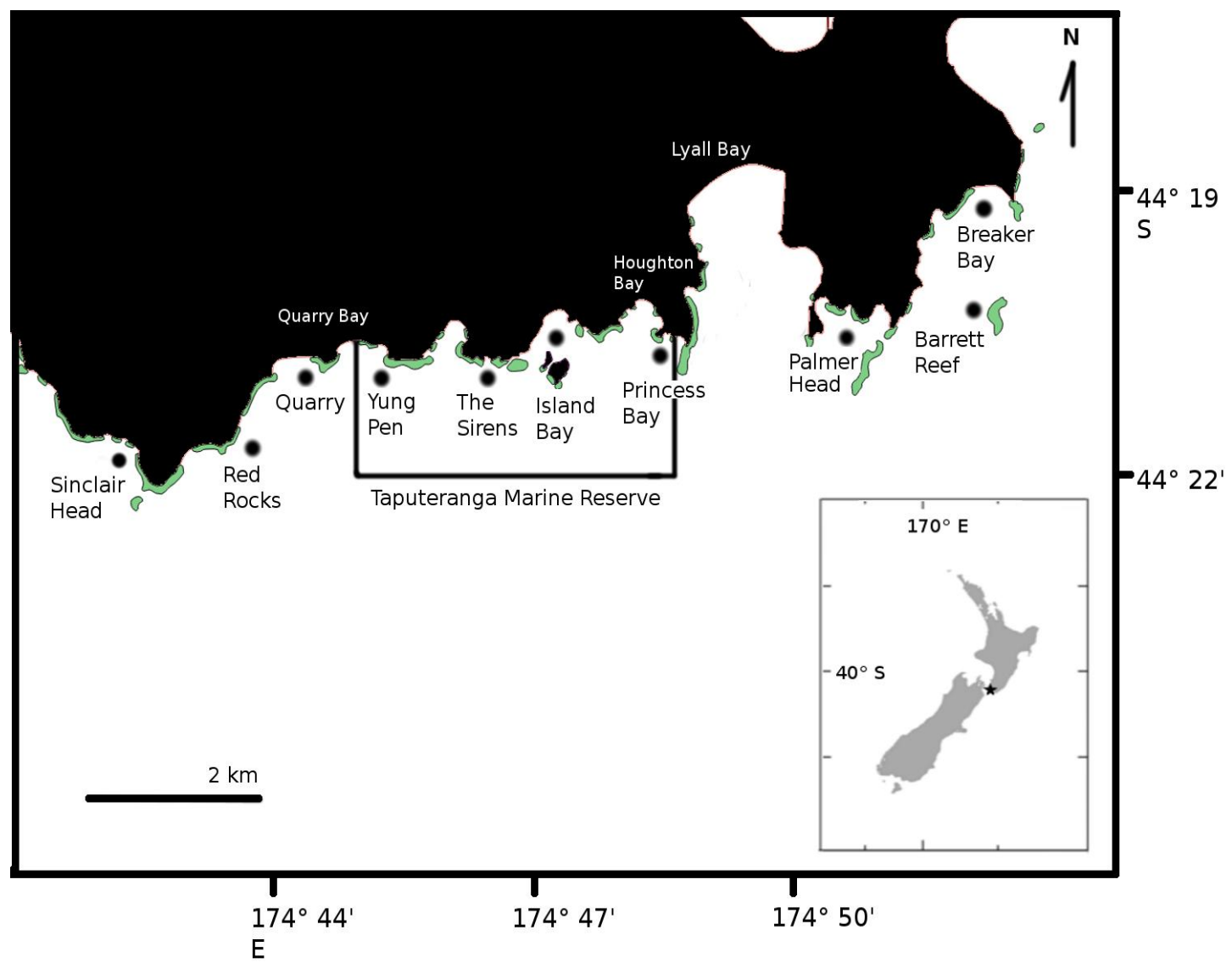

Figure 5.1: Map of the study area showing the sites surveyed inside the Taputeranga MR and in the adjacent fishing grounds. From west to east: Sinclair Head, Red Rocks, Quarry, Yung Pen, The Sirens, Island Bay, Princess Bay, Palmer Head, Barrett Reef, and Breaker Bay. Green area corresponds to intertidal reef.

\subsubsection{Site selection}

Eight sites (Sinclair Head, Red Rocks, Yung Pen, The Sirens, Princess Bay, Palmer Head, Barrett Reef and Breaker Bay) were surveyed with the underwater visual census (UVC) methodology. These eight sites have been the focus of the monitoring program 
of the TMR since before the establishment of the reserve (surveys carried out by Victoria University of Wellington and the Department of Conservation) (see chapter three).

Originally twelve sites (eight monitoring sites plus four new sites) were chosen for surveying with the BUV methodology in order to sample a greater area and to facilitate the detection of gradients of abundance extending from the centre of the reserve to fished areas. However, due to adverse weather conditions in the area and habitat characteristics, I was not able to survey them all. Consequently, only nine sites were surveyed (seven monitoring sites plus two new sites). A detailed summary of the sites surveyed with each methodology and dates is shown in Table 5.1.

\subsubsection{Species surveyed}

The present study focused only on fish. All fish species recorded with each methodology were considered for the analysis. Of special interest were the eight species that have been the focus of earlier monitoring surveys at the TMR: Notolabrus fucicola (banded wrasse), Parapercis colias (blue cod), Latridopsis ciliaris (blue moki), Odax pullus (butterfish), Cheilodactylus spectabilis (red moki), Notolabrus celidotus (spotty), Nemadactylus macropterus (tarakihi) and Pseudocaranx dentex (trevally). With the exception of banded wrasse and spotty, all species are commercially or recreationally important, or both, and all are common along the Wellington's south coast (Francis 2008, Pande \& Gardner 2008).

Due to the different characteristics of the species surveyed, especially those related to food preferences, the use of two different methodologies may result in differences in species detection. Most of the species surveyed here are carnivorous and even though the BUV technique is able to detect both herbivorous and carnivorous species, the abundances of herbivorous species is expected to be low compared to carnivorous species. For a detailed description of the species surveyed refer to chapter three. 
Table 5.1: Sites surveyed with each methodology in the 2011 and 2012 surveys. Status; F (fished) and R reserve).

\begin{tabular}{lcccc}
\hline \multicolumn{1}{c}{ Site (Status) } & \multicolumn{3}{c}{ Survey methodology } & UVC \\
\hline & 2011 & 2012 & 2011 & 2012 \\
\hline Sinclair Head (F) & $\mathrm{X}$ & $\mathrm{X}$ & $\mathrm{X}$ & $\mathrm{X}$ \\
Red Rocks (F) & $\mathrm{X}$ & $\mathrm{X}$ & $\mathrm{X}$ & $\mathrm{X}$ \\
Quarry (F) & $\mathrm{X}$ & $\mathrm{X}$ & & \\
Yung Pen (R) & $\mathrm{X}$ & $\mathrm{X}$ & $\mathrm{X}$ & $\mathrm{X}$ \\
The Sirens (R) & $\mathrm{X}$ & $\mathrm{X}$ & $\mathrm{X}$ & $\mathrm{X}$ \\
Island Bay (R) & $\mathrm{X}$ & $\mathrm{X}$ & & \\
Princess Bay (R) & $\mathrm{X}$ & $\mathrm{X}$ & $\mathrm{X}$ & $\mathrm{X}$ \\
Palmer Head (F) & $\mathrm{X}$ & $\mathrm{X}$ & $\mathrm{X}$ & $\mathrm{X}$ \\
Barrett Reef (F) & & & $\mathrm{X}$ & $\mathrm{X}$ \\
Breaker Bay (F) & $\mathrm{X}$ & $\mathrm{X}$ & $\mathrm{X}$ & $\mathrm{X}$ \\
\hline
\end{tabular}

\subsubsection{Survey methodologies}

\subsubsection{Underwater visual census survey}

The UVC data were obtained from the monitoring surveys carried out by Victoria University of Wellington and the Department of Conservation during summer- autumn (February- March) 2011 and summer (February) 2012 (see chapter three). These surveys were focused only on the eight species previously mentioned.

Divers swam a $25 \mathrm{~m}$ strip transect along a measuring tape, counting fish $2.5 \mathrm{~m}$ either side of the tape. Thus, fish were counted in a $25 \mathrm{~m}$ x $5 \mathrm{~m}$ corridor ( $2.5 \mathrm{~m}$ high) (Cole 1994, Pande \& Gardner 2008). Nine replicate transects were conducted at each site, giving a total area of $1125 \mathrm{~m}^{2}$ sampled per survey per site. Density was expressed as the number of fish per $125 \mathrm{~m}^{2}$. For a detailed description of the UVC methodology see chapter three.

Fish length was estimated by divers by measuring fish total length (visual estimation) to the nearest $5 \mathrm{~cm}$ (Pande \& Gardner 2008). In order to address the issue of variability 
in the ability to estimate fish sizes, divers were tested to determine their average error in fish size estimation. A transect line was laid out, with numbered plastic cut out fish positioned on either side of the transect line. The divers swam along the transect line estimating the length of each fish and these estimates were then compared with the actual value. The cut outs ranged in size from 5 to $60 \mathrm{~cm}$. The average error was found to be smaller than the $5 \mathrm{~cm}$ size interval used in the estimation of fish sizes. The same group of trained divers was used for conducting the surveys.

\subsubsection{Baited underwater video survey}

BUV surveys were performed during spring- summer in 2011 (late October to midDecember) and autumn in 2012 (early March). Based on the results obtained in chapter four I chose the horizontal BUV set up for the present study. Sampling consisted of three haphazard replicated 15 min deployments of the camera at each of the sites (total of 30 and 28 drops for 2011 and 2012, respectively). Replicates were deployed within a radius of $\sim 10$ to $50 \mathrm{~m}$ depending on the site. Refer to chapter four for a detailed description of the horizontal BUV methodology and video footage analysis.

Density was estimated during the video footage analysis by calculating the maximum number of individuals $\left(\mathrm{N}_{\max }\right)$ of each species observed in a single frame for each 15 min deployment and expressed as number of fish per 15 min deployment. Fish length was estimated from the video footage analysis by measuring the total length to the nearest 1 $\mathrm{cm}$ of each individual present in each $\mathrm{N}_{\max }$ frame by comparison to the five $\mathrm{cm}$ gradations marked on the camera stand. Measurements were only made of those fish

present when the $\mathrm{N}_{\max }$ was recorded to avoid repeated measurements of the same fish. Only those fish that were close to the graduated pole were measured to ensure accuracy as on many occasions it was not possible to measure all the fish in each $\mathrm{N}_{\max }$ frame, especially for some species (e.g., Gardner \& Struthers 2012). 


\subsubsection{Statistical analysis}

\subsubsection{Spatial differences in fish density, species richness and individual length between reserve and fished areas}

To study the differences between reserve and fished areas, among sites and between years in terms of species richness, I used Margalef's richness index (Margalef 1968):

$\mathrm{d}=\frac{(S-1)}{\left(\log _{e} N\right)}$,

where $\mathrm{S}$ is the total number of species and $\mathrm{N}$ is the total number of individuals in the sample.

Mean density and mean fish length estimates were calculated for each species (target and non-target) and used to compare density and length of fish between reserve and fished areas, among sites and between years for both methodologies.

Due to the nature of the data (refer to chapters three and four for a detailed explanation), a Linear Mixed-Effects Model (LMEM) was used to determine whether fish density, species richness and fish length differed significantly between area, among sites or between years for each methodology.

The analysis was carried out using the $\mathrm{R}$ statistical software package ( $\mathrm{R}$ Core Team 2012). A model was fitted using the generic function lme of the nlme $\mathrm{R}$ package (Pinheiro et al. 2011). The model was fitted with status (reserve/fished) and year (2011/2012) as fixed factors, and with site as a random factor. In addition, the interaction between the fixed factors was tested (i.e., status x year). A log-linear model was used to describe the expected values and was fitted using maximum likelihood. Data were $\log$ transformed to meet analysis assumptions when necessary. I used the Bonferroni correction for multiple comparisons. 


\subsubsection{Trends in fish density across reserve boundaries}

Fish species were classified into two groups "target species" and "non-target species" and within the target species group the species were also classified into two categories based on their patterns of mobility. Classification was made mainly based on published information (including Francis 1988, 2001, 2008, Froese \& Pauly 2013). Target species were classified into three mobility groups "sedentary" "moderate mobility" and "vagile" based on their range of mobility (Table 5.2).

Table 5.2: Classification of target species according to mobility patterns.

\begin{tabular}{lc}
\hline \multicolumn{1}{c}{ Species } & Mobility category \\
\hline Parapercis colias (blue cod) & Moderate mobilitty \\
Latridopsis ciliaris (blue moki) & Vagile \\
Odax pullus (butterfish) & Sedentary \\
Cheilodactylus spectabilis (red moki) & Sedentary \\
Nemadactylus macropterus (tarakihi) & Vagile \\
Arripis trutta (kahawai) & Vagile \\
Trachurus novaezelandiae (jack mackerel) & Vagile \\
\hline
\end{tabular}

A linear regression analysis was used to determine whether a significant relationship existed between mean fish density and distance from the centre of the reserve (i.e., decreasing trend in fish density from the centre of the reserve towards fished areas). These regressions were performed separately for the two lateral boundaries of the reserve. Linear regression attempts to fit a straight line across what may be a sharp, downward, step-like pattern, and thus is not the most appropriate analysis to detect spillover (Abesamis et al. 2006b). If a significant decreasing trend in density of any fish species was obtained by linear regression for any boundary, based on the approach used by Halpern et al. (2010), I fitted three models in order to find the best fit to the empirical 
data: exponential decay, Eq. 1; linear decay, Eq. 2; and logistic decay, Eq. 3.

1) $\mathrm{Y}=\exp ((\alpha \times x))$,

2) $Y=\alpha \times x+\beta$,

3) $\mathrm{Y}=\frac{\alpha}{(1+\beta(\exp (\delta \times x)))}$,

where $\mathrm{Y}$ represents fish density and $\mathrm{x}$ represents the distance from the reserve boundary (negative values are inside the reserve). For Eqs (1) and (2), $\alpha$ estimates the rate of decline in spillover, while in Eq. (3) $\alpha$ is the magnitude of the reserve effect (i.e., how much density changes due to protection provided by the reserve), $\beta$ is where the midpoint of the diminishing reserve effect is centred (this 'inflection point' is inside the reserve if $\beta>1$, outside the reserve if $\beta<1$, and centred on the reserve boundary if $\beta=$ $1)$ and $\delta$ is how steeply the reserve effect declines (larger values of $\delta$ represent steeper declines). In Eq. (3), the combination of $\beta$ and $\delta$ determines how far spillover spreads beyond the reserve boundary.

Past studies have primarily calculated the inflection point of logistic fits to estimate spillover distance (e.g., Kaunda-Arara \& Rose 2004, Abesamis et al. 2006b), but this approach captures the midpoint, not the detectable extent, of spillover. The method proposed by Halpern et al. (2010), and applied here, better captures detectable spillover distance.

Both exponential and linear functions were successfully fitted in every analysis, while the logistic function could not be fitted. According to Halpern et al. (2010), this is expected because spatially explicit monitoring data are often not sufficient to capture the full spatial pattern, especially when there are limited sampling sites within the reserve. The use of multiple models allowed me to find the best fit to the empirical data. The models were fitted using the preview function in the nlstools package (Baty \& Delignette-Muller 2013) and the nls function in the statistical package (Grothendieck 2013), which seeds the fitting procedure with chosen parameter values and then searches for those that produce the best fit. The Akaike information criterion (AIC) model 
selection procedure was used to compare model fits (Akaike (1973).

As an alternative approach, for those species exhibiting a significant decreasing trend in density identified from linear regression, I plotted running (cumulative) totals and then tested the curve against different theoretical distributions using the non-parametric Kolmogorov-Smirnov (K-S) test (R Core Team 2012). This approach allowed me to determine whether there is evidence against the density dataset having arisen from a given distribution.

\subsection{Results}

In total, 13 species of reef fish belonging to nine families were recorded in the present study (Table 5.3). Trevally was not included in the analyses due to the fact that this species was not observed at all in any of the UVC and BUV surveys during the course of the study.

Ten fish species were recorded with the UVC methodology in the 2011 survey and 12 species were recorded in the 2012 survey (Table 5.3). Nine species were recorded in both years. Jack mackerel were only recorded in the 2011 survey, whereas red moki, pufferfish and tarakihi were only recorded in the 2012 survey. Spotty, banded wrasse, scarlet wrasse, blue moki and butterfish were recorded at most of the eight sites surveyed (at least at four of the eight sites) in both years and therefore classified as common species. Even though blue cod was detected at only three sites in the 2011 survey, it was detected at more sites in the 2012 survey and it was also classified as a common species. All of the other species were classified as rare species.

Six fish species were recorded with the BUV methodology in the 2011 survey and nine species in the 2012 survey (Table 5.3). All six species recorded in the 2011 survey were recorded again in the 2012 survey along with three further species (butterfish, tarakihi and leatherjacket) (Table 5.2). From the species recorded with this methodology in both the 2011 and 2012 surveys, only blue cod, spotty and banded wrasse were recorded in most of the nine sites surveyed both years and were therefore classified as common species. All other species were recorded at only a few sites in both years and were classified as rare species. 


\subsubsection{Differences between reserve and fished areas}

\subsubsection{Species richness}

The results of the LME analysis indicated no significant differences in mean species richness between reserve and fished areas with any of the methodologies ( $p>0.05)$ or between years ( $p>0.05$ ) (Fig. 5.2). Even though mean species richness recorded with the UVC methodology increased substantially at two of the three reserve sites from 2011 to 2012 i.e., more species were detected in 2012 comparing to 2011 especially at Yung Pen (western reserve), resulting in the species richness being almost twice as high in 2012 (Fig. 5.2a), no significant interaction between factors (i.e., status x year) was detected with this methodology $(\mathrm{p}=0.0786)$. Also, no significant interaction between factors (i.e., status x year) was recorded with the BUV methodology (p>0.05) (Fig. $5.2 b)$ and no differences in mean species richness were detected among sites with either of the methodologies ( $\mathrm{p}>0.05)$ (Fig. 5.2).

Table 5.3. Species recorded with each methodology in the 2011 and 2012 surveys.

\begin{tabular}{|c|c|c|c|c|c|}
\hline \multirow[t]{3}{*}{ Family } & \multirow[t]{3}{*}{ Species } & \multicolumn{4}{|c|}{ Survey methodology } \\
\hline & & \multicolumn{2}{|c|}{ BUV } & \multicolumn{2}{|c|}{ UVC } \\
\hline & & 2011 & 2012 & 2011 & 2012 \\
\hline Pinguipedidae & $\begin{array}{l}\text { Parapercis colias } \\
\text { (blue cod) }\end{array}$ & $\mathrm{x}$ & $\mathrm{x}$ & $\mathrm{x}$ & $\mathrm{x}$ \\
\hline \multirow[t]{3}{*}{ Labridae } & $\begin{array}{l}\text { Notolabrus fucicola } \\
\text { (banded wrasse) }\end{array}$ & $\mathrm{x}$ & $\mathrm{X}$ & $\mathrm{x}$ & $\mathrm{x}$ \\
\hline & $\begin{array}{l}\text { Notolabrus celidotus } \\
\text { (spotty) }\end{array}$ & $\mathrm{X}$ & $\mathrm{x}$ & $\mathrm{x}$ & $\mathrm{x}$ \\
\hline & $\begin{array}{l}\text { Pseudolabrus miles } \\
\text { (scarlet wrasse) }\end{array}$ & $\mathrm{X}$ & $\mathrm{x}$ & $\mathrm{x}$ & $\mathrm{x}$ \\
\hline \multirow[t]{3}{*}{ Latridae } & $\begin{array}{l}\text { Cheilodactylus spectabilis } \\
\text { (red moki) }\end{array}$ & & & & $\mathrm{x}$ \\
\hline & $\begin{array}{l}\text { Latridopsis ciliaris } \\
\text { (blue moki) }\end{array}$ & $\mathrm{x}$ & $\mathrm{x}$ & $\mathrm{x}$ & $\mathrm{x}$ \\
\hline & $\begin{array}{l}\text { Nemadactylus macropterus } \\
\text { (tarakihi) }\end{array}$ & & $\mathrm{X}$ & & $\mathrm{X}$ \\
\hline Odacidae & $\begin{array}{l}\text { Odax pullus } \\
\text { (butterfish) }\end{array}$ & & $\mathrm{X}$ & $\mathrm{x}$ & $\mathrm{x}$ \\
\hline Arripidae & $\begin{array}{l}\text { Arripis trutta } \\
\text { (kahawai) }\end{array}$ & $\mathrm{x}$ & $\mathrm{x}$ & $\mathrm{x}$ & $\mathrm{X}$ \\
\hline Monacanthidae & $\begin{array}{l}\text { Parika scaber } \\
\text { (leatherjacket) }\end{array}$ & & $\mathrm{x}$ & $\mathrm{x}$ & $\mathrm{x}$ \\
\hline Carangidae & $\begin{array}{l}\text { Trachurus novaezelandiae } \\
\text { (jack mackerel) }\end{array}$ & & & $\mathrm{x}$ & \\
\hline Aplodactylidae & $\begin{array}{l}\text { Aplodactylus arctidens } \\
\text { (marblefish) }\end{array}$ & & & $\mathrm{x}$ & $\mathrm{X}$ \\
\hline Tetraodontidae & $\begin{array}{l}\text { Contusus richei } \\
\text { (pufferfish) }\end{array}$ & & & & $\mathrm{X}$ \\
\hline
\end{tabular}




\subsubsection{Fish density and length}

\subsection{Underwater visual census}

The results of the LME analysis indicated that no significant differences existed in mean density between reserve and fished areas for any of the species ( $p>0.05)$ (Figs. 5.3 and 5.4). Differences in mean density between years were observed only for blue cod ( $\mathrm{p}=$ 0.0360). Mean density was almost 3 times higher for blue cod in 2012 compared to 2011(Fig. 5.3a). No significant interaction between factors (i.e., status x year) was detected for any of the species surveyed ( $p>0.05)$ (Fig. 5.3).

Significant differences in mean density among sites were only observed for spotty ( $\mathrm{p}<0.05$ ). Spotty mean density increased steadily towards the eastern sites in the 2011 survey and was almost 7 times higher in the far east site compared to the far west site; a similar pattern was observed in 2012 (Fig. 5.3c).

The length analysis for this methodology only included the species classified as common because there were insufficient data to allow a meaningful comparison among sites for the other species. No differences in mean fish length were observed between reserve and fished areas for any of the species surveyed ( $p>0.05)$ (Fig. 5.5). Significant differences in mean fish length between years were only observed for spotty $(\mathrm{p}<0.001)$, which were larger at all the sites surveyed except one (YP) in 2012 compared to 2011 (Fig. 5.4c). The difference between the maximum and minimum mean fish lengths recorded in the 2011 and 2012 surveys was approximately $10 \mathrm{~cm}$ for this species. No. significant interaction between factors (i.e., status x year) was detected for any of the species surveyed. Significant differences in mean fish length among sites were only observed for scarlet wrasse $(\mathrm{p}<0.05)$ (Fig. 5.4b), but a general pattern was not observed.. 

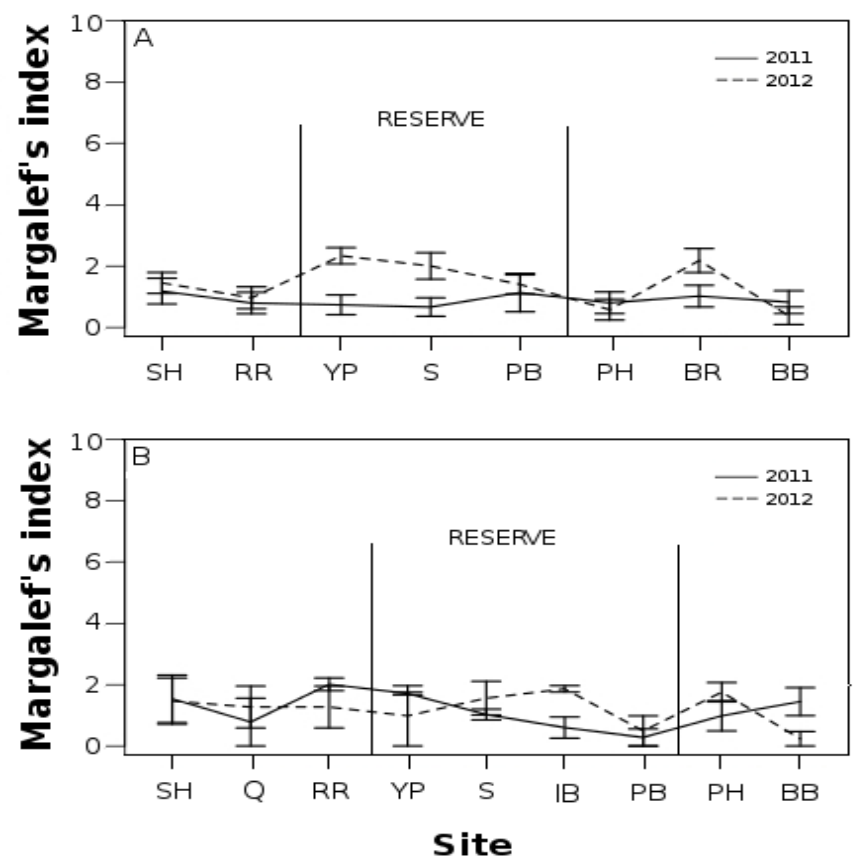

Figure 5.2. Mean species richness \pm SE recorded at each site in 2011 and 2012 for the two different methodologies: (A) Underwater Visual Census (UVC); and (B) Baited Underwater Video (BUV). Dashed vertical lines indicate the boundaries of the Taputeranga MR. SH: Sinclair Head; RR: Red Rocks; Q: Quarry; YP: Yung Pen; S: The Sirens; IB: Island Bay; PB: Princess Bay; PH: Palmer Head; BB: Breaker Bay. The vertical lines indicate the location of reserve boundaries. 

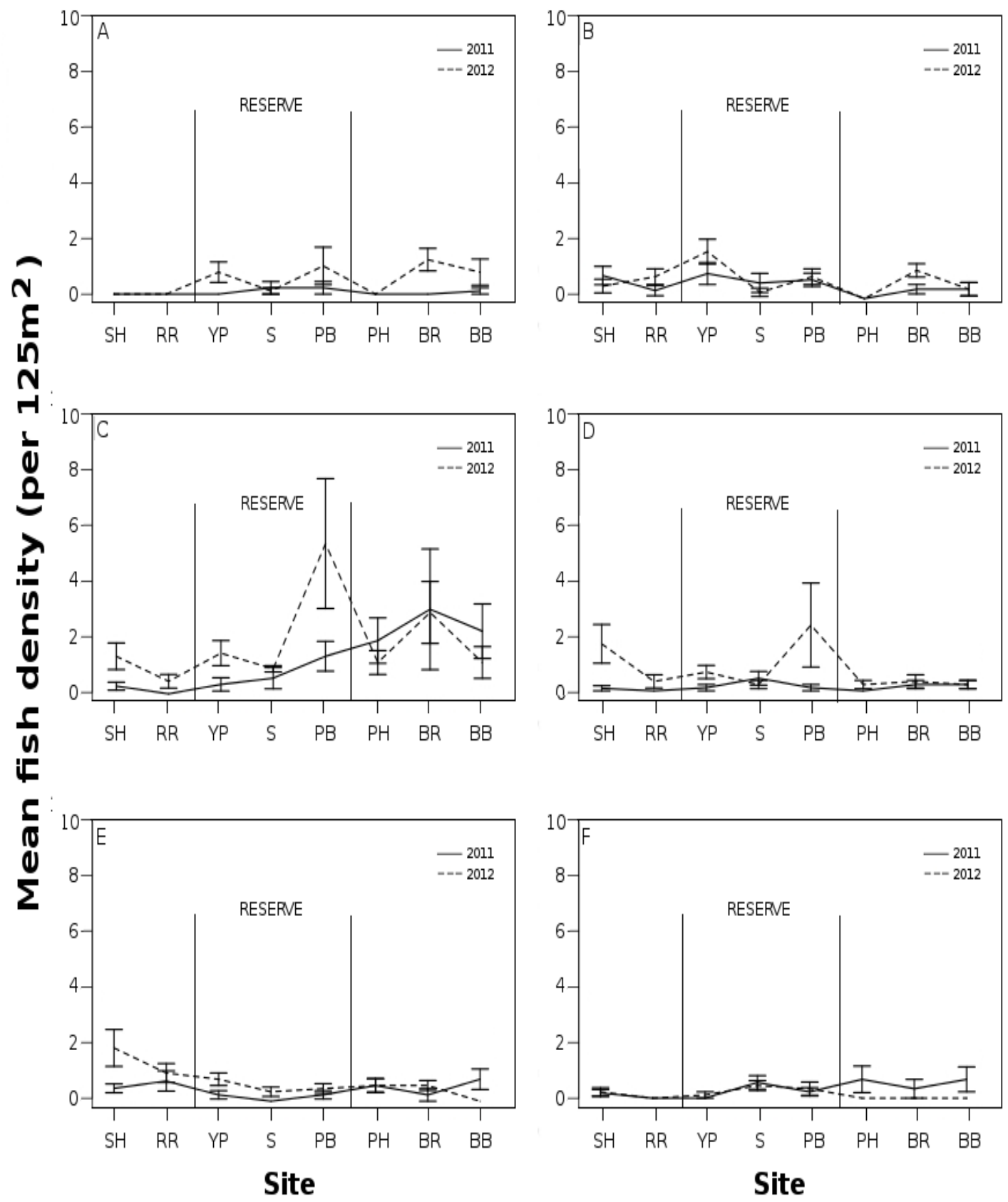

Figure 5.3: Mean fish density (per $125 \mathrm{~m}^{2}$ ) \pm SE recorded with the UVC methodology at each site in 2011 and 2012 for common species: (A) blue cod, (B) scarlet wrasse, (C) spotty, (D) blue moki, (E) banded wrasse, and (F) butterfish. Dashed vertical lines indicate the boundaries of the Taputeranga MR. SH: Sinclair Head; RR: Red Rocks; YP: Yung Pen; S: The Sirens; PB: Princess Bay; PH: Palmer Head; BR: Barrett Reef; BB: Breaker Bay. 

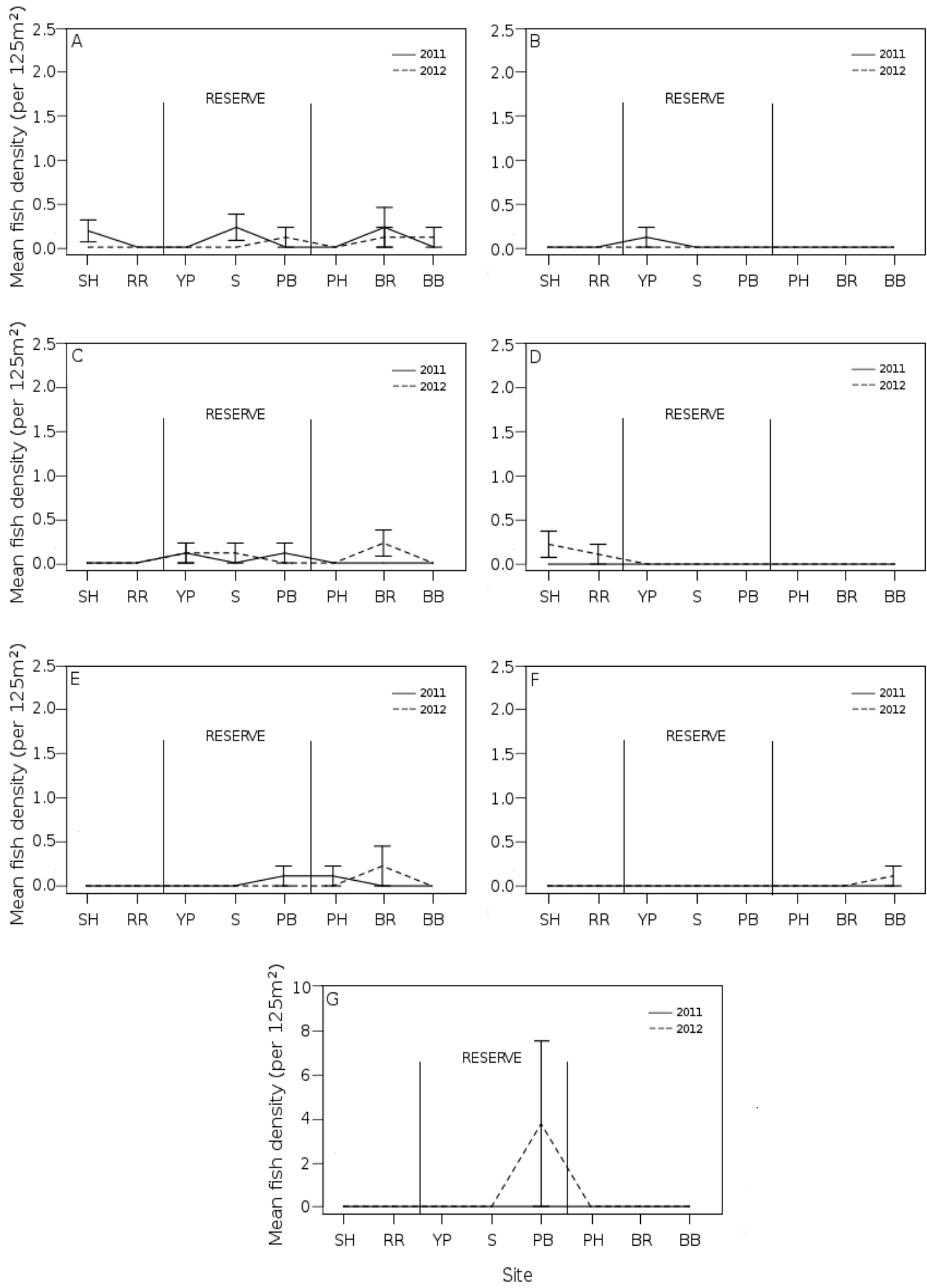

Figure 5.4: Mean density fish density (per $125 \mathrm{~m}^{2}$ ) \pm SE recorded with the UVC methodology at each site in 2011 and 2012 for uncommon species: (A) leatherjacket, (B) jack mackerel, (C) marblefish, (D) red moki, (E) kahawai, (F) pufferfish (G), tarakihi. Dashed vertical lines indicate the boundaries of the Taputeranga MR. SH: Sinclair Head; RR: Red Rocks; YP: Yung Pen; S: The Sirens; PB: Princess Bay; PH: Palmer Head; BR: Barrett Reef; BB: Breaker Bay. The vertical lines indicate the location of reserve 
boundaries.

\subsection{Baited underwater video}

The results of the LME analysis indicated that no significant differences existed in mean density between reserve and fished areas for any of the species surveyed ( $p>0.05)$ (Fig. 5.6 and 5.7). However, mean blue cod density was higher in reserve areas in both years, being approximately 6 and 5 times higher in 2011 and 2012, respectively (Fig. 5.6a). No significant differences in mean density between years were detected for any of the species surveyed ( $\mathrm{p}>0.05)$. A significant interaction between factors (i.e., status $x$ year) was only detected for kahawai $(\mathrm{p}=0.0420)$. Mean kahawai density decreased at fished sites from 2011 to 2012, while it increased at reserve sites, but kahawai was detected at only one site in both years (at a fished site in 2011 and at a reserve site in 2012 (Fig. $5.7 \mathrm{~d})$.

Significant differences in mean density among sites were only observed for scarlet wrasse and blue cod $(\mathrm{p}<0.05)$. Blue cod mean density was considerably higher at Yung Pen, The Sirens and Island Bay, all of which are reserve sites, compared to PB (reserve) and all the fished sites (Fig. 5.6a). Scarlet wrasse mean density was higher in the far west in both the 2011 and 2012 surveys but the species was only recorded at two sites (one reserve and one fished) in the 2011 survey and at one fished site in the 2012 survey (Fig. 5.7a).

The length analysis for this methodology only included three fish species, i.e., blue cod, spotty and banded wrasse, because estimation of fish length was difficult for the other species recorded (see methods section). No differences in mean fish length were observed between reserve and fished areas for any of the species surveyed ( $p>0.05)$ (Fig. 5.8). Significant differences in mean fish length between years were only detected for spotty ( $\mathrm{p}<$ 0.0426), which were larger in 2011 compared to 2012 (Fig. 5.8b). No significant interactions between factors (i.e., status $\mathrm{x}$ year) were detected for any of the species surveyed. Significant differences in mean fish length were only detected for blue $\operatorname{cod}(\mathrm{p}<0.05)$, whose length was greater at reserve than at fished sites (Fig. 5.8a).

species surveyed. 

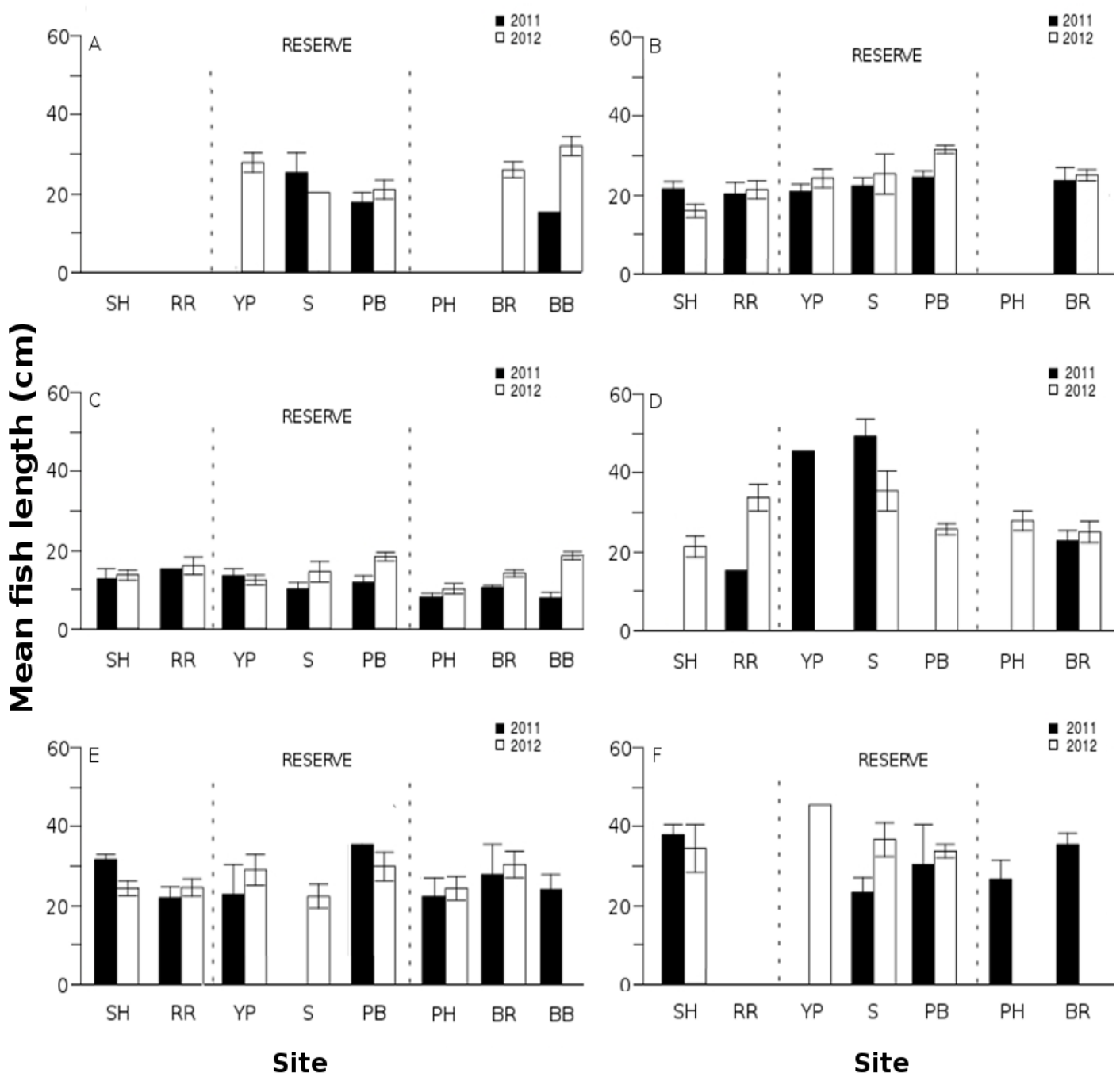

Figure 5.5: Mean length \pm SE recorded with the UVC methodology at each site in 2011 and 2012 for common species: (A) blue cod, (B) scarlet wrasse, (C) spotty, (D) blue moki, (E) banded wrasse, and (F) butterfish. Dashed vertical lines indicate the boundaries of the Taputeranga MR. No error bars are displayed when the SEs are too small. SH: Sinclair Head; RR: Red Rocks; YP: Yung Pen; S: The Sirens; PB: Princess Bay; PH: Palmer Head; BR: Barrett Reef; BB: Breaker Bay. The vertical lines indicate the location of reserve boundaries. 


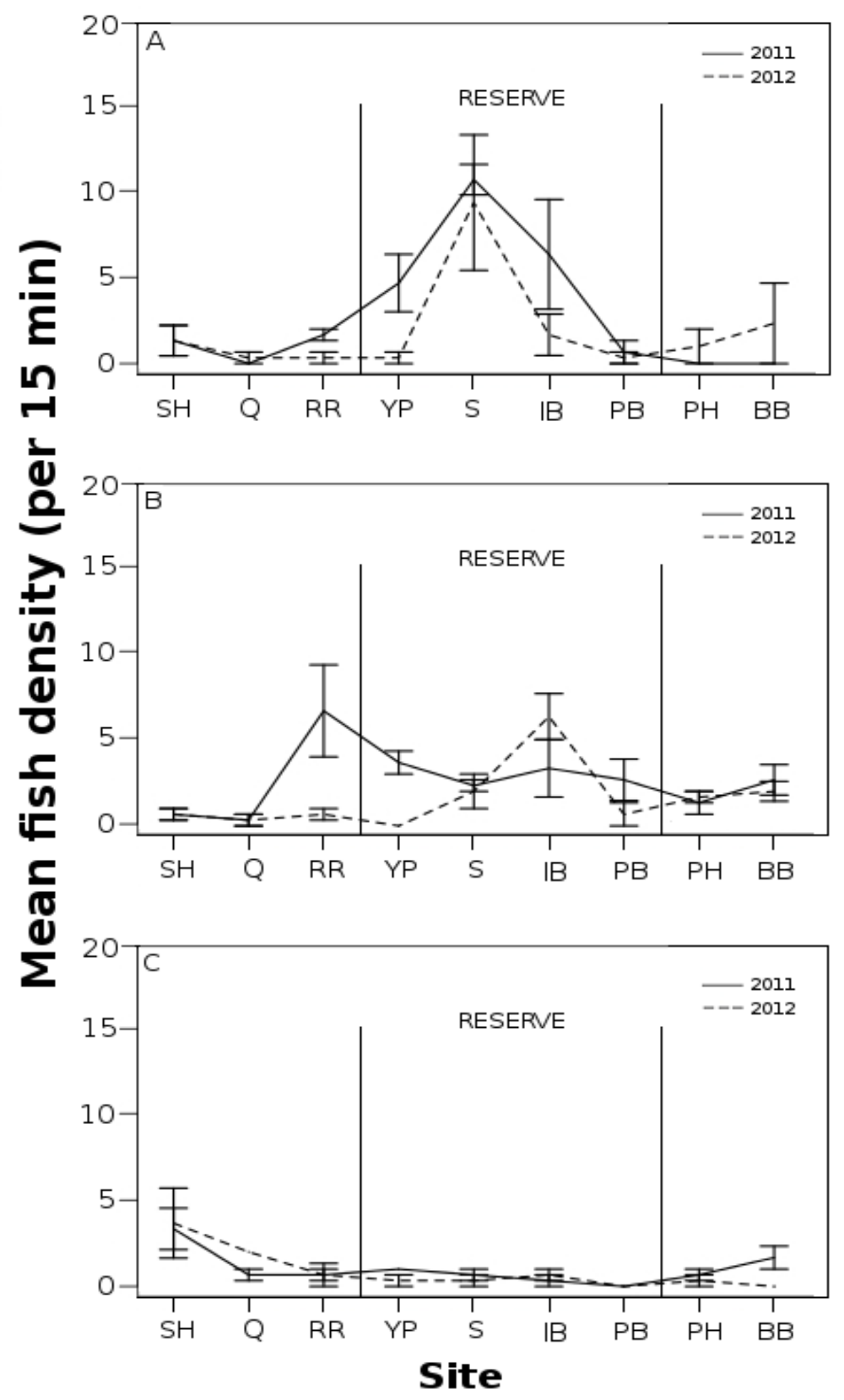

Figure 5.6: Mean fish density (per $125 \mathrm{~m}^{2}$ ) \pm SE recorded with the BUV methodology at each site in 2011 and 2012 for common species: (A) blue cod, (B) spotty, and (C) banded wrasse. Dashed vertical lines indicate the boundaries of the Taputeranga MR. SH: Sinclair Head; RR: Red Rocks; Q: Quarry; YP: Yung Pen; S: The Sirens; IB: Island Bay; PB: Princess Bay; PH: Palmer Head; BB: Breaker Bay. 

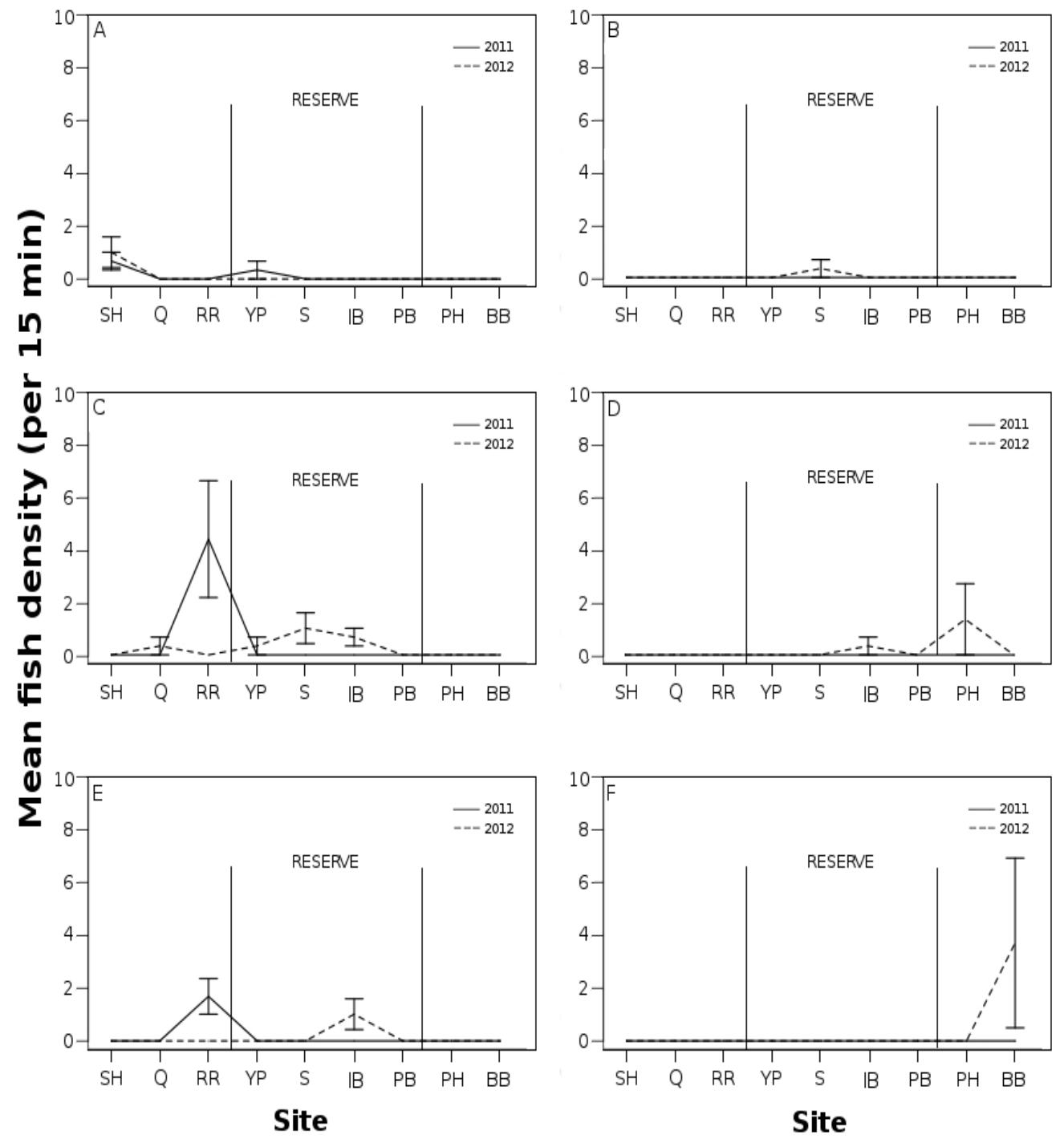

Figure 5.7: Mean fish density (per $125 \mathrm{~m}^{2}$ ) \pm SE recorded with the BUV methodology at each site in 2011 and 2012 for uncommon species: (A) scarlet wrasse, (B) butterfish, (C) blue moki, (D) tarakihi (E) kahawai, and (F) leatherjacket. Dashed vertical lines indicate the boundaries of the Taputeranga MR. SH: Sinclair Head; RR: Red Rocks; Q: Quarry; YP: Yung Pen; S: The Sirens; IB: Island Bay; PB: Princess Bay; PH: Palmer Head; BB: Breaker Bay. 


\subsubsection{Trends in fish density across reserve boundaries}

\subsubsection{Underwater visual census}

The results of the linear regression analysis indicated that significant decreasing trends in density across the boundaries of the reserve were only found for blue moki at the western boundary in the 2011 survey $(\mathrm{p}=0.0405)$ and for butterfish at the eastern boundary in the 2012 survey $(\mathrm{p}=0.0168)$. For blue moki, a gradual pattern of decreasing density from the centre of the reserve towards the western sites was observed (Fig. 5.3d). However, blue moki density declined sharply inside the reserve (mean abundance reduced by more than 50\%) and continued to decline gradually in the western fished sites (weak gradient). The best fit for the data for blue moki was the linear decay model (Fig. 5.9a, Table 5.4). The analysis of the cumulative totals curve indicated that the data resemble a logistic distribution $(\mathrm{p}=0.7761)$ (Table 5.4). For butterfish, a gradual pattern of decreasing density from the centre of the reserve towards the eastern sites was also detected but this species was not observed at all in any of the eastern fished sites. The best fit for the butterfish data was the linear decay model (Fig. 5.9b, Table 5.4).

A significant increasing trend in density across the western boundary of the reserve was found for banded wrasse in the 2012 survey $(\mathrm{p}=0.039)$; this was a gradual increase.

\subsubsection{Baited underwater video}

A significant decreasing trend in density across the boundaries of the reserve was only found for blue cod at the western boundary in the 2011 survey $(p=0.0264)$. A sharp pattern of decreasing density from the centre of the reserve towards the western reserve sites was detected for blue cod. Density declined sharply inside the reserve (mean abundance reduced by more than 50\%) and continued to decline in the western fished sites but increased again at the most western site (flat gradient). The best fit for the data was the exponential decay model (Fig. 5.9c, Table 5.4). The analysis of the cumulative 
totals curve indicated that the data resemble a logistic distribution $(\mathrm{p}=0.5884)$ (Table 5.4). Also a non-significant decreasing trend in density was found for blue cod in the east boundary in the 2011 survey and also in the west boundary in 2012 (Fig. 5.6a).

A significant increasing trend in density across the eastern boundary was found for banded wrasse in the 2011 survey $(\mathrm{p}=0.0451)$ and across the western boundary in the 2012 survey $(\mathrm{p}=0.0108)$. For both years a gradual increasing pattern of density from the reserve site adjacent to the boundaries of the reserve was detected. 

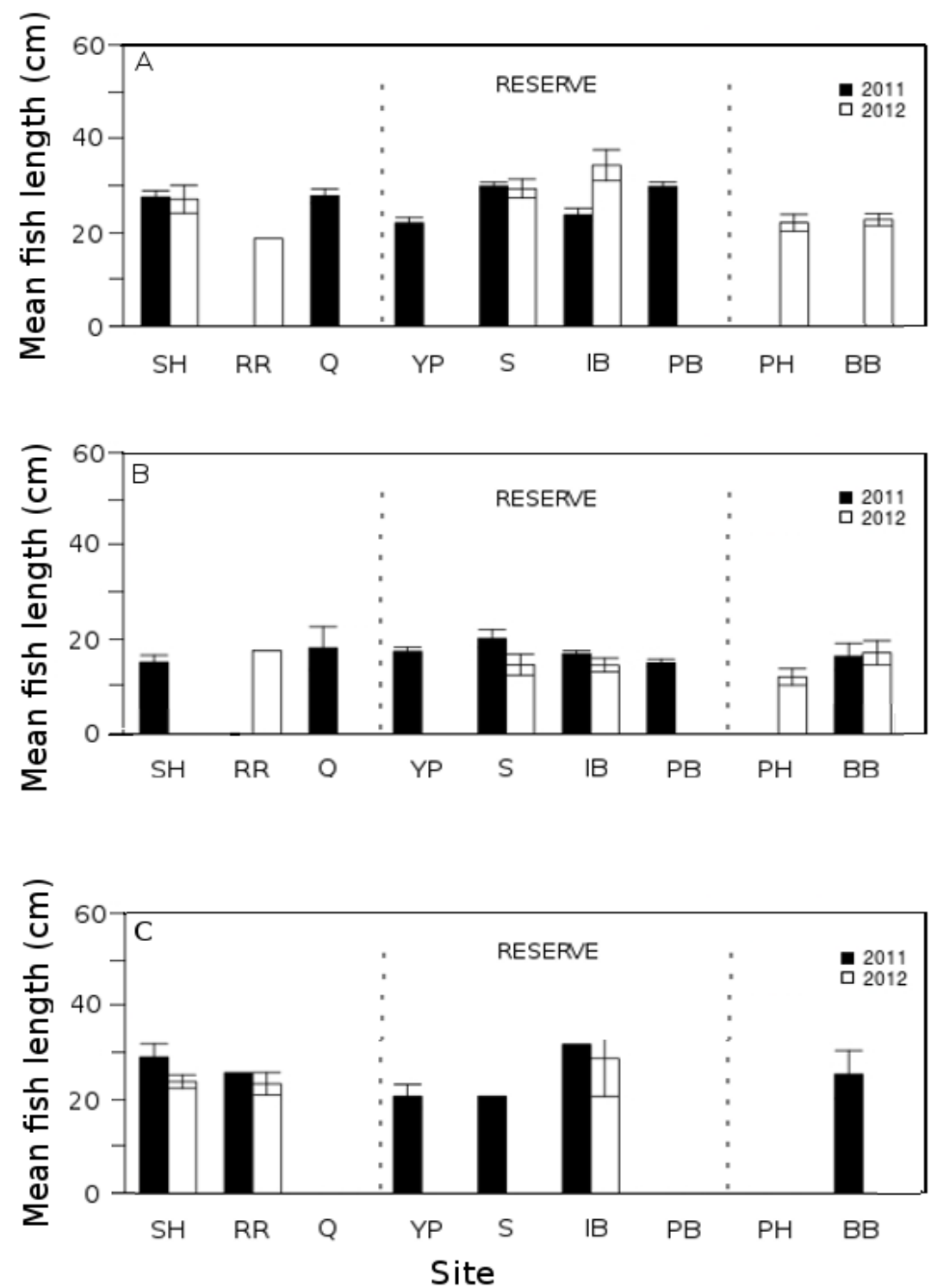

Figure 5.8: Mean length $(\mathrm{cm}) \pm$ SE recorded with the BUV methodology at each site in 2011 and 2012 for common species: (A) blue cod, (B) spotty, and (C) banded wrasse. Dashed vertical lines indicate the boundaries of the Taputeranga MR. No error bars are displayed when the SEs are too small. SH: Sinclair Head; RR: Red Rocks; Q: Quarry; YP: Yung Pen; S: The Sirens; IB: Island Bay; PB: Princess Bay; PH: Palmer Head; Breaker Bay. 

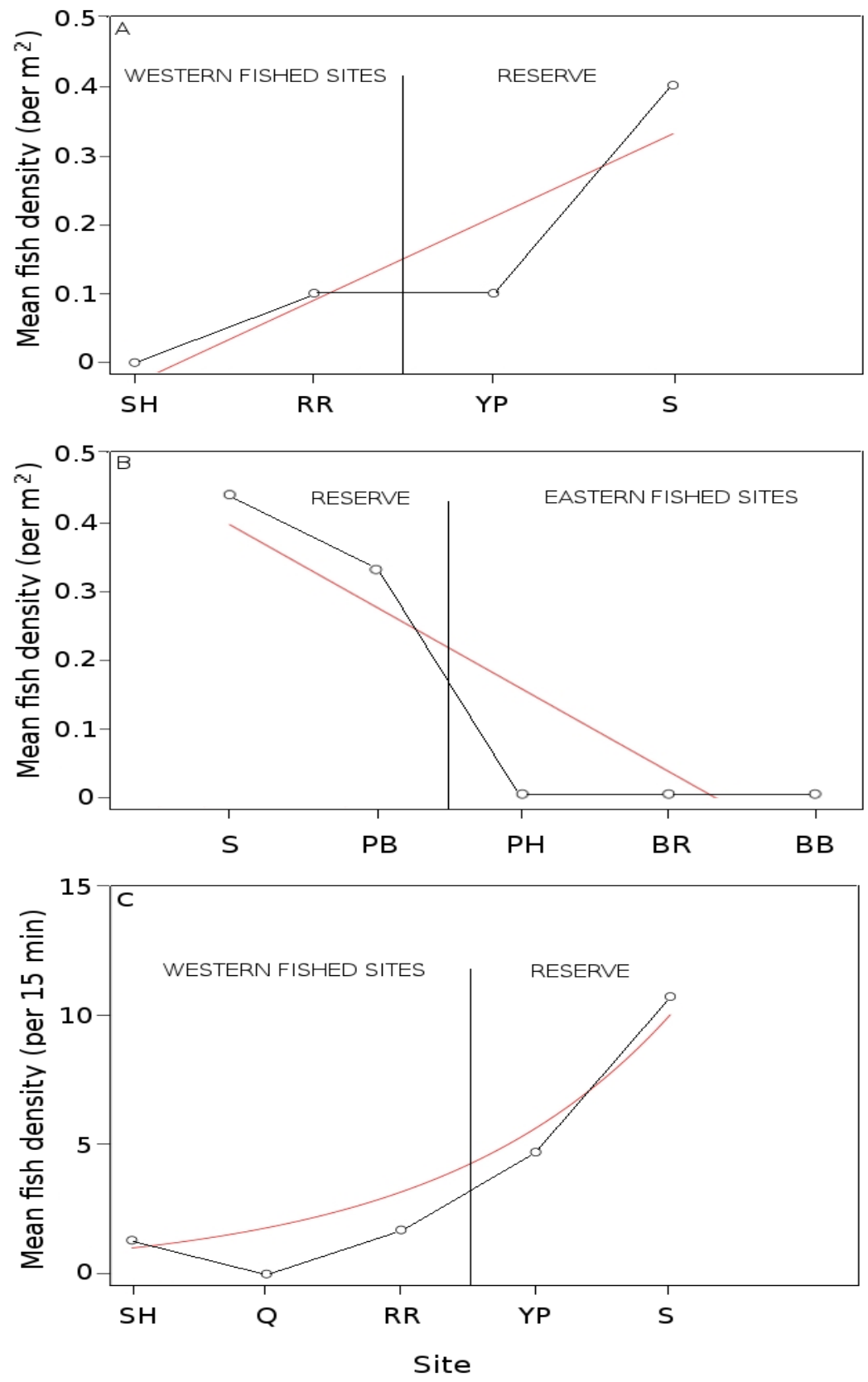

Figure 5.9: Best fit relationships between mean fish density and distance from the boundaries of the Taputeranga MR . (A) blue moki (UVC survey) best fit linear decay model , (B) butterfish (UVC survey) best fit linear decay model and (C) blue cod (BUV survey) best fit exponential decay model.SH: Sinclair Head; RR: Red Rocks; Q: Quarry; YP: Yung Pen; S: The Sirens; IB: Island Bay; PB: Princess Bay; PH: Palmer Head; BR: Barrett Reef; BB: Breaker Bay. 
Table 5.4: Details of significant linear regressions of density versus distance at the western and eastern boundary of the Taputeranga MR and the output for the best model fit found in the analysis.

\begin{tabular}{llccccl}
\hline \multicolumn{1}{c}{ Species } & $\begin{array}{c}\text { Boundary } \\
\text { (year/methodology) }\end{array}$ & Slope & Intercept & $\mathrm{r}^{2}$ & $\mathrm{p}$ & Selected model fit \\
\hline Blue cod & West (2011/BUV) & -2.333 & 3.66 & 0.75 & 0.026 & Exponential \\
Blue moki & West (2011/UVC) & -0.133 & 0.1 & 0.8 & 0.045 & Linear \\
Butterfish & East (2012/UVC) & -0.122 & 0.15 & 0.79 & 0.017 & Linear \\
Banded wrasse & West (2012/UVC) & 0.5 & 1.22 & 0.93 & 0.008 & $\mathrm{~N} / \mathrm{A}$ \\
& East (2011/BUV) & 0.43 & 0.96 & 0.79 & 0.045 & $\mathrm{~N} / \mathrm{A}$ \\
& West (2012/BUV) & 0.83 & 1.4 & 0.84 & 0.011 & $\mathrm{~N} / \mathrm{A}$ \\
\hline
\end{tabular}

\subsection{Discussion}

The aim of this chapter was to determinate if there were any differences in fish species richness, density and size between reserve and fished areas that may indicate spillover across the boundaries of the TMR. Spillover is mostly expected to occur in reserves where the density of targeted fish has increased substantially (Russ 2002, HarmelinVivien et al. 2008). However, density-independent movements across reserve boundaries may also occur as a result of random dispersal of fish during their routine activities that can be detected as soon as the abundance is higher at reserves sites compared to fished areas (Abesamis \& Russ 2005). In chapter three, as part of a multispecies analysis of the reef fish assemblage in the TMR, I found that early changes were evident for most of the species surveyed i.e., the density of most of the fish species surveyed was higher inside the reserve after 1-3 year since reserve establishment, depending on the species. In this context, it may therefore be possible to detect spillover, especially for those species that are known to respond positively to reserve protection, e.g., blue cod. 


\subsubsection{Patterns of species richness across the boundaries of the Taputeranga MR.}

Results of the species richness analysis were consistent between the two methodologies and no significant differences in mean richness was detected between areas (reserve vs fished), between years or among sites with either methodology. Also, no significant interaction between factors (status $\mathrm{x}$ year) was detected. Nevertheless, the results suggested that species richness increased in all reserve sites from 2011 to 2012, especially at Yung Pen (western side of the reserve). Increased species richness inside the reserve may result from better habitat inside than outside the reserve, rather than effects of protection from fishing in the reserves. For example, it has been suggested that habitat characteristics may influence the distribution patterns of fish, complex habitats may for example enhance food and refuge availability thereby affecting the propensity of fish to move out of the reserves (Charbonnel et al. 2002, Rodwell et al. 2003, Gratwicke \& Speight 2005, Claudet et al. 2010, Toller et al. 2010). However, habitat change due to reserve protection has also been reported (e.g., Lindholm et al. 2004, Ceccherelli et al. 2006, Ballantine 2008). Even though the effects of MRs on diversity have remained unclear until recently (Stobart et al. 2009), there is good evidence that fishing leads to reduced species richness and several studies report greater species diversity inside MPAs relative to those in fished areas (e.g. Côté et al. 2001, KaundaArara \& Rose 2004, Stewart et al. 2008). However, there is also evidence to indicate that in some cases fishing may also increase diversity (Bianchi et al. 2000, Greenstreet et al. 2007). Recent studies warn that the response of diversity indices to reserve protection is not straightforward, for example, Russ \& Alcala (2011) showed that species richness of large predatory reef fish increased four-fold and 11-fold inside two Philippine no-take marine reserves over 14 and 25 years, respectively. Assuming habitat homogeneity among sites surveyed in the present study as reported by the baseline study in the area, the increased richness observed in all reserve sites from 2011 to 2012, even though no significant, may indicate early changes in the community protected inside the TMR. 


\subsubsection{Patterns of individual species density and length across the boundaries of the Taputeranga MR}

Overall, my results did not suggest early changes (after 3-4 years of reservation) in the TMR in density or length for any of the species surveyed. However, there was some evidence to support differences in fish density among sites. For example, blue cod mean density and mean length detected with the BUV methodology, were higher at reserve sites, especially a The Sirens, located in the centre of the reserve, compared to fished sites. It is important to recognize that the BUV methodology is considered the best method for observing mobile predators and species targeted by fishing (e.g., Willis \& Babcock 2000, Watson et al. 2005, Colton \& Swearer 2010). Gardner \& Struthers (2012) in a study that describes the application and testing of three different methodologies, including UVC and BUV, for the quantification of blue cod abundance and size at Kapiti MR, found that BUV is likely to be the most accurate, cost-effective and easy to use methodology for surveying carnivorous temperate reef fishes. In this context, it is not surprising that differences, at least for blue cod, were only detected with the BUV methodology. However, the RR analysis (descriptive analysis) performed in chapter three using the same dataset (UVC surveys during 2011 and 2012) did revealed differences between reserve and fished sites for several species (i.e., RR > 1 for both years), blue cod among them. It is possible that the differences between areas for other species were not big enough to be detected with the statistical analysis performed here. The descriptive analyses of effect sizes analysis performed in chapter three (both response ratio: $\mathrm{RR}$ and before and after control impact paired series: BACIPS) suggested differences between fished and reserve areas found over a 14-yr period for most of the species surveyed in the study area but those differences were not evident with the statistical analyses performed on the same dataset (see chapter three).

It is important to notice that, in the case of the TMR, estimations of fish density and distribution in the study area prior to the establishment of the reserves are available i.e., a baseline study in the area was performed before the establishment of the reserve. The baseline study (UVC survey) did not revealed differences between reserve and fished sites for any fish species but indicated that the density of many species in the area varied from site to site, suggesting the existence of a gradient in community structure from east 
to west (i.e., greater density at more easterly sites) that has been attributed to differences in water column parameters (concentrations of dissolved nutrients and particulate material) along the coastline and not related to differences in habitat types (Pande \& Gardner 2008). The results reported in the present study with both methodologies (UVC and BUV) do not follow the patterns observed in the baseline survey (except for spotty), suggesting a change in the patterns of distribution of the species surveyed even though they do not suggest a positive reserve effect (i.e., higher density in reserve sites).

The results of the length analysis indicated significant differences in fish length (i.e., greater length at reserve sites) for both scarlet wrasse with the UVC methodology and spotty with the BUV methodology. No previous evidence of increased fish length inside the TMR has been detected for scarlet wrasse due to the fact that this species has not been commonly detected in the monitoring surveys performed to date (e.g., Pande \& Gardner 2008). No evidence of length difference between reserve and fished sites has been detected for spotty(e.g., Pande \& Gardner 2008). Also, in chapter four, not differences in mean fish length were detected for spotty with both BUV methodologies (horizontal and vertical). However, only two reserve sites and two reserve sites were analysed. These results highlight the importance of including non- target species in studies monitoring the changes inside vs outside MRs.

Many studies around the world have reported early changes in the community protected inside MRs using the C-I design, especially for large predatory reef fish species (e.g., Halpern \& Warner 2002, Halpern 2003, Micheli et al. 2004, Díaz-Guisado et al. 2012, Horta e Costa et al. 2013). For example, blue cod, a highly valuable fish species in New Zealand, is known to show a marked response to reservation status (reviewed by Pande et al. 2008). This evidence is not consistent with the results of the present study except for the evidence found with the BUV methodology for blue cod. However, evidence found in chapter suggested early changes in the area protected by the TMR, i.e., 1-3 year since reserve establishment, depending on the species. Among the analysis performed in chapter three, the BACIPS analysis has been identified as the most powerful assessment design by Osenberg et al. (2006). As suggested by Osenberg et al. (2006), the methodology used in chapter three seems to be most appropriate for the detection of changes occurring in MRs. Also, the RR analysis performed in chapter three seems to be a better methodology to detect even small changes between reserve 
and fished areas over a long-time series dataset compared to other commonly used C-I methodologies.

\subsubsection{Trends in fish density across the boundaries of the Taputeranga MR}

Overall, my findings were consistent with those reported in other studies (e.g., Abesamis \& Russ 2005, Alcala et al. 2005, Abesamis et al. 2006 b), as patterns of decreasing density through reserve boundaries were only detected for target species, i.e., blue cod and blue moki. Both species have also shown a marked positive response to reservation status in other MRs (e.g., Willis et al. 2000, Davidson \& Abel 2002, Davidson 2004, Taylor et al. 2003, Haggitt et al. 2008, Davidson \& Richards 2005, Davidson et al. 2007, Davidson et al. 2009, Díaz-Guisado et al. 2012).

The results of the present study suggested a significant decreasing pattern of density across one of the reserve boundaries (western) in the 2011 survey for both blue cod and blue moki. A sharp pattern of decreasing density was detected for both species inside the reserve, i.e., mean density reduced by more than $50 \%$ inside the reserve and continued to decrease outside the reserve. Even though density decreased abruptly suggesting a steep decay pattern, the best-fit for blue cod data was the exponential decay model that suggested a gradual decline and for blue moki the best-fit was the linear decay model. According to Kellner et al. (2007) this patterns of fish density inside reserve (i.e., sharp decline) are expected to occur inside reserves, while the presence of gradients away from the boundaries outside the reserve may depends upon the distribution of fishing effort outside reserve and species mobility. The density gradients found here were only detected in the western boundary which is further away from people (less accessible to people) and fishing pressure may be therefore lower compared to the eastern fished sites. According to Kellner et al. (2007) if fishing effort is distributed uniformly outside the reserve, a gradient of density outside the reserve that declines from the boundary would be expected (i.e., highest fish density inside reserve and near the boundary) indicating that the presence of gradients outside reserve indicate that fishing effort is low. Also, for highly mobile species, the gradients are expected to be weak. This was the case of the gradients observed for blue moki, a highly mobile species. Blue moki is a 
highly valuable commercial and customary resource, especially in the northern territory (top of the north island). Adult individuals (larger than $40 \mathrm{~cm}$ ) join the spawning stocks offshore (Francis 2008). The legal size for the species is $40 \mathrm{~cm}$, therefore, the fishing effort concentrates in deeper areas. However, no formal statistics on fishing effort in the study area exists.

On the other hand, Kellner et al. (2007) suggested that if fishing effort concentrates near the boundary of the reserve, a completely flat density gradient outside reserve would be expected for a single species fishery. Also for species with sedentary and moderate mobility, the gradients are expected to be sharp. This was the case of the gradients observed for blue cod. Blue cod is considered a sedentary species i.e., most studies have shown that most of the recaptured fish moved less than $1 \mathrm{~km}$ (e.g., Rapson 1956, Mace \& Johnson 1983, Cole et al. 2000, Carbines \& McKenzie 2004). However, some studies have suggested that a small percentage of the recaptured fish had moved more than $16 \mathrm{~km}$ (\%) (e.g., Mace \& Johnson 1983, Carbines 2003) and the results of a tagging study performed in chapter six highlighted the potential of the species to travel long distances as from the total of recaptured fish (48), 4,2\% moved between 10-50 km, 4,2 \% moved between 50-100 km and 8,3\% moved $>100 \mathrm{~km}$. Blue cod aggressive behaviour may also be an important factor determining the occurrence of spillover as the higher rates of aggressive interactions that occur inside reserves due to the high levels of fish abundance are predicted to induce subordinate individuals to relocate their home range to outside the reserve (Kramer \& Chapman 1999). On the video footage analysis I observed large blue cod excluding small individuals from the bait pot, a behaviour that may result in small fish moving towards non-protected areas. Here I also found differences in blue cod length between reserve and fished areas. Abesamis \& Russ (2005) found that aggressive interactions of the planktivorous fish Naso vlamingii at Apo Island Marine Reserve in the Philippines (a 20 year old reserve at that time) were significantly higher (by 3.7 times) inside than outside the reserve, suggesting that the density-dependent interactions were more intense inside the reserve. This may be an important factor determining the different patterns observed for blue cod and blue moki, in terms of the evidence found for blue cod i.e., larger fish found in the marine reserve.

In terms of the detection of gradients of density for both species only at the western boundary, directionality of movement may be considered as a potential driver for these 
patterns. The results of the tagging study performed in chapter six indicated an asymmetry in the movement patterns of blue cod in the study area, i.e., most of the recaptured fish that crossed reserve boundaries (tagged inside /recaptured outside) moved towards the west (crossing the western boundary). This asymmetry in the movements of blue cod could account for the differences in the patterns of density across reserve boundaries found I the present study. However, no significant decreasing trends on density were found for blue cod in the east boundary in the 2011 survey and in the west boundary in 2012 with the baited underwater video methodology. This may indicate that spillover is likely to be detected in the future at both reserve boundaries for this species.

Another important factor to consider is the power of the analysis performed here in terms of the number of sites sampled inside the reserve and their location (i.e., distance from centre of MR). In the present study, I sampled three sites with the UVC methodology and four sites with the BUV methodology. In this context, it could be that the number of sites sampled at TMR is not enough to detect spillover for most of the species surveyed. Also it could be possible that the time elapsed since the establishment of the TMR has not been enough for spillover to be detected yet (i.e., only four years have passed since the establishment of the reserve until the present study took place). Halpern et al. (2010) found evidence of spillover in eight out of 13 MRs included in their analysis and all were eight years old or older.

Overall, my findings, here and in chapter three, contrast with the assumptions of many theoretical studies that have suggested that species that move distances greater than the diameter of a reserve will not be fully protected from fishing and cannot be expected to substantially increase in population biomass within reserves (e.g., Moffitt et al. 2009, Langebrake et al. 2011). Consistently, Claudet et al. (2010) in a recent metaanalysis of Mediterranean MPAs, also found that the effect of protection was at least as strong for mobile species as it was for sedentary ones. Also, Edgar et al. (2004c) suggested that reserves should provide maximal spillover benefits for species with intermediate movement capabilities, or with both sedentary and mobile phases. 


\subsection{Conclusions}

This chapter provides little evidence consistent with a positive effect of reserve protection in the TMR resulting in the detection of differences in density estimates among sites and length estimates between areas for some fish species, including target and non-target species.

Also, there was little evidence of spillover except the possible exception of two target species (blue cod and blue moki) and in contrast with the findings of previous studies, density gradients were found for species with low and high mobility. It may be necessary for more time to pass before spillover can be detected at the TMR. 


\section{Chapter 6}

\section{Movement Patterns of Blue Cod Across \\ the Boundaries of the Taputeranga \\ Marine Reserve: Evidence for Spillover}




\subsection{Introduction}

Species mobility may be important for the design of marine reserves (MRs) used for both conservation and management of fish species (Chapman \& Kramer 2000). Movements across the boundaries of MRs can affect the abundance and distribution of fishes within and outside reserves (Rakitin \& Kramer 1996, Russ \& Alcala 1996, Kramer \& Chapman 1999). Consequently, knowledge of fish mobility is critical for evaluating the ability of reserves to protect fish (e.g., determine the optimal size of MRs) and to enhance surrounding fisheries through the emigration of fish from MRs (Sladek Nowlis \& Roberts 1997, Sale et al. 2005, Goñi et al. 2006). Direct measurement of individuals' movements (e.g., sonic tracking or mark-recapture experiments) can be very expensive and time consuming, restricting the number of species that can be studied at one time (Rakitin \& Kramer 1996). Consequently, empirical studies on the effects of MRs on fisheries have usually focused on the detection of differences in spatial patterns of fishing effort yield and catch rates, all of which are considered indirect indicators of emigration from reserves (e.g., McClanahan \& Kaunda- Arara 1996, McClanahan \& Mangi 2000, Kelly et al. 2002, Russ et al. 2003, Murawski et al. 2005, Abesamis et al. 2006a, Goñi et al. 2006, 2008).

Although some studies have quantified movements of reef fishes across reserve boundaries through mark-release-recapture programmes (e.g., Attwood \& Bennett 1994, Zeller \& Russ 1998, Cole et al. 2000, Zeller et al. 2003, Tremain et al. 2004, Goñi et al. 2006, Tupper 2007), the degree to which these movements represent a response to protection is often difficult to assess (Goñi et al. 2006). Measuring the movement of biomass into MRs should be equally important to measuring outward movements, but only a few tagging studies have attempted to directly measure net flux rate across reserve boundaries (e.g., Funicelli et al. 1989, Beinssen \& Beinssen 1991, Rowe 2001, Zeller et al. 2003, Tremain et al. 2004). Another major problem associated with such tagging studies is that the movement patterns of the study species are often measured at one reserve location, with no control for the natural movement patterns of the species in the area (Zeller et al. 2003). Consequently, it is imperative that studies attempting to quantify spillover examine multiple reserve and control locations (Zeller et al. 2003).

Traditionally, capture-mark-recapture (CMR) methods have simply sought to provide 
qualitative information on distribution patterns and migration routes of tagged animals, but the analysis and modeling of tagging data has evolved along with new demands and possibilities. CMR analysis has significantly contributed to the advancement of population biology by allowing the comparison between populations and groups in the population and by obtaining unbiased estimates of crucial demographic parameters like survival and growth (Pradel 1996, White \& Burham 1999, Harmsen et al. 2011 and references therein). A number of approaches have been proposed for improving basic mark-recovery analysis. For example, Burnham et al. (1987) used Maximum Likelihood Theory to estimate survival rates that, given the availability of specialized easy-to-use software, have been widely applied. Estimates obtained through CMR analysis can be used to determine whether populations are declining, stable or increasing and also to evaluate the impacts of threats, assess responses to management actions designed to alleviate threats, and highlight areas where further research is needed (e.g., Lettink \& Armstrong 2003, Lopez-Rivera \& Sabat 2009, Gormley et al. 2012, Kay et al. 2012). Estimates of survival rates have been used to make comparisons between management treatments, for example to determine the potential effectiveness of MRs (e.g., Rowe 2001, Lambert 2005, Lopez- Rivera \& Sabat 2009). The success of a MRs may depend on individuals therein having greater survival than those outside (Rowe 2001). For example, Rowe (2001) found that a MR in Bonavista Bay (Newfoundland, Canada) offered increased survival to lobsters protected within it and thereby may provide benefits to fisheries. Lambert (2005) found that a significant proportion of adult female blue crabs remained in the Chesapeake Bay sanctuary (Virginia, USA) to spawn and were not captured by the fishery suggesting that the sanctuary is an effective means of protecting females migrating to or residing in the spawning grounds. Contrastingly, Lopez-Rivera \& Sabat (2009) did not find differences in survival sites located inside the Luis Peña Channel Marine Fishery Reserve in Puerto Rico and sites adjacent to the reserve.

Blue cod is endemic to New Zealand waters and is one of the most popular recreational coastal fish species in the country. It is highly valued by all sectors and is especially abundant in the South Island, where it supports both a commercial and a recreational fishery (Ministry of Fisheries 2008). Tagging surveys indicate that blue cod 
tends to be resident to a specific home area and are therefore susceptible to local depletion, although most of the studies have been performed in the South Island and may therefore not apply elsewhere (e.g., Cole et al. 2000, Carbines \& McKenzie 2004). However, despite the importance of blue cod large population, declines have been reported in some locations. For example, due to concerns about the sustainability of blue cod within the Marlborough Sounds the fishery was closed in 2008, but improvement in the adult biomass in recent surveys (Beentjes \& Carbines 2012) the Minister of Fisheries and Aquaculture re-opened the recreational blue cod fishery in the Marlborough Sounds in April 2011). Studies performed in the Marlborough Sounds area have shown that blue cod remain within relatively small areas (Rapson 1956, Mace \& Johnston 1983, Cole et al. 2000). Carbines (2003), examined the patterns of movement of blue cod populations in the Foveaux Strait, located at the bottom of the South Island, and found that they were similar to those reported for Marlborough Sounds, however, the mobile portion of the Foveaux Strait population moved greater distances than the mobile portion of the Marlborough Sounds population, i.e., the largest distance moved was $156.1 \mathrm{~km}$ compared to $48 \mathrm{~km}$ and $41.7 \mathrm{~km}$ reported by Rapson (1956) and Mace \& Johnston (1983), respectively.

Recovery of blue cod in NZ MRs has been evaluated in several studies using different methodologies, including underwater visual census (UVC), baited underwater video (BUV) and catch measure and release (CMR) surveys, and the results generally indicate that the abundance and size of blue cod inside reserves are higher compared to control sites (Cole et al. 2000, Willis et al. 2000, Davidson \& Abel 2002, Davidson 2004, Taylor et al. 2003, Haggitt et al. 2008, Pande et al. 2008, Eddy 2011, Díaz-Guisado et al. 2012, Pande \& Gardner 2012). Davidson et al. (2009) reported a 12 year dataset for several species at the Long Island-Kokomohua MR and adjacent fished areas (Marlborough Sounds) and demonstrated that the exclusion of fishing has produced changes in the blue cod population size structure, abundance, and behaviour. In 2000, approximately 7 years after the reserve was established, blue cod was more than $125 \%$ more abundant within the reserve, and on average $80 \mathrm{~mm}$ longer, compared to control sites. The increased mean length and density of blue cod in the reserve was in stark contrast to changes in fish length and also density at fished sites (Davidson et al. 2009). However, some studies have shown that the abundance of blue cod inside reserves has 
declined over time since reserve establishment (Stewart \& MacDiarmid 2003, Haggitt et al. 2008).

According to Eddy (2011), as a result of the construction of present (2010) and historical (i.e., prior to large scale exploitation in the area) ecosystem models, among the fish species targeted by recreational fishers, blue cod fisheries have the greatest impacts on the ecosystem. While commercial catches of blue cod in the Wellington region are negligible, most of the recreational fishing pressure in the Fisheries Management Area (FMA) 2, which stretches from East Cape to the Wellington's west coast, comes from this heavily populated region (Francis 2008). Before the establishment of the Taputeranga Marine Reserve (TMR) in 2008, a baseline study in the area was performed. The baseline study included blue cod and detected differences in abundance of many species in the area from site to site, suggesting the existence of a gradient in community structure from east to west along the Wellington South coast (i.e., greater abundance at more easterly sites). In addition, patterns of seasonal variation in abundance were observed for this species (Pande \& Gardner 2008). In Chapter three I analyzed a 14-year time series data set of abundance in order to detect early changes in a multi-species fish assemblage in the TMR and found evidence that suggested the recovery of blue cod in the TMR. Also, in Chapter five, through an analysis of gradients of abundance across the TMR boundaries, I found indirect evidence that may be consistent with spillover for blue cod.

The aim of the present study was to perform a capture-mark-recapture study to quantify spatial differences in community parameters (CPUE, length, weight and survival estimates) of blue cod between reserve and fished areas and to assess the potential for spillover of this species across the east and west boundaries of the TMR. 


\subsection{Methods}

\subsubsection{Study area}

The present study took place in the TMR and surrounding fishing grounds located on the Wellington south coast (Fig. 6.1). The survey was conducted in a $\sim 12 \mathrm{~km}$ long section of shallow reef slope including a $\sim 3.8 \mathrm{~km}$ section protected inside the TMR and two sections extending $\sim 1.6 \mathrm{~km}$ and $\sim 2.6 \mathrm{~km}$ outside to the west and east lateral boundaries of the reserve, respectively (total of $\sim 4.2 \mathrm{~km}$ section outside the reserve). Refer to chapters three for a detailed description of the study area.

\subsubsection{Sites surveyed}

Twelve sites along the Wellington south coast were chosen for the study (Fig. 6.1). Eight of those sites (Sinclair Head, Red Rocks, Yung Pen, The Sirens, Princess Bay, Palmer Head, Barrett Reef and Breaker Bay) have been the focus of the monitoring programme of the TMR since before its establishment (see chapter three). The other four sites, Quarry, Island Bay, Waitaha Cove and Moa Point were selected in order to be able to sample a greater area and to facilitate the study of the movement patterns of the species.

\subsubsection{Species surveyed}

the present study focused on blue cod, Parapercis colias. The species has been subject to high fishing pressure in the study area, mainly from the recreational sector. Recreational fishers take around 100-200 tonnes of blue cod from the Fishery Management Area (FMA) 2, which stretches from East Cape in the east coast of the North Island to the Wellington west coast, while commercial catches of blue cod in this region are negligible (Francis 2008). Blue cod is one of the eight fish species that has 
been the focus of the monitoring surveys at the TMR (e.g., Pande \& Gardner 2008).

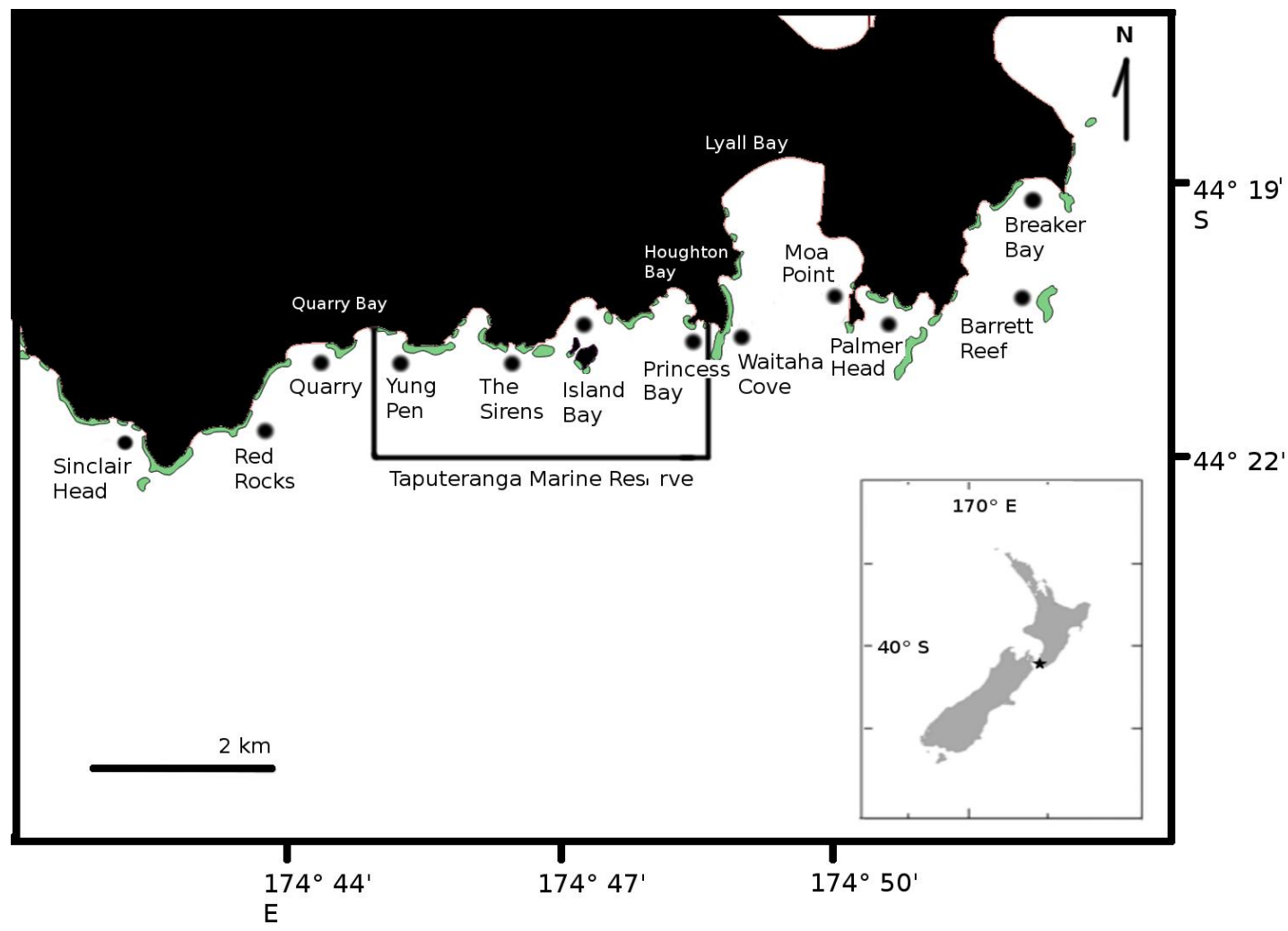

Figure 6.1: Map of the study area showing the sites surveyed. Green areas correspond to intertidal reef.

\subsubsection{Survey methodology: capture-mark-recapture (CMR) survey}

A CMR survey was performed between October 2010 and May 2012. In concordance with the Scientific Research permit (DOCDM 489168) granted by the Department of Conservation in September 2009, a maximum of 100 blue cod were tagged at each site. Fishing was undertaken using standard commercial cod pots. Pots were rectangular $(1.87 \times 1.40 \times 0.93 \mathrm{~m})$, constructed from a $40 \mathrm{~mm}$ diameter steel rod framework and covered with $60 \mathrm{~mm}$ nylon mesh. Each pot had two entrances of $10 \mathrm{~cm}$ external diameter leading into a $20 \mathrm{~cm}$ long steel rod tube with an internal diameter of $8 \mathrm{~cm}$. The bait (frozen pilchard, Sardinops neopilchardus) was enclosed in a bait bag attached to 
the inside bottom face of the pot. Baited pots were deployed at depths in the range 5 - 25 $\mathrm{m}$ on rocky reef habitat. Deployment time varied and usually did not exceed one hour based on recommendation by Beentjes \& Francis (2011). Due to the low capture rate, i.e., 13 fish caught over a period of approximately 3 months (a total of seven hours fished), line fishing was incorporated in October 2010 as an alternative methodology in order to improve catch rates. Pot fishing was maintained as an alternative methodology until February 2011 but after that line fishing was the only methodology used. Fish were caught using the fishing gear recommended by the Ministry of Fisheries (i.e., 6/0 or larger circle hooks with no offset) to ensure the survival of fish after they were released. Hooks were baited with a small piece of squid. After fish were caught they were placed in a tank containing seawater on board the vessel. The water in the tank was replaced frequently to avoid any increase in temperature. All fish were handled using rubber gloves, while the tagging area was covered with a plastic sheet to minimize the risk of infection to fish. Contact between the fish and the deck was minimized. They were removed from the tank to be measured and weighed (Fig. 6.2). Fish size was estimated by directly measuring fish total length to the nearest $0.1 \mathrm{~cm}$ and fish weight was estimated to the nearest $0.5 \mathrm{~g}$. I used $15 \mathrm{~mm}$ (tail size) Hallprint T-bar anchor tags with numbers imprinted onto them (0001- 1200) to mark the fish. Different tag colours were used (i.e., one colour for each site) to allow for easy identification of the site where the fish were tagged, especially in case the tag number was not recorded or could not be read in the future (e.g., in case of re-sights by diver or with the BUV methodology). Fish were tagged using a Dennison T-bar tagging gun (Fig. 6.3). Tags were inserted into the fish's muscular tissue at the base of the dorsal fin (Fig. 6.2). Injured fish, that is, fish that were damaged with the fishing gear (e.g., gut hooked fish), were not tagged and were returned to the water. Tagged fish were returned to the water at the same location that they were caught. Tag number, location, depth and date were recorded.

Fishing effort (pot and line fishing) varied randomly among sites and mainly depended on weather conditions. Depth also varied among sites; usually within each site several fishing locations were sampled (44 and 64 for reserve and fished areas respectively) and depth varied between locations. A detailed summary of the number of fish caught and tagged is shown in Table 6.1. 


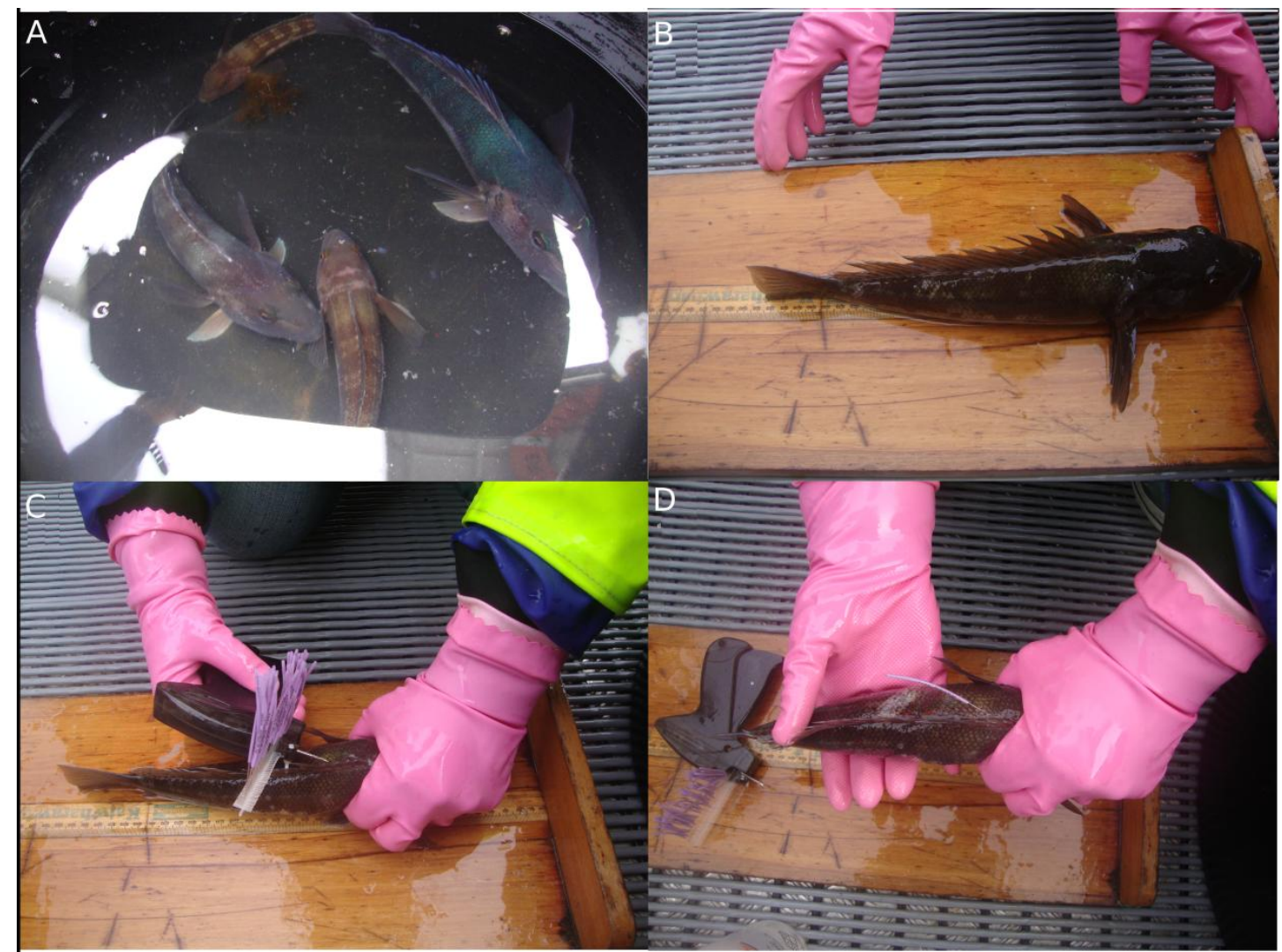

Figure 6.2: Photographic sequence showing the tagging procedure on board the Victoria University research vessel. (A) fish inside the holding tank aboard the vessel, (B) measuring fish length, (C) inserting the tag at the base of the dorsal fin, and (D) tagged individual before being released.

Due to the low capture rate compared to other studies, i.e., number of fish tagged in other studies was usually higher (e.g., Rapson 1956, Mace \& Johnston 1983, Carbines 2003), the tagging survey extended longer than expected. Fish were tagged during a 15 month period (October 2010 - December 2011) and the recapture survey was performed in conjunction with the tagging survey in the same area and extended for six more months (until May 2012). Due to the variable weather conditions in the area of study and resource limitation (e.g., boat availability), both the tagging and recapture surveys were conducted when time and resources permitted, and not at a standard time of year for a discrete time period as usually is done in this kind of study. To increase information return, the study was publicized in fishing association newsletters, magazine articles and posters were also placed at local notice boards, diving centers and major 
fishing access points around the Wellington south coast. Information (recapture location, tag number, fish length and weight) was voluntarily provided by fishers. Recaptures reported until 31 December 2012 were considered in the analysis.

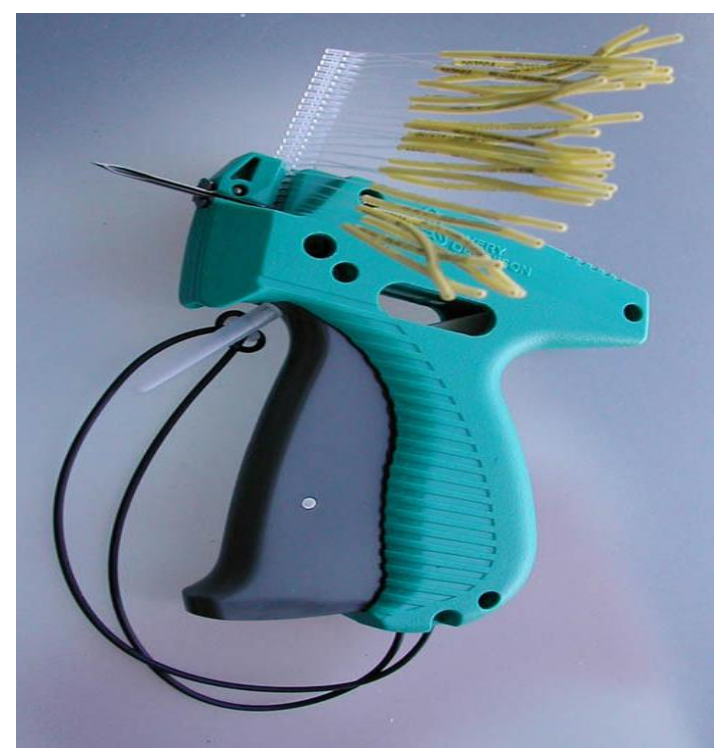

Figure 6.3: Denison gun (tag applicator) with T-bar anchor tags inserted and ready for application.

Table 6.1: Summary table of the total numbers of fish tagged in the catch-mark-recapture survey and additional information. Total catch included tagged fish, recaptured fish, dead fish and injured fish that were released.

\begin{tabular}{lcccccc}
\hline \multicolumn{1}{c}{ Area } & $\begin{array}{c}\text { Fishing } \\
\text { occasions }\end{array}$ & $\begin{array}{c}\text { Time fished } \\
(\mathrm{min})\end{array}$ & $\begin{array}{c}\text { Mean depth } \\
(\mathrm{m})\end{array}$ & $\begin{array}{c}\mathrm{N}^{\circ} \text { of } \\
\text { recaptured fish }\end{array}$ & $\begin{array}{c}\mathrm{N}^{\circ} \text { of } \\
\text { tagged fish }\end{array}$ & Total catch \\
\hline Reserve & 37 & 1265 & $15.2 \pm 6.79$ & 18 & 244 & 276 \\
Fished & 58 & 3584 & $16.9 \pm 7.12$ & 9 & 295 & 309 \\
Total & 95 & 4829 & $13.4 \pm 7.09$ & 27 & 539 & 585 \\
\hline
\end{tabular}

\subsubsection{Statistical analysis}

For analytic purposes I grouped the sites into two areas, reserve (four sites) and fished (eight sites) areas. 


\subsubsection{Differences in fish density, length and weight between areas}

Mean fish density per area (fished and reserve) was estimated by calculating the catch per unit of effort (CPUE) expressed as number of fish caught per hour (for pot data) and number of fish caught per hook per hour (for line data). I included in the analysis fish that died (tagged and non-tagged), injured fish that were released and recaptured fish.

I used a linear model (LM) to determine whether fish density, length and weight differed significantly between areas. The analysis was carried out using the $\mathrm{R}$ statistical software package (R Core Team 2012). The model was fitted using the generic function $\mathrm{Im}$ in the Stats $\mathrm{R}$ package. For the density analysis, the model was fitted with area (fished/reserve), year (2010/2011) and season (four seasons) as fixed factors. Interaction between factors area and year was also tested. I used the Bonferroni correction for multiple comparisons. For the length and weight analyses, the model was fitted with area (fished/reserve) and year (2010/2011) as fixed factors.

In order to determine differences in the length frequency distribution of fish between reserve and fished areas I classified the length data into size classes according to Sturges' Formula to determine an optimal number of size classes, k (Sturges 1926).

$$
\mathrm{K}=1+3.322 \log (n)
$$

where $\mathrm{n}$ is the number of observations.

I used six, five $\mathrm{cm}$ size classes. Five $\mathrm{cm}$ size classes are usually used in standard underwater visual transect methods to classify fish size (Kingsford 1998). I used a nonparametric Kolmogorov-Smirnov (K-S) (R Core Team 2012) test to test pair-wise differences in blue cod length-frequency distributions between areas for each year separately. To detect differences in the density of legal sized fish $(>33 \mathrm{~cm})$ between reserve and fished areas I calculated the percentage of legal size fish present inside and outside the reserve for 2010 and 2011. Finally, a descriptive statistical analysis was performed using the function fivenum in the Stats $\mathrm{R}$ package and the Mood's twosample test was used to test for differences between medians. 


\subsubsection{Analysis of survival and recapture probabilities}

In order to test for differences between areas (reserve/fished) in survival and capture rates I performed a multigroup analysis in Program MARK (White \& Burnham 1999). For this analysis I only included the recaptures inside the study area. The data consisted of 539 individuals, which belonged to one of two groups (244 and 295 fish captured in reserve and fished, respectively) over 21 sampling occasions $(\mathrm{k}=21)$.

The analysis was performed with the software Program MARK. This software provides parameter estimates by analyzing the encounter history of each animal and fitting different models. The number of parameters that are estimable in the model are determined numerically and the estimates of model parameters are computed via numerical maximum likelihood techniques. The quasi-likelihood AIC value is calculated for each model.

I fitted a live encounters model, the Cormack-Jolly-Seber model (CJS) (Lebreton et al. 1992) i.e., open population mark-recapture model (Pollock et al. 1990) where survival and capture probability are estimated for each time period. Two attribute groups were modeled (reserve/fished) giving a total of 16 possible models where time effects, group effects, time $\mathrm{x}$ group effects and a null model of none of the above, were provided for each parameter. I used unequal time intervals between re-encounters. The logit function was used to link the design matrix to the parameters of the model. Models were compared using adjusted Akaike's Information Criterion (AICc) that corresponds to the AIC with a correction for finite sample sizes. The AICc selects the most parsimonious model, which is the model that best explains the variation in the data while using the fewest parameters (Burhan \& Anderson 2002).Using AIC, instead of AICc when $n$ (sample size) is small, increases the probability of selecting models that have too many parameters, i.e. of overfitting. Model fit was assessed with the bootstrap Goodness of fit procedure (500 simulations). To check for over-dispersion, the over-dispersion parameter, c was estimated. Survival and recapture probabilities for both groups were estimated from the best model and then compared. It is important to notice that estimates of survival with these data set may be very uncertain due to the fact that fish were tagged over a long time interval (as opposed to clustered in a few discrete intervals, as this approach is designed for) and there are very few recaptures. However, 
due to the variable weather conditions in the study area and resource availability, these limitations can not be addressed in the analyses performed.

To compare survival probabilities between areas I used a One-way ANOVA. The analysis was carried out by the R statistical software package (R Core Team 2012). To compare the probability of recapture for fish tagged outside the reserve to the probability of recapture for fish tagged inside the reserve I used a relative risk (RR) analysis (Daniel 1999). RR is a ratio of two probabilities and is calculated by $\mathrm{p} 1 / \mathrm{p} 2$, where pi is the proportion of the animals in group $i$ that are recaptured and $i$ takes on the values "tagged inside" and "tagged outside" the reserve. The RR was calculated by the shortcut formula:

$$
\mathrm{RR}=\frac{a /(\mathrm{a}+\mathrm{b})}{c /(\mathrm{c}+\mathrm{d})}
$$

where $a, b, c, d$ are the number of fish tagged outside and recaptured, number of fish tagged outside and not recaptured, number of fish tagged inside and recaptured, and number of fish tagged inside and not recaptured, respectively (Daniel 1999). The null hypothesis is that tag recapture and location of release (inside vs outside of the reserve) are independent. A relative risk of one indicates that the probability of recapture is the same for both groups of fish, whereas a relative risk greater than one implies that the probability of recapture for fish tagged outside is greater than that of fish tagged inside. The $95 \%$ confidence interval for the relative risk is calculated by:

$$
\operatorname{RR}^{1 \mathrm{x}}=\left(\frac{Z_{a}}{\sqrt{X^{2}}}\right)
$$

where $\mathrm{z} \alpha$ is the two-sided $\mathrm{z}$ value corresponding to the chosen confidence interval $(\mathrm{z}=$ 1.96) and $\chi^{2}$ is the Chi square test statistic (Daniel 1999). The $\chi^{2}$ value derived from a 2 x 2 contingency table (comparing frequency of tagged fish that are recaptured and not recaptured within the reserve and outside of the reserve) can be calculated by the shortcut formula:

$$
X^{2}=\frac{n(a d-b c)^{2}}{(a+c)(b+d)(a+b)(c+d)}
$$


where $\mathrm{z}_{\alpha}$ is the two-sided $\mathrm{z}$ value corresponding to the chosen confidence interval ( $\alpha=$ $\left.5 \%,\left|Z_{0.025}\right|=1.96\right)$.

\subsubsection{Analysis of the movement patterns of blue cod across reserve boundaries}

In order to quantify the movement patterns of blue cod across reserve boundaries I analysed both the recaptures inside the study area and those reported by fisherman outside the study area.

The distance travelled (kilometers) by recaptured fish was calculated as the straightline distance between release and recapture locations. Only occasionally did the calculated route intersect land, and in these cases distance travelled was estimated by a series of straight lines drawn to mark the shortest possible sea route. For estimates of direction (compass heading) moved, intersection with land was ignored. I calculated the time elapsed (days) between the sampling occasion when fish were tagged and the sampling occasion when the fish were recaptured and then calculated the distance

travelled as a function of time (i.e., $\mathrm{km} \mathrm{d}^{-1}$ ). Recaptures reported by fishers that occurred outside the study area were also considered.

A linear and non-liner regression analysis was used to determine whether a significant relationship existed between fish length (when fish were tagged) and distance travelled by fish. The non-liner models (exponential and power) were fitted using the preview function in the nlstools package (Baty \& Delignette-Muller 2013) and the nls function (Grothendieck 2013). The Akaike information criterion (AIC) model selection procedure was used to compare model fits (Akaike 1973). Depth differences between tagged site and recapture site were also calculated.

\subsection{Results}

The CMR survey ran for approximately one year and seven months with a total of $112 \mathrm{~h}$ 50 min of fishing. A total of 585 fish were captured, including those fish that died (17 fish, representing $2.91 \%$ ), were not tagged and released (8 fish, representing $1.4 \%$ ) and 
recaptured (27 fish, representing $4.62 \%$ ). A detailed summary is presented in Table 6.1.

\subsubsection{Differences in fish density, length and weight between areas}

From the 585 fish captured, $52.8 \%$ (309) were captured in non-protected (fished) areas and $47.2 \%$ (276) in protected (reserve) areas (Table 6.1). The results of the LM analysis revealed no significant differences in mean CPUE between areas $(\mathrm{p}=0.3779)$ or among seasons $(p>0.05)$ in the analysis per season. Significant differences in mean CPUE between years $(\mathrm{p}<0.0080)$ were found in both areas, with mean CPUE being significantly higher in 2011 compared to 2010 (Fig. 6.4a). No significant interaction between factors (area x year) was also found $(\mathrm{p}=0.5142)$.

The results of the LM analysis of fish length revealed significant differences in mean fish length between areas $(\mathrm{p}<0.0001)$. On average fish were larger in reserve areas (Fig. 6.5a). No significant difference in fish length between years was found $(p=0.104)$ and there was no significant interaction between factors (year $x$ area) ( $p>0.1631$ ). When removing the interaction term and re-testing, similar results were obtained.

Results of the length-frequency distribution analysis revealed no significant differences between areas $(p=0.4413$ and $p=0.9307$ for the 2010 and 2011 surveys, respectively) (Fig. 6.6). The range of fish length varied from a minimum of $18.5 \mathrm{~cm}$ to a maximum of $45 \mathrm{~cm}$. The minimum length was smaller in both years in fished areas compared to reserve areas. The maximum length was smaller in reserve sites in 2010, but it was larger in reserve sites in 2011. The median length was statistically different between areas in both years $(\mathrm{p}=0.0067$ and $\mathrm{p}<0.0001$ for 2010 and 2011, respectively). The median was smaller in fished sites, compared to reserve sites in both years (i.e., 6 and $4.5 \mathrm{~cm}$ of difference between reserve and fished areas in 2010 and 2011, respectively) and also the mode followed this pattern (i.e., 1 and $12 \mathrm{~cm}$ of difference between reserve and fished areas in 2010 and 2011, respectively) (Table 6.2; Fig. 6.6). The analysis of the differences in density of legal size fish indicated that $60.7 \%$ of blue cod in the TMR were $>33 \mathrm{~cm}$ long, (legal size) compared to $10.8 \%$ of blue cod in nearby areas in 2010 while in $2011,51.2 \%$ of blue cod in the TMR were $>33 \mathrm{~cm}$ long (legal 
size) compared to $16.2 \%$ of blue cod in nearby areas.

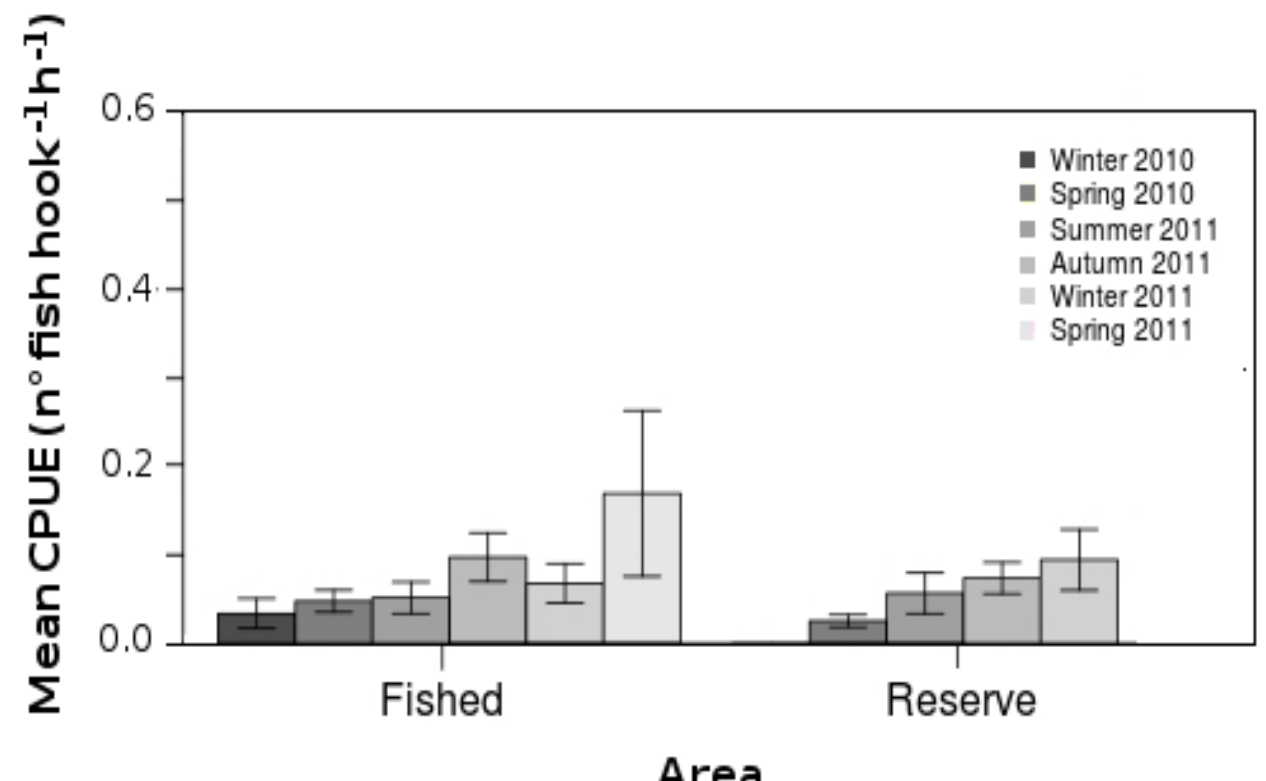

Figure 6.4: Mean blue cod CPUE (number of fish per hook per min) \pm SE in each season for reserve and fished areas in 2010 and 2011.

Table 6.2. Descriptive statistics derived from the blue cod length frequency distribution analysis.

\begin{tabular}{lcccc}
\hline Length index & 2010 & & \multicolumn{2}{c}{2011} \\
\hline Minimum & Fished & Reserve & Fished & Reserve \\
$1^{\text {s }}$ Quartile & 18.5 & 22 & 19 & 20 \\
Median & 24.5 & 28 & 26 & 28 \\
Mode & 27 & 33 & 28.5 & 33 \\
$3^{\text {rd }}$ Quartile & 26 & 27 & 28 & 40 \\
Maximum & 30 & 37 & 31 & 37 \\
\hline
\end{tabular}

The results of the $\mathrm{lm}$ analysis of fish weight revealed significant differences in mean fish weight between areas $(\mathrm{p}<0.0001)$ and between years $(\mathrm{p}=0.0095)$. Mean fish 
weight was significantly greater in reserve areas compared to fished areas and was greater in 2010 compared to 2011 (Fig. 6.5b). A significant interaction between factors (year $\mathrm{x}$ area) $(\mathrm{p}=0.0043)$ was observed. When removing the interaction, significant differences in mean fish weight was found between areas $(\mathrm{p}<0.0001)$ but there were no significant differences between years $(\mathrm{p}>0.05)$.
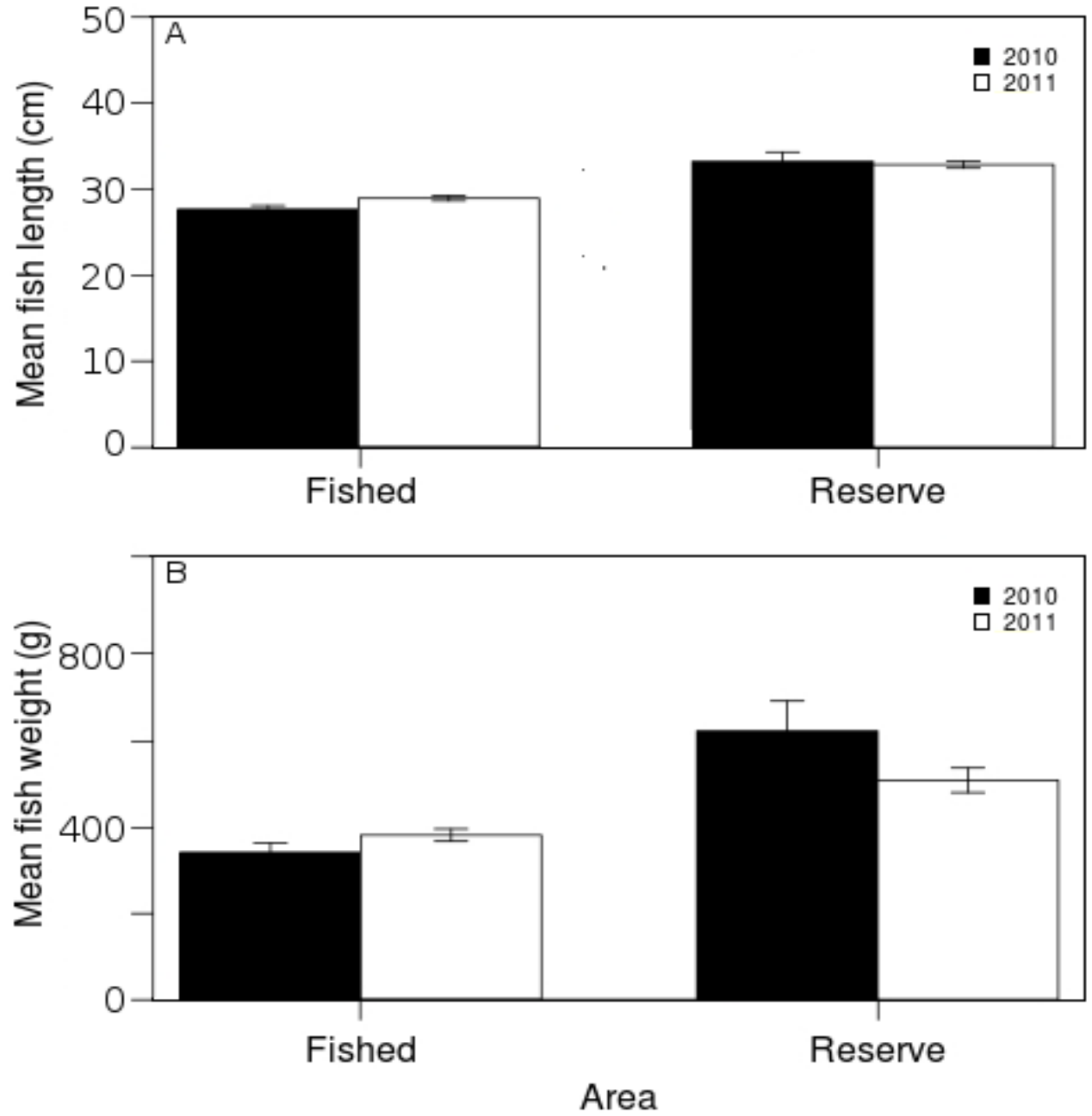

Figure 6.5: Mean blue cod length $(\mathrm{cm}) \pm \mathrm{SE}$ recorded in 2010 and 2011 in reserve and fished areas. (A) fished area 2010 survey, (B) fished area 2011 survey, (C) reserve area 2010 survey and (D) reserve area 2011 survey. 

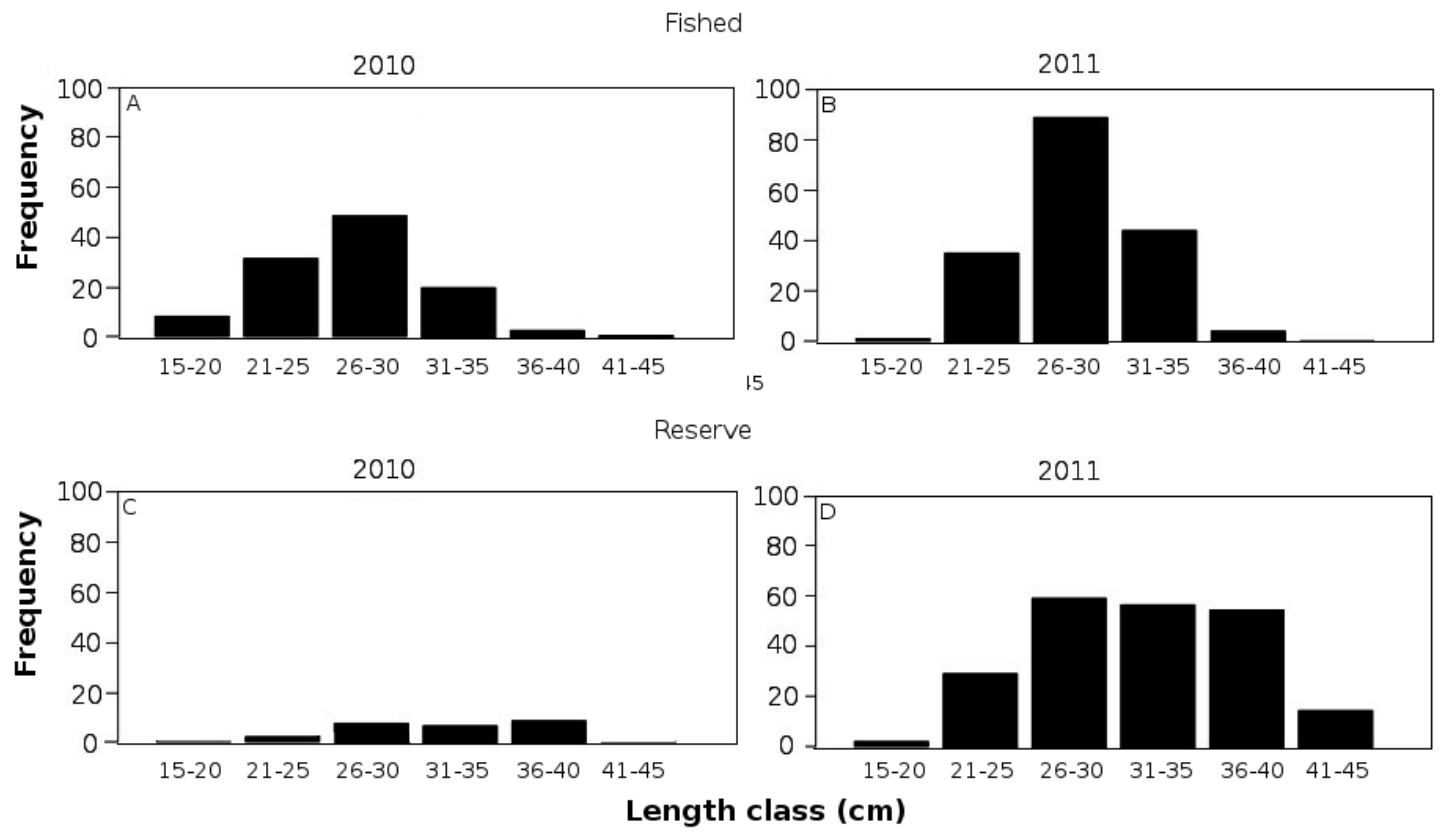

Figure 6.6: Length-frequency distribution of blue cod recorded in 2010 and 2011 in reserve and fished areas. (A) fished area 2010 survey, (B) fished area 2011 survey, (C) reserve area 2010 survey and (D) reserve area 2011 survey.

\subsubsection{Differences in the survival and recapture probabilities between areas}

According to AICc, the model that best explains the variation in the data was the model $\mathrm{Phi}_{(\mathrm{s} * \mathrm{t})} \mathrm{p}(\mathrm{t})(\mathrm{AICc}=-4138.90)$. The " $\mathrm{s} * \mathrm{t}$ " subscript for survival or Phi means a 'full' model, including both the main effects (status and time) and the interaction of the two (' $\mathrm{s} * \mathrm{t}$ ' $=\mathrm{s}+\mathrm{t}+\mathrm{s} . \mathrm{t}+$ error). That is, status and time interact, such that the relationship between survival and time can differ depending upon the status (or conversely, the relationship between survival and status can differ depending upon the time interval). The " $t$ " subscript, for recapture, means that the recapture parameter is time-specific; in other words, that the recapture estimates may differ over time. Consequently, 60 parameters were estimated for this model, 20 survival parameters for 'reserve', 20 survival parameters for the 'fished' areas, and 20 recapture probabilities (the same for both areas). The observed deviance from the fit of the model in question to the original data falls into the distribution of the deviances from the data simulated in the goodness of fit analysis. The deviance of the original model was 78.8667, whereas the largest 
deviance from 500 simulations was 93,711 . The $498^{\text {th }}$ deviance was 78.416 , while the $499^{\text {th }}$ deviance was 91.254 so the possibility of observing a deviance as large as 78.8667 was less than $2 / 500$ (i.e., $\mathrm{P}=0.004)$. No evidence of over-dispersion was found $(\mathrm{c}=$ $1.0)$.

Mean survival estimated between sampling occasions for reserve areas was not significantly higher than mean survival estimated in fished areas (0.892 and 0.724 respectively) $(\mathrm{p}=0.0623)$ (Fig. 6.7). Estimated capture rates were $<1$ in all sampling occasions. Also, the $m$ arrays in Table 6.3 show that the capture probabilities were low, i.e., the maximum observed recapture probability was 0.74 (Fig. 6.7). The results of the RR analysis indicated that fish tagged inside the reserve had significantly higher probabilities of recapture than those tagged outside the reserve $(\mathrm{RR}=0.41,95 \% \mathrm{CI}$ 0.19 to 0.90$)$. 
Table 6.3: A summary of blue cod resighting information based on the number of individuals released on each occasion, and when (and how many) they were captured on subsequent occasions. Where $\mathrm{i}=$ tagging occasions, $\mathrm{j}$ = recapture occasions, $\mathrm{R}(\mathrm{i})=$ number of individuals in total marked and released on each occasion, $m(i, j)=$ number of individuals from a given release event which are captured for the first time at a particular occasion, $\mathrm{r}(\mathrm{i})=$ the total number of marked individuals captured from a given release batch, $m(j)=$ total number of recaptures in sampling occasion $j$, and $z(j)=$ total number of marked individuals that were not captured from sampling occasion $\mathrm{j}$.

\begin{tabular}{|c|c|c|c|c|c|c|c|c|c|c|c|c|c|c|c|c|c|c|c|c|c|c|c|}
\hline \multirow{2}{*}{\multicolumn{2}{|c|}{ i $\quad R(i)$}} & \multicolumn{21}{|c|}{$m(i, j)$} & \multirow[t]{2}{*}{$r(i)$} \\
\hline & & $j=2$ & 3 & & 4 & 5 & 6 & 7 & 8 & 9 & 10 & 11 & 12 & 13 & 14 & 15 & 16 & 17 & 18 & 19 & 20 & 21 & \\
\hline \multicolumn{24}{|c|}{ Reserve } \\
\hline 1 & 1 & 0 & 0 & & 0 & 0 & 0 & 0 & 0 & 0 & 0 & 1 & 0 & 0 & 0 & 0 & 0 & 0 & 0 & 0 & 0 & 0 & 1 \\
\hline 2 & 1 & & 0 & & 0 & 0 & 0 & 0 & 0 & 0 & 1 & 0 & 0 & 0 & 0 & 0 & 0 & 0 & 0 & 0 & 0 & 0 & 1 \\
\hline 3 & 1 & & & & 1 & 0 & 0 & 0 & 0 & 0 & 1 & 0 & 0 & 0 & 0 & 0 & 0 & 0 & 0 & 0 & 0 & 0 & 1 \\
\hline 4 & 1 & & & & & 0 & 0 & 0 & 0 & 0 & 0 & 0 & 0 & 0 & 0 & 0 & 0 & 0 & 0 & 0 & 0 & 0 & 0 \\
\hline 5 & 0 & & & & & & 0 & 0 & 0 & 0 & 0 & 0 & 0 & 0 & 0 & 0 & 0 & 0 & 0 & 0 & 0 & 0 & 0 \\
\hline 6 & 0 & & & & & & & 0 & 0 & 0 & 0 & 0 & 0 & 0 & 0 & 0 & 0 & 0 & 0 & 0 & 0 & 0 & 0 \\
\hline 7 & 0 & & & & & & & & 0 & 0 & 0 & 0 & 0 & 0 & 0 & 0 & 0 & 0 & 0 & 0 & 0 & 0 & 0 \\
\hline 8 & 0 & & & & & & & & & 0 & 0 & 0 & 0 & 0 & 0 & 0 & 0 & 0 & 0 & 0 & 0 & 0 & 0 \\
\hline 9 & 0 & & & & & & & & & & 0 & 0 & 0 & 0 & 0 & 0 & 0 & 0 & 0 & 0 & 0 & 0 & 0 \\
\hline 10 & 4 & & & & & & & & & & & 0 & 0 & 1 & 0 & 0 & 0 & 0 & 0 & 0 & 0 & 0 & 0 \\
\hline 11 & 6 & & & & & & & & & & & & 0 & 0 & 0 & 0 & 0 & 2 & 2 & 0 & 0 & 0 & 3 \\
\hline 12 & 3 & & & & & & & & & & & & & 0 & 0 & 0 & 0 & 6 & 0 & 0 & 0 & 0 & 2 \\
\hline 13 & 1 & & & & & & & & & & & & & & 0 & 0 & 0 & 0 & 0 & 0 & 0 & 0 & 6 \\
\hline 14 & 0 & & & & & & & & & & & & & & & 0 & 0 & 0 & 0 & 0 & 0 & 0 & 0 \\
\hline 15 & 0 & & & & & & & & & & & & & & & & 0 & 0 & 0 & 0 & 0 & 0 & 0 \\
\hline 16 & 0 & & & & & & & & & & & & & & & & & 0 & 0 & 0 & 0 & 0 & 0 \\
\hline 17 & 8 & & & & & & & & & & & & & & & & & & 0 & 0 & 0 & 0 & 0 \\
\hline 18 & 2 & & & & & & & & & & & & & & & & & & & 0 & 0 & 0 & 0 \\
\hline 19 & 0 & & & & & & & & & & & & & & & & & & & & 0 & 0 & 0 \\
\hline 20 & 0 & & & & & & & & & & & & & & & & & & & & & 0 & 0 \\
\hline$m(j$ & & 0 & ) & 0 & 1 & 0 & 0 & 0 & 0 & 0 & 1 & 1 & 0 & 1 & 0 & 0 & 0 & 8 & 2 & 0 & 0 & 0 & \\
\hline$z(j)$ & & 1 & 1 & 2 & 2 & 2 & 2 & 2 & 2 & 2 & 1 & 3 & 5 & 10 & 10 & 10 & 10 & 20 & 0 & 0 & 0 & 0 & \\
\hline \multicolumn{24}{|c|}{ Fished } \\
\hline 1 & 0 & 0 & c & 0 & 0 & 0 & 0 & 0 & 0 & 0 & 0 & 0 & 0 & 0 & 0 & 0 & 0 & 0 & 0 & 0 & 0 & 0 & 0 \\
\hline 2 & 0 & & c & 0 & 0 & 0 & 0 & 0 & 0 & 0 & 0 & 0 & 0 & 0 & 0 & 0 & 0 & 0 & 0 & 0 & 0 & 0 & 0 \\
\hline 3 & 0 & & & & 0 & 0 & 0 & 0 & 0 & 0 & 0 & 0 & 0 & 0 & 0 & 0 & 0 & 0 & 0 & 0 & 0 & 0 & 0 \\
\hline 4 & 0 & & & & & 0 & 0 & 0 & 0 & 0 & 0 & 0 & 0 & 0 & 0 & 0 & 0 & 0 & 0 & 0 & 0 & 0 & 0 \\
\hline 5 & 1 & & & & & & 1 & 0 & 0 & 0 & 0 & 0 & 0 & 0 & 0 & 0 & 0 & 0 & 0 & 0 & 0 & 0 & 1 \\
\hline 6 & 4 & & & & & & & 2 & 1 & 0 & 0 & 0 & 0 & 0 & 0 & 0 & 0 & 0 & 0 & 0 & 0 & 0 & 3 \\
\hline 7 & 2 & & & & & & & & 0 & 0 & 0 & 0 & 0 & 0 & 0 & 0 & 0 & 0 & 0 & 0 & 0 & 0 & 0 \\
\hline 8 & 1 & & & & & & & & & 0 & 0 & 0 & 0 & 0 & 0 & 0 & 0 & 0 & 0 & 0 & 0 & 0 & 0 \\
\hline 9 & 0 & & & & & & & & & & 0 & 0 & 0 & 0 & 0 & 0 & 0 & 0 & 0 & 0 & 0 & 0 & 0 \\
\hline 10 & 0 & & & & & & & & & & & 0 & 0 & 0 & 0 & 0 & 0 & 0 & 0 & 0 & 0 & 0 & 0 \\
\hline 11 & 0 & & & & & & & & & & & & 0 & 0 & 0 & 0 & 0 & 0 & 0 & 0 & 0 & 0 & 0 \\
\hline 12 & 0 & & & & & & & & & & & & & 0 & 0 & 0 & 0 & 0 & 0 & 0 & 0 & 0 & 0 \\
\hline 13 & 0 & & & & & & & & & & & & & & 0 & 0 & 0 & 0 & 0 & 0 & 0 & 0 & 0 \\
\hline 14 & 1 & & & & & & & & & & & & & & & 0 & 1 & 0 & 0 & 0 & 0 & 0 & 1 \\
\hline 15 & 0 & & & & & & & & & & & & & & & & 0 & 0 & 0 & 0 & 0 & 0 & 0 \\
\hline 16 & 2 & & & & & & & & & & & & & & & & & 0 & 0 & 1 & 0 & 0 & 1 \\
\hline 17 & 0 & & & & & & & & & & & & & & & & & & 0 & 0 & 0 & 0 & 0 \\
\hline 18 & 3 & & & & & & & & & & & & & & & & & & & 2 & 1 & 0 & 3 \\
\hline 19 & 3 & & & & & & & & & & & & & & & & & & & & 0 & 1 & 1 \\
\hline 20 & 1 & & & & & & & & & & & & & & & & & & & & & 0 & 0 \\
\hline$m(j$ & & 0 & ) & 0 & 0 & 0 & 1 & 2 & 1 & 0 & 0 & 0 & 0 & 0 & 0 & 0 & 1 & 0 & 0 & 3 & 1 & 1 & \\
\hline$z(j)$ & & 0 & 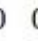 & 0 & 0 & 0 & 0 & 1 & 0 & 0 & 0 & 0 & 0 & 0 & 0 & 1 & 0 & 1 & 1 & 1 & 1 & 0 & \\
\hline
\end{tabular}



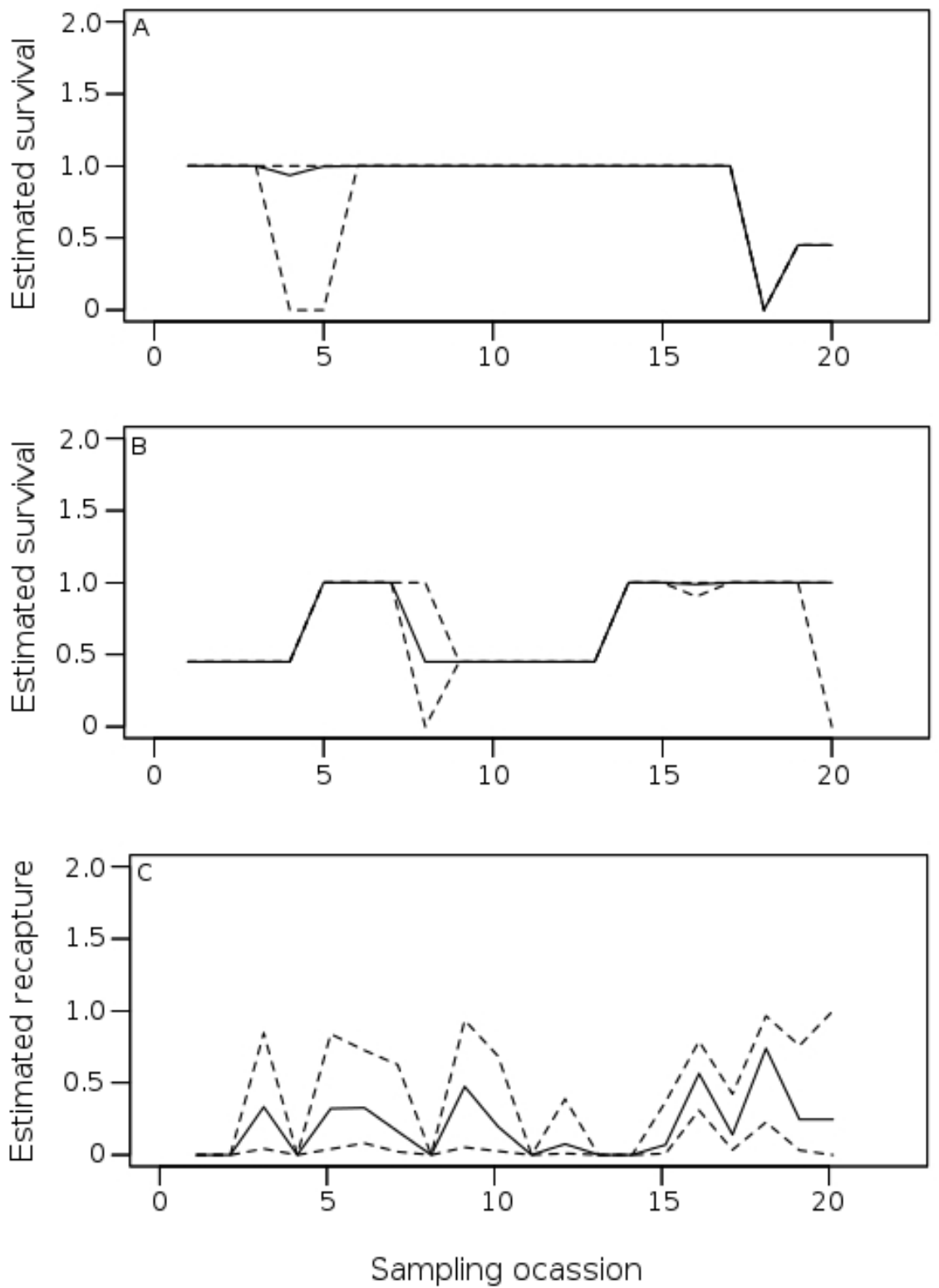

Figure 6.7: Estimated parameters $( \pm 95 \% \mathrm{CI}$, represented by dashed lines) of blue cod in reserve and fished areas, according to model Phi $(\mathrm{s} * \mathrm{t}) \mathrm{p}(\mathrm{t})$.(A) estimated and $(\mathrm{C})$ estimated capture probability.

\subsubsection{Movement patterns of blue cod across reserve boundaries}

A detailed summary of fish movements is shown in Table 6.4 and Table 6.5 for movement of fish inside and outside the study area, respectively. From the 539 fish tagged, $8.91 \%$ (48) were recaptured. 
From the total fish recaptures, $83.3 \%$ (40) were recaptured inside the study area (short distance movement). Mean time at liberty (i.e., number of days between the first capture and final recapture) was 146 days, with a maximum time at liberty of 635 days. Mean distance moved by fish recaptured inside the study area was $0.35 \mathrm{~km}$ with $47.5 \%$ (19) of the individuals moving < $0.01 \mathrm{~km}, 35 \%$ (14) moving between $0.1-0.5 \mathrm{~km}, 7.5$ $\%$ (3) moving between $0.5-1 \mathrm{~km}$ and $10 \%(4)$ moving $>1 \mathrm{~km}$. The maximum distance moved was $2 \mathrm{~km}$. The mean distance travelled per day (speed) by fish recaptured inside the study area was $0.015 \mathrm{~km} \mathrm{~d}^{-1}$ (Table 6.4). Based on start (tagging location) and end (recapture location) points alone, none of these fish crossed reserve boundaries (Fig. 6.8). From the total fish recaptured inside the study area (40), 37.5\% (15) were tagged and recaptured inside the reserve and $62.5 \%$ (25) were tagged and recaptured outside the reserve. Most of the fish recaptured inside the study area moved towards deeper areas $(53.8 \%)$ and fewer moved towards shallower areas (46.2\%) (Table 6.4). Based on the AIC values, the best fit for the relationship between fish size and distance travelled was the power model but the relationship was not significant ( $\mathrm{P}>0.05)$ (Fig. 6.9a). A unimodal peak can be observed at about $33 \mathrm{~cm}$ length.

Most of the fish recaptured inside the study area were only recaptured once during the study, but one fish was recapture twice, the first time only one day after it was tagged and it was recaptured again about three months later in the same area, outside the reserve (i.e., moved less than $0.5 \mathrm{~km}$ ).

From the total number of fish recaptured, $16.6 \%$ (8) were recaptured outside the study area (i.e., showed evidence of long distance movement). Mean time at liberty for those fish was 295 days (maximum time at liberty $=590$ days). Mean distance moved was $143.4 \mathrm{~km}$ with $25 \%$ (2) of the individuals moving between 10-50 km, $25 \%$ (2) moving between $50-100 \mathrm{~km}$ and $50 \%$ (4) moving > $100 \mathrm{~km}$. The maximum distance moved corresponded to $315 \mathrm{~km}$. The mean distance travelled per day (speed) by fish recaptured outside the study area was $0.89 \mathrm{~km} \mathrm{day}^{-1}$ (Table 6.5). Four of these fish crossed the reserve boundaries (i.e., were tagged inside the reserve). The four fish that did not cross reserve boundaries were all tagged and recaptured outside the reserve. Most of the fish recaptured outside the study area moved towards the west (i.e., six to the west coast of the North Island and one towards the South Island) and only one of them moved east towards Wellington Harbour) (Fig. 6.10, Table 6.5). All fish 
recaptured outside the study area moved towards deeper offshore areas. The mean depth difference between tagging and recapture site was $19.2 \mathrm{~m}$ (Table 6.5). Based on the AIC values, the best fit for the relationship between fish size and distance travelled was the exponential model and the relationship was significant $(\mathrm{p}<0.0001)$ (Fig. 6.9b).

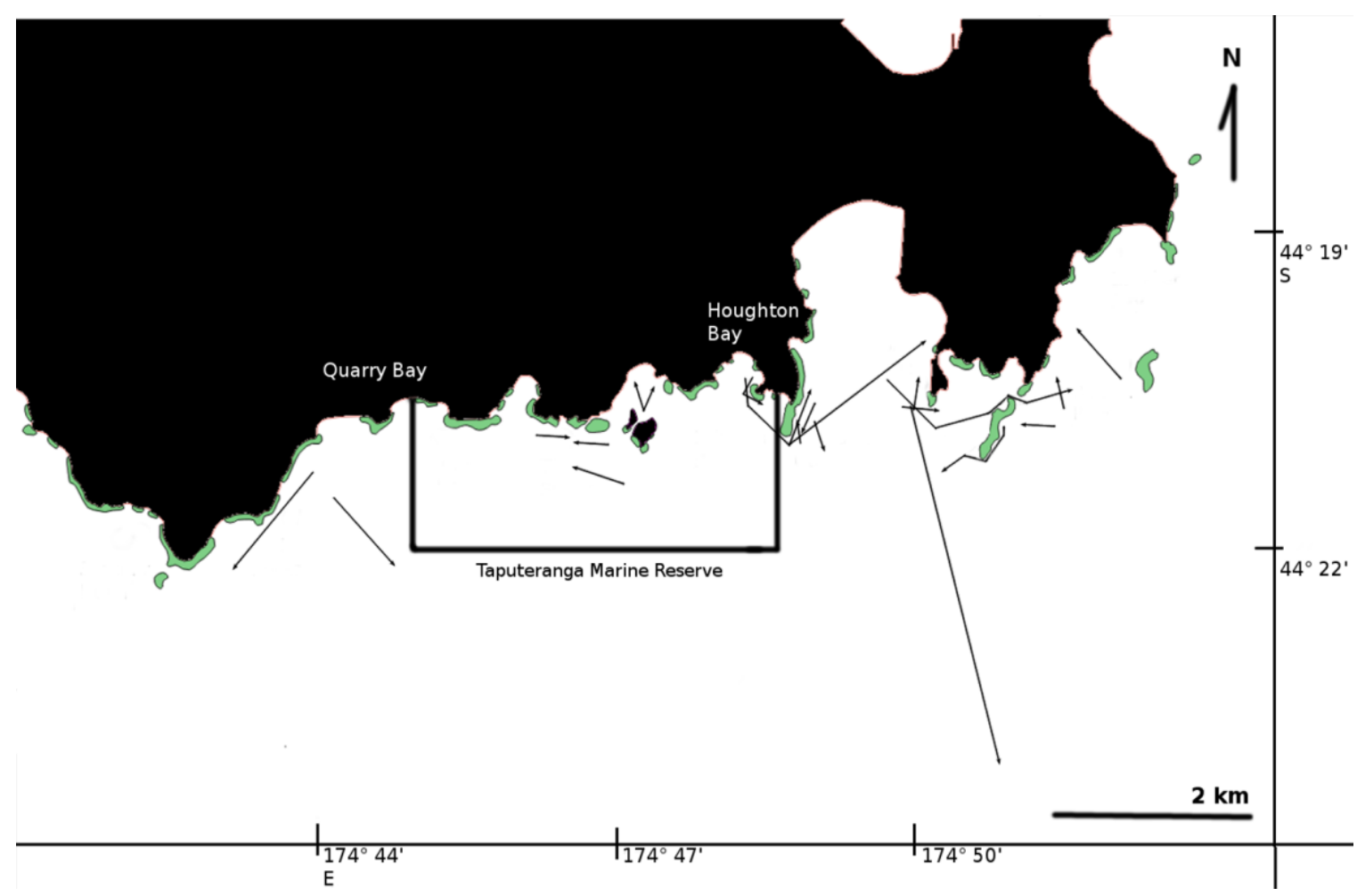

Figure 6.8: Map of study area and surrounding locale showing the direction of movement and distance travelled by fish recaptured inside the study area (short distance movement). 
Table 6.4: Summary of blue cod movements derived from the analysis of fish recaptures inside the study area. R: reserve, F: fished. Negative values for the depth difference implies that fish were recaptured at a shallower depth than the first capture.

\begin{tabular}{|c|c|c|c|c|c|c|c|}
\hline $\begin{array}{c}\text { Tag } \\
\text { Number }\end{array}$ & $\begin{array}{c}\text { Site } \\
\text { tagged }\end{array}$ & $\begin{array}{c}\text { Site } \\
\text { recaptured }\end{array}$ & $\begin{array}{c}\text { Time at } \\
\text { liberty (d) }\end{array}$ & $\begin{array}{c}\text { Distance } \\
\text { traveled }(\mathrm{km})\end{array}$ & $\begin{array}{c}\text { Speed } \\
(\mathrm{km} \mathrm{d}-1)\end{array}$ & $\begin{array}{r}\text { Direction of } \\
\text { movement }\end{array}$ & $\begin{array}{c}\text { Depth } \\
\text { difference }(\mathrm{m})\end{array}$ \\
\hline 506 & $\mathrm{R}$ & $\mathrm{R}$ & 14 & 0.53 & 0.038 & NW & -7 \\
\hline 504 & $\mathrm{R}$ & $\mathrm{R}$ & 91 & 0.06 & 0.001 & $\mathrm{~N}$ & -17.5 \\
\hline 413 & $\mathrm{R}$ & $\mathrm{R}$ & 162 & 0.36 & 0.002 & W & -2.5 \\
\hline 632 & $\mathrm{R}$ & $\mathrm{R}$ & 43 & 0.46 & 0.011 & SE & -9.2 \\
\hline 446 & $\mathrm{R}$ & $\mathrm{R}$ & 97 & 0.01 & 0 & $\mathrm{E}$ & 1.1 \\
\hline 443 & $\mathrm{R}$ & $\mathrm{R}$ & 97 & 0.01 & 0 & E & 1.1 \\
\hline 426 & $\mathrm{R}$ & $\mathrm{R}$ & 97 & 0.01 & 0 & E & 1.1 \\
\hline 436 & $\mathrm{R}$ & $\mathrm{R}$ & 97 & 0.01 & 0 & E & 1.1 \\
\hline 414 & $\mathrm{R}$ & $\mathrm{R}$ & 114 & 0.01 & 0 & E & 4.3 \\
\hline 452 & $\mathrm{R}$ & $\mathrm{R}$ & 114 & 0.01 & 0 & E & 4.3 \\
\hline 437 & $\mathrm{R}$ & $\mathrm{R}$ & 97 & 0.01 & 0 & E & 1.1 \\
\hline 438 & $\mathrm{R}$ & $\mathrm{R}$ & 97 & 0.01 & 0 & E & 1.1 \\
\hline 520 & $\mathrm{R}$ & $\mathrm{R}$ & 118 & 0.21 & 0.002 & NW & 17.5 \\
\hline 548 & $\mathrm{R}$ & $\mathrm{R}$ & 118 & 0.21 & 0.002 & NW & 17.5 \\
\hline 456 & $\mathrm{R}$ & $\mathrm{R}$ & 10 & 0.31 & 0.031 & SE & 6.3 \\
\hline 258 & F & F & 254 & 0.77 & 0.049 & SE & 0 \\
\hline 226 & $\mathrm{~F}$ & F & 26 & 1.27 & 0.017 & SW & -2.3 \\
\hline 812 & F & F & 3 & 0.05 & 0 & SE & 6.2 \\
\hline 908 & $\mathrm{~F}$ & $\mathrm{~F}$ & 397 & 0.05 & 0.05 & SW & -12.6 \\
\hline 1108 & $\mathrm{~F}$ & $\mathrm{~F}$ & 1 & 0.05 & 0.006 & S & 1.6 \\
\hline 918 & F & F & 56 & 0.34 & 0.05 & SW & 12.5 \\
\hline 1109 & F & F & 1 & 0.05 & 0.017 & $\mathrm{~S}$ & 1.6 \\
\hline 806 & $\mathrm{~F}$ & F & 3 & 0.05 & 0 & SE & 6.2 \\
\hline 1104 & $\mathrm{~F}$ & $\mathrm{~F}$ & 164 & 0.01 & 0 & S & -10.9 \\
\hline 1109 & $\mathrm{~F}$ & $\mathrm{~F}$ & 191 & 0.01 & 0.004 & S & -4.9 \\
\hline 726 & $\mathrm{~F}$ & F & 369 & 1.31 & 0.001 & NE & 3.4 \\
\hline 1037 & $\mathrm{~F}$ & $\mathrm{~F}$ & 420 & 0.61 & 0.003 & SW & -18.2 \\
\hline 815 & $\mathrm{~F}$ & $\mathrm{~F}$ & 207 & 0.1 & 0 & $\mathrm{E}$ & 7.4 \\
\hline 172 & $\mathrm{~F}$ & $\mathrm{~F}$ & 204 & 0.1 & 0 & $\mathrm{NE}$ & 1.2 \\
\hline 734 & $\mathrm{~F}$ & $\mathrm{~F}$ & 251 & 0.28 & 0.001 & $\mathrm{NE}$ & -20.5 \\
\hline 1115 & $\mathrm{~F}$ & $\mathrm{~F}$ & 63 & 0.2 & 0.003 & NW & 1.1 \\
\hline 818 & $\mathrm{~F}$ & $\mathrm{~F}$ & 23 & 0.28 & 0.012 & $\mathrm{~N}$ & -12.6 \\
\hline 191 & F & $\mathrm{F}$ & 20 & 2.5 & 0.125 & SE & -18 \\
\hline 817 & $\mathrm{~F}$ & $\mathrm{~F}$ & 128 & 0.26 & 0.002 & $\mathrm{E}$ & -12.6 \\
\hline 723 & $\mathrm{~F}$ & $\mathrm{~F}$ & 313 & 0.2 & 0.001 & $\mathrm{E}$ & -6.6 \\
\hline 710 & F & F & 344 & 0.37 & 0.001 & SE & -13.7 \\
\hline 1156 & F & F & 49 & 0.24 & 0.005 & NW & -6 \\
\hline 722 & $\mathrm{~F}$ & $\mathrm{~F}$ & 635 & 0.01 & 0 & NW & -6.6 \\
\hline 814 & F & $\mathrm{F}$ & 85 & 2.01 & 0.024 & E & -12.6 \\
\hline 1156 & F & F & 299 & 0.59 & 0.002 & NE & 10 \\
\hline
\end{tabular}



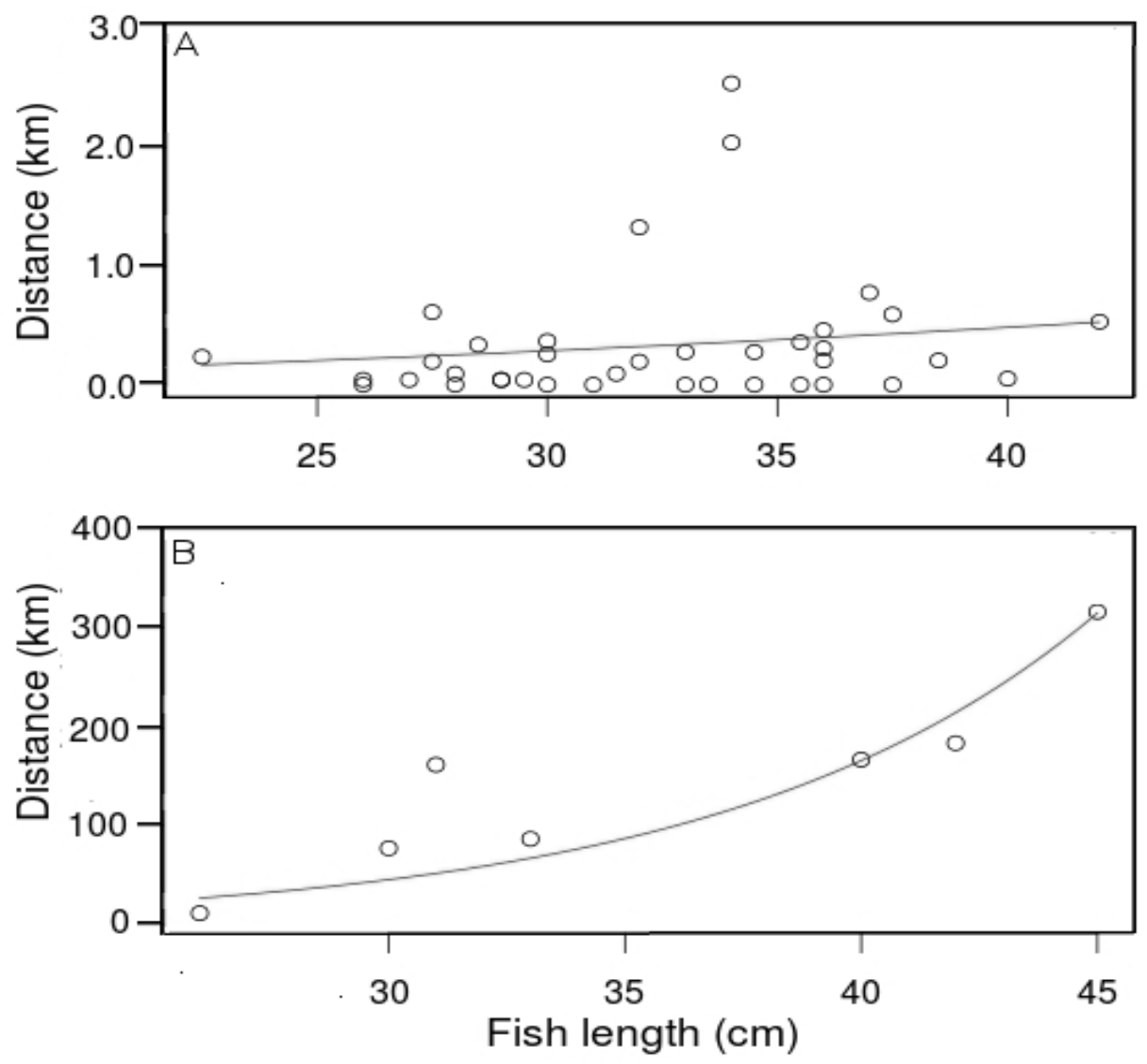

Figure 6.9: Relationship between blue cod length $(\mathrm{cm})$ and distance moved $(\mathrm{km})$ for fish recaptured. (A) fish recaptured inside the study area (short distance movement), (B) fish recaptured outside the study area (long distance movement).

Table 6.5: Summary of blue cod movements derived from the analysis of fish recaptures outside the study area. R: reserve, F: fished. Negative values for the depth difference implies that fish were recaptured at a shallower depth than first capture.

\begin{tabular}{cccccccc}
\hline $\begin{array}{c}\text { Tag } \\
\text { number }\end{array}$ & $\begin{array}{c}\text { Site } \\
\text { tagged }\end{array}$ & $\begin{array}{c}\text { Site } \\
\text { recaptured }\end{array}$ & $\begin{array}{c}\text { Time at } \\
\text { liberty }(\mathrm{d})\end{array}$ & $\begin{array}{c}\text { Distance } \\
\text { traveled }(\mathrm{km})\end{array}$ & $\begin{array}{c}\text { Speed } \\
(\mathrm{km} \mathrm{d}-1)\end{array}$ & $\begin{array}{c}\text { Direction of } \\
\text { movement }\end{array}$ & $\begin{array}{c}\text { Depth } \\
\text { difference }(\mathrm{m})\end{array}$ \\
\hline 417 & $\mathrm{R}$ & Wanganui coast & 60 & 166.71 & 2.78 & $\mathrm{NW}$ & -15.5 \\
921 & $\mathrm{~F}$ & Wanganui coast & 80 & 161.57 & 2.02 & $\mathrm{NW}$ & -26.5 \\
518 & $\mathrm{R}$ & New Plymouth & 244 & 315.13 & 1.29 & $\mathrm{NW}$ & -26.5 \\
914 & $\mathrm{~F}$ & Kapiti Island & 327 & 87.07 & 0.27 & $\mathrm{NW}$ & 0 \\
435 & $\mathrm{R}$ & Wanganui coast & 510 & 183.24 & 0.36 & $\mathrm{NW}$ & 12.3 \\
532 & $\mathrm{R}$ & Brothers Island & 173 & 44.96 & 0.26 & $\mathrm{NW}$ & -6.5 \\
167 & $\mathrm{~F}$ & Kapiti Island & 590 & 77.66 & 0.13 & $\mathrm{NW}$ & -23.7 \\
1109 & $\mathrm{~F}$ & Vellington Harbou & 384 & 12.488 & 0.03 & $\mathrm{E}$ & 10.9 \\
\hline
\end{tabular}




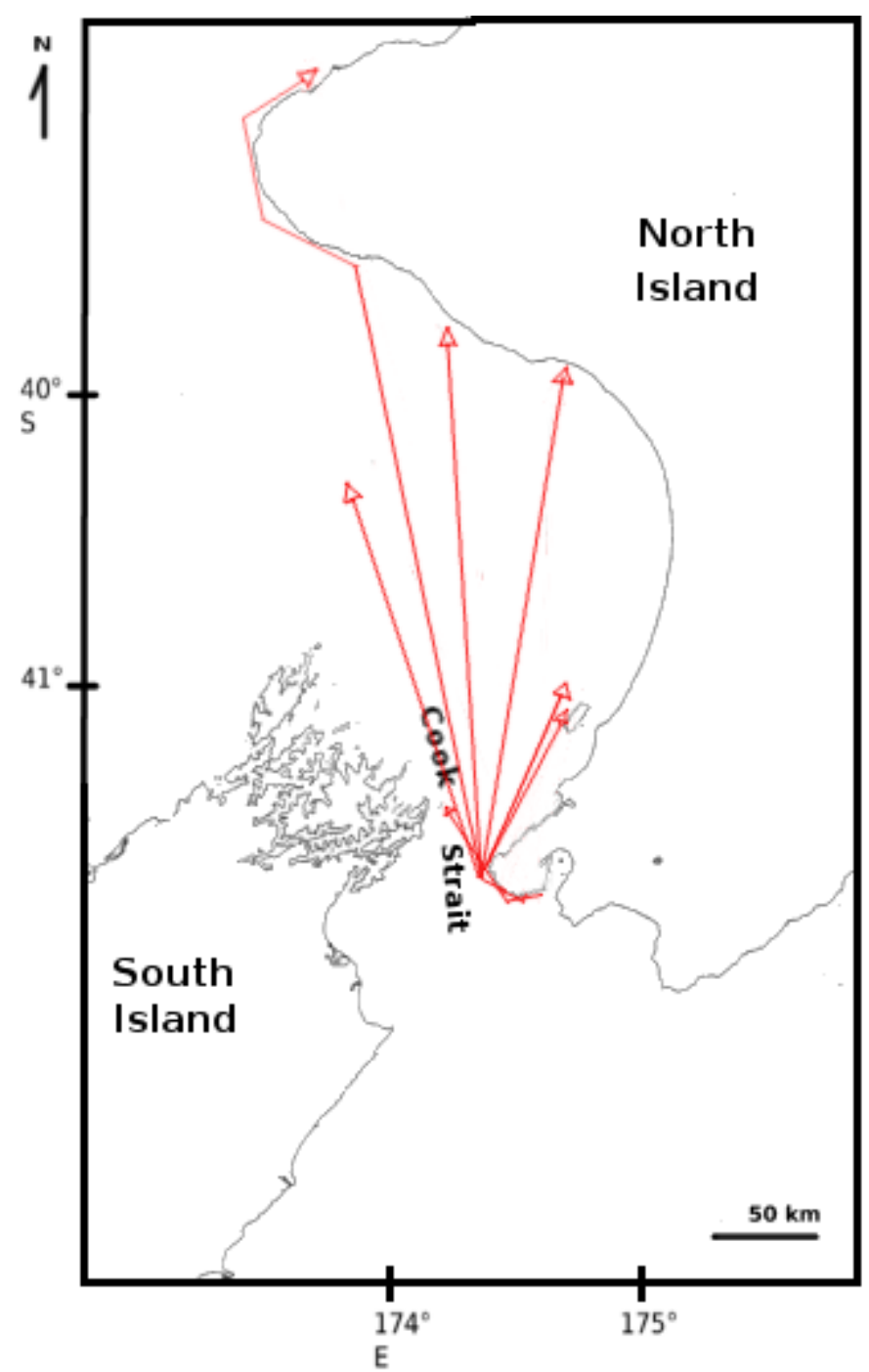

Figure 6.10: Map of study area and surrounding locale showing the direction of movement and distance travelled $(\mathrm{km})$ by fish recaptured outside the study area (large distance movement).

\subsection{Discussion}

The aim of this chapter was to determine the potential for spillover of the species by analysing its movement patterns in the study area particularly across reserve boundaries. Several previous studies have investigated the effects of MRs on this species in order to detect changes in fish mean density and mean length inside New Zealand MRs (e.g., Willis et al. 2000, Davidson \& Abel 2002, Davidson 2004, Taylor et al. 2003, Haggitt et al. 2008, Pande et al. 2008, Eddy 2011, Díaz-Guisado et al. 2012, Pande \& Gardner 2008, Gardner \& Struthers 2013). In the study area, a baseline survey was carried out by 
Pande \& Gardner (2008) providing important information that defined the status of several species, blue cod among them, in the area before the establishment of the reserve. More recently Eddy (2011), using an ecosystem-based modelling approach to evaluate the changes in the subtidal community structure in the study area as a result of several decades of exploitation, detected that the biomass of most of the fish groups in the area had decreased due to fishing and blue cod recreational fisheries are likely to have a considerable impact on the ecosystem.

Even though a few studies have investigated the movement patterns of blue cod in New Zealand, most of them have focused in the determination of patterns of movement between management zones (e.g., Carbines 2003, Carbines \& McKenzie 2004), and only a few have investigated the movement patterns across reserve boundaries (e.g., Cole et al. 2000, Gardner \& Struthers 2012), although none of them have been performed in the Wellington south coast region.

\subsubsection{Effect of protection on the density, length and weight of blue cod}

Overall I found little evidence suggesting a positive effect of protection on blue cod density, i.e., the analysis of CPUE (including season) only suggested increased blue cod density as a function of time (from 2010 to 2011) but not as a function of area (reserve versus fished). However, the results of the lme analysis of blue cod length and the analysis of the measures of central tendency indicating differences in fish length between areas suggest a positive effect of protection on fish length, i.e., bigger fish in reserve. Also a higher percentage of legal size fish were found in reserve areas compared to fished areas indicating a positive effect of the reserve on blue cod. Overall, these findings contrast with the results of the meta-analysis presented in chapter two that indicated that several New Zealand MRs are having a rapid, consistent and positive effect on the density of blue cod. However, the results presented in this chapter are consistent with the results reported in chapter two where differences between control and reserve areas were found in many NZ MRs and in chapter three where the differences between control and reserve areas over a 14-yr period reveal little evidence 
of early changes in blue cod density and length in the area protected by the TMR (i.e., increased density in the reserve).

The catch, measure and release (CMR) methodology used in the present study has been used before to assess MR effects. For example, some studies have documented the recovery (i.e., increased density and length) of fish stocks by comparing CPUE between protected and fished areas (e.g., Bennett \& Attwood 1991, 1993, Davidson 2001b, Pillans et al. 2005, Stobart et al. 2009). Bennett \& Attwood (1991, 1993) recorded an increase in modal sizes for particular fish species and an increase in CPUE data over the 4.5 years following reserve protection in a South African MR, whereas Davidson (2001b, 2004) found that 11 months after reservation, blue cod CPUE in the Long Island - Kokomohua MR had increased by over 100\% compared with the control sites and continued to increase in the reserve for 4 years after the reserve was established. Despite the widespread use of CPUE as an index of relative abundance, some authors have considered CPUE to be biased and not strictly proportional to abundance (e.g., Millar \& Fryer 1999, Harley et al. 2001, Cox et al. 2002). However, Haggarty \& King (2006), by comparing species density measurements derived from a UVC survey, verified that CPUE is a useful measurement of the relative abundance of reef fish when the appropriate depth and habitat was targeted. In addition, Gardner \& Struthers (2012) in a comparison of survey methodologies to test for abundance and size of blue cod, recognised that experimental angling (EA) and baited underwater video (BUV), were more efficient than underwater visual census (UVC). Those methodologies also provided high ability to detect fish, had high statistical power and small standard errors, and despite a relatively low sampling effort were good methodologies to detect differences between reserve and fished areas (Gardner \& Struthers 2012). CPUE have also been used to detect density gradients across MR boundaries (e.g., Goñi et al. 2006, Abesamis et al. 2006a, b). In this context the results of the present study may provide reliable estimates of the effects of protection on blue cod. 


\subsubsection{Effect of protection on blue cod survival}

Parameters estimates obtained from CMR studies can also be used as direct estimates of the effectiveness of management areas (e.g., Rowe 2001, Lambert 2005, Lettink \& Armstrong 2003, Lopez-Rivera \& Sabat 2009, Gormley et al. 2012). Lambert et al. (2005) studied the effectiveness of a Marine Sanctuary in Virginia (U.S.A.) by comparing the survival and recapture probabilities of blue crabs tagged outside the sanctuary to the probability of recapture for crabs tagged inside the sanctuary and detected that survival and recapture probabilities were higher inside the reserve compared to fished areas. Rowe (2001) in order to determine the potential effectiveness of a MR in Canada in sustaining fisheries for American lobster showed that the reserve offered increased survival to lobsters and thereby may provide benefits to fisheries. My results contrast with those reported by Rowe (2001) and Lambert et al. (2005) as I detected no differences in the survival estimates between areas. However, I did find differences in the recapture probabilities between areas, these being higher inside the reserve, suggesting that a significant proportion of the fish that were tagged remained in the reserve. This result could indirectly indicate higher survival inside the reserve relative to fished areas, where tagged fish were exposed to fishing; this assumes that individuals in the reserve and those in the fished areas have the same potential of displacement. However, it is important to bear in mind the limitations of the analyses performed here as due to the experimental design of the present study (i.e., extension of the tagging survey) there is a high uncertainty associated to the estimates of survival obtained.

Increased survival inside reserves can also be indirectly estimated from differences in size, i.e., larger individuals inside marine reserves usually indicate that individuals inside reserves have survived to larger sizes because they are not removed by fishing. Lopez-Rivera \& Sabat (2009), in a study of the effect of a MR in Puerto Rico, found that the survival rates of the red hind grouper did not vary significantly between protected and fished areas, however, red hind groupers inside the reserve were significantly larger than those outside suggesting that red hinds are surviving to larger

sizes. Increased length of individual inside MRs is a very common finding derived from 
studies reporting the effects of MR protection for a range of vertebrate and invertebrate species (i.e., direct and indirect reserve effects) (e.g., Lester et al. 2009, Babcock et al. 2010, Díaz- Guisado et al. 2012, Micheli et al. 2012). Lopez-Rivera \& Sabat (2009) suggested that the recapture methodology used in their study was not statistically powerful enough to detect the small differences in survivorship that could result in the observed differences in size structure. My findings are consistent with those reported by Lopez-Rivera \& Sabat (2009), suggesting a positive effect of protection on fish length, i.e., bigger fish in reserve, and even though not significant, a small differences in fish survival was detected between reserve and fished areas (i.e., higher survival in reserve).

\subsubsection{Movement patterns of blue cod across MR boundaries}

Only a few CMR studies have been performed in New Zealand in order to assess blue cod movement patterns. Most of these studies have reported low recapture rates i.e., less than $10 \%$ of the tagged fish recaptured over the course of a study in studies extending between nine and 20 months) independently of the amount of fish tagged (e.g., Rapson 1956, Mace \& Johnston 1983, Cole et al. 2000, Carbines 2003, Struthers 2004). The overall recapture rate recorded in the present study was similar to that previously reported, i.e., $8.91 \%$ of the tagged fish were recaptured over a 19 month period. It has been suggested that low recapture rates associated with population estimates can lead to biased estimation of those parameters (Harmsen et al. 2011). Also, a CMR study focused on the determination of animal movement patterns depends largely on taggingrelated mortality, tag loss, and the rates of tag detection and reporting (Björnsson et al. 2011). Therefore, studies that report low rates of tag return cannot provide clear results and also may bias parameter estimation and care should be taken in the interpretation of these values (e.g., Pollock et al. 2001, Oosthuizen et al. 2009).

Most of the surveys on blue cod movement (e.g., Cole et al. 2000, Govier 2001, Carbines 2003, Carbines \& McKenzie 2004, Struthers 2004) have indicated that blue cod tends to be resident in a specific home area, suggesting limited migration potential. For example, Carbines (2003) reported that $60.2 \%$ of tagged fish moved less than $1 \mathrm{~km}$ and Carbines (2003) reported that $65 \%$ of the tagged fish moved less than $1 \mathrm{~km}$. Similar 
results, i.e., most fish moving less than $1 \mathrm{~km}$, were reported by Cole et al. (2000) (75\%) and Struthers (2004) (83.3\%). Even though Cole et al. (2000) and Struthers (2004) found that fish at reserve sites moved longer distances than those at fished sites, and overall my results also suggested that most of the fish tagged both inside reserve and in fished areas moved very little. Also, Roger \& Wing (2008), found similar results in and analysis of stable isotope for the blue cod population in the Doubtoul Sound and later similar results were also found by Beer et al. (2011) in an analysis of the otolith microchemistry in the same area. The results obtained in the present study are consistent with those reported in previous studies, as most of the fish recaptured were recaptured within the study area (i.e., $83.3 \%$ ) and $90 \%$ of them (i.e., $77.1 \%$ from the total recaptured fish) moved less than $1 \mathrm{~km}$ and had not crossed reserve boundaries. For those fish that moved short distances (were recaptured within the study area), the distance travelled was related to fish size (exponential relationship) while no significant relationship was found for long distance movements. My results also suggest that legal size fish move longer distances than small and large fish. This may indicate that small fish (non-reproductive) and big fish (reproductively active fish) may not move as much as medium sized fish, while, probably, medium sized fish may need to move to find territories or mates. Previous studies have not detected a significant relationship between fish length and distance travelled (e.g., Carbines 2003, Carbines \& McKenzie 2004, Struthers 2004). However, the maximum distance moved reported in the present study (i.e., $315.1 \mathrm{~km}$ ) was considerably larger than the maximum distance reported in previous studies (i.e., $156 \mathrm{~km}$ ) (Carbines 2003).

In most of the other studies on blue cod movement, very few fish moved more than $100 \mathrm{~km}$, while in the present study I detected longer distance movement, most of them corresponding to fish tagged inside reserve areas. In this context, the results of the present study highlight the potential of blue cod to travel long distances and therefore contribute biomass to surrounding areas via spillover, as several fish moved more than $100 \mathrm{~km}$ (i.e., approximately $1 \mathrm{~km}$ per day). Also, in contrast to previous findings, I found a positive relationship between fish length and distance, at least for short distance movements. Furthermore, several fish travelled distances over $100 \mathrm{~km}$ and crossed reserve boundaries, all of them moving towards fished areas. The present study is one of 
the few CMR studies performed in New Zealand that has focused on determining the movement patterns of blue cod across MR boundaries. Others included Cole et al. (2000), who studied blue cod at the Long Island-Kokomohua Marine Reserve in the South Island, and Struthers (2004), who worked at the Kapiti MR in the North Island. Struthers (2004) also reported a few fish crossing reserve boundaries while Cole et al. (2000) did not observe any fish to cross the reserve boundary. Struthers (2004) suggested that these differences could be due to the habitat differences between study sites. Some advocates claim that for MRs spillover to occur there must be a biological link between the closed and open areas defined by the migration/dispersal patterns of fish stocks residing within and outside the protected areas along with the geographic or oceanographic characteristics of the marine environment (Sanchirico 2000). Struthers (2004) suggested that fish in the Long Island-Kokomohua MR would have had to move large distances over soft sediment to reach fished sites, while at Kapiti MR reef between reserve and fished sites is generally continuous, which permits fish movement between areas. Indeed, the distribution of habitat types relative to reserve boundaries is known to be an important factor determining movement of species (Buechner 1987, Chapman \& Kramer 1999, Kramer \& Chapman 1999, Freeman et al. 2009). However, at TMR, sites are very similar in their physical habitat types (greywacke reef interspersed with patches of medium-grained sand; similar wave exposure) (Pande \& Gardner 2008), allowing the movement of fish between areas. Despite this, I was able to detect very little movement between areas. High site fidelity has been reported for several fish species (e.g., Topping et al. 2006, Green et al. 2012, Lowerre-Barbieri et al. 2013) and the implications for marine conservation have been investigated (e.g., Starr 2005).

Finally, the fact that most of the fish recaptured outside the study area (long distance movement), with the exception of only one fish, moved towards the west (moved away from Wellington Harbour) and most of them towards west coast of the North Island, could suggest a pattern of unidirectional movement as far as TMR blue cod are concerned. These findings are not surprising due to the fact that the sand cover, characteristic of the inner bay areas, increase towards the eastern areas, especially from the east boundary onward, being particularly extensive closer to the Wellington Harbour entrance. Even though blue cod is often found on reef edges and shingle/gravel or sandy bottoms, close to rocky outcrops (Andrew \& Francis 2003), Carbines (2003) found that 
most blue cod were tagged and recaptured on reef habitats. Overall, the movement patterns observed in the present study indicate the potential of the species to travel long distances and move through a wide range of habitat types, especially for larger fish.

\subsection{Conclusions}

This chapter provides little evidence consistent with a positive effect of reserve protection in the TMR for blue cod in terms of increased density in reserve areas, while differences in fish length (i.e., larger fish inside reserve compared to fished areas) may indicate increased survival in reserve areas.

Also, the present study provided direct evidence of high site fidelity of blue cod in both reserve and fished areas, with the majority of individuals moving short distances over a period of approximately 20 months. However, I confirmed the potential of the species to travel long distances, suggesting possible spillover of the species from reserved to fished areas. These findings suggest that, in the future, blue cod is likely to largely benefit due to the protection in the TMR and further increased in density and length may be expected. 


\section{Chapter 7}

\section{General Discussion}


This investigation advances our understanding of the impacts of marine reserves (MRs) on both the communities they protect and the adjacent non-protected areas. The evidence presented here adds to a growing body of literature that suggests that MRs have a positive effect on the species they protect. Specifically, the present study makes the following contributions: (1) chapter two summarized and quantified the effects of protection provided by New Zealand MRs on two widely distributed and heavily fished species, describing the effects of MR age and size on the response to protection. Also, it described the advantages of the use of the RR meta-analysis as an alternative to Hedges' $g$ statistic, (2) chapter three provided evidence of the effect of MRs derived from an unique set of long-term time series of data revealing that target and non-target species and also species with different mobility rates can benefit from MR protection, (3) chapters three and four highlighted the importance of using different survey methodologies for the evaluation of the effect of MRs on reef fish species in order to detect a wide of variety of species and avoid overestimation of the effects of MRs, (4) chapter five provided evidence supporting the occurrence of spillover from MRs for both vagile species and species with moderate mobility, and (5) chapter six provided direct evidence of high site fidelity of blue cod in both reserve and fished areas, but in contrast to other studies confirmed the potential of the species to travel long distances, suggesting possible spillover of the species from reserved to fished areas.

In this chapter, I will discuss the evidence presented in chapters two to six in order to contextualize the results of the present study.

\subsection{Direct effects of MRs on target and non-target species}

MRs in different parts of the world are set up and managed for different purposes (e.g., fisheries enhancement, biodiversity protection, and scientific research), and potentially constitute a powerful tool for counteracting the harmful effects of fishing (Ballantine \& Langlois 2008). Recent syntheses of data from many reserves at a variety of locations around the world have shown positive direct effects of protection for a variety of marine species and communities i.e., higher density, biomass, body length and species diversity 
inside marine reserves than in nearby fished sites (e.g., Claudet et al. 2008, Lester et al. 2009, Molloy et al. 2009, Guarderas et al. 2011, Fenberg et al. 2012).

The evidence provided in the present study adds to a growing body of evidence that suggests that heavily targetted species respond positively to protection provided by MRs. For example, evidence of a positive effect of MRs in the density and length of blue cod and rock lobster in many NZ MRs was found in chapter two. Furthermore, in chapter three and five, early changes in density and length were evident in the area protected by the TMR for several fish species targetted by the commercial and recreational fisheries in the study area, or both. Blue cod was one of the fish species that showed a greater positive response in the TMR. Due to the high levels of fishing pressure that blue cod experience in many locations around New Zealand and the lifehistory characteristics of the species (i.e., blue cod tends to be resident to a specific home area), the species is considered to be susceptible to local depletion. Indeed, blue cod fishing was banned in the Marlborough Sounds area from October 2008 to April 2011 due to concerns about the sustainability of the species in the area. As a highly targetted species, blue cod is expected to recover (i.e., increase in density and length) inside MRs. In this context my finding are not surprising.

My results also indicated that MRs are having positive effects on the density and length of several other fish species, including non-target species The effects of MRs on non-target species have not been the focus of monitoring surveys and not too much evidence is available to allow comparisons. However, it has been established that reserve effects are not restricted to the recovery of target species alone and the recovery of keystone species may influence the abundance of other species in the reserve (e.g., Castilla 1999, Babcock 2003, Shears \& Babcock 2003, Babcock et al. 2010). In the present study, the evidence found in chapter three and five suggests that the TMR is having a positive effect in the density and length of spotty, a non-target species. Spotty is one of the most abundant species in the area of study (TMR and adjacent fishing grounds) and given their abundance and widespread distributions they are likely to have an ecologically important role in the community (Pande \& Gardner 2008). Indeed, the recovery of such species may have considerable influence on the abundance of other species in the reserve (indirect effects) (e.g., Castilla 1999, Babcock 2003, Shears \& 
Babcock 2003, Guarderas et al. 2011). Therefore, monitoring of non-target species leads to a more reasonable estimation of community-wide effects of protection (Guarderas et al. 2011). The present study indicate that changes in density of non-target species are expected and should be monitored.

In this context, it is important to bear in mind that different sampling methodologies may be adequate for monitoring different species. The present study highlight the importance of the use of different methodologies for the detection of the effects of MRs protection on a variety of species. In this context, the use of the BUV methodology represents an advantage as this methodology has been described to be the most effective survey methodology for the detection of large predatory species and also a good method to detect differences between reserve and fished areas. In this context, even though this methodology allows the acquisition of more accurate estimates of abundance for some species compared to other methodologies (i.e., UVC), the UVC methodology may be able to detect a wider range of species. In light of the results reposted in the present study, I suggest that a combination of methodologies should be used in those monitoring surveys that are focused in a assemblage of fish species.

Also, in terms of the analyses performed in the present study, these results highlight the importance of the use of different statistical approaches to detect change in protected areas. The present study revealed differences in the power to detect change between the approaches used. For example, in chapter three, the effect size analysis (descriptive approach) revealed a positive effect of MRs protection on the abundance of several fish species in the area protected by the TMR, while these changes were too small to be detected by the statistical tests performed (i.e., $\mathrm{p}<0.05$ ). In this context, some authors have suggested that the focus of assessment studies should be on the magnitude of effects and their uncertainty, and scientists should care less about whether there is a demonstrable (but possibly tiny) effect of the response (e.g., Stewart-Oaten 1996a, Osenberg et al. 2006). An inferential test may be statistically significant (i.e., unlikely to have occurred by chance), but this does not necessarily indicate how large the effect is while effect size does (Gupta 2012). In the present study the detection of differences between protected and fished sites through the analysis of effect sizes may indicate a positive response to protection but as previously suggested, the response may not be large enough to be detected with the statistical analysis performed. 
It is important to notice that both the type of methodology used to sample different species and the analyses used to evaluate the any differences in the variables assessed may be carefully chosen not only in studies monitoring the effects of MRs but also in other areas of marine science. In this context, this investigation provides new tools that could be applied in several areas of marine science.

\subsection{MR effects related to species characteristics}

Many theoretical and empirical studies have investigated how fish movement affects the success of the reserve in terms of the likelihood of persistence of fish inside the reserve. Many theoretical studies have suggested that highly mobile species may not respond positively to reserve protection or they would need larger reserves to show a positive response because they will protect more mobile species (Botsford et al. 2003; Hastings \& Botsford 2003). However, empirical studies have not supported this suggestion (Halpern 2003, Guidetti \& Sala 2007, Côté et al. 2001, Díaz-Guisado et al. 2012 but see Gell \& Roberts 2003a). Indeed, increasing evidence suggests that marine reserves can also benefit these highly mobile species (Willis et al. 2003a, Micheli et al. 2004, Claudet et al. 2010, Koldewey et al. 2010). For example, Micheli et al. (2004) suggested that because highly mobile species are often also the most heavily exploited, they may receive some benefit even from small marine reserves, although the probability of adequate protection increases with increasing reserve size.

My results suggested that the effects of the TMR can be detected in species of different mobility categories. My results indicated that blue moki was the only highly mobile species showing a positive response to reserve protection but other highly mobile fish species like tarakihi and trevally were only detected in very low densities in the area and not in all sampling occasions. Blue moki has previously shown a marked response to protection in other MRs in New Zealand (NZ) probably due to the fact that this species is heavily fished in many parts of the country. My results add to a body of evidence, mainly empirical, suggesting that mobile species can benefit from MRs. Also, sedentary species shown signs of recovery inside the TMR (e.g, spotty) and blue cod, a 
species usually described to be sedentary but that according to the results of tagging study performed in chapter six was classified in the present study as a species with moderate mobility, was one of the fish species that showed a greater positive response in the TMR.

\subsection{Effects of MR age and size in the response of targetted species}

Contrasting evidence on the effect of MR age and size on the response to protection have been continuously reported in the literature. For example, while theoretical studies suggest that large reserves should be more effective for conservation purposes than small reserves (Botsford et al. 2003, Hastings \& Botsford 2003, Roberts et al. 2003, Le Quesne \& Codling 2009), empirical studies have reached conflicting results (e.g., Halpern \& Warner 2002, Micheli et al. 2004, Russ \& Alcala 2004, Lester et al. 2009, Babcock et al. 2010, Guarderas et al. 2011). Also, MR age is usually considered to be an important factor in MR effectiveness and even though evidence indicates that a new reserve results in a rapid and significant increase in average levels of density, biomass, and diversity within 1 to $3 \mathrm{yr}$ before the response slows down or stabilises (e.g., Halpern \& Warner 2002, Halpern 2003, Micheli et al. 2004), recent evidence of the response of fish populations to MR protection determined that older reserves are more effective than younger reserves. In chapter two, I found evidence that at a national level, the recovery of previously targetted species (e.g., blue cod and rock lobster) within MRs occurs rapidly after only a few years following reserve establishment (i.e., 1-3 yr). Also, the evidence reported in chapters three and five reaffirms these findings and also suggested that several other fish species, including target species that are not under heavy fishing pressure and non-target species, are experiencing early changes (i.e., after 1-4 yr since reserve establishment) in the area protected by the TMR (e.g., increased density and/or length inside reserve). As previously reported, although for many of the fish species included in the analysis (excluding blue cod, blue moki and butterfish) these changes were too small to be detected with the statistical analyses that were performed, they were evident when analysing the effect sizes derived from a long term time series of 
abundance data i.e., RR analysis and delta values (BACIPS analysis). These results may be interpreted as an early indication of the reserve effect in the area of study. My results are consistent with those reported by some authors that have carried out empirical studies. For example, Babcock et al. (2010), combining and analysing a set of long-term time series of data from multiple marine reserves in both tropical and temperate reef habitats, found that initial detection of direct effects on target species occurred faster than the detection of indirect effects $(5.13 \pm 1.9$ years vs $13.1 \pm 2.0$ years for direct and indirect effects respectively). The time of initial detection of direct effects recorded by Babcock et al. (2010) was similar to the time recorded in the present study. For example, at Maria Island, Australia, Babcock et al. (2010) found that rock lobsters increased in abundance after only 1 year and the same results were obtained here for rock lobster in at least two MRs included in the meta-analysis performed in chapter two. A similar pattern was reported by Babcock et al. (2010) in the coral reef ecosystems of Kenya, where the abundance of predatory fish increased significantly after only 1 or 2 years. Here, in the analysis performed in chapter two, the blue cod abundance increased in the same period of time in at least three MRs. Also, even though Guarderas et al. (2011), in a meta-analysis of MRs in Latin America and the Caribbean, found that the response of these reserves was unaffected by MR age, they found that abundance in several MRs was higher in comparison to fished sites after only a few years since reserves establishment (i.e., $<5$ years). Overall, these results have reaffirmed the hypothesis that MR have rapid effects on the abundance and size of species targetted by fishing as it has been reported in several other studies (review by Babcock et al. 2010)

In terms of MR size, in chapter two I found evidence that MRs of all sizes can generate a positive change in targetted species but the response to protection scales with reserve size. The TMR protects 854 ha of coastal waters and among the existing MRs in NZ (excluding the Auckland Island and Kermadec MRs), the TMR is larger than some of the reserves where an effect on target species has been detected for several species, e.g., Long Island Kokomohua MR, Cape Rodney- Okakari Point MR and Kapiti MR (the portion of the reserve that have been the focus of the monitoring studies) (Department of Conservation 2014. In this context, the response to protection in the TMR can be expected to be as strong or strongest compared to other reserves in NZ. 


\subsection{The effect of MRs in adjacent non-protected areas}

In the present study, I evaluated both the indirect and direct evidence of spillover of fish across the boundaries of the TMR. In chapter five, gradients of fish density across reserve boundaries were evaluated. My findings were consistent with those reported elsewhere, as patterns of decreasing density were found only for target species, i.e., blue cod and blue moki, species that have shown signs of recovery in the area of study. According to the literature, gradients are expected to vary with according fish mobility and other factors, e.g., fishing effort distribution outside reserve. Overall, my findings were consistent with the models of spillover designed by Kellner et al. (2007) as gradients of density inside reserves were sharper for blue cod, a species with moderate mobility and weaker for blue moki, a highly mobile species. Gradients outside the boundaries of the TMR were also consistent with the patterns reported by Kellner et al. (2007) according to the distribution of the fishing effort outside reserve (i.e., flat gradient found were fishing effort was higher near the boundaries of the reserve and weak gradient were fishing effort was uniform).

In terms of the direct evidence of spillover obtained in the present study, blue cod was found to exhibit high site fidelity in both reserve and fished areas. Direct measurement of fish mobility is critical for evaluating the ability of reserves to enhance surrounding fisheries through the emigration of fish from MRs (Sladek Nowlis \& Roberts 1997, Sale et al. 2005, Goñi et al. 2006). Some studies have quantified movements of reef fishes across reserve boundaries but the degree to which these movements represent a response to protection is often difficult to assess (Goñi et al. 2006). In the present study I measured the movement of fish into the TMR and also the outward movements, and even though I found that fish movements were usually restricted to very small areas, I confirmed the potential of the species to travel long distances, suggesting possible spillover of the species from reserve to fished areas. The present study represents a valuable contribution in terms of the detection of large-scale movements of blue cod, as in many other studies performed around New Zealand, long distance movements have been anecdotal and fish have moved much shorter distances. Furthermore, an symmetry in the movement of the species was detected, i.e., most of the 
fish moved towards the west, crossing the western boundary of the reserve. This symmetry may contribute to the occurrence of spillover. Indeed, gradients of density were only detected in the western boundary. In this context, species mobility may be an important consideration for the design of MRs in terms of the benefits of reserves to the adjacent non-protected areas, as movements across the boundaries of MRs can affect the abundance and distribution of fishes within and outside reserves (Rakitin \& Kramer 1996, Russ \& Alcala 1996, Kramer \& Chapman 1999, Starr 2005, Botsford et al. 2009, Langebrake et al. 2011). Also, it is important to notice that the consideration of the patterns of movement of the species protected inside reserves may be useful for the design of marine reserve networks. For example, the Kapiti MR (KMR) is located in the west coast of the NZ North Island, approximately $30 \mathrm{~km}$ from Wellington, where the TMR is located. Results in chapter six indicate that some blue cod travelling from the TMR towards the west coast were found in the area surrounding the KMR. In terms of the benefits expected from a network of MRs, this may play an important role. For example, species with high mobility rates may easily found protection inside a network of MRs. It has been suggested that appropriately designed and managed MR networks can have many benefits compared with a single MR. A network may be more flexible with regard to the distribution of social and economic costs and benefits among various stakeholders and users, while still achieving fisheries management and biodiversity conservation objectives (Gaines et al. 2010, FAO 2012). In this context, the patterns of movement detected for blue cod may be an indicator of the potential of the species to benefit from MRs but also the potential to drive community wider benefits, i.e., social and economic benefits outside the reserve as spillover. Furthermore, the recovery of blue cod inside MRs and the occurrence of spillover from reserves may lead to important changes in adjacent non -protected areas, i.e., drive wider community changes. 


\subsection{Contribution to the science of marine reserves}

In the last few decades various attempts have been made to reform ocean management and balance the multiple human uses to more effectively address the impacts affecting the health of ecosystems (Gaines et al. 2010). In this context, MRs have gained much traction around the world but, considering that only a tiny fraction of the ocean has been set aside as marine reserves (Gaines et al. 2010, Eddy 2013), further evidence on the effects of MR may be needed in order to demonstrate the multiple benefits they provide. It is acknowledged that how users perceive the performance of Marine Protected Areas (including MRs) may be fundamental for the social acceptance of these zones. Moreover, their perceptions may be relevant for monitoring their effects on extractive activities (Leleu et al. 2012). It is true that many studies around the globe on the effects of MRs have provided evidence suggesting that the use of MRs in both fisheries management and conservation are positive, but they also indicate that the benefits provided by MRs are proportional to the level of protection and that these benefits can be dissipated quickly by targetted fishing: high levels of protection and resolute enforcement may be necessary (Roberts 2012). Therefore, due to the fact that the fishing industry often vigorously opposes MRs, it may be necessary to provide evidence supporting the hypothesis that the fishery industry has much to gain from protected areas.

In New Zealand, MRs are created under The Marine Reserves Act (1971) for the purposes of "preserving the marine environment in the natural state as the habitat of marine life for scientific study" and as it has been demonstrated here that MRs allow for the detection of the impacts of fishing in the ecosystem. In addition, they may act as a reference or baseline for what marine systems may be like and how they might function in the absence of disturbance produced by fisheries. In the TMR, early changes in several reef fish species are already evident after a few years since reserve establishment and the comparison between reserve and fished sites makes evident the effects of fishing in the areas not protected by the reserve. Further changes are expected to occur in the Wellington's south coast due to the effect of the TMR, and according to Eddy (2011) the TMR is capable of restoring the future ecosystem to a state more similar to that 
observed during historic times. If Eddy's predictions are correct, we will be able, in a few more years, to detect a stronger response in those species targetted by fishing (direct effects). We may also be able to detect indirect effects as has occurred in other MRs in New Zealand, for example at Leigh (the Cape Rodney to Okakari Point MR) where trophic cascades affecting the abundance of sea urchins have been reported (Babcock et al. 2010). Certainly, the changes that have been reported in MRs around the globe, demonstrate that several variables can result in varying community states (i.e., varying community structure) in marine ecosystems . For example, some studies have shown that disturbance through fishing can affect resilience of such systems and even though marine ecosystems contain very similar components, not all respond in the same way to human interventions, whether these are fishing or conservation (Babcock et al. 2010). Babcock et al. (2005) suggested that by studying these variations and understanding the reasons behind them, we will increase our ability to manage not only marine reserves but also to implement effective ecosystem-based management in a broader context. In this context, obtaining adequate data may be challenging but should be crucial in order to provide the necessary to support reliable quantitative scientific advice for management and decision-making (Pelletier et al. 2008, Halpern et al. 2010). Finally, Babcock et al. (2010) suggested that it may take decades to observe, predict, and validate the full implications of marine reserves, because many of the processes we need to understand operate on these time scales.

Finally, it is important to notice that many limitations, especially regarding the analyses performed, were identified in the present study. In this context, most of the comparison between methodologies gave me the possibility to analyse such differences and think of a way to overcome them. Indeed, I throughout the text I suggested some possible solutions that I suggest may be incorporated in future analyses. 


\section{Bibliography}

Adams DC, Gurevitch J, Rosenberg MS (1997) Resampling tests for meta-analysis of ecological data. Ecology, 78: 1277-1283.

Abesamis RA, Russ GR (2005) Density- dependent spillover from a marine reserve: long- term evidence. Ecological Applications, 15: 1798-1812.

Abesamis RA, Alcala AC, Russ GR (2006a) How much does the fishery at Apo Island benefit from spillover of adult fish from the adjacent marine reserve? Fishery Bulletin, 104(3): 360-375.

Abesamis RA, Russ GR, Alcala AC (2006b) Gradients of abundance of fish across notake marine reserve boundaries: evidence from Philippine coral reefs. Aquatic Conservation: Marine and Freshwater Ecosystems, 16: 349-371.

Ackerman JL, Bellwood DR (2000) Reef fish assemblages: a re-evaluation using enclosed rotenone stations. Marine Ecology Progress Series, 206: 227-237. 
Akaike $H$ (1973) Information theory as an extension of the maximum likelihood principle. In: Second International Symposium on Information Theory, Petrov BN, Csaki F (eds.). Akademiai Kiado, Budapest, pp. 267-281.

Alcala AC, Russ GR, Maypa AP, Calumpong HP (2005) A long-term spatially replicated experimental test of the effect of marine reserves on local fish yields. Canadian Journal of Fisheries Aquatic Sciences, 62: 98-108.

Allison GW, Lubchenco J, Carr MH (1998) Marine reserves are necessary but no sufficient for marine conservation. Ecological Applications, 8(1): S79-S92.

Allison GW, Gaines SD, Lubchenco J, Possingham HP (2003) Ensuring persistence of marine reserves: catastrophes require adopting an insurance factor. Ecological Applications, 13(1): S8-S24.

Andrew N, Francis M (2003) The living reef. The ecology of New Zealand's rocky reefs. Craig Potton Publishing, Nelson, New Zealand. pp. 283.

Arnqvist G, Wooster D (1995) Meta-analysis: synthesizing research findings in ecology and evolution. Trends in Ecology and Evolution, 10: 236-240.

Ashworth JS, Ormond RFG (2005) Effects of fishing pressure and trophic group on abundance and spillover across boundaries of a no-take zone. Biological Conservation, 121: 333-344.

Attwood CG, Bennet BA (1994) Variation in dispersal of galjoen (Coracinus capensis) (Teleostei: Coracinidae) from a marine reserve. Canadian Journal of Fisheries and Aquatic Sciences, 51: 1247-1257.

Babcock RC (2003) The New Zealand marine reserve experience: the science behind the politics. In: Conserving marine environments. Out of sight, out of mind? Hutchings P, Lunney D (eds.). Royal Zoological Society of New South Wales, Mosman, pp. 108-119. 
Babcock RC, Kelly S, Shears NT, Walker JW, Willis TJ (1999) Changes in community structure in temperate marine reserves. Marine Ecology Progress Series, 198: 125-134.

Babcock EA, Pikitch EK, McAllister MK, Apostolaki P, Santora C (2005) A perspective on the use of spatialized indicators for ecosystem-based fishery management through spatial zoning. Journal of Marine Science, 62: 469-476.

Babcock RC, Shears NT, Alcala AC, Barrett NS, Edgar GJ, Lafferty KD, McClanahan TR, Russ GR (2010) Decadal trends in marine reserves reveal differential rates of change in direct and indirect effects. Proceedings of the National Academy of Sciences of the United States of America, 107: 18256-18261.

Bailey DM, Priede IG (2002) Predicting fish behaviour in response to abyssal food falls. Marine Biology, 141: 831-840.

Ballantine B (1991) Marine Reserves for New Zealand. Leigh Laboratory Bulletin 25. University of Auckland. pp. 196.

Ballantine B (1999) Marine reserves in New Zealand: the development of the concept and the principles. Proceedings of the International Workshop on Marine Conservation for the New Millenium, Korean Ocean Research and Development Institute, Cheju Is.pp.26.

Ballantine B (2008) Marine reserves in New Zealand: Past, present and future. In: The Taputeranga Marine Reserve, Gardner J, Bell J (eds.). First Edition Limited, Wellington, New Zealand. pp. 39-52.

Ballantine B (2014) Fifty years on: Lessons from marine reserves in New Zealand and principles for a worldwide network Biological Conservation, http://dx.doi.org/10.1016/j.biocon.2014.01.014. 
Ballantine WJ, Langlois TJ (2008) Marine reserves: the need for systems. Hydrobiologia, 606: 35-44.

Barret NS (1995) Short- and long- term movement patterns of six temperate reef fishes (families Labridae and Monacanthidae). Marine and Freshwater Research, 46: 853- 860.

Barrett NS, Edgar GJ, Buxton CD, Haddon M (2007) Changes in fish assemblages following 10 years of protection in Tasmanian marine protected areas Journal of Experimental Marine Biology and Ecology, 345: 141-157.

Baty F, Delignette-Muller ML (2013) nlstools: tools for nonlinear regression diagnostics. $\mathrm{R}$ package version $0.0-15$.

Battershill CN, Murdoch RC, Grange KR, Singleton RJ, Aaron ES, Page MJ, Oliver MD (1993) A survey of the marine habitats and communities of Kapiti Island. Department of Conservation, Wellington, New Zealand. pp. 152.

Beentjes MP, Francis RICC (2011) Blue cod potting surveys: standards and specifications Version 1. New Zealand Fisheries Assessment Report, 2011/29. Ministry of Fisheries, Wellington, New Zealand. pp. 47.

Beentjes MP, Carbines GD (2012) Relative abundance, size and age structure, and stock status of blue cod from the 2012 survey in Marlborough Sounds, and review of historical surveys. New Zealand fisheries assessment report 2012/ 43. Ministry of Fisheries, New Zealand. pp. 137. Available at http://www.mpi.govt.nz

Beer NA, Wing SR, Swearer SSE (2011) Otolith elemental evidence for spatial structuring in a temperate reef fish population. Marine Ecology Progress Series, 442: 217-227.

Rodgers KL, Wing SR (2008) Spatial structure and movement of blue cod Parapercis colias in Doubtful Sound, New Zealand, inferred from $\delta 13 \mathrm{C}$ and $\delta 15 \mathrm{~N}$. Marine Ecology 
Progress Series, 359: 239-248.

Beinssen P, Beinssen K (1991) Heron Island reef fish movement study. Report of the Department of Conservation, Parks and Wildlife, Rockhampton, Australia.

Bell JJ (2008) Connectivity between island Marine Protected Areas and the mainland. Biological Conservation, 141: 2807-2820.

Bell JS, Craik GJS, Pollard DA, Russell BC (1985) Estimating length frequency distributions of large reef fish underwater. Coral Reefs, 4: 41-44.

Benedetti-Cecchi L (2001) Beyond BACI: optimization of environmental sampling designs through monitoring and simulation. Ecological Applications, 11(3): 783-799.

Berman NG, Parker RA (2002) Meta-analysis: neither quick nor easy. BMC Medical Research Methodology, 2: 10, DOI: 10.1186/1471-2288-2-10.

Bennett BA, Attwood CG (1991) Evidence for recovery of a surf-zone fish assemblage following the establishment of a marine reserve on the southern coast of South Africa. Marine Ecology Progress Series, 75: 173-181.

Bennett BA, Attwood CG (1993) Shore-angling catches in the De Hoop Reserve and further evidence for the protective value of marine reserves. South African Journal of Marine Science, 13: 213-222.

Bernstein B, Iudicello S, Stringer C (2004) Lessons learned from recent marine protected area designations in the United States. Report for The National Marine Protected Area Center. National Fisheries Conservation Center NOAA, Ojai, CA. pp. 88.

Bianchi G, Gislason H, Graham K, Hill L, Jin X, Koranteng K, Manickchand-Heileman 
S, Paya I, Sainsbury K, Sanchez F \& Zwanenburg K (2000) Impact of fishing on size composition and diversity of demersal fish communities. ICES Journal of Marine Science, 57: 558-571.

Björnsson B, Karlsson H, Thorsteinsson B , Solmundsson J (2011) Should all fish in mark- recapture experiments be double-tagged? Lessons learned from tagging coastal cod (Gadus morhua). ICES Journal of Marine Science, 68(3): 603-610.

Bohnsack JA (1998) Application of marine reserves to reef fisheries management. Australian Journal of Ecology, 23: 298-304.

Botsford LW, Castilla JC, Peterson CH (1997) The management of fisheries and marine ecosystems. Science, 277: 509-515.

Botsford LW, Micheli F, Hastings A (2003) Principles for the design of marine reserves. Ecological Applications (Supplement: Marine Reserves), 13: 25-31.

Botsford LW, Brumbaugh DR, Grimes C, Kellner JB, Largier J, O'Farrell MR, Ralston S, Soulanille E, Wespestad V (2009) Connectivity, sustainability, and yield: bringing the gap between conventional fisheries management and marine protected areas. Reviews in Fish Biology and Fisheries, 19: 69-95.

Bozec Y, Kulbicki M, Laloë F, Mou-Tham G, Gascuel D (2011). Factors affecting the detection of distances of reef fish: implications for visual counts. Marine Biology, 158: 969-981.

Blyth-Skyrme RE, Kaiser MJ, Hiddink JG, Edwards-Jones G, Hart PJB (2006) Conservation benefits of temperate marine protected areas: variation among Fish Species. Conservation Biology, 20(3): 811-820.

Brock RE (1982) A critique of the visual census method for assessing coral reef fish populations. Bulletin of Marine Science, 32: 269-276. 
Browman HI, Stergiou KI (2004) Perspectives on ecosystem-based approaches to the management of marine resources. Marine Ecology Progress Series, 274: 269-303.

Buechner M (1987) Conservation in insular parks: simulation models of factors affecting the movement of animals across park boundaries. Biological Conservation, 41: $57-76$.

Burnham K P, Anderson DR (2002) Model Selection and Multimodel Inference: A Practical Information-Theoretic Approach (2nd ed.) Springer-Verlag, New York. pp. 488. ISBN 0-387-95364-7

Burnham K, Anderson DR, White GC, Brownie C, Pollock K (1987) Design and analysis methods for fish survival experiments based on release-recapture. American Fisheries Society, Monograph num. 5, Bethesda, Maryland. pp. 437.

Cappo M, Speare P, De'ath G (2004) Comparison of baited remote underwater video stations (BRUVS) and prawn (shrimp) trawls for assessments of fish biodiversity in inter- reefal areas of the Great Barrier Reef Marine Park. Journal of Experimental Marine Biology and Ecology, 302: 123-152.

Cappo M, Harvey E, Shortis M (2006) Counting and measuring fish with baited underwater video techniques - an overview. In Lyle JM, Furlani DM, Buxton CD (eds.). Cutting-edge technologies in fish and fisheries science. Australian Society for Fish Biology Workshop Proceedings, Hobart, Australia. pp. 101-114.

Carbines (2003) Age, growth, movement and reproductive biology of blue cod (Parapercis colias - Pinguipedidae): Implications for fisheries management in the South Island of New Zealand. A thesis submitted for the degree of Doctor of Philosophy at the University of Otago, Dunedin, New Zealand.

Carbines GD, Beentjes MP (2011) Relative abundance, size and age structure, and stock status of blue cod in Dusky Sound, Fiordland, in 2008. New Zealand Fisheries Assessment Report 2011/35. Ministry of Fisheries, Wellington, New Zealand. pp. 56. 
Carbines GD, McKenzie J (2004) Movement patterns and stock mixing of blue cod in Dusky Sound in 2002. Ministry of Fisheries, Wellington. pp. 13.

Carter L (2008) Below low tide- a sea bed in motion. In: The Taputeranga Marine Reserve, Gardner J, Bell J (eds.). First Edition Limited, Wellington, New Zealand. pp. $130-140$.

Castilla JC (1999) Coastal marine communities: trends and perspectives from human exclusion experiments. Trends in Ecology \& Evolution, 14: 280-283.

Ceccherelli G, Casu D, Pala D, Pinna S, Sechi N (2006) Evaluating the effects of protection on two benthic habitats at Tavolara-Punta Coda Cavallo MPA (north-east Sardinia, Italy). Marine Environmental Research, 61: 171-185.

Chapman MR, Kramer DL (1999) Gradients in coral reef fish density and size across the Barbados Marine Reserve boundary: effects of reserve protection and habitat characteristics. Marine Ecology Progress Series, 181: 81-96,

Chapman MR, Kramer DL (2000) Movements of fishes within and among fringing coral reefs in Barbados. Environmental Biology of Fishes, 57: 11-24.

Chapman CJ, Johnstone ADF, Dunn JR, Creasey DJ (1974) Reactions of fish to sound generated by diver's open-circuit underwater breathing apparatus. Marine Biology, 27: 357-366.

Charbonnel E, Serre C, Ruitton S, Harmelin J-G, Jensen A (2002) Effects of increased habitat complexity on fish assemblages associated with large artificial reef units (French Mediterranean coast). ICES Journal of Marine Science, 59: S208-S213.

Choat JH, Ayling AM (1987) The relationship between habitat structure and fish faunas on New Zealand reefs. Journal of Experimental Marine Biology and Ecology, 110: 257- 
284.

Claudet J, Guidetti P (2010) Improving assessments of marine protected areas. Aquatic Conservation, 20: 239-242.

Claudet J, Pelletier D, Jouvenelc J-Y, Bachet F, Galzin R (2006) Assessing the effects of marine protected area (MPA) on areef fish assemblage in a northwestern Mediterranean marine reserve: identifying community-based indicators. Biological Conservation, 130: 349-369.

Claudet J, Osenberg CW, Domenici P, Badalamenti F, Milazzo M, Falcón JM, Bertocci I, Benedetti-Cecchi L, García-Charton JA, Goñi R, Borg JA, Forcada A, de Lucia GA, Pérez-Ruzafa A, Alfonso P, Brito A, Guala I, Le Direach, Sanchez-Jerez P, Somerfield PJ, Planes S (2010) Marine reserves: fish life history and ecological traits matter. Ecological Applications, 20(3): 830-839.

Claudet J, Osenberg CW, Benedetti-Cecchi L, Domenici P, García-Charton JA, PérezRuzafa A, Badalamenti F, Bayle-Sempere J, BritoA, Bulleri F, Culioli J-M, Dimech M, Falcón JM, Guala I, Milazzo M, Sánchez-Meca J, Somerfield PJ, Stobart B, Vandeperre F, Valle C, Planes S (2008) Marine reserves: size and age do matter. Ecology Letters, 11 $: 481-489$.

Cole RG (1994) Abundance, size structure, and diver-oriented behaviour of three large benthic carnivorous fishes in a marine reserve in northeastern New Zealand. Biological Conservation, 70: 93-99.

Cole RG, Ayling AM, Creese RG (1990) Effects of marine reserve protection at Goat Island, northern New Zealand. New Zealand Journal of Marine and Freshwater Research, 24: 197-210.

Cole RG, Villouta E, Davidson RJ (2000) Direct evidence of limited dispersal of the reef 
fish Parapercis colias (Pinguipedidae) within a marine reserve and adjacent fished areas. Aquatic Conservation: Marine and Freshwater Ecosystems, 10: 421-436.

Cole RG, Syms C, Davey NK, Gust N, Notman P, Stewart R, Radford C, Carbines G, Carr MH, Jeffs AG (2007) Does breathing apparatus affect fish counts and observations? A comparison at three New Zealand fished and protected areas. Marine Biology, 50 (6): 1379-1395.

Colton MA, Swearer S (2010) A comparison of two survey methods: differences between underwater visual census and baited remote underwater video. Marine Ecology Progress Series, 400: 19-36.

Costello C, SD Gaines, J Lynham (2008). Can catch shares prevent fisheries collapse? Science, 231: 1678-1681.

Côté IM, Mosquera I, Reynolds JD (2001) Effects of marine reserve characteristics on the protection of fish populations: a meta-analysis. Journal of Fish Biology 59 (Suppl A): $178-189$.

Cox SP, Beard TD, Walters C (2002) Harvest control in open-access sport fisheries: hot rod or asleep at the wheel? Bulletin of Marine Science, 70: 749-761.

Creese R, Jeffs A (1992) Biological research in New Zealand marine reserves. In: Proceedings of the Second International Temperate Reef Symposium, Battershill CN et al. (eds.). NIWA Marine, Wellington. pp. 15-22.

Cudney-Bueno R, Lavín MF, Marinone SG, Raimondi PT, Shaw WW (2009) Rapid effects of marine reserves via larval dispersal. PLoS ONE: e0004140 DOI 10.1371/journal.pone.0004140.

Cunningham S, Bostock T (2005) Successful fisheries management issues, case studies and perspectives. Eburon Academic Publishers, Delft. pp. 240. 
Daniel WW (1999) Biostatistics: A Foundation for Analysis in the Health Sciences. John Wiley \& Sons, Inc, New York. pp. 755.

Davidson RJ (1999) Tonga Marine Reserve, Abel Tasman, Nelson: subtidal biological baseline report. Survey and Monitoring Rep. No. 175a, Department of Conservation, Nelson.

Davidson RJ (2001a) Changes in population parameters and behaviour of blue cod (Parapercis colias; Pinguipedidae) in Long Island-Kokomohua Marine Reserve, Marlborough Sounds, New Zealand. Aquatic Conservation, 11: 417-435.

Davidson RJ (2001b) Tonga Island Marine Reserve: pro- posed protocol for ongoing subtidal biological monitoring. Survey and Monitoring Rep No. 316, Department of Conservation, Nelson. Available at www.doc.govt.nz.

Davidson RJ (2004) Long Island-Kokomohua Marine Reserve, Queen Charlotte Sound: 1992-2003. Prepared by Davidson Environmental Limited for Department of Conservation, Nelson. Survey and Monitoring Report No. 343. Available at $\underline{\text { www.doct.govt.nz }}$

Davidson RJ (2006) Horoirangi Marine Reserve, North Nelson rocky shore baseline biological report. Survey and Monitoring Rep No. 513, Department of Conservation, Nelson.

Davidson RJ, Abel W (2002) Second sampling of Pohatu Marine Reserve, Flea Bay, Banks Peninsula. A report prepared for: Department of Conservation. Survey and Monitoring Report No. 443. Available at www.doct.govt.nz

Davidson RJ, Richards LA (2005) Comparison of fish at reserve and control sites from Long Island-Kokomohua and Tonga Island marine reserves using baited underwater 
video (BUV), catch, measure, release (CMR) and underwater visual counts (UVC). Prepared by Davidson Environmental Limited for Department of Conservation, Nelson. Survey and Monitoring Report No. 466.

Davidson RJ, Barrier R, Pande A (2001) Pohatu Marine Reserve baseline survey. Survey and Monitoring Rep No. 352, Department of Conservation, Canterbury. Available at www.doc.govt.nz

Davidson R, Richards L, Baxter A (2007) Tonga Island Marine Reserve, Abel Tasman National Park update of biological monitoring, 1993-2007. Survey and Monitoring Rep No. 484, Department of Conservation, Nelson. Available at www.doc.govt.nz

Davidson RJ, Abel W, Richards LA (2009) Biological monitoring update 1992-2009: Long Island-Kokomohua Marine Reserve, Queen Charlotte Sound. Survey and Monitoring Report No.573, Department of Conservation, Nelson,. Available at www.doc.govt.nz

Davidson RJ, Villouta E, Cole RG, Barrier RGF (2002) Effects of marine reserve protection on spiny lobster (Jasus edwardsii) abundance and size at Tonga Island Marine Reserve, New Zealand. Aquatic Conservation, 12: 213-227.

Davis GE, Anderson TW (1989) Population estimates of four kelp forest fishes and an evaluation of three in situ assessment techniques. Bulletin of Marine Science, 44: 11381151.

Denny CM, Babcock RC (2004) Do partial marine reserves protect reef fish assemblages? Biological Conservation, 116: 119-129.

Denny CM, Willis TJ, Babcock RC (2003) Effects of Poor Knights Islands Marine Reserve on demersal fish populations Department of Conservation Science Internall 
Series 142. Available at http://www.doc.govt.nz.

Denny CM, Willis TJ, Babcock RC (2004) Rapid recolonisation of snapper (Pagrus auratus: Sparidae) within an offshore island marine reserve after implementation of notake status. Marine Ecology Progress Series, 272: 183-190

Department of Conservation (2014) Marine Reserves. http://www.doc.govt.nz/ conservation/marine-and-coastal/marine-protected-areas/marine-reserves-a-z/ (accessed 5.5.14).

Department of Conservation and Ministry of Fisheries (2005) Marine protected areas policy and implementation plan. Department of Conservation, Ministry of Fisheries, Wellington.

Díaz- Guisado D, Cole RG, Davidson RJ, Freeman DJ, Kelly S, MacDiarmid A, Pande A, Stewart R, Struthers C, Bell JJ, Gardner JPA (2012) Comparison of methodologies to quantify the effects of age and size of marine reserves on the density and size of targeted species. Aquatic Biology, 14: 185-200, DOI 10.3354/ab00391

Dickens LC, Goatley CHR, Tanner JK, Bellwood DR (2010) Quantifying relative diver effects in underwater visual censuses. PLoS ONE 6(4): e18965, DOI 10.1371/journal.pone.0018965

Eddy TD (2011) Marine reserves as conservation and management tools: Implications for coastal resource use. Ph.D. Thesis. School of Biological Sciences, Victoria University of Wellington. Wellington, New Zealand.

Eddy TD (2013) On the need for meaningful marine protected area (MPA) standards. Aquatic Conservation: Marine and Freshwater Ecosystems, 23(4): 481-482, DOI 10.1002/aqc. 2381 
Eddy TD, Gardner JPA, Bell JJ (2008) A status report on the biological and physical information for Wellington's south coast with monitoring recommendations for the Taputeranga Marine Reserve. Department of Conservation Report.

Eddy TD, Gardner JPA, Pérez-Matus A (2010) Applying fishers' ecological knowledge to construct past and future lobster stocks in the Juan Fernández Archipelago, Chile. PLoS ONE, 5(11), DOI 10.1371/journal.pone.0013670.

Edgar GJ (2004) Biases associated with the use of underwater visual census techniques to quantify the density and size-structure of fish populations. Journal of Experimental Marine Biology and Ecology, 308 (2): 269-290.

Edgar GJ, Barrett NS (1999) Effects of the declaration of marine reserves on Tasmanian reef fishes, invertebrates and plants. Journal of Experimental Marine Biology and Ecology, 242: 107-144.

Edgar GJ, Bustamante RH, Farina JM, Calvopina M, Martinez C, Toral-Granda MV (2004a) Bias in evaluating the effects of marine protected areas: the importance of baseline data for the Galapagos Marine Reserve. Environmental Conservation, 31: 212218.

Edgar GJ, Barrett NS, Morton AJ (2004b) Biases associated with the use of underwater visual census techniques to quantify the density and size-structure of fish populations. Journal of Experimental Marine Biology and Ecology, 308: 269-290.

Edgar GJ, Barrett NS, Morton AJ (2004c) Patterns of fish movement on eastern Tasmanian rocky reefs. Environmental Biology of Fishes, 70: 273-284.

Egger M, Smith GD, Phillips AN (1997) Meta-analysis, principles and procedures. British Medical Journal, 315: 1533-1537. 
FAO (2009) The state of world fisheries and aquaculture 2008. FAO, Rome. pp. 176.

FAO (2012) The state of world fisheries and aquaculture 2012. FAO, Rome. pp. 209.

Feary DA, Cinner JE, Graham NAJ, Hartley FA (2010) Effects of customary marine closures on fish behavior, spear-fishing success, and underwater visual surveys. Conservation Biology, 25(2): 341-349, DOI 10.1111/j.1523-1739.2010.01613.x.

Fenberg PB, Caselle JE, Claudet JE, Clemence M, Gaines SD, García-Charton JA, Gonçalves EJ, Grorud-Colvert K, Guidetti P, Jenkins SR, Jones PJS, Lester SE, McAllen R, Moland E, Planes S, Sørensen TK (2012). The science of European marine reserves: Status, efficacy, and future needs. Marine Policy, 36(5): 1012-1021.

Forcada A, Valle C, Bonhomme P. Criquet G, Cadiou G, Lenfant P, Sánchez- Lizaso JL (2009) Effects of habitat on spillover from marine protected areas to artisanal fisheries. Marine Ecology Progress Series 379: 197-211.

Francis MP (1988) Coastal Fishes of New Zealand. A Diver's Identification Guide. Heinemann, Jerusalem. pp. 64.

Francis M (2001) Coastal Fishes of New Zealand. An identification guide. Third edition. Reed Books, Auckland, New Zealand. pp. 103.

Francis M (2008) Fishes of the marine reserve. In: The Taputeranga Marine Reserve, Gardner J, Bell J (eds.). First Edition Limited, Wellington, New Zealand. pp. 401-423.

Fraschetti S, Claudet J, Grorud-Colvert K (2011) Transitioning from single-sector management to ecosystem-based management: What can marine protected areas offer? In:Claudet J (ed) Marine protected areas - a multidisciplinary approach. Cambridge University Press, Cambridge. pp. 11-34. 
Freeman DJ (2001) Te Tapuwae o Rongokako Marine Reserve baseline Survey Report. Technical Support Series report, Department of Conservation, Gisborne.

Freeman DJ (2005) Reef fish monitoring, Te Tapuwae o Rongokako Marine Reserve. East Coast Hawke's Bay Conservancy. Technical Support Series No. 25, Department of Conservation, Gisborne. Available at www.doc.govt.nz.

Freeman DJ (2008) The Ecology of Spiny Lobsters (Jasus edwardsii) on Fished and Unfished Reefs. PhD thesis, The University of Auckland.

Freeman DJ, Duffy CAJ (2003) Te Angiangi Marine Reserve reef fish monitoring 1995-2003. Technical Support Series No. 14, Department of Conservation, Hawke's Bay.

Freeman DJ, MacDiarmid AB, Taylor RB (2009) Habitat patches that cross marine reserve boundaries: consequences for the lobster Jasus edwardsii. Marine Ecology Progress Series, 388: 159-167.

Froese R, Pauly D (2013). FishBase. World Wide Web electronic publication. www.fishbase.org

Funicelli NA, Meineke DA, Bryant HE, Dewey MR, Ludwig GM, Mengel LS (1989) Movements of striped mullet, Mugil cephalus, tagged in Everglades National Park, Florida. Bulletin of Marine Science, 44: 171-178.

Gaines SD, Lester SE, Grorud-Colvert K, Costello C, Pollnac R (2010) Evolving science of marine reserves: New developments and emerging research frontiers. PNAS, 107 (43): 18251-18255 
Gardner JPA, Struthers CD (2012) Comparisons among survey methodologies to test for abundance and size of a highly targeted fish species. Journal of Fish Biology, 82(1): 242-62, DOI 10.1111/j.1095-8649.2012.03478.x.

Gardner JPA, Cutler A, Ryder C (2008) Introduction: the history and development of the Taputeranga Marine Reserve. In: The Taputeranga Marine Reserve, Gardner J, Bell J (eds.). First Edition Limited, Wellington, New Zealand. pp. 17-38.

Gastwirth JL, Gel YR, Hui WLW, Lyubchich V, Miao W, Noguchi K (2013) lawstat: An $\mathrm{R}$ package for biostatistics, public policy, and law. R package version 2.4.

Gates S (2002) Review of methodology of quantitative reviews using meta-analysis in ecology. Journal of Animal Ecology, 71: 547-557.

Gell FR, Roberts CM (2003a) Benefits beyond boundaries: the fishery effects of marine reserves. Trends in Ecology and Evolutio, 18(9): 448-455.

Gell FR, Roberts CM (2003b) The fishery effects of marine reserves and fishery closures. World Wildlife Fund- US, Washington D.C., USA. pp. 90.

Goh A (2008) Human impacts: past and present. In: The Taputeranga Marine Reserve, Gardner J, Bell J (eds.). First Edition Limited, Wellington, New Zealand. pp. 152-179.

Goldberg DE, Rajaniem T, Gurevitch J, Stewart-Oaten A (1999) Empirical approaches to quantifying interaction intensity: competition and facilitation along productivity gradients. Ecology, 80: 1118-1131.

Goñi R, Quetglas A, Reñones O (2006) Spillover of spiny lobsters Palinurus elephas from a marine reserve to an adjoining fishery. Marine Ecology Progress Series, 308: 207-219. 
Goñi R, Hilborn R, Díaz D, Mallol S, Adlerstein S (2010) Net contribution of spillover from a marine reserve to fishery catches. Marine Ecology Progress Series, 400: 233-243.

Goñi R, Adlerstein S, Alvarez-Berastegui D, Forcada A, Reñones O, Criquet G, Polti S, Cadiou G, Valle C, Lenfant P, Bonhomme P, Pérez-Ruzafa5 A, Sánchez-Lizaso JL, García-Charton5 JA, Bernard6 G, Stelzenmüller V, Planes S (2008) Spillover from six western Mediterranean marine protected areas: evidence from artisanal fisheries. Marine Ecology Progress Series, 366: 159- 174.

Gormley AM, Slooten E, Dawson S, Barker RJ, Rayment W, du Fresne S, Bräger S (2012). First evidence that marine protected areas can work for marine mammals. Journal of Applied Ecology, 49: 474-480.

Govier D (2001) Growth and movement of blue cod (Parapercis colias) in Paterson Inlet, Stewart Island, New Zealand. University of Otago, Dunedin.

Grafton RQ, Kompas T, Ha PV (2009) Cod today and none tomorrow: the economic value of a marine reserve. Land Economics, 85: 454-469.

Grapes R, Goh A (2008) Geomorphology. In: The Taputeranga Marine Reserve, Gardner J, Bell J (eds.). First Edition Limited, Wellington, New Zealand. pp. 108-129.

Gratwicke B, Speight MR (2005) Effects of habitat complexity on Caribbean marine fish assemblages. Marine Ecology Progress Series, 292: 301-310, DOI 10.3354/meps292301.

Green RH (1979) Sampling design and statistical methods for environmental biologists. John Wiley \& Sons, New York. pp. 272.

Green BC, Smith DJ, Grey J, Underwood GJ (2012) High site fidelity and low site connectivity in temperate salt marsh fish populations: a stable isotope approach. 
Oecologia, 168(1): 245-55, DOI 10.1007/s00442-011-2077-y.

Greenstreet S, Robinson L, Callaway R, Reiss H, Ehrich S, Piet G, Kröncke I, Craeymeersch J, Lancaster J, Jorgensen L, Degraer S, Goffin A (2007). Managing fisheries to conserve north sea groundfish and benthic invertebratespecies diversity. Fisheries Research Services Collaborative Report No. 05/07. pp. 136.

Grothendieck G (2013). nls2: Non-linear regression with brute force. R package version 0.2 .

Guarderas A, Hacker SD, Lubchenco J (2011) Ecological effects of marine reserves in Latin America and the Caribbean. Marine Ecology Progress Series, 429: 219-225, DOI 10.3354/meps09103.

Guidetti P, Sala E (2007) Community-wide effects of marine reserves in the Mediterranean Sea. Marine Ecology Progress Series, 335: 43-56.

Gupta SK (2012) The relevance of confidence interval and P-value in inferential statistics. Indian Journal of Pharmacologyl, 44(1): 143-144, DOI 10.4103/0253$\underline{7613.91895}$

Gurevitch J, Hedges LV (1999). Statistical issues in ecological meta-analyses. Ecology, 80: $1142-1149$.

Haggarty DR, King JR (2006) CPUE as an index of relative abundance for nearshore reef fishes. Fisheries Research, 81: 89-93.

Haggitt T (2011) Cape Rodney to Okakari Point Marine Reserve and Tawharanui Marine Park Reef Fish Monitoring: UVC Survey Autumn 2011. A report prepared for: 
Department of Conservation. Coastal \& Aquatic Systems Limited, Environmental consultants. Available at http://www.doc.govt.nz.

Haggitt T, Kelly S (2004) Cape Rodney to Okakari Point Marine Reserve Lobster Monitoring Programme: 2004 Survey. A report prepared for: Department of Conservation. Available at www.doct.govt.nz.

Haggitt T, Denny C, Mead S (2008) Cape Rodney to Okakari Point Marine Reserve and Tawharanui Marine Park Reef Fish Monitoring: Autumn 2008. A report prepared for: Department of Conservation. Coastal \& Aquatic Systems Limited, Environmental consultants.

Halpern B (2003) The impact of marine reserves: Do reserves work and does reserve size matter? Ecological Applications (Supplement: Marine Reserves), 13: 117-137.

Halpern BS, Warner RR (2002) Marine reserves have rapid and lasting effects. Ecology Letters, 5: 361-366.

Halpern BS, Warner RR (2003) Matching marine reserve design to reserve objectives. Proceedings of the Royal Society B-Biological Sciences, 270: 1871-1878.

Halpern BS, Lester S, Kellner JB (2010) Spillover from marine reserves and the replenishment of fished stocks. Environmntal Conservation, 36(4): 268-276.

Halpern BS, Longo C, Hardy D, McLeod KL, Samhouri JF , Katona SK ,Kleisner K, Lester SE, O’Leary J, Ranelletti M, Rosenberg AA, Scarborough C, Selig ER, Best BD, Brumbaugh DR, Chapin FS, Crowder LB, Daly KL, Doney SC, Elfes C, Fogarty MJ, Gaines SD, Jacobsen KI, Karrer LB, Leslie HM, Neeley E, Pauly D, Polasky S, Ris B, St Martin K, Stone GS, Sumaila UR, Zeller D (2012). An index to assess the health and benefits of the global ocean. Nature, 488: 615-622, DOI: 10.1038/nature11397. 
Hannah RW, Blume MTO (2012) Tests of an experimental unbaited video lander as a marine fish survey tool for high-relief deepwater rocky reefs. Journal of Experimental Marine Biology and Ecology, 430-431: 1-9.

Harley SJ, Myers RA, Dunn A (2001) Is catch-per-unit-effort proportional to abundance? Canadian Journal of Fisheries Aquatic Sciences, 58: 1760-1772.

Harmelin-Vivien M, Le Diréach L, Bayle-Semperec J, Charbonnel E, García- Charton JA, Ody D, Pérez-Ruzafa A, Reñones O, Sánchez-Jerez P, Valle. C (2008) Gradients of abundance and biomass across reserve boundaries in six Mediterranean marine protected areas: Evidence of fish spillover? Biological Conservation, 141: 1829-1839.

Harmsen BJ, Foster RJ, Doncaster CP (2011) Heterogeneous capture rates in low density populations and consequences for capture-recapture analysis of camera-trap data. Population Ecology, 53: 253-259, DOI 10.1007/s10144-010-0211-z.

Harnik PG, Lotze HK, Anderson SC, Finkel ZV, Finnegan S, Lindberg DR, Liow LH, Lockwood R, McClain CR, McGuire JL, O'Dea A, Pandolfi J, Simpson C, Tittensor DP (2012) Extinctions in ancient and modern seas. Trends in Ecology and Evolution, 27(11): 608-617. DOI:10.1016/j.tree.2012.07.010.

Harrison HB, Williamson DH, Evans RD, Almany GR, Trorrold SR, Russ GR, Feldheim KA, van Herwerden L, Planes S, Srinivasan M, Berumen ML, Jones GP (2012). Larval export from marine reserves and the recruitment benefit for fish and fisheries. Current Biology, 22(11): 1023-1028.

Hart DR (2013) Quantifying the tradeoff between precaution and yield in fishery reference points. ICES Journal of Marine Science, DOI.10.1093/icesjms/fss204.

Hartney KB (1996) Site fidelity and homing behaviour of some kelp-bed fishes. Journal of Fish Biology, 49: 1062-1069.

Harvey ES, Fletcher D, Shortis M (2001) A comparison of the precision and accuracy of 
estimates of reef-fish lengths determined visually by divers with estimates produced by a stereo-video system. Fishery Bulletin, 99: 63-71

Harvey ES, Fletcher D, Shortis MR, Kendrick GA (2004) A comparison of underwater visual distance estimates made by scuba divers and a stereo-video system: implications for underwater visual census of reef fish abundance. Marine and Freshwater Research, 55: 573- 580

Harvey ES, Cappo M, Butler JJ, Hall N, Kendrick GA (2007) Bait attraction affects the performance of remote underwater video stations in assessment of demersal fish community structure. Marine Ecology Progress Series, 350: 245-254.

Hastings A, Botsford LW (2003) Comparing designs of marine reserves for fisheries and for biodiversity. Ecological Applications, 13:65-70.

Hedeker D, Gibbons RD (2006) Longitudinal Data Analysis. Wiley Interscience, New Jersey. pp. 360.

Hedges LV, Olkin I (1985) Statistical methods for meta-analysis. Academic Press, San Diego, CA. pp. 369.

Hedges LV, Gurevitch J, Curtis PS (1999) The meta-analysis of response ratios in experimental ecology. Ecology, 80: 1150-1156.

Hilborn R (2007a) Reinterpreting the state of fisheries and their management. Ecosystems, 10: 1362-1369.

Hilborn R (2007b) Defining success in fisheries and conflicts in objectives. Marine Policy, 31: 153-158. 
Hilborn R, Stokes K, Maguire JJ, Smith T, Botsford LW, Mangel M, Orensanz J, Parma A, Rice J, Bell J, Cochrane KL, Garcia S, Hall SJ, Kirkwood GP, Sainsbury K, Stefansson G, Walters C (2004) When can marine reserves improve fisheries management? Ocean Coastal Management, 47: 197-205.

Horta e Costa B, Erzini K, Caselle JE, Folhas H, Gonçalves EJ (2013) The reserve effect within a temperate marine protected area in the north-eastern Atlantic (the Arrábida Marine Park, Portugal). Marine Ecology Progress Series, 481: 11-24.

Hurlbert SH (1984) Pseudoreplication and the design of ecological field experiments. Ecological Monographs, 54: 187-211.

Hyrenbach KD, Forney KA, Dayton PK (2000) Marine protected areas and ocean basin management. Aquatic Conservation: Marine and Freshwater Ecosystems, 10: 437-458.

IBM Corp. Released 2011. IBM SPSS Statistics for Windows, version 20.0. Armonk, NY: IBM Corp.

ICES (2003) Advisory Committee on Fisheries Management (ACFM) Annual Report. Available at www.ices.dk.

Jackson JBC, Kirby MX, Berger WH, Bjorndal KA, Botsford LW, Bourque BJ, Bradbury RH, Cooke R, Erlandson J, Estes JA, Hughes TP, Kidwell S, Lange CR, Lenihan HS, Pandolfi JM, Peterson CH, Steneck RS, Tegner MJ, Warner RR (2001) Historical overfishing and the recent collapse of coastal ecosystems. Science, 293: 629638.

Januchowski-Hartley FA, Graham NAJ, Cinner JE, GR Russ (2013) Spillover of fish näiveté from marine reserves. Ecology Letters, 16: 191-197, DOI 10.1111/ele.12028. 
Jennings S (2000) Patterns and prediction of population recovery in marine reserves. Reviews in Fish Biology and Fisheries, 10: 209-231.

Jennings S, Kaiser MJ(1998) The effects of fishing on marine ecosystems. Advances in Marine Biology, 34: 201-351.

Jennings S, Polunin NVC (1995) Biased underwater visual census biomass estimates for target-species in tropical reef fisheries. Journal of Fish Biology, 47: 733-736.

Jind S (2012) A comparison of two underwater visual sampling techniques used to estimate tropical reef fish communities A thesis submitted in partial fulfilment of the requirements for the degree of Honours Bachelor of Science in MarineBiology at Dalhousie University Halifax, Nova Scotia.

Kaiser MJ (2005) Are marine protected areas a red herring or fisheries panacea? Canadian Journal of Fisheries and Aquatic Sciences, 62(5): 1194-1199.

Kaunda-Arara B, Rose GA. 2004. Effects of marine reef National Parks on fishery CPUE in coastal Kenya. Biological Conservation, 118: 1-13.

Kay MC, Lenihan HS, Kotchen MJ, Miller CJ (2012) Effects of marine reserves on California spiny lobster are robust and modified by fine-scale habitat features and distance from reserve borders. Marine Ecology Progress Series, 451: 137-150, DOI 10.3354/meps09592.

Kelleher G, Bleakley C, Wells SC (1995) A Global Representative System of Marine Protected Areas: Antarctic, Artic, Mediterranean, Northwest Atlantic and Baltic. The International Bank for Reconstruction/The World Bank: Washington, DC. pp. 147. 
Kellner JB, Nisbet RM, Gaines SD (2008) Spillover from marine reserves related to mechanisms of population regulation. Theoretical Ecology, 1(2): 117-127, DOI 10.1007/s12080-008-0012-6.

Kellner JB, Tetreault I, Gaines SD, Nisbet RM (2007) Fishing the line near marine reserves in single and multi-species fisheries. Ecological Applications, 17: 1039-1054.

Kelly S, Scott D, MacDiarmid AB (2002) The value of a spillover fishery for a spiny lobsters around a marine reserve in New Zealand. Coastal Management, 30: 153-166.

Kelly S, Scott D, MacDiarmid AB, Babcock RC (2000) Spiny lobster, Jasus edwardsii, recovery in New Zealand marine reserves. Biological Conservation, 92: 359-369.

Kingsford MJ (1998) Reef fishes. In Kingsford MJ, Battershill CN (editors) Studying temperate marine environments. A handbook for ecologists. Canterbury University Press, Christchurch, NZ. pp. 132-166

Kingsford M, Battershill C (1998) Studying emperate Marine Environments. A Handbook For Ecologists. Canterbury University Press, Christchurch, NZ. pp. 336.

Koldewey HJ, Curnick D, Harding S, Harrison LR, Gollock M (2010) Potential benefitsto fisheries and biodiversity of the Chagos Archipelago/British IndianOcean Territory as a no- take marine reserve. Marine Pollution Bulletin, 60, 1906-1915.

Kramer DL, Chapman MR (1999) Implications of fish home range size and relocation for marine reserve function. Environmental Biology of Fishes, 55: 65-79.

Kulbicki M (1998) How the acquired behaviour of commercial reef fishes may influence the results obtained from visual censuses. Journal of Experimental Marine Biology and Ecology, 222: 11-30. 
Kulbicki M, Sarramegna S (1999) Comparison of density estimates derived from strip transect and distance sampling for underwater visual censuses: a case study of Chaetodontidae and Pomacanthidae. Aquatic Living Resources, 12: 315-325.

Lajeunesse MJ (2011) On the meta-analysis of response ratios for studies with correlated and multi-group designs. Ecology, 92: 2049-2055.

Lambert DM (2005) Estimation of annual and semi-annual survival of adult female blue crabs and assessment of the effectiveness of the Virginia blue crab sanctuary using tagreturn methodology. A Thesis Presented to The Faculty of the School of Marine Science The College of William and Mary in Virginia In Partial Fulfillment Of the Requirements for the Degree of master of Science.

Langebrake J, Riotte-Lambert L, Osenberg CW, De Leenheer P (2011). Differential movement and movement bias models for marine protected areas. Mathematical Biology, 64(4): 667-96, DOI 10.1007/s00285-011-0407-7.

Langlois T, Chabanet P, Pelletier D, Harvey EH (2006) Baited underwater video for assessing reef fish populations in marine reserves. SPC Fisheries Newsletter, 118: 53-57.

Lauck T, Clark C, Mangel M, Munro GR (1998) Implementing the precautionary principle in fisheries management through marine reserves. Ecological Applications, 8: 72-78.

Leach F (2006) Fishing in pre- European New Zealand. New Zealand Journal of Archaeology Special Publication, and Archaeofauna. ISBN 0-476-00864-6..

Lebreton JD, Burnham KP, Clobert J, Anderson DR (1992) Modelling survival and testing biological hypotheses using marked animals: A unified approach with case studies. Ecological Monographs, 62: 67-118. 
Leleu K, Alban F, Pelletier D, Charbonnel E, Letourneur Y, Boudouresque CF (2012) Fishers' perceptions as indicators of the performance of Marine Protected Areas (MPAs). Marine Policy, 36(2): 414-422.

Le Quesne WJF, Codling EA (2009). Managing mobile species with MPAs: the effects of mobility, larval dispersal, and fishing mortality on closure size. ICES Journal of Marine Science, 66: 122-131.

Lester SE, Halpern BS (2008) Biological responses in marine no-take reserves versus partially protected areas. Marine Ecology Progress Series, 367: 49-56.

Lester SE, Halpern BS, Grorud-Colvert K, Lubchenco J, Ruttenberg BI, Gaines SD, Airamé S, Warner RR (2009) Biological effects within no-take marine reserves: a global synthesis. Marine Ecology Progress Series, 384: 33-46.

Lettink M, Armstrong DP (2003) An introduction to using mark-recapture analysis for monitoring threatened species. Department of Conservation Technical Series, 28A: 5-32.

Lincoln-Smith MP, Pitt KA, Bell JD, Mapstone BD (2006) Using impact assessment methods to determine the effects of a marine reserve on abundances and sizes of valuable tropical invertebrates. Canadian Journal of Fisheries and Aquatic Science, 63: 1251-1266.

Lindholm J, Auster P, Valentine P (2004) Role of a large marine protected area for conserving landscape attributes of sand habitats on Georges Bank (NW Atlantic). Marine Ecology Progress Series, 269: 61-68.

Little R, An H (2004) Robust likelihood-based analysis of multivariate data with missing values. Statistica Sinica, 14: 949-968.

Lopez-Rivera M, Sabat A (2009) Effects of a marine fishery reserve and habitat characteristics in the abundance and demography of the red hind grouper, Epinephelus 
guttatus. Caribbean Journal of Science, 45(2-3): 4348-362.

Lowerre-Barbieri SK, Walters S, Bickford J, Cooper W, Muller R (2013) Site fidelity and reproductive timing at a spotted seatrout spawning aggregation site: individual versus population scale behavior. Marine Ecology Progress Series, 481: 181-197, DOI $10.3354 /$ meps 10224 .

Lubchenco J, Palumbi SR, Gaines SD, Andelman S (2003) Plugging a hole in the ocean: the emerging science of marine reserves. Ecological Applications, 13(Suppl): S3-S7.

Ludwig D, Hilborn R, Walters C (1993) Uncertainty, resource exploitation, and conservation: lessons from history. Science, 260: 17-18.

Mace JT, Johnston AD (1983) Tagging Experiments on Blue Cod (Parapercis colias) in the Marlborough Sounds, New Zealand. New Zealand Journal Marine and Freshwater Research, 17: 207-211.

MacDiarmid AB, Breen PA (1993) Spiny lobster population change in a marine reserve. In: Battershill CN, Schiel DR, Jones GP, Creese RG, MacDiarmid AB (eds.) Proc 2nd Int Temp Reef Ecol Symp. National Institute of Water and Atmospheric Research, Wellington.

McClanahan TR (2000) Recovery of a coral reef keystone predator, Balistapus undulatus, in East African marine parks. Biological Conservation, 94: 191-198.

McClanahan TR (2010) Effects of fisheries closures and gear restrictions on fishing income in a Kenyan coral reef. Conservation Biology, 24: 1519-1528.

McClanahan TR, Kaunda- Arara B (1996) Fishery recovery in a coral- reef marine park and its effects on the adjacent fishery. Conservation Biology, 10: 1187-1199. 
McClanahan TR, Mangi S (2000) Spillover of exploitable fishes from a marine park and its effect on the adjacent fishery. Ecological Applications, 10: 1792-1805.

McCormick MI, Choat JH (1987) Estimating total abundance of a large temperate-reef fish using visual strip-transects. Marine Biology, 96: 469-478.

McCormick ML, Choat JH (1987) Estimating total abundance of a large temperate-reef fish using visual strip transects. Marine Biology, 96: 469-478.

Micheli F, Halpern BS, Botsford LW, Warner RR (2004) Trajectories and correlates of community change in no-take marine reserves. Ecological Applications, 14: 1709-1723.

Malvadkar U, Hastings A (2008) Persistence of mobile species in marine protected areas. Fisheries Research, 91: 69-78.

Mapstone BD, Ayling AM (1993) An investigation of optimum methods and unit sizes for the visual estimation of abundances of some coral reef organisms. Report to the Great Barrier Reef Marine Park Authority, Townsville.

Margalef R (1968) Perspectives in ecological theory. University of Chicago Press, Chicago, IIL. pp. 111.

Marine Reserves Act (1971) N.Z. Government printer, Wellington.

Micheli F, Saenz-Arroyo A, Greenley A, Vazquez L, Espinoza Montes JA, Rossetto M, De Leo GA (2012) Evidence That Marine Reserves Enhance Resilience to Climatic Impacts. PLoS ONE 7(7): e40832, DOI 10.1371/journal.pone.0040832.

Millar RB, Fryer RJ (1999) Estimating the size-selection curves of towed gears, traps, nets and hooks. Reviews in Fish Biology and Fisheries, 9: 89-116. 
Ministry of Fisheries (2008) The state of our fisheries annual report 2008. pp. 51.

Mitchell W (2012) An assessment of community-managed marine reserves in the Central Philippines, and the identification of key variables impacting reserve success. A thesis submitted in partial fulfilment of the requirements for the degree of Master of Science and the Diploma of Imperial College London.

Moffitt EA, Botsford LW, Kaplan DM, O’Farrell MR (2009) Marine reserve networks for species that move within a home range. Ecological Applications, 19: 1835-1847.

Molloy PP, McLean IB, Côté IM (2009) Effects of marine reserve age on fish populations: a global meta-analysis. Journal of Applied Ecology, 46: 743-751.

Mora C, Andréfouët S, Costello MJ, Kranenburg C, Rollo A, Veron J, Gaston KJ, Myers RA (2006) Coral reefs and global network of marine protected areas. Science, 312: 1750-1751.

Mosquera I, Côté IM, Jennings S, Reynolds JD (2000) Conservation benefits of marine reserves for fish populations. Animal Conservation, 3: 321-332.

Munn A (2000) Lobster survey of Piopiotahi Marine Reserve, Milford Sound. Southland Conservancy, Department of Conservation, Wellington.

Murawski SA, Wigley SE, Fogarty MJ, Rago PJ, Mountain DG (2005) Effort distribution and catch patterns adjacent to temperate MPAs. ICES Journal of Marine Science, 62: 1150-1167.

National Research Council (2002) Effect of trawling and dredging on seafloor 
habitat/Commitee on Ecosystem Effects of Fishing: Phase 1- Effect of bottom trawling on seafloor habitats, Ocean Studies Board, Division on Earth and Life Sciences, National Research Council. Washington, DC: National Academy Press.

Navarrete SA, Gelcich S, Castilla JC (2010) Long-term monitoring of coastal ecosystems at Las Cruses, Chile: defining baselines to build ecological literacy in a world of change. Revista Chilena de Historia Natural, 83: 143-157.

Neubauer P, Jensen OP, Hutchings JA. Baum JK (2013). Resilience and recovery of overexploited marine populations. Science, 340: 347-349.

NOAA (2002) Assessment of 20 Northeast groundfish stocks through 2001: a report of the groundfish assessment review meeting (GARM), Northeast Fisheries Science Center, Woods Hole, Massachusetts. pp. 521.

Nursey-Bray M (2011) More than fishy business: A literature review on the benefits of marine parks, University of Adelaide. pp. 39.

Oosthuizen WC, Nico de Bruyn PJ, Bester MN, Girondot M (2009) Cohort and tag-sitespecific tag-loss rates in mark-recapture studies: A southern elephant seal cautionary case. Marine Mammal Science, 26(2): 350-369, DOI 10.1111/j.17487692.2009.00328.x.

Osenberg CW, Sarnelle O, Goldberg DE (1999a) Special feature: meta-analysis in ecology: concepts, statistics, and applications. Ecology, 80 :1103-1104.

Osenberg CW, Sarnelle O, Cooper SD, Holt RD (1999b) Resolving ecological questions through meta-analysis: goals, metrics and models. Ecology, 80: 1105-1117.

Osenberg CW, Shima JS, Miller SL, Stier AC (2011) Assessing the effects of marine protected areas: confounding in space and possible solutions. In: Marine protected areas 
- a multidisciplinary approach, Claudet J (ed). Cambridge University Press, Cambridge. pp. 143-167.

Osenberg CW, Bolker BM, White J-SS, St. Mary CM, Shima JS (2006) Statistical issues and study design in ecological restorations: lessons learned from marine reserves. Foundations of restoration ecology By Donald A. Falk, Margaret A. Palmer, Joy B. Zedler, Society for Ecological Restoration International Island Press Washington, USA. pp. 47.

Pande A (2001) Evaluating biological change in New Zealand marine reserves. Ph.D. Thesis. School of Biological Sciences, Victoria University of Wellington. Wellington, New Zealand.

Pande A (2008) Marine reserve baselines and monitoring: the Wellington south coast. In: The Taputeranga Marine Reserve, Gardner JPA, Bell JJ (eds.).First Edition Publishers, Wellington, New Zealand. pp. 74-85.

Pande A, Gardner JPA (2008) A baseline biological survey of the proposed Taputeranga Marine Reserve (Wellington, New Zealand): spatial and temporal variability along a natural environmental gradient. Aquatic Conservation: Marine and Freshwater Ecosystems, DOI 10.1002/aqc.984.

Pande A, Gardner JPA (2012) The Kapiti Marine Reserve (New Zealand): Spatial and temporal comparisons of multi-species responses after 8 years of protection. New Zealand Journal of Marine and Freshwater Research, 46: 71-89.

Pande A, MacDiarmid AB, Smith PJ, Davidson RJ, Cole RG, Freeman D, Kelly S, Gardner JPA (2008) Marine reserves increase the abundance and size of blue cod and rock lobster. Marine Ecology Progress Series 366: 147-158. 
Pauly D, Christensen V, Dalsgaard J, Froese R, Torres FJ (1998) Fishing down marine food webs. Science, 279: 860-863.

Pelc RA, Warner RR, Gaines SD, Paris CB (2010) Detecting larval export from marine reserves. PNAS, DOI 10.1073/pnas.0907368107.

Pelletier D, Claudet J, Ferraris J, Benedetti-Cecchi L, Garcìa-Charton JA (2008) Models and indicators for assessing conservation and fisheries-related effects of marine protected areas. Canadian Journal of Fisheries and Aquatic Sciences, 65(4): 765-779.

Pelletier D, Leleu K, Mou-Tham G, Guillemot N, \& Chabanet P. (2011). Comparison of visual census and high definition video transects for monitoring coral reef fish assemblages. Fisheries Research, 107: 84-93.

Pelletier D, García-Charton JA, Ferraris J, David G, Thébaud O, Letourneur Y, Claudet J, Amand M, Kulbicki M, Galzin R (2005) Designing indicators for assessing the effects of marine protected areas on coral reef ecosystems: A multidisciplinary standpoint. 18: $15-33$.

Pérez- Rafufa A, Martín E, Marcos C, Zamarro JM, Stobart B, Harmelin- Vivien M, Polti S, Planes S, García- Charton JA, González- Wangüemert M (2008) Modelling spatial and temporal scales for spill-over and biomass exportation from MPAs and their potential for fisheries enhancement. Journal for Nature Conservation, 16(4): 234-255.

Pikitch EK, Santora C, Babcock EA, Bakun A, Bonfil R, Conover DO, Dayton P, Poukakis P, Fluharty D, Heneman B, Houde ED, Link J, Livingstone PA, Mangel M, McAllister MK, Pope J, Sainsbury KJ (2004) Ecosystem-based fishery management. Science 305: 346-7.

Pillans S, Pillans RD, Johnstone RW, Kraft PG, Haywood MDE, Possingham HP (2005) Effects of marine reserve protection on the mud crab Scylla serrata in a sex-biased 
fishery in subtropical Australia. Marine Ecology Progress Series, 295: 201-213.

Pinheiro J, Bates D, DebRoy S, Sarkar D, R Development Core Team (2011). nlme: linear and nonlinear mixed effects models. R package version 3.1-102.

Pollock KH, Nicholls JD, Brownie C, Hines JE (1990) Statistical inference for capturerecapture experiments. Wildlife Monographs, 107: 1-97.

Pollock KH, Hoenig JM, HearnWS, Calingaert B (2001) Tag reporting rate estimation: an evaluation of the high-reward tagging method. North American Journal of Fisheries Management, 21:521-532.

Pomeroy RS, Parks JE, Watson LM (2004) How is your MPA doing? A guidebook of natural and social indicators for evaluating marine protected area management effectiveness. IUCN, Gland, Switzerland and Cambridge, UK.

Pradel R (1996) Utilization of Capture- Mark- Recapture for the study of recruitment and population growth rate. Biometrics, 52: 703-709.

Priede IG, Merrett NR (1996) Estimation of abundance of abyssal demersal fishes: a comparison of data from trawls and baited cameras. Journal of Fish Biology, 49 (Suppl A): 207-216.

Priede I G, Addison S, Bradley S, Bagley P M, Gray P, Yau C, Rolin J-F, Blandin J, Legrand J, Khripounoff A, Vangriesheim A, Cremer A, Witte U, Pfannkuche O, Tengberg A, Hulth S, Hall P, Helder W, Van Weering T, Duineveld G (1998) Autonomous deep-ocean lander vehicles; modular approaches to design and operation. OCEANS '98 Conference Proceeding, Volume:3, DOI 10.1109/OCEANS.1998.726266 
R Core Team (2012) R: A language and environment for statistical computing. R Foundation for Statistical Computing, Vienna, Austria. ISBN 3-900051-07-0, URL http://www.R-project.org/.

Rakitin A, Kramer DL (1996) Effect of a marine reserve on the distribution of coral reef fishes in Barbados. Marine Ecology Progress Series, 131:97-113.

Rapson AM (1956) Biology of the Blue Cod (Parapercis colias Forster) of New Zealand. Unpublished Ph.D. Thesis, Victoria University, Wellington, New Zealand.

Rife AN, Aburto-Oropeza O, Hastings PA, Erisman B, Ballantyne F, Wielgus J, Sala E, Leah G (2013) Long-term effectiveness of a multi-use marine protected area on reef fish assemblages and fisheries landings. Journal of Environmental Management,117: 276286.

Roberts C (2012) Marine Ecology: Reserves Do Have a Key Role in Fisheries. Current Biology, 22(11): R444- R446, DOI 10.1016/j.cub.2012.04.030.

Roberts CM, Hawkins JP (2000) Fully-protected marine reserves: a guide. WWF Endangered Seas Campaign, 1250 24th Street, NW, Washington, DC 20037, USA and Environment Department, University of York, York, YO10 5DD, UK.

Roberts CM, Polunin NVC (1991) Are marine reserves effective in management of coral reef fisheries? Reviews in Fish Biology and Fisheries, 1: 65-91.

Roberts CM, Hawkins JP, Gell FR (2005) The role of marine reserves in achieving sustainable fisheries. Philosophical Transactions of the Royal Society B: Biological Sciences, 360: 123-132. 
Roberts DE, Smith A, Anjani P, Davis AR (1998) Rapid changes in encrusting marine assemblages exposed to anthropogenic point-source pollution: a 'Beyond BACI' approach. Marine Ecology Progress Series, 63: 213-224.

Roberts CM, Andelman S, Branch G, Bustamante RH, Castilla JC, Dugan JE, Halpern BS, Lafferty KD, Leslie H, Lubchenco J, McCardle D, Possingham HP, Ruckelshaus M, Warner RR (2003). Ecological criteria for evaluating candidate sites for marine reserves. Ecological Applications, 13(1): S199-S214.

Rodwell LD, Barbier EB, Roberts CM, McClanahan TR (2003) The importance of habitat quality for marine reserve-fishery linkages. Canadian Journal of Fisheries and Aquatic Sciences, 60: 171-181.

Rowe S (2001) Movement and harvesting mortality of American lobsters (Homarus americanus) tagged inside and outside no-take reserves in Bonavista Bay, Newfoundland. Canadian Journal of Fisheries and Aquatic Science, 58: 1336-1346.

Russ GR (2002) Yet another review of marine reserves as reef fisheries management tools. In: Coral reef fishes: dynamics and diversity in a complex ecosystem, Sale PF (ed). Academic Press, San Diego, California. . pp. 421-443.

Russ GR, Alcala AC (1996) Do marine reserves export adult fish biomass? Evidence from Apo Island, central Philippines. Marine Ecology Progress Series, 132: 1-9.

Russ GR, Alcala AC (2004) Marine reserves: long-term protection is required for full recovery of predatory fish populations. Oecologia, 138: 622-62.7

Russ GR, Alcala AC (2011) Enhanced biodiversity beyond marine reserve boundaries: the cup spillith over. Ecological Applications, 21(1): 241-50.

Russ GR, Alcala AC, Maypa AP (2003) Spillover from marine reserves: the case of 
Naso vlamingii at Apo Island, the Philippines. Marine Ecology Progress Series, 264: 1520.

Russ GR, Stockwell B, Alcala AC (2005) Inferring versus measuring rates of recovery in no-take marine reserves. Marine Ecology Progress Series, 292 (2): 1-12.

Russ GR, Alcalá AC, Maypa AP, Calumpong HP, White AT (2004) Marine reserve benefits local fisheries. Ecological Applications, 14(2): 597-606.

Sainte-Marie B, Hargrave BT (1987) Estimation of scavenger abundance and distance of attraction to bait. Marine Biology, 94: 431-443.

Sala E, Costello C, Dougherty D, Heal G, Kelleher K, Murray JH, Rosenberg AA, Sumaila R (2013) A General Business Model for Marine Reserves. PLoS ONE, 8 (4): e58799, DOI 10.1371/journal.pone.0058799.

Sale PF, Douglas WA (1981) Precision and accuracy of visual census technique for fish assemblages on coral patch reefs. Environmental Biology of Fishes, 6: 333-339.

Sale PF, Sharp BJ (1983) Correction for bias in visual transect censuses of coral reef fishes. Coral Reefs, 2: 37-42.

Sale PF, Cowen RK, Danilowicz BS, Jones GP, Kritzer JP, Lindeman KC, Planes S, Polunin NVC, Russ GR, Sadovy YJ, Steneck RS (2005) Critical science gaps impede use of no- take fishery reserves. Trends in Ecology and Evolution, 20(2): 74-79.

Samoilys MA, Martin-Smith KM, Giles BG, Cabrera B, Anticamara JA, Brunio EO, Vincent ACJ (2007) Effectiveness of five small Philippines' coral reef reserves for fish populations depends on site-specific factors, particularly enforcement history. Biological Conservation, 136: 584-601. 
Sánchez Lizaso JL, Goñi R, Reñones O, García Charton JA, Galzin R, Bayle JT, Sánchez Jerez P, Pérez Ruzafa A Ramos AA (2000) Density dependence in marine protected populations: a review. Environmental Conservation, 27 (2): 144-158.

Sanchirico J (2000) Marine protected areas: can they revitalize our nation's fisheries? Resources, 140: 6-9.

Shears NT, Babcock RC (2003) Continuing trophic cascade effects after 25 years of notake marine reserve protection. Marine Ecology Progress Series, 246: 1-16.

Shears NT, Graceb RV, Usmar NR, Kerr V, Babcock RC (2006). Long-term trends in lobster populations in a partially protected vs. no-take marine park. Biological Conservation, 132: 222-231.

Sladek Nowlis J, Roberts CM (1997) You can have your fish and eat it, too: theoretical approaches to marine reserve design. Proceedings of the 8th International Coral Reef Symposium, 2: 1907-1910.

Smith ED (2001) Lobster survey of Te Awaatu Marine Reserve, Doubtful Sound. Southland Conservancy, Department of Conservation, Wellington.

Smith ED (2002) Lobster survey of Piopiotahi Marine Reserve, Milford Sound. Southland Conservancy, Department of Conservation, $\mathrm{Te}$ Anau. Available at www.doc.govt.nz.

Smith MD, Lynham J, Sanchirico JN, Wilson JA (2010) Political economy of marine reserves: Understanding the role of opportunity costs. PNAS, 107 (43): 18300-18305.

St. John J, Russ GR, Gladstone W (1990) Accuracy and bias of visual estimates of numbers, size structure and biomass of a coral reef fish. Marine Ecology Progress 
Series, 64: 253-262.

Stanley DR, Wilson CA (1995) Effect of scuba divers on fish density and target strength estimates from stationary dual-beam hydroacoustics. Transactions of the American Fisheries Society, 124: 946-949.

Starr 2005 Species Movements and Implications for Marine Protected Area (MPA) Network Design. MLPA Central Coast Regional Stakeholder Group Meeting Handout \#4.

Steward RA, MacDiarmid AB (2003) A survey of Kaimoana at Kapiti Island 1999 and 2000. NIWA Project: DOC 03402. A report prepared for: Department of Conservation. Available at www.doct.govt.nz.

Stewart GB, Côté IM, Kaiser MJ, Halpern BS, Lester SE, Bayliss HR, Mengersen K, Pullin AS (2008). Are marine protected areas effective tools for sustainable fisheries management? I. Biodiversity impact of marine reserves in temperate zones. Systematic Review No. 23. Collaboration for Environmental Evidence.

Stewart-Oaten A (1996a). Goals in environmental monitoring. In: Detecting ecological impacts: Concepts and applications in coastal habitats, Schmitt RJ, Osenberg CW (eds.). Academic Press, San Diego. pp. 17-27.

Stewart-Oaten A (1996b) Problems in the analysis of environmental monitoring data. In: Detecting ecological impacts: Concepts and applications in coastal habitats, Schmitt RJ, Osenberg CW (eds.). Academic Press, San Diego. pp. 109-131.

Stewart-Oaten A, Murdoch WW, Parker KR (1986). Environmental impact assessment:"pseudoreplication" in time? Ecology, 67: 929-940. 
Stobart B, Warwick R, González C, Mallol S, Díaz D, Reñones O, Goñi R (2009) Longterm and spillover effects of a marine protected area on an exploited fish community. Marine Ecology Progress Series, 384: 47-60.

Stobart B, García-Charton JA, Espejo C, Rochel E, Goñi R , Reñones O, Herrero A, Crec'hriou R, Polti S, Marcos C, Planes S, Pérez-Ruzafa A (2007) A baited underwater video technique to assess shallow-water Mediterranean fish assemblages: methodological evaluation. Journal of Experimental Marine Biology and Ecology, 345: 158- 174.

Struthers C (2004) Monitoring of blue cod (Parapercis colias) at Kapiti Marine Reserve, New Zealand: a comparison of survey methodologies. MSc thesis, Victoria University of Wellington.

Sturges HA (1926) "The choice of a class interval". Journal of the American Statistical Association. 21 (153) 65-66.

Sutherland WJ, Gill JA, Norris K (2002) Density- dependent dispersal in animals: concepts, evidence, mechanisms and consequences. In: Dispersal ecology. Bullock JM, Kenward RE, Hails RS (eds.). Blackwell Publishing, Malden, Massachusetts, USA. pp. $135-151$.

Taylor RB, Anderson MJ, Egli D, Willis TJ (2003) Cape Rodney to Okakari Point Marine Reserve fish monitoring 2003: Final Report. A report prepared for: Department of Conservation. Available at www.doct.govt.nz.

Taylor RB, Anderson MJ, Egli D, Usmar N, Willis TJ (2005) Cape Rodney to Okakari Point Marine Reserve fish monitoring 2005: final report. Department of Conservation, Auckland. Available at http://www.doc.govt.nz. 
Tewfik A, Bene C (2003) Effects of natural barriers on the spillover of a marine mollusc: implications for fisheries reserves. Aquatic Conservation: Marine and Freshwater Ecosystems, 13: 473-488.

Thompson AA, Mapstone BD (1997) Observer effect and training in underwater visual surveys of reef fishes. Marine Ecology Progress Series, 154: 53-63.

Toller W, Debrot AO, Vermeij MJA, Hoetjes PC (2010) Reef Fishes of Saba Bank, Netherlands Antilles: Assemblage Structure across a Gradient of Habitat Types. PLoS ONE 5(5): e9207, DOI:10.1371/journal.pone.0009207.

Topping DT, Lowe CG, Caselle JE (2005) Home range and habitat utilization of adult California sheephead Semicossyphus pulcher (Labridae), in a temperate no-take marine reserve. Marine Biology, 147: 301-311.

Topping, D.T., Lowe, C.G., Caselle, J.E., 2006 Site fidelity and seasonal movement patterns of adult California sheephead, Semicossyphus pulcher (Labridae), ascertained via long-term acoustic monitoring. Marine Ecology Progress Series, 326: 257-267.

Tremain DM, Harnden CW, Adams DH (2004) Multidirectional movements of sportfish species between an estuarine no-take zone and surrounding waters of the Indian River Lagoon, Florida. Fishery Bulletin, 102: 533-544.

Tupper MH (2007) Spillover of commercially valuable reef fishes from marine protected areas in Guam, Micronesia. Fishery Bulletin, 105: 527-537.

Underwood AJ (1991). Beyond BACI: experimental designs for detecting human environmental impacts on temporal variations in natural populations. Australian Journal of Marine and Freshwater Research, 42: 569-87. 
Vandeperre F, Higgins R, Sanchez Meca J, Maynou F, Goñi R, Martin-Sosa P, Perez Ruzafa A, Afonso P, Bertocci I, Crec'hriou R, D'Anna G, Dimech M, Dorta C, Esparza O, Falcon JM, Forcada A, Guala I, Le Direach L, Marcos C, Ojeda-Martinez C, Pipitone C, Schembri PJ, Stelzenmuller V, Stobart B, Serrao Santos R (2011) Effects of no-take area size and age of marine protected areas on fisheries yields: a meta-analytical approach. Fish Fisheries, 12: 412-426.

Vié J-C, Hilton- Taylor C, Stuart SN (2009) Wildlife in a Changing World -An Analysis of the 2008 IUCN Red List of Threatened Species. Gland, Switzerland.pp. 155.

Walls K (2008) Marine reserves: the need is now, the benefits are for the future. Chapter Three in Gardner JPA, Bell JJ (editors). The Taputeranga Marine Reserve. First Edition Publishers, Wellington, New Zealand. pp. 53-73.

Ward-Paige C, Flemming JM, Lotze HK (2010) Overestimating fish counts by non instantaneous visual censuses: consequences for population and community descriptions. PLoS ONE, 5(7): e11722, DOI: 10.1371/journal.pone.0011722

Watson DL, Harvey ES (2007) Behaviour of temperate and sub-tropical reef fishes towards a stationary SCUBA diver. Marine and Freshwater Behaviour and Physiology, 40: 85-103.

Watson RA, Carlos GM, Samoilys MA (1995) Bias introduced by the non-random movement of fish in visual transect surveys. Ecological Modelling, 77: 205-214.

Watson DL, Harvey ES, Anderson MJ, Kendrick GA (2005) A comparison of temperate reef fish assemblages recorded by three underwater stereo-video techniques. Marine Biology, 148: 415-425. 
Westera M, Lavery P, Hyndes G (2003) Differences in recreationally targeted fishes between protected and fished areas of a coral reef marine park. Journal of Experimental Marine Biology and Ecology, 294: 145-168.

White GC, Burnham KP (1999) Program MARK: Survival estimation from populations of marked animals. Bird Study, 46: S1, S120-S139, DOI 10.1080/00063659909477239.

Willians M (2003) Lobster survey, Te Awaatu (The Gut) Marine Reserve, Doubtfu Sound. Southland Conservancy, Department of Conservation, Wellington. http://doc.govt.nz.

Willis TJ (2001) Visual census methods underestimate density and diversity of cryptic reef fishes. Journal of Fish Biology, 59: 1408-1411.

Willis TJ, Babcock RC (2000) A baited underwater video system for the determination of relative density of carnivorous reef fish. Marine and Freshwater Research, 51: 755763.

Willis T J, Millar RB, Babcock RC (2000) Detection of spatial variability in relative density of fishes: comparison of visual census, angling, and baited underwater video. Marine Ecology Progress Series, 198: 249-260.

Willis TJ, Parsons DM, Babcock RC (2001) Evidence for long-term site fidelity of snapper (Pagrus auratus) within a marine reserve. New Zealand Journal of Marine and Freshwater Research, 35: 581-590.

Willis TJ, Millar RB, Babcock RC (2003a) Protection of exploited fish in temperate regions: high density and biomass of snapper Pagrus auratus (Sparidae) in northern New Zealand marine reserves. Journal of Applied Ecology, 40: 214-227. 
Willis TJ, Millar RB, Babcock RC, Tolimieri N (2003b) Burdens of evidence and the benefits of marine reserves: putting Descartes before des horse? Environmental Conservation, 30: 97-103.

Wilson JR, Valencia SR, Kay MC, Lenihan HS (2013) Integration of no-take marine reserves in the assessment of data-limited fisheries. Conservation Letters, DOI: 10.1111/con1.12073.

Worm B, Barbier EB, Beaumont N, Duffy JE, Folke C, Halpern BS, Jackson JBC, Lotze HK, Micheli F, Palumbi SR, Sala E, Selkoe KA, Stachowicz JJ, Watson R (2006) Impacts on biodiversity loss on ocean ecosystem services. Science, 314: 787-790.

Worm B, Hilborn R, Baum JK, Branch TA, Collie JS, Costello C, Fogarty MJ, Fulton EA, Hutchings JA, Jennings S, Jensen OP, Lotze HK, Mace PM, McClanahan TR, Minto C, Palumbi SR, Parma AM, Ricard D, Rosenberg AA, Watson R, Zeller D (2009) Rebuilding global fisheries. Science, 325: 578-583, DOI 10.1126/science. 1173146.

Zeller DC, Russ GR (1998) Marine reserves: patterns of adult movement of the coral trout (Plectropomus leopardus) (Serranidae). Canadian Journal of Fisheries and Aquatic Science, 55: 917-924.

Zeller DC, Stoute SL, Russ GR (2003) Movements of reef fishes across marine reserve boundaries: effects of manipulating a density gradient. Marine Ecology Progress Series, 254: $269-280$. 


\section{Appendix A}

Díaz- Guisado et al. (2012). Comparison of Methodologies to Quantify the Effects of age and size of Marine Reserves on the Density and Size of Targeted Species. Aquatic Biology. 14: 185-200. 


\title{
Comparison of methodologies to quantify the effects of age and area of marine reserves on the density and size of targeted species
}

\author{
Daniela Diaz Guisado ${ }^{1}$, Russell G. Cole ${ }^{2}$, Robert J. Davidson ${ }^{3}$, Debbie J. Freeman ${ }^{4}$, \\ Shane Kelly ${ }^{5}$, Alison Macdiarmid ${ }^{6}$, Anjali Pande ${ }^{1,7}$, Rob Stewart ${ }^{6}$, Carl Struthers ${ }^{1,8}$, \\ James J. Bell ${ }^{1}$, Jonathan P. A. Gardner ${ }^{1, *}$ \\ ${ }^{1}$ Centre for Marine Environmental \& Economic Research, School of Biological Sciences, Victoria University of Wellington, \\ Wellington 6140, New Zealand \\ ${ }^{2}$ National Institute of Water and Atmospheric Research (NIWA), Nelson 7010, New Zealand \\ ${ }^{3}$ Davidson Environmental Ltd, PO Box 958, Nelson 7040, New Zealand \\ ${ }^{4}$ Department of Conservation, Research and Development Group, Wellington 6143, New Zealand \\ ${ }^{5}$ Coastal and Aquatic Systems Ltd, Clevedon, Auckland 2248, New Zealand \\ ${ }^{6}$ National Institute of Water and Atmospheric Research (NIWA), Wellington 6021, New Zealand \\ ${ }^{7}$ Present address: Investigation and Diagnostic Centre, Biosecurity NZ, Ministry of Agriculture and Forestry, PO Box 40742 , \\ Wallaceville 0000, New Zealand \\ ${ }^{8}$ Present address: Museum of New Zealand Te Papa Tongarewa, Wellington 6011, New Zealand
}

\begin{abstract}
We quantified the biological response of 2 exploited species to marine reserve (MR) protection by comparing meta-analysis results based on response ratio (RR) and Hedges' $g$ statistics. To determine the effect of MR area and age on biological responses, a RR analysis was performed on density and size data for both species from sites inside versus outside 13 MRs. Most MRs supported a greater density of larger individuals than unprotected areas. Linear and non-linear plots of MR age and area with respect to species-specific density and size were used to quantify the trajectories of the responses. In the RR meta-analysis but not in the Hedges' $g$ meta-analysis, MR age explained significant variation in the density and size of both species, while no effect of MR area was detected in either analysis. Comparison of the performance of RR with that of Hedges' $g$ revealed no overall evidence of a relationship between them, probably because the RR does not include an estimate of variance, whereas the Hedges' $g$ analysis does. While RR analysis is an appropriate alternative to Hedges' $g$ statistic meta-analysis assessments of MR effectiveness because of its ease of use and interpretation, we recommend that future RR analyses include both an estimate of variance and a test for 'effect size'. Finally, we recommend that research be aimed at determining why different MRs produce different biological responses - that is, address why significant 'effect size' exists.
\end{abstract}

KEY WORDS: Response ratio $\cdot$ Meta-analysis $\cdot$ Marine conservation $\cdot$ Biological response $\cdot$ Marine management

Resale or republication not permitted without written consent of the publisher

\section{INTRODUCTION}

While no-take marine reserves (MRs) have become a highly advocated form of marine conservation, there is widespread recognition of the need to quantify the conservation benefits they provide (Allison et al. 1998, Halpern \& Warner 2002, Pande et al. 2008,
Botsford et al. 2009). Because MRs in different parts of the world are set up and managed for different purposes (e.g. fisheries enhancement, biodiversity protection, scientific research), the extent and direction of their biological outcomes may vary considerably. However, several recent reviews that have evaluated results from separate studies to quantify 
MR outcomes suggest that many species, especially those that are actively targeted by fisheries, increase in abundance and/or size inside MRs (Jones et al. 1992, Mosquera et al. 2000, Côté et al. 2001, Halpern \& Warner 2002, Halpern 2003, Lester et al. 2009, Pande et al. 2008).

The first MR in New Zealand (NZ) was created in 1975, and as of late 2011 there are 34 no-take MRs protecting $\sim 7.6 \%$ of NZ's territorial waters (New Zealand Department of Conservation http://doc. govt.nz/conservation/marine-and-coastal/marineprotecteted-areas). Partially or well-established ecological monitoring programmes exist in many of these MRs. However, despite a long lead-in time for the establishment of each MR, very few baseline data sets have been gathered to allow 'before versus after' comparisons. Such comparisons are a recommended measure for any restoration activity, because by sampling at one or more control sites and the impact site both before and after the intervention, they identify spatial and temporal variation (Osenberg et al. 1999). Due to the lack of baseline data, historical assessments of the efficacy of MRs are usually not possible (but see Pande \& Gardner 2009). Consequently, monitoring typically involves the comparison of sites inside MRs with non-MR 'control' sites (i.e. 'inside versus outside' comparisons). Although some monitoring results have shown increases in the mean size and/or mean density of some species at MR sites compared with unprotected sites, it is still difficult to assess the possible conservation benefits of MRs based on individual studies because the generality of response cannot be determined from single MRs (Kelly et al. 2000, Willans 2003, Pande et al. 2008, Davidson et al. 2009). Nonetheless, the aim of the NZ government is to protect $10 \%$ of the coastal marine environment via the establishment of Marine Protected Areas (MPAs, defined here as any form of protection and not just notake MRs) to assure the maintenance and/or recovery of biological diversity at the habitat and ecosystem level. A key component of this strategy is to monitor MPAs to assess their effectiveness at achieving biodiversity conservation objectives (Department of Conservation and Ministry of Fisheries 2005).

A variety of statistical approaches can be used to quantify MR effects. Commonly, meta-analysis is used to combine the results of multiple independent studies, all of which have tested the same hypothesis. This approach determines if enough evidence exists in the combined studies to detect an 'overall' outcome. This statistically rigorous approach moves beyond simple 'vote counting' or narrative review because it is a quantitative synthesis that allows for objective appraisal of the evidence (Arnqvist \& Wooster 1995, Egger et al. 1997, Osenberg et al. 1999). Perhaps because of its lack of familiarity to marine scientists or because of its statistical complexity (e.g. Berman \& Parker 2002), or because of the lack of accurate error estimates in the studies being reviewed, few meta-analyses of this type have been conducted for MRs or MPAs. However, those that have been conducted have reported that MRs support more and/or larger individuals of many species than neighbouring unprotected areas (e.g. Mosquera et al. 2000, Côté et al. 2001, Pande et al. 2008).

The most frequently employed effect-size metric in meta-analysis (Hedges' $g$ ) requires that variances, as well as means, are known, but in fact this is often not the case from published reports (Mosquera et al. 2000). From this information the magnitude and significance of an overall effect can be calculated across all studies. The overall effect size is calculated from the effect size of each individual study. An important step in this meta-analysis is the calculation of effectsize homogeneity across all studies. If the test fails, then the meta-analysis stops at this stage due to the significant difference among the effects that individual MRs have on the biological index because it is inappropriate to combine 'heterogeneous' data from the separate studies (e.g. Pande et al. 2008). An alternative approach to Hedges' statistic meta-analysis is the response ratio (RR) meta-analysis that has been used widely to describe the effects of MRs. This method does not require knowledge of variances because it quantifies the proportional change resulting from MR implementation by measuring the relative differences in a biological response (e.g. size or density) inside versus outside the MR (Adams et al. 1997, Goldberg et al. 1999, Hedges et al. 1999, Gates 2002). While it is possible to test RRs for homogeneity of responses analogous to the effect-size test described above (Mosquera et al. 2000), very few analyses employing RR do so.

Recent studies by Halpern \& Warner (2002), Halpern (2003), Micheli et al. (2004), Lester et al. (2009) and Molloy et al. (2009) all calculated RRs from multiple MRs worldwide to evaluate effects of protection on many invertebrate and fish species. They found consistent positive effects of MRs, suggesting that MRs achieve their stated or implicit conservation goals. Pande et al. (2008) employed the Hedges' $g$ index to assess the response of blue cod and rock lobster to full no-take MR protection in NZ. These authors also reported consistent positive effects of MRs. Importantly, both forms of metaanalysis demonstrate that marine protection can 
increase species abundance and size, particularly for species targeted by fishers. They also demonstrate that the response to MR protection may be independent of MR area and age, and it is usually dependent on the species being analysed. Despite the burgeoning publication of papers that use results from multiple studies to test hypotheses about biological change resulting from marine protection, there is presently no standard statistical approach for such studies. Having previously conducted a Hedges' statistic meta-analysis (Pande et al. 2008), we were keen to address this point.

The aim of the present study was twofold: (1) to compare the efficacy of the commonly used RR analysis against the less commonly used meta-analysis based on Hedges' $g$ to determine ease of use and comparability of results (compared to Pande et al. 2008); and (2) to quantify, using the RR analysis, the biological response of 2 heavily exploited species to MR protection along a north-south latitudinal gradient of $\sim 11$ degrees $(\sim 1250 \mathrm{~km})$ in New Zealand.

\section{METHODS}

Our analyses combined published and unpublished data from 13 New Zealand MRs (Fig. 1), each of which was sampled at different times over a maximum time period of $\sim 30 \mathrm{yr}$ (Table 1 ). We selected 2 widely distributed species in New Zealand for this analysis; blue cod Parapercis colias and rock lobster Jasus edwardsii. Both species are heavily exploited and have been monitored in a number of MRs. Comparable data for other NZ species do not exist. For both species, we extracted density (no. ind. $\mathrm{m}^{-2}$ ) and

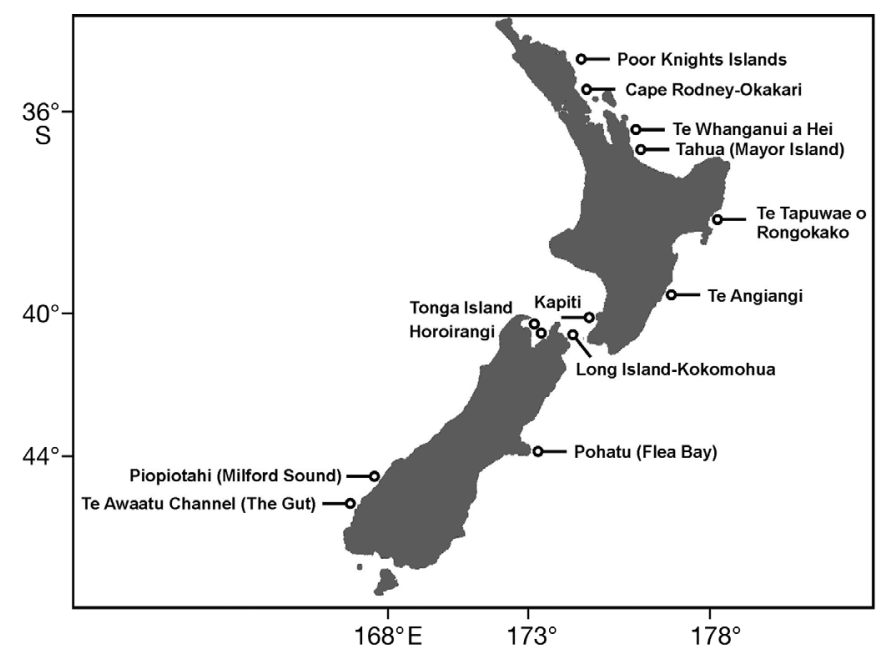

Fig. 1. Location of New Zealand marine reserves included in the response ratio (RR) analysis size $(\mathrm{cm})$ data from studies using only an Underwater Visual Census methodology (McCormick \& Choat 1987). The blue cod analysis used data from 8 MRs, including 20 separate studies (density: $8 \mathrm{MRs}$; size: 5 MRs). The rock lobster analysis used data from 13 MRs, including 24 separate studies (density: $13 \mathrm{MRs}$; size: $12 \mathrm{MRs}$ ): see Table 1 for details. All studies included measurements from inside MRs and from at least one control (fished) area outside the same reserve and in close proximity to it. This is the same data set used by Pande et al. (2008) for their Hedges' $g$ meta-analysis but with the addition of new survey periods and new sites (blue cod: 8 versus $5 \mathrm{MRs}$; rock lobster: 13 versus $10 \mathrm{MRs}$ ). All original studies included in our analyses were specifically conducted for the purposes of monitoring either blue cod or rock lobsters, and as such all were conducted in habitat appropriate for each taxon. We note that in an ideal world the MR sites will be the same in all respects as the nearby control sites. However, we also note that spillover from the MR into the control region may actually reduce the chance of seeing a significant difference between the MR(s) and the control(s). Thus, analyses of this type may tend to be conservative. However, the spillover effect may be counteracted by other factors, such as increased fishing effort in the control region (i.e. displacement of fishing activity from the MR to regions just outside). Thus, the spillover effect and the displaced fishing effort may balance out. Because of the absence of knowledge about site-specific spillover and displaced fishing activity, analytical consideration of such matters is not possible in any meta-analysis. While the number of sites surveyed, the duration (total no. of yr) of each study, and the timing of surveys all varied among studies, all studies were given equal weight in our analyses because there was no a priori reason to provide greater weight to any one study or group of studies than to the rest.

Consistent with their use elsewhere (e.g. Halpern \& Warner 2002, Halpern 2003, Lester et al. 2009), response ratios (RRs) were calculated by dividing values of mean density or mean size inside the reserve by values from control sites. RRs $>1$ indicate individuals are bigger or more abundant inside reserves relative to control sites. RRs are site-specific and therefore reflect local conditions. For example, where increased growth rates of blue cod in colder waters may be expected, this will be true of the coldwater MR site and its neighbouring fished site. Thus, the RR calculated for this site may be compared directly with the RR calculated from a northern, warm water site because both tell us about the mag- 
Table 1. Marine reserve variables (area, year of establishment, age) and species-specific data sets used in the analysis

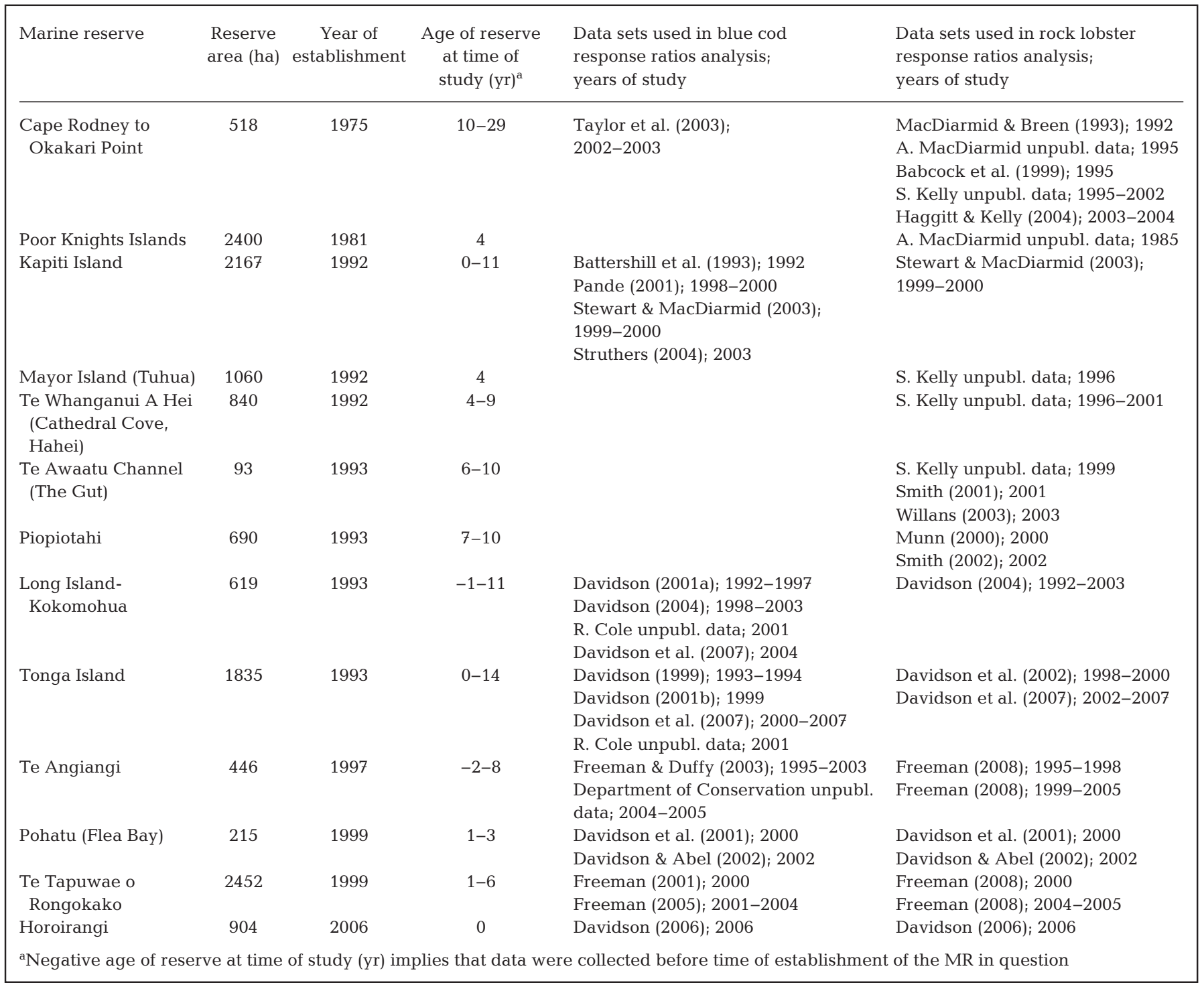

nitude of the local response. However, the RR values do not provide information about actual fish size or density inside versus outside the MR, or about actual fish size or density when comparing between cold and warm sites. From this survey data, with associated RR values for each year of each survey, we generated 2 separate data sets for statistical analysis, as described below.

First, for all data sets (blue cod size and density, rock lobster size and density) we identified the single most recent survey regardless of its date (and its associated RR value) per site. We call this the $R_{\text {recent }}$ data set because it contains a single value per marine reserve based on only the most recent survey. This approach gives no weighting or consideration to ear- lier survey data-that is, the history of change is not considered-with the result that the data set may be strongly influenced by one unusual data point for any one MR.

Second, for all data sets individual RR values were calculated for each year of each survey for each MR. The strength of this approach is that individual MRs contributed many year-specific data points reflecting their history of change. The weakness is that such data points are not independent in a statistical sense. Non-independence of data in meta-analyses may be a problem (e.g. Mosquera et al. 2000, Gates 2002, Pande et al. 2008), and for this approach many of the points within this data set are not independent. Nonetheless, this approach is informative and we 
employ it here to better understand the responses of blue cod and rock lobster to protection and the effect of MR age and size on these species. We call this approach $\mathrm{RR}_{\max }$ because it provides the maximum number of data points per analysis. For only the $\mathrm{RR}_{\max }$ analyses we separated the MRs into 2 groups to test specific patterns, where size of the data set permitted. Based on area we recognised small and large MRs ( $\leq$ or $>1000$ ha), whilst based on age we recognised young and old reserves $(\leq$ or $>10 \mathrm{yr}$ ). While these distinctions are somewhat arbitrary there is some theoretical underpinning to support these cut off points in terms of the average area and age of NZ MRs, the rate of biological response recorded from various regions, and the life history characteristics of the species in question (Halpern \& Warner 2002, Halpern 2003, Micheli et al. 2004, Pande et al. 2008, Lester et al. 2009, Molloy et al. 2009). Importantly the divisions at $10 \mathrm{yr}$ and 1000 ha allow for sufficient data points for analysis of young versus old and small versus large data sets, and minimise the bias caused by having data from only 1 or 2 older (larger) and well monitored MRs.

The 2 RR indices are appropriate for answering different questions and their applicability depends on the type of data available. $R_{\text {recent }}$ is appropriate for assessment of overall reserve effect, whereas $R R_{\max }$ is appropriate for assessment of temporal changes within reserves. Because we are interested in both aspects (overall reserve effect on blue cod and rock lobsters and temporal change), we employ both indices here.

Following Mosquera et al. (2000), we tested to determine if all biological responses were homogeneous using the homogeneity statistic of Hedges \& Olkin (1985). In all instances, the test statistic was non-significant ( $p>0.05)$, indicating that each data set was homogeneous, and that no single MR had an undue effect.

To evaluate the effects of MR area and age on biological response for both data sets, $R R$ values were plotted against MR area (ha) and age (yr) (Table 1). Linear and non-linear functions were fitted to species-specific plots to determine the best fits based on correlation coefficient values (SlideWrite Plus v.3, Advanced Graphics). This approach permits the identification of the best-fit relationship without a priori knowledge of the trajectory of the relationship being examined, or without imposing assumptions about the nature of the response. We used this approach as an exploratory tool to see if a pattern exists within our data that may help us to better understand the generalised trajectory of response for the 2 different species. As a third and final approach to better understand the relationships between $\mathrm{RR}$ and MR age and MR area for both data sets, we employed the Spearman's rank correlation analysis (1-tailed tests) to test the statistical basis of the linear relationship between RR and MR area and age. We employed this analysis because it is a non-parametric (rank) test of a linear relationship with minimal assumptions about data distribution. This analysis was conducted using the Statistica software (v7.1 StatSoft Software). In all cases where fitted lines/curves were highly leveraged by a single point, we removed that point from the data set and re-fitted the line/curve to re-test for significance. Finally, to compare directly between the RR and Hedges' approaches, we plotted $R_{\text {recent }}$ against Hedges' $g$ for all comparisons where such data exist. We used Pearson's correlation coefficient to test for a linear relationship between the 2 different indices.

\section{RESULTS}

In most instances the values for both RR indices for both species were $>1.0$, indicating greater mean size or density inside the MR than outside $\left(R_{\text {recent }}\right.$ Fig. 2; $\mathrm{RR}_{\max }$ : Fig. 3). Spearman's rank correlation analyses are presented as rank-rank plots. Because of the different number of data points per analysis (see degrees of freedom columns, Tables $2 \& 3$ ) the 2 RR indices have different powers to detect significance.

\section{$\mathbf{R R}_{\text {recent }}$ analyses for blue cod}

The relationship between blue cod density and MR age was statistically significant (Fig. 2B, Table 2) for all 3 tests. The best fit was observed for the nonlinear model, but the 2 linear models both had $\mathrm{R}$ values similar to that reported for the non-linear model. Removal of one outlier (data point at $28 \mathrm{yr}$ ) removed the significant nature of the relationship for both the parametric and non-parametric linear fits, but increased the significance of the non-linear fit. All other analyses of $\mathrm{RR}_{\text {recent }}$ were not statistically significant (Table 2).

\section{$\mathbf{R R}_{\text {max }}$ analyses for blue cod}

There was a statistically significant positive relationship between MR age and the density (Fig. 3B) 

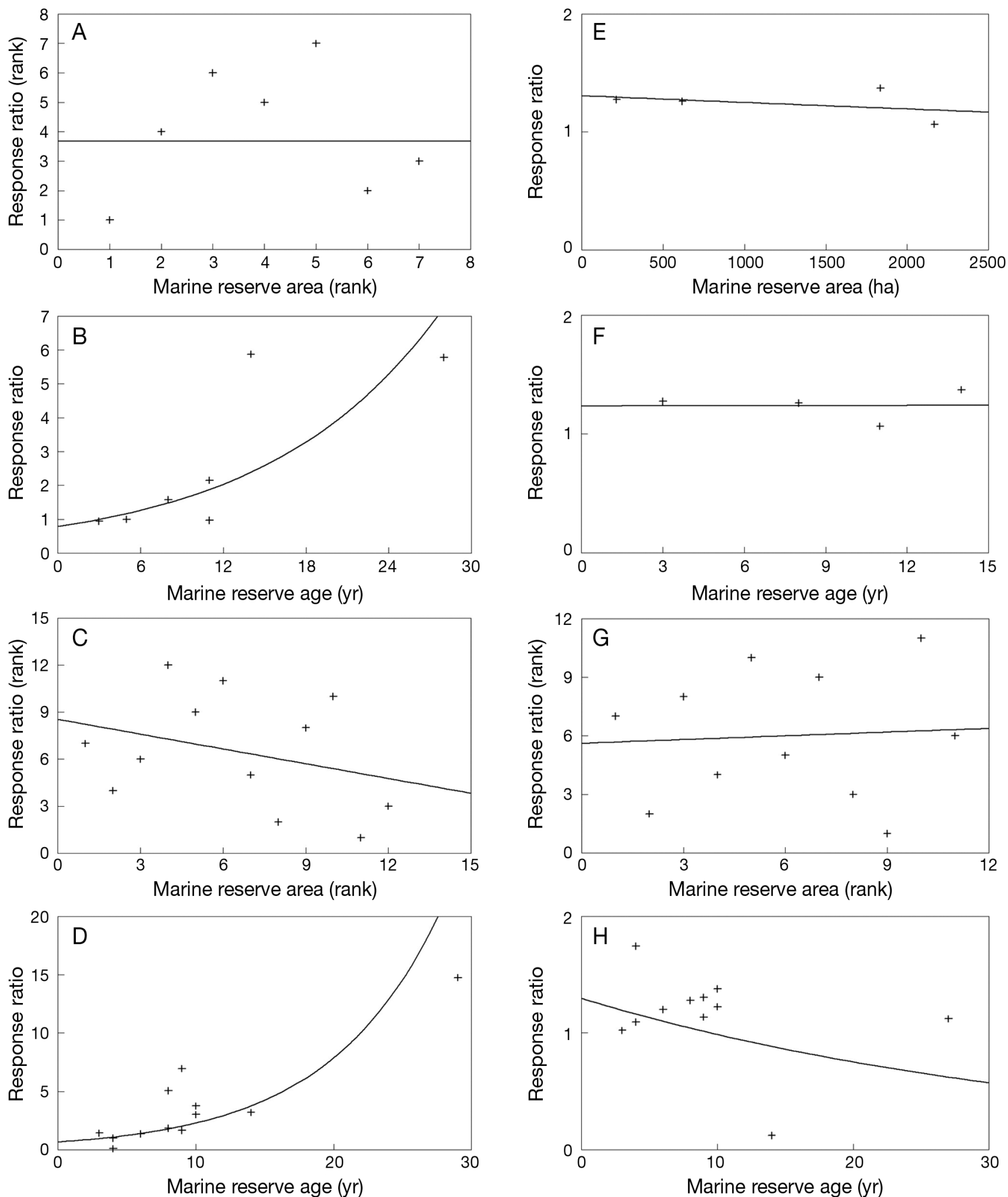

Fig. 2. Best-fit relationship for the scatter plot of response ratio values $\left(R_{\text {recent }}\right)$ as a function of marine reserve (MR) area and $\mathrm{MR}$ age. $\mathrm{RR}_{\text {recent }}$ is calculated from the single most recent survey, regardless of how many previous surveys have been conducted, at any one site. (A) Blue cod density as a function MR area ( $>$ > 0.05) and (B) age (p < 0.05). (C) Rock lobster density as a function of MR area $(p>0.05)$ and $(D)$ age $(p<0.05)$. (E) Blue cod size as a function of MR area $(p>0.05)$ and $(F)$ MR age $(p>0.05) .(G)$ Rock lobster size as a function of MR area $(p>0.05)$ and $(H)$ age $(p>0.05)$ 

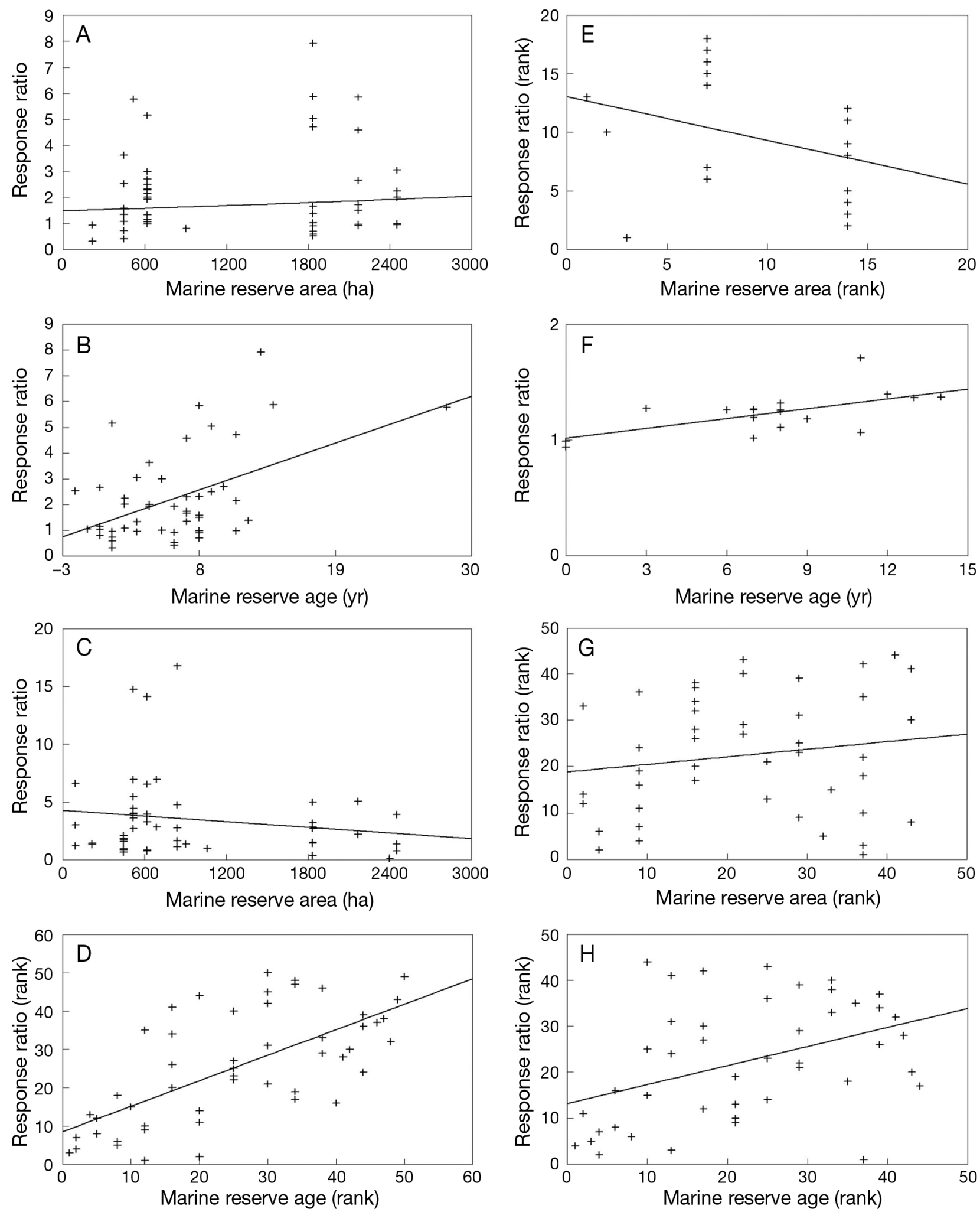

Fig. 3. Best-fit relationship for the scatter plot of response ratio values $\left(R_{\max }\right)$ as a function of marine reserve (MR) area and $M R$ age. $R R_{\max }$ is calculated as an average value across all surveys that have been conducted for any one site. (A) Blue cod density as a function of MR area ( $p>0.05)$ and (B) MR age $(p<0.001)$. (C) Rock lobster density as a function of MR area ( $>>$ $0.05)$ and (D) MR age $(p<0.001)$. (E) Blue cod size as a function of MR area (p > 0.05) and (F) MR age (p < 0.01). (G) Rock lobster size as a function of MR area $(p>0.05)$ and $(H)$ MR age $(p<0.01)$ 
Table 2. Test results (linear and non-linear functions plus Spearman's rank correlation analysis) for the response ratio (RR $\mathrm{R}_{\mathrm{recent}}$ see Fig. 2) for blue cod (BC) and rock lobster (RL) density and size with respect to marine reserve (MR) area and age. Bold values are significant at $\mathrm{p}<0.05$; ns: not significant

\begin{tabular}{|c|c|c|c|c|c|c|c|}
\hline \multirow{3}{*}{$\begin{array}{l}\text { Index }\left(\mathrm{RR}_{\text {recent }}\right) \\
\text { (Figure reference) }\end{array}$} & \multirow[t]{3}{*}{$\mathrm{df}$} & \multicolumn{4}{|c|}{ Best-fit relationship analyses } & \multirow{2}{*}{\multicolumn{2}{|c|}{$\begin{array}{l}\text { Spearman's rank } \\
\text { correlation results }\end{array}$}} \\
\hline & & \multicolumn{2}{|c|}{ Linear model } & \multicolumn{2}{|c|}{ Non-linear model } & & \\
\hline & & $\mathrm{R}$ & $\mathrm{p}$ & $\mathrm{R}$ & $\mathrm{p}$ & $\mathrm{R}$ & $\mathrm{p}$ \\
\hline BC density vs. MR area (Fig. 2A) & 5 & -0.079 & ns & -0.033 & ns & 0.107 & ns \\
\hline \multirow[t]{2}{*}{ BC density vs. MR age (Fig. 2B) } & 5 & 0.813 & $<0.05$ & 0.822 & $<0.05$ & 0.811 & $<0.05$ \\
\hline & $4^{\mathrm{a}}$ & 0.722 & ns & 0.980 & $<0.001$ & 0.754 & ns \\
\hline BC size vs. MR area (Fig. 2E) & 2 & -0.363 & ns & -0.813 & ns & -0.400 & ns \\
\hline BC size vs. MR age (Fig. 2F) & 2 & 0.045 & ns & 0.616 & ns & 0.200 & ns \\
\hline RL density vs. MR area (Fig. 2C) & 10 & -0.264 & ns & -0.315 & ns & -0.315 & ns \\
\hline \multirow[t]{2}{*}{ RL density vs. MR age (Fig. 2D) } & 10 & 0.900 & $<0.001$ & 0.910 & $<0.001$ & 0.787 & $<0.05$ \\
\hline & $9^{\mathrm{a}}$ & 0.543 & ns & 0.548 & ns & 0.693 & $<0.05$ \\
\hline RL size vs. MR area (Fig. 2G) & 9 & -0.0268 & ns & $<0.001$ & ns & 0.0636 & ns \\
\hline \multirow[t]{2}{*}{ RL size vs. MR age (Fig. 2H) } & 9 & -0.289 & ns & -0.353 & ns & -0.050 & ns \\
\hline & $8^{\mathrm{a}}$ & -0.552 & ns & -0.871 & $<0.01$ & 0.031 & ns \\
\hline
\end{tabular}

Table 3. Test results (linear and non-linear functions plus Spearman's rank correlation analysis) for the response ratio (RR $\mathrm{max}$ see Fig. 3) of blue cod (BC) and rock lobster (RL) density and size with respect to marine reserve (MR) area (small [ $\leq 1000$ ha] and large [>1000 ha]) and age (young [ $\leq 10 \mathrm{yr}]$ and old [>10 yr]). Bold values are significant at $\mathrm{p}<0.05$; ns: not significant

\begin{tabular}{|c|c|c|c|c|c|c|c|}
\hline \multirow{3}{*}{$\begin{array}{l}\text { Index }\left(\mathrm{RR}_{\max }\right) \\
\text { (Figure reference) }\end{array}$} & \multirow[t]{3}{*}{ df } & \multicolumn{4}{|c|}{ Best-fit relationship analyses } & \multirow{2}{*}{\multicolumn{2}{|c|}{$\begin{array}{l}\text { Spearman's rank } \\
\text { correlation results }\end{array}$}} \\
\hline & & \multicolumn{2}{|c|}{ Linear model } & \multicolumn{2}{|c|}{ Non-linear model } & & \\
\hline & & $\mathrm{R}$ & $\mathrm{p}$ & $\mathrm{R}$ & $\mathrm{p}$ & $\mathrm{R}$ & $\mathrm{p}$ \\
\hline BC density vs. MR area (Fig. 3A) & 47 & 0.123 & ns & 0.221 & ns & 0.106 & ns \\
\hline MR area, small reserves (Fig. 4A) & 23 & 0.179 & ns & 0.318 & ns & 0.258 & ns \\
\hline MR area, large reserves (Fig. 4F) & 22 & -0.163 & ns & $<-0.001$ & ns & 0.079 & ns \\
\hline MR age (Fig. 3B) & 47 & 0.487 & $<0.001$ & 0.487 & $<0.001$ & 0.351 & $<0.02$ \\
\hline BC size vs. MR area (Fig. 3E) & 16 & $<-0.001$ & ns & -0.077 & ns & -0.345 & ns \\
\hline MR age (Fig. 3F) & 16 & 0.617 & $<0.01$ & 0.617 & $<0.01$ & 0.564 & $<0.02$ \\
\hline RL density vs. MR area (Fig. 3C) & 48 & -0.167 & ns & -0.167 & ns & -0.055 & ns \\
\hline MR area, small reserves (Fig. 4B) & 34 & 0.191 & ns & 0.191 & ns & 0.231 & ns \\
\hline MR area, large reserves (Fig. 4G) & 12 & 0.033 & ns & -0.206 & ns & -0.064 & ns \\
\hline MR age (Fig. 3D) & 48 & 0.412 & $<0.01$ & 0.434 & $<0.01$ & 0.665 & $<0.001$ \\
\hline MR age, young reserves (Fig. 4C) & 37 & 0.490 & 0.001 & 0.500 & $<0.001$ & 0.693 & $<0.05$ \\
\hline MR age, old reserves (Fig. 4H) & 9 & 0.653 & $<0.05$ & 0.883 & $<0.001$ & 0.798 & $<0.01$ \\
\hline RL size vs. MR area (Fig. 3G) & 42 & 0.086 & ns & $<0.001$ & ns & 0.162 & ns \\
\hline MR area, small reserves (Fig. 4D) & 30 & 0.199 & ns & 0.247 & ns & 0.282 & ns \\
\hline MR area, large reserves (Fig. 4I) & 10 & 0.302 & ns & 0.369 & ns & 0.291 & ns \\
\hline MR age (Fig. 3H) & 42 & 0.084 & $\mathrm{~ns}$ & $<0.001$ & ns & 0.414 & $<0.01$ \\
\hline MR age, young reserves (Fig. 4E) & 32 & 0.444 & $<0.02$ & 0.466 & $<0.01$ & 0.549 & $<0.001$ \\
\hline MR age, old reserves (Fig. $4 \mathrm{~J}$ ) & 8 & 0.312 & ns & 0.316 & ns & -0.129 & ns \\
\hline
\end{tabular}

and size (Fig. 3F) of blue cod (Table 3). In both cases there was no difference (to 3 decimal places) between the correlation coefficients for the linear and non-linear (exponential) relationships. MR area did not explain variation in RRs for either the density or size of blue cod in any of the 3 separate analyses (Figs. 3 \& 4, Table 3). Because of small sample sizes, we were unable to test the blue cod data for the effect of MR age young ( $\leq 10 \mathrm{yr}$ ) versus old (>10 yr).
Fig. 4. Best-fit relationship for the scatter plot of response ratio values ( $R R_{\max }$, see Fig. 3) as a function of marine reserve (MR) area for small and large reserves and as a function of MR age for young and old reserves (see Table 3). (A) Blue cod density as a function of MR area for small ( $p>0.05)$ and $(F)$ large reserves ( $p>0.05)$. (B) Rock lobster density as a function of $M R$ area for small ( $p>0.05)$ and $(G)$ large reserves $(p>0.05)$. (C) Rock lobster density as a function of MR age for young $(\mathrm{p}<$ $0.001)$ and $(\mathrm{H})$ old reserves $(\mathrm{p}<0.001)$. (D) Rock lobster size as a function of MR area for small ( $p>0.05$ ) and (I) large reserves ( $p>0.05$ ). (E) Rock lobster size as a function of MR age for young $(p<0.001)$ and $(J)$ old reserves $(p>0.05)$ 

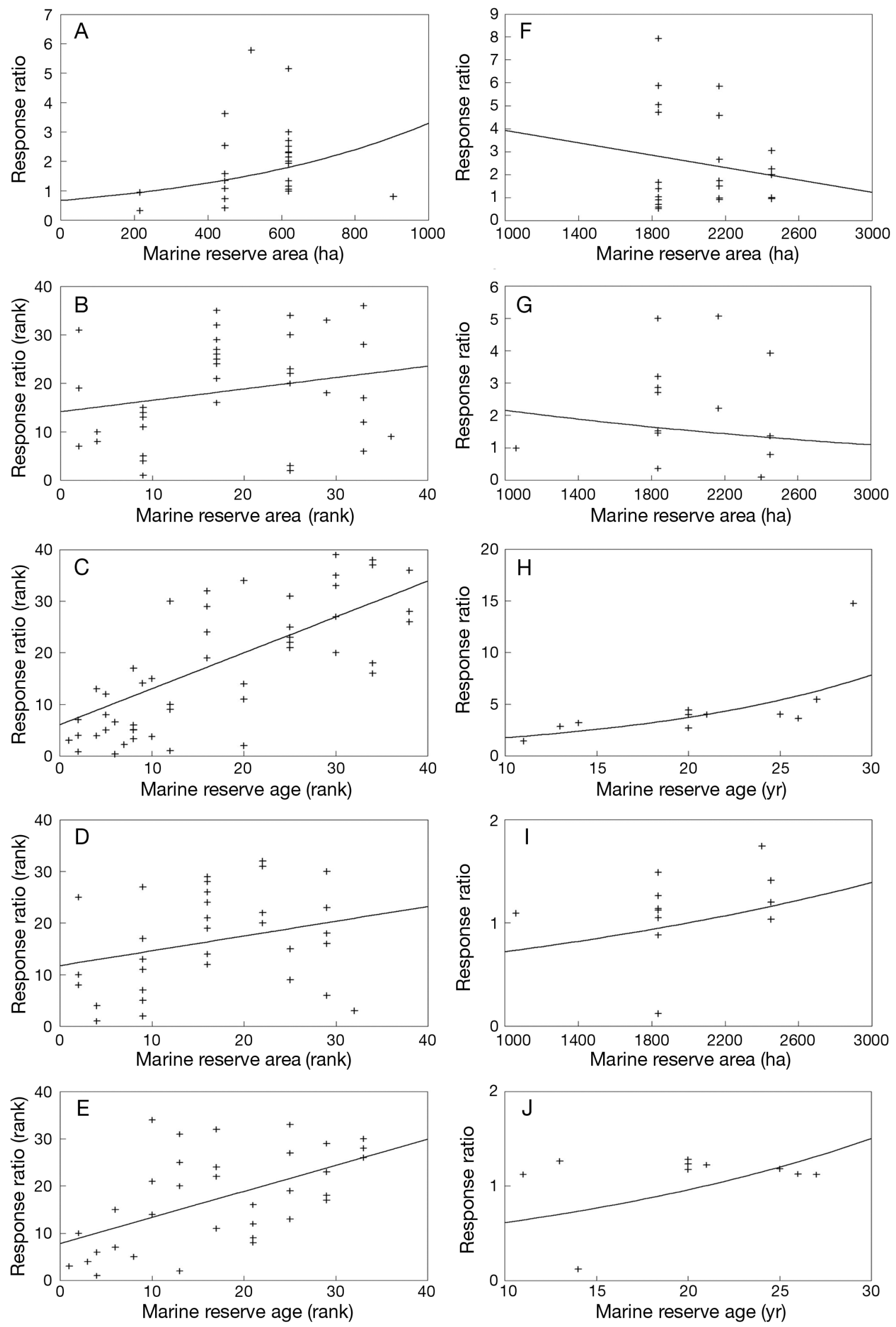


\section{$\mathbf{R R}_{\text {recent }}$ analyses for rock lobster}

Statistically significant results for all 3 analyses were observed for rock lobster density and MR age (Fig. 2D, Table 3). The best fit was for the non-linear model, but the linear parametric model had only a slightly lower R value. Dropping one outlier from this analysis resulted in only the Spearman's rank correlation being statistically significant. The only other statistically significant model was the non-linear fit for rock lobster size and MR age: this relationship was negative and only significant after an outlier had been dropped (Fig. 2H, Table 3).

\section{$\mathbf{R R}_{\max }$ analyses for rock lobster}

There was a statistically significant positive relationship between MR age and rock lobster density (best fit = linear rank relationship; Fig. 3D) and between MR age and rock lobster size (best fit = linear rank relationship; Fig. 3H, Table 3). In young MRs, the best fit was a linear rank relationship with rock lobster density (Fig. 4C), whereas in old MRs the best fit was an exponential relationship with density (Fig. 4H). For rock lobster size, the best fit relation- ship with MR age among young reserves was a linear rank relationship (Fig. 4E), whilst the relationship between MR age and rock lobster size for old reserves was not significant (Fig. 4J, Table 3). MR area did not explain variation in rock lobster size or density estimates inside versus outside the reserves in any of the analyses (Figs. $3 \& 4$, Table 3 ).

\section{Comparison of $\mathbf{R} R_{\text {recent }}$ versus Hedges' $g$ statistics}

Plots of Hedges' $g$ statistic as a function of $\mathrm{RR}_{\text {recent }}$ revealed no obvious linear relationship for the blue cod density data set $(n=5, p=0.489$, Fig. 5a) or for the rock lobster size data set $(n=8, p=0.069$, Fig. $5 d)$, but did reveal significant linear relationships for the blue cod size data set $(n=4, p=0.048$, Fig. 5b) and for the rock lobster density data set $(n=10, p=0.043$, Fig. $5 c)$. When all the data was pooled and plotted, we observed a non-statistically significant positive relationship ( $\mathrm{n}=27, \mathrm{p}=0.206$, Fig. 6a) that was heavily influenced by a single point. When we removed this point (for rock lobster density from the Cape Rodney to Okakari Point MR) we observed a non-statistically significant negative relationship ( $\mathrm{n}=26, \mathrm{p}=0.212$, Fig. 6b) between $\mathrm{RR}_{\text {recent }}$ and Hedges' $g$ statistic.

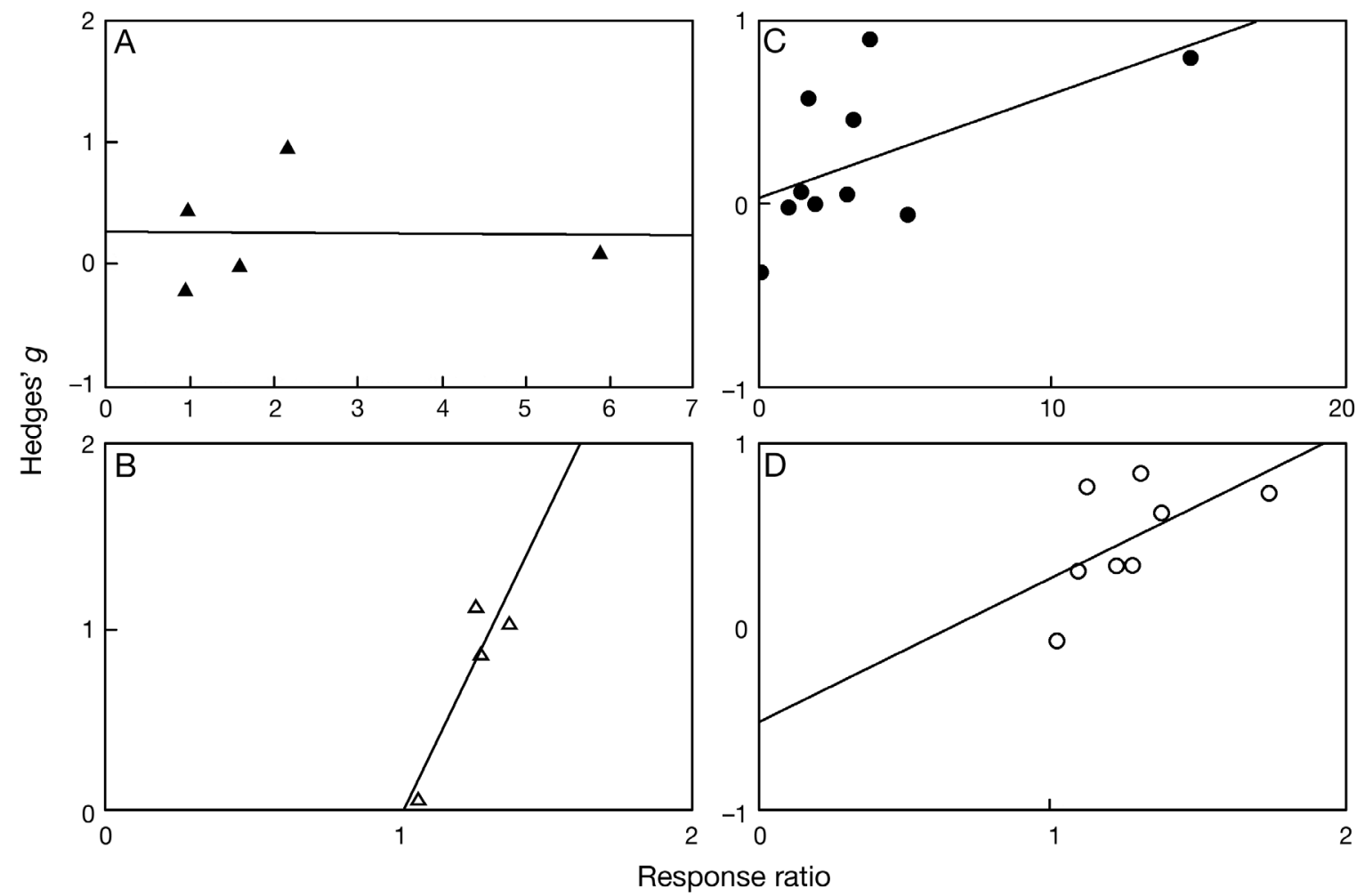

Fig. 5. Species-specific relationships between response ratio values $\left(R_{\text {recent, }}\right.$ see Fig. 2) and Hedges' $g$ statistic for (A) blue cod density data $(n=5)$, (B) blue cod size data $(n=4)$, (C) rock lobster density $(n=10)$, and (D) rock lobster size data $(n=8)$ 


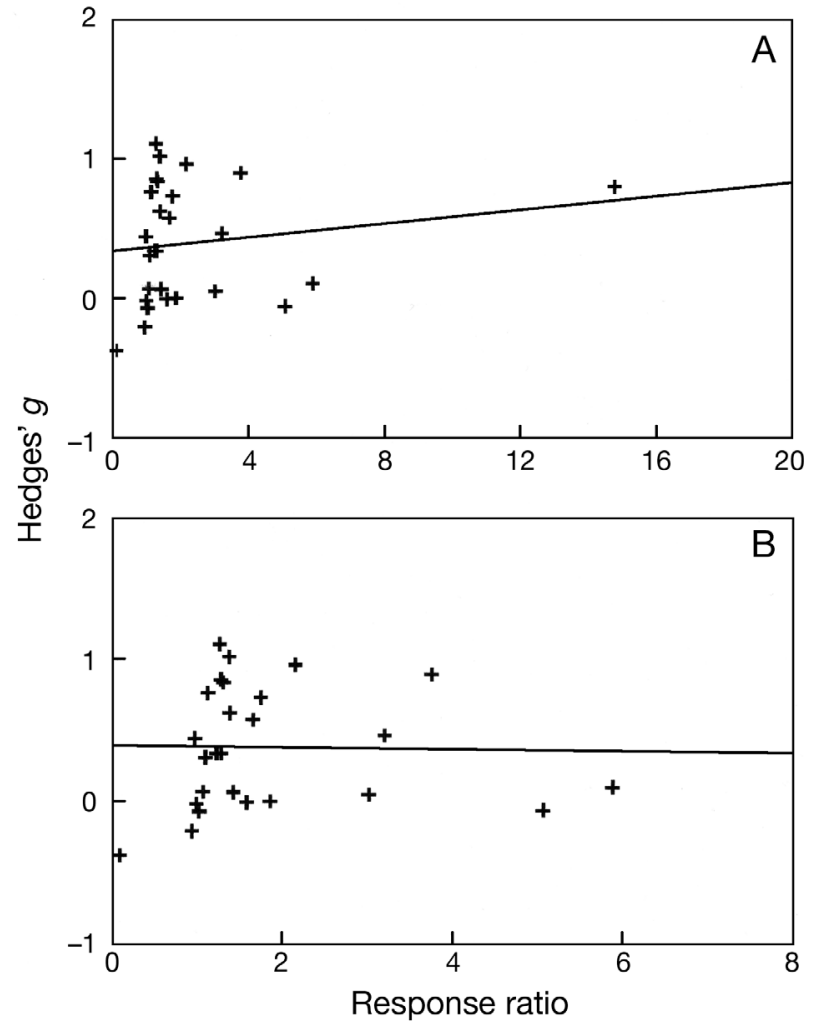

Fig. 6. Hedges' $g$ statistic as a function of response ratio values $\left(R_{\text {recent, }}\right.$ see Fig. 2) for $(A)$ all data $(n=27)$ and $(B)$ all data with a single heavily weighted point for rock lobster density at the Cape Rodney to Okakari Point Marine Reserve removed $(n=26)$

\section{DISCUSSION}

The main intention of the present study is to compare the RR approach with the Hedges' statistic meta-analysis approach to quantifying biological responses in marine reserves using NZ examples. In addition, we are interested in determining how MR age and area affect the biological responses of these 2 targeted species. To do this, we highlight the novel findings from this RR analysis and contrast these with the findings from the Hedges' $g$ meta-analysis (Pande et al. 2008).

\section{Effects of MRs on the density and size of individuals}

As expected, our results indicate positive effects of MRs on the density and size of both blue cod and rock lobster. We obtained RR values $>1$ for almost all MRs used in the analysis (the 4 exceptions were Pohatu, Horoirangi, Poor Knights Islands, and Mayor Island). For these reserves, we had little data (only 1 or 2 yr), or data only existed for 1 yr after reserve establishment. In contrast, all the RRs calculated for Cape Rodney to Okakari Point MR (the oldest MR in New Zealand) were $>1$. Data for this reserve included several studies performed by different investigators from 10 to $29 \mathrm{yr}$ after establishment. Based on the RR values, the biological responses that we observed for both species were greater for density than for size, and were generally, but not consistently, greater for rock lobster than for blue cod. Overall, and consistent with other studies (e.g. Mosquera et al. 2000, Côté et al. 2001, Halpern \& Warner 2002, Halpern 2003, Pande et al. 2008, Lester et al. 2009), our results demonstrate that MRs produce positive increases in the density and size of species that are heavily targeted for recreational, customary, and/or commercial harvesting.

\section{Effect of MR area on biological response}

Previous studies indicate that MR area may not always influence the biological response to MR protection (e.g. Côté et al. 2001, Halpern \& Warner 2002, Halpern 2003, Guidetti \& Sala 2007, Pande et al. 2008, but see Claudet et al. 2008 for counter example). Theoretical studies suggest that larger MRs should be more effective than smaller MRs, mainly because larger reserves allow more mobile species with wide home ranges to remain protected inside reserves. This is because larger MRs tend to have increased area to boundary ratios and because they may also increase self-recruitment by protecting areas of settlement for larvae produced inside reserves (Botsford et al. 2003, Hastings \& Botsford 2003, Roberts et al. 2003). Despite this, most evidence demonstrates that when a MR is established the biological response is rapid and occurs independently of MR area (Halpern \& Warner 2002, Halpern 2003, Micheli et al. 2004), at least over the range of MR sizes and species so far considered (e.g. see Cole et al. 1990).

All of our analyses revealed no effect of MR area on the density or size of blue cod and rock lobster across a wide range of $\mathrm{MR}$ sizes (for blue cod MR size range was 215 to 2452 ha, mean size $=1144.5$ ha; for rock lobster MR size range was 93 to 2452 ha, mean size = 1095.3 ha). These results indicate that biological response is independent of MR area and suggest that small reserves function as well as large reserves for these species. While it is encouraging from a conservation perspective to think that small reserves can produce meaningful conservation outcomes (at least for some species), the apparent absence of a relationship between biological response and MR area is 
notable given the importance of habitat area in other studies (e.g. Claudet et al. 2008) and the fact that theoretical studies indicate that large MRs should be more effective for conservation than small MRs (e.g. Botsford et al. 2003, Hastings \& Botsford 2003, Roberts et al. 2003). Our result is surprising given that species such as blue cod and rock lobster are not highly vagile, although they do display some movement ability (Davidson 2001a, Kelly 2001, Kelly \& MacDiarmid 2003, Struthers 2004). As such they are expected to benefit from MR protection, and larger areas are, on average, expected to protect more individuals (Pande et al. 2008, Pande \& Gardner 2009). The result may be explained by features or properties that are specific to each MR. For example, the effect of protection in each individual reserve may be determined by many local factors other than just the area (size) of the reserve. These may include reserve location, site-specific coastal oceanography, physical complexity and habitat quality, and extent and distribution (Freeman et al. 2009). The latter 2 factors are very difficult to evaluate and are likely to be independent of reserve area, but nonetheless are expected to contribute substantially to the biological responses observed in each MR (Halpern \& Warner 2003, Guidetti \& Sala 2007). Finally, we note that enforcement (policing of the no-take areas) has been identified as being a key factor contributing to MR success (e.g. Samoilys et al. 2007). Because no data exist about levels of illegal extractive use or about enforcement differences across the MRs studied here, we are not in a position to know if or how this factor may have contributed to our study. However, based on anecdotal information from the NZ Department of Conservation and our own experience, we do not believe that differences in enforcement explain the results that we report here.

\section{Effect of MR age on biological response}

All analyses revealed the importance of MR age as a factor explaining positive biological responses. Reserve age is usually considered to be an important factor in MR effectiveness, because the response of individuals to protection is thought to depend upon the relationship between life-history traits of the species protected and the duration of protection (Guidetti \& Sala 2007, Molloy et al. 2009). Increases in size and/or density of target species may be expected for a number of different reasons, including increased protection (no extractive use), increased recruitment to the MR itself (recruitment to the MR of offspring derived from adults in the MR or recruitment to the MR from outside the MR), decreased natural mortality of the target species inside the MR as a consequence of ecosystem changes arising from protection, and the mobility of the species in question. Perhaps not surprisingly, different species react to MR status in different ways and at different rates. For example, decadal-scale indirect effects on taxa that occur as a consequence of cascading trophic interactions take longer to develop than direct effects on target species (Babcock et al. 2010).

Evidence indicates that a new reserve results in a rapid and significant increase in average levels of density, biomass, and diversity within 1 to 3 yr before the response slows down or stabilises (e.g. Halpern \& Warner 2002, Halpern 2003, Micheli et al. 2004). However, a recent meta-analysis of the response of fish populations to MR protection determined that older reserves $(>15 \mathrm{yr}$ ) are more effective than younger reserves $(\leq 15 \mathrm{yr})$ at increasing fish densities, indicating that $\mathrm{MR}$ age is an important factor explaining biological response (Molloy et al. 2009). Our results demonstrate that MR age has a strong positive effect on the biological responses of blue cod and rock lobster. For the $\mathrm{RR}_{\text {recent }}$ analyses we observed a strong positive effect of MR age on blue cod and rock lobster density but not size, despite the fact that most RR values for size for both species were $>1.0$, indicating larger individuals exist inside versus outside the MR. For the $\mathrm{RR}_{\max }$ approach, our results demonstrate that MR age has a strong positive effect on the density and size of blue cod and the density of rock lobster. We found evidence of significant positive relationships for all analyses except for that between rock lobster size and old ( $>10 \mathrm{yr}$ ) reserves. The findings indicate that both species respond rapidly to protection, with $\mathrm{RR}$ values $>1$ being recorded in the first few years after MR designation, consistent with estimates of species-specific growth rates and also density-dependent responses (e.g. Cole et al. 2000, Davidson 2001a, Davidson et al. 2002, Freeman 2008 and references therein). When analysed as a function of time, the best-fit response in all cases was linear. The association between rock lobster density and MR age for young reserves was best described by a linear relationship, whereas that for old reserves was best described by a nonlinear relationship (despite a small sample size for this latter analysis we observed $\mathrm{p}<0.001$ ). This difference in age-dependent response may reflect density-dependent factors, as rock lobsters increase in density towards site-specific carrying capacity. The association between rock lobster size and MR 
age for young reserves was linear and strongly positive, but was not significant among the old reserves. These results suggest that rock lobster size can respond rapidly and positively after MRs are declared, but after $\sim 10$ yr the response becomes independent of MR age. This may reflect the biological ability of rock lobsters to grow to larger sizes as a rapid response to MR protection, but after $10 \mathrm{yr}$ such a response is no longer possible because a growth response plateau has been achieved. Thus, in terms of size response, the notable changes occur rapidly, but plateau (reach an asymptote) after $10 \mathrm{yr}$.

\section{Use of RR indices and curve fitting}

Response ratios (RR) may easily be calculated in different ways, as demonstrated by our use of $R R_{\text {recent }}$ and $R_{\max }$. Despite the different origins of the $2 R R$ indices $\left(R R_{\text {recent }}\right.$ t the most recent survey only; $R R_{\max }$ : an average value calculated from all surveys) and also their different properties $\left(\mathrm{RR}_{\text {recent }}\right.$ independence of data points; $\mathrm{RR}_{\max }$ : non-independence of points leading to pseudo-replication), both tended to give very similar results. $\mathrm{RR}_{\text {recent }}$ was surprisingly informative given its limited power to detect significance (low degrees of freedom because one RR value per study). We employed 3 different best fit approaches (parametric linear and non-linear, rank linear) to test for a relationship between $\mathrm{RR}$ and $\mathrm{MR}$ age or area for each biological response. This is a powerful approach in the absence of a priori knowledge about the biological response to MR protection, and provides new insights into the trajectories of change that we can expect for 2 target species. Although in all cases except one the best line relationship was curvilinear, the goodness of fit (as judged by the correlation coefficients) for the linear functions was only fractionally less than that for the non-linear functions. Thus, in terms of predicting or modelling biological responses, it is reasonable (at least for these 2 species and presumably other species with similar life-history characteristics and histories of extractive use) to employ a linear function, which is simple to fit and more easily understood and interpreted in a biological sense. The consistency of outcomes across both analyses (2 different RR indices and 3 different curve-fitting approaches) provides some degree of confidence in the interpretation of the quantifiable biological responses of blue cod and rock lobster to protection in NZ.

Direct comparison of the $\mathrm{RR}_{\text {recent }}$ values with the Hedges' $g$ values for species-specific responses revealed that 3 of 4 comparisons had positive slopes, and 2 of 4 comparisons were borderline statistically significant $(0.05>\mathrm{p}>0.04)$, suggesting that a linear relationship may exist between the 2 indices (Fig. 5). Given that both metrics are measuring the comparative biological response inside versus outside the MR in question, one might reasonably expect that a (linear) relationship exists between them. However, when the data for both species and both biological measures were combined, the relationship between $\mathrm{RR}_{\text {recent }}$ values and Hedges' $g$ values was positive but not statistically significant $(\mathrm{p}=0.206, \mathrm{n}=27$ ) or slightly negative when one point heavily influencing the plot $\left(\mathrm{RR}_{\text {recent }}\right.$ for rock lobster density at Cape Rodney to Okakari Point MR) was removed ( $\mathrm{p}=0.212$, $\mathrm{n}=26$ ) (Fig. 6). Thus, overall, there is little to indicate that a simple relationship exists between $R_{\text {recent }}$ values and Hedges' $g$ values. The reason for this is because the RR values are calculated as a simple function of mean size (density) inside versus outside each $\mathrm{MR}_{i}$ this ratio therefore is independent of any estimate of variance. In contrast, Hedges' $g$ is calculated not as a ratio, but as an estimate of mean size (density) inside minus mean size (density) outside the MR and then divided by a pooled variance estimate. The absence of a variance component in the RR statistic and the inclusion of a pooled variance component in the Hedges' $g$ statistic therefore generates 2 indices that are largely independent. From a biological perspective, it might be argued that the Hedges' $g$ statistic is in fact more meaningful than the RR statistic because its calculation includes the pooled variance estimate, thereby reflecting variability in size (density), which is known to be ecologically important. This apparent shortcoming of the RR index could be addressed by taking an approach that includes a variance component (e.g. Lajeunesse 2011).

\section{Use of the RR approach for assessing MR effectiveness}

Meta-analyses based on Hedges' $g$ are computationally difficult to conduct (e.g. Berman \& Parker 2002, Pande et al. 2008) when compared to other approaches such as response ratios; they require knowledge of sample variance that are often not reported in the literature, and they also include steps such as testing for differences in 'effect size', which, if significant, will preclude the completion of the meta-analysis. Whilst this latter step may be included in a RR analysis (e.g. Mosquera et al. 2000, present study), this is rarely done. 
Using a similar data set to that tested in the present study, Pande et al. (2008) observed significant differences in 'effect size' in their meta-analysis of blue cod and rock lobster size and density data. This meant that data from the different studies could not be combined to provide an overall significance estimate of the effect that all MRs had on these species. The significant differences in 'effect size' highlighted the significant differential contribution that individual MRs had on size and density of both species (although it was not possible to identify the nature of that response), and also precluded the completion of the analysis. In contrast, the RR analyses presented here are less constrained because our testing did not reveal a significant effect size, and have, as a consequence, permitted us to contribute significant new findings to the results of Pande et al. (2008). Nonetheless, we recommend that all RR studies should test for heterogeneity of the data set because such heterogeneity points to the differential effects across MRs, something that the researcher needs to appreciate.

The meta-analysis of Pande et al. (2008) did not identify either MR age or area as being significant factors explaining the biological responses of both species. The RR analyses presented here (Tables 2 \& 3) have identified MR age, but not MR area, as being important. The general concordance between the 2 analytical approaches is encouraging (notwithstanding the importance difference identified above) and suggests that the Hedges' statistic approach and the RR approach are equally valid. At the moment we cannot know if this statement holds true for only our NZ data set or for other data sets, but our comparison indicates that further exploration of this is worthwhile. Given that the RR approach does not require estimates of variance (which are often not provided in papers), there is a clear advantage to using this technique over the Hedges' statistic meta-analysis technique. However, the inclusion of a pooled variance estimate in the Hedges' $g$ index is likely to reflect biologically significant information that is lost in the present RR approach. Further investigation of an RR index that incorporates variance estimates is an approach that we recommend. Overall, there appears however to be no loss of information when using the RR compared to the Hedges' statistic metaanalysis, and the additional gain of information about the effect of MR age is important, as is the ease of use of the RR approach. In addition, we note that new developments will help resolve some of the common challenges faced when undertaking a meta-analysis (Lajeunesse 2011).

\section{CONCLUSIONS}

Our RR analyses of blue cod and rock lobster data from NZ MRs are consistent with a body of evidence that indicates that MRs are having consistent and positive effects on the density and size of protected species. While we could not identify an effect of MR area on biological responses, our results offer evidence that at the national level MRs of all sizes can generate positive biological responses.

We recommend that response ratio analysis should be used in preference to the Hedges' statistic metaanalysis because it is easier (less time-consuming) to employ, has fewer limitations, provides at least as much information as Hedges' statistic, and because its results are easier to interpret. Consistent with an increasing body of evidence, this RR analysis and the earlier meta-analysis based on Hedges' $g$ statistic (Pande et al. 2008) illustrate that MRs support larger and more abundant targeted species (in this case blue cod and rock lobster) than non-reserve areas. We suggest that the next important step in this line of investigation is to determine why and how individual MRs respond differently in their biological outcomesthat is, to test why a significant 'effect size' exists.

Acknowledgements. D. Diaz Guisado was supported by a $\mathrm{PhD}$ joint scholarship from CONICYT (Comisión Nacional de Investigación Científica y Tecnológica, Chile) and Victoria University of Wellington (New Zealand). This research was supported by funding from the New Zealand Department of Conservation and also from the Centre for Marine Environmental \& Economic Research at Victoria University of Wellington.

\section{LITERATURE CITED}

Adams DC, Gurevitch J, Rosenberg MS (1997) Resampling tests for meta-analysis of ecological data. Ecology 78: 1277-1283

Allison GW, Lubchenco J, Carr MH (1998) Marine reserves are necessary but not sufficient for marine conservation. Ecol Appl 8(Suppl):S79-S92

> Arnqvist G, Wooster D (1995) Meta-analysis: synthesizing research findings in ecology and evolution. Trends Ecol Evol 10:236-240

Babcock RC, Kelly S, Shears NT, Walker JW, Willis TJ (1999) Changes in community structure in temperate marine reserves. Mar Ecol Prog Ser 189:125-134

Babcock RC, Shears NT, Alcala AC, Barrett NS and others (2010) Decadal trends in marine reserves reveal differential rates of change in direct and indirect effects. Proc Natl Acad Sci USA 107:18256-18261

Battershill CN, Murdoch RC, Grange KR, Singleton RJ, Aaron ES, Page MJ, Oliver MD (1993) A survey of the marine habitats and communities of Kapiti Island. Department of Conservation, Wellington

Berman NG, Parker RA (2002) Meta-analysis: neither quick 
nor easy. BMC Med Res Methodol 2:10 available at www.biomedcentral.com/1471-2288/2/10

Botsford LW, Micheli F, Hastings A (2003) Principles for the design of marine reserves. Ecol Appl 13(Suppl Mar Reserv):25-31

Botsford LW, Brumbaugh DR, Grimes C, Kellner JB and others (2009) Connectivity, sustainability, and yield: bridging the gap between conventional fisheries management and marine protected areas. Rev Fish Biol Fish 19:69-95

> Claudet J, Osenberg CW, Benedetti-Cecchi L, Domenici P and others (2008) Marine reserves: size and age do matter. Ecol Lett 11:481-489

Cole RG, Ayling AM, Creese RG (1990) Effects of marine reserve protection at Goat Island, northern New Zealand. NZ J Mar Freshw Res 24:197-210

Cole RG, Villouta E, Davidson RJ (2000) Direct evidence of limited dispersal of the reef fish Parapercis colias (Pinguipedidae) within a marine reserve and adjacent fished areas. Aquat Conserv 10:421-436

Côté IM, Mosquera I, Reynolds JD (2001) Effects of marine reserve characteristics on the protection of fish populations: a meta-analysis. J Fish Biol 59(Suppl A):178-189

Davidson RJ (1999) Tonga Marine Reserve, Abel Tasman, Nelson: subtidal biological baseline report. Survey and Monitoring Rep. No. 175a, Department of Conservation, Nelson

Davidson RJ (2001a) Changes in population parameters and behaviour of blue cod (Parapercis colias; Pinguipedidae) in Long Island-Kokomohua Marine Reserve, Marlborough Sounds, New Zealand. Aquat Conserv 11:417-435

Davidson RJ (2001b) Tonga Island Marine Reserve: proposed protocol for ongoing subtidal biological monitoring. Survey and Monitoring Rep No. 316, Department of Conservation, Nelson, www.doc.govt.nz/publications/ conservation/marine-and-coastal/marine-protected-areas/ marine-reserve-monitoring/tonga-island-proposed-monitoring-protocol/

Davidson RJ (2004) Long Island-Kokomohua Marine Reserve, Queen Charlotte Sound: 1992-2003. Survey and Monitoring Rep No. 343, Department of Conservation, Nelson, http://doc.govt.nz/upload/documents/conservation/marine-and-coastal/marine-protected-areas/ report-on-monitoring.pdf

Davidson RJ (2006) Horoirangi Marine Reserve, North Nelson rocky shore baseline biological report. Survey and Monitoring Rep No. 513, Department of Conservation, Nelson

Davidson RJ, Abel W (2002) Second sampling of Pohatu Marine Reserve, Flea Bay, Banks Peninsula. Survey and Monitoring Rep No. 443, Department of Conservation, DeVauchelle, www.doc.govt.nz/upload/documents/conservation/marine-and-coastal/marine-protected-areas/ report-on-monitoring-pohatu.pdf

Davidson RJ, Barrier R, Pande A (2001) Pohatu Marine Reserve baseline survey. Survey and Monitoring Rep No. 352, Department of Conservation, Canterbury, www. doc.govt.nz/upload/documents/conservation/marineand-coastal/marine-protected-areas/pohatu-report-onbaseline-survey.pdf

> Davidson RJ, Villouta E, Cole RG, Barrier RGF (2002) Effects of marine reserve protection on spiny lobster (Jasus edwardsii) abundance and size at Tonga Island Marine Reserve, New Zealand. Aquat Conserv 12:213-227

Davidson R, Richards L, Baxter A (2007) Tonga Island Marine Reserve, Abel Tasman National Park update of biological monitoring, 1993-2007. Survey and Monitoring Rep No. 484, Department of Conservation, Nelson, www.doc.govt.nz/upload/documents/conservation/ marine-and-coastal/marine-protected-areas/tongaisland-monitoring.pdf

Davidson RJ, Abel W, Richards LA (2009) Biological monitoring update 1992-2009: Long Island-Kokomohua Marine Reserve, Queen Charlotte Sound. Survey and Monitoring Rep No. 573, Department of Conservation, Nelson, www.doc.govt.nz/upload/documents/conservation/ marine-and-coastal/marine-protected-areas/Long \% 20 Island\%20update\%201992-2009.pdf

Department of Conservation and Ministry of Fisheries (2005) Marine protected areas policy and implementation plan. Department of Conservation, Ministry of Fisheries, Wellington

Egger M, Smith GD, Phillips AN (1997) Meta-analysis, principles and procedures. Brit Med J 315:1533-1537

Freeman DJ (2001) Te Tapuwae o Rongokako Marine Reserve baseline Survey Report. Technical Support Series report, Department of Conservation, Crisborne

Freeman DJ (2005) Reef fish monitoring, Te Tapuwae o Rongokako Marine Reserve. East Coast Hawke's Bay Conservancy. Technical Support Series No. 25, Department of Conservation, Gisborne, www.doc.govt.nz/upload/ documents/conservation/marine-and-coastal/marineprotected-areas/mmimp-reef-fish-monitoring.pdf

Freeman DJ (2008) The ecology of spiny lobsters (Jasus edwardsii) on fished and unfished reefs. PhD thesis, University of Auckland

Freeman DJ, Duffy CAJ (2003) Te Angiangi Marine Reserve reef fish monitoring 1995-2003. Technical Support Series No. 14, Department of Conservation, Hawke's Bay

Freeman DJ, MacDiarmid AB, Taylor RB (2009) Habitat patches that cross marine reserve boundaries: consequences for the lobster Jasus edwardsii. Mar Ecol Prog Ser 388:159-167

Gates S (2002) Review of methodology of quantitative reviews using meta-analysis in ecology. J Anim Ecol 71: $547-557$

Goldberg DE, Rajaniem T, Gurevitch J, Stewart-Oaten A (1999) Empirical approaches to quantifying interaction intensity: competition and facilitation along productivity gradients. Ecology 80:1118-1131

Guidetti P, Sala E (2007) Community-wide effects of marine reserves in the Mediterranean Sea. Mar Ecol Prog Ser 335:43-56

Haggitt T, Kelly S (2004) Cape Rodney to Okakari Point Marine Reserve Lobster Monitoring Programme: 2004 Survey. Department of Conservation, Auckland, www. doc.govt.nz/upload/documents/conservation/marineand-coastal/marine-protected-areas/report-on-lobstermonitoring.pdf

Halpern B (2003) The impact of marine reserves: Do reserves work and does reserve size matter? Ecol Appl 13(Suppl Mar Reserv):117-137

Halpern B, Warner RR (2002) Marine reserves have rapid and lasting effects. Ecol Lett 5:361-366

Halpern BS, Warner RR (2003) Matching marine reserve design to reserve objectives. Proc Biol Sci 270:1871-1878

Hastings A, Botsford LW (2003) Comparing designs of marine reserves for fisheries and for biodiversity. Ecol Appl 13:65-70

Hedges LV, Olkin I (1985) Statistical methods for metaanalysis. Academic Press, San Diego, CA 
Hedges LV, Gurevitch J, Curtis PS (1999) The meta-analysis of response ratios in experimental ecology. Ecology 80: 1150-1156

Jones GP, Cole RG, Battershill CN (1992) Marine reserves: Do they work? In: Battershill CN, Schiel DR, Jones GP, Creese RG, MacDiarmid AB (eds) Proc 2nd Int Temp Reef Ecol Symp. Nat Inst of Water and Atm Res, Wellington, p 29-45

Kelly S (2001) Temporal variation in the movement of the spiny lobster Jasus edwardsii. Mar Freshw Res 52: 323-331

Kelly S, MacDiarmid AB (2003) Movement patterns of mature spiny lobsters, Jasus edwardsii, from a marine reserve. New Zeal Mar Fresh 37:149-158

Kelly S, Scott D, MacDiarmid AB, Babcock RC (2000) Spiny lobster, Jasus edwardsii, recovery in New Zealand marine reserves. Biol Conserv 92:359-369

Lajeunesse MJ (2011) On the meta-analysis of response ratios for studies with correlated and multi-group designs. Ecology 92:2049-2055

Lester SE, Halpern BS, Grorud-Colvert K, Lubchenco J and others (2009) Biological effects within no-take marine reserves: a global synthesis. Mar Ecol Prog Ser 384: $33-46$

MacDiarmid AB, Breen PA (1993) Spiny lobster population change in a marine reserve. In: Battershill CN, Schiel DR, Jones GP, Creese RG, MacDiarmid AB (eds) Proc 2nd Int Temp Reef Ecol Symp. Nat Inst of Water and Atm Res, Wellington, p 47-56

McCormick ML, Choat JH (1987) Estimating total abundance of a large temperate-reef fish using visual strip transects. Mar Biol 96:469-478

Micheli F, Halpern BS, Botsford LW, Warner RR (2004) Trajectories and correlates of community change in no-take marine reserves. Ecol Appl 14:1709-1723

Molloy PP, McLean IB, Côté IM (2009) Effects of marine reserve age on fish populations: a global meta-analysis. J Appl Ecol 46:743-751

Mosquera I, Côté IM, Jennings S, Reynolds JD (2000) Conservation benefits of marine reserves for fish populations. Anim Conserv 3:321-332

Munn A (2000) Lobster survey of Piopiotahi Marine Reserve, Milford Sound. Southland Conservancy, Department of Conservation, Wellington

Osenberg CW, Sarnelle O, Goldberg DE (1999) Special feature: meta-analysis in ecology: concepts, statistics, and applications. Ecology 80:1103-1104

Pande A (2001) Evaluating biological change in New Zealand marine reserves. PhD thesis, Victoria University

Editorial responsibility: Riccardo Cattaneo-Vietti, Genova, Italy of Wellington

Pande A, Gardner JPA (2009) A baseline biological survey of the proposed Taputeranga Marine Reserve (Wellington, New Zealand): spatial and temporal variability along a natural environmental gradient. Aquat Conserv Mar Freshw Ecol 19:237-248

Pande A, MacDiarmid AB, Smith PJ, Davidson RJ and others (2008) Marine reserves increase the abundance and size of blue cod and rock lobster. Mar Ecol Prog Ser 366: $147-158$

Roberts CM, Branch G, Bustamante RH, Castilla JC and others (2003) Application of ecological criteria in selecting marine reserves and developing reserve Networks. Ecol Appl 13:215-228

Samoilys MA, Martin-Smith KM, Giles BG, Cabrera B, Anticamara JA, Brunio EO, Vincent ACJ (2007) Effectiveness of five small Philippines' coral reef reserves for fish populations depends on site-specific factors, particularly enforcement history. Biol Conserv 136:584-601

Smith ED (2001) Lobster survey of Te Awaatu Marine Reserve, Doubtful Sound. Southland Conservancy, Department of Conservation, Wellington

Smith ED (2002) Lobster survey of Piopiotahi Marine Reserve, Milford Sound. Southland Conservancy, Department of Conservation, Te Anau, www.doc.govt.nz/ upload/documents/conservation/marine-and-coastal/ marine-protected-areas/piopiotahi-lobster-monitoringreport.pdf

Stewart RA, MacDiarmid AB (2003) A Survey of Kaimoana at Kapiti Island 1999 and 2000. NIWA Project: DOC 03402. Department of Conservation, Nelson, www.doc. govt.nz/upload/documents/conservation/marine-andcoastal/marine-protected-areas/survey-of-kaimoana.pdf

Struthers C (2004) Monitoring of blue cod (Parapercis colias) at Kapiti Marine Reserve, New Zealand: a comparison of survey methodologies. MSc thesis, Victoria University of Wellington

Taylor RB, Anderson MJ, Egli D, Willis TJ (2003) Cape Rodney to Okakari Point Marine Reserve fish monitoring 2003: final report. Department of Conservation, Auckland, www.doc.govt.nz/upload/documents/conservation/ marine-and-coastal/marine-protected-areas/report-onfish-monitoring.pdf

Willans M (2003) Lobster survey, Te Awaatu (The Gut) Marine Reserve, Doubtful Sound. Southland Conservancy, Department of Conservation, Wellington. http:// doc.govt.nz/upload/documents/conservation/marineand-coastal/marine-protected-areas/te-awaatu-lobstermonitoring-report.pdf

Submitted: June 8, 2011; Accepted: October 31, 2011

Proofs received from author(s): January 13, 2012 